\title{
Personality Correlates of Response to Motivation-Based Branding Appeals of Developing Countries
}

\author{
By \\ John Nadeau \\ Eric Sprott School of Business
}

A thesis submitted to the Faculty of Graduate Studies and Research in conformity with the requirement for the degree of Doctor of Philosophy (Management)

Carleton University

September 2007

(C) John Nadeau, 2007 


$\begin{array}{ll}\begin{array}{l}\text { Library and } \\ \text { Archives Canada }\end{array} & \begin{array}{l}\text { Bibliothèque et } \\ \text { Archives Canada }\end{array} \\ \begin{array}{l}\text { Published Heritage } \\ \text { Branch }\end{array} & \begin{array}{l}\text { Direction du } \\ \text { Patrimoine de l'édition }\end{array} \\ \begin{array}{l}\text { 395 Wellington Street } \\ \text { Ottawa ON K1A ON4 }\end{array} & \begin{array}{l}\text { 395, rue Wellington } \\ \text { Ottawa ON K1A ON4 } \\ \text { Canada }\end{array}\end{array}$

Your file Votre référence ISBN: 978-0-494-33505-5 Our file Notre référence ISBN: 978-0-494-33505-5

NOTICE:

The author has granted a nonexclusive license allowing Library and Archives Canada to reproduce, publish, archive, preserve, conserve, communicate to the public by telecommunication or on the Internet, loan, distribute and sell theses worldwide, for commercial or noncommercial purposes, in microform, paper, electronic and/or any other formats.

The author retains copyright ownership and moral rights in this thesis. Neither the thesis nor substantial extracts from it may be printed or otherwise reproduced without the author's permission.
AVIS:

L'auteur a accordé une licence non exclusive permettant à la Bibliothèque et Archives Canada de reproduire, publier, archiver, sauvegarder, conserver, transmettre au public par télécommunication ou par l'Internet, prêter, distribuer et vendre des thèses partout dans le monde, à des fins commerciales ou autres, sur support microforme, papier, électronique et/ou autres formats.

L'auteur conserve la propriété du droit d'auteur et des droits moraux qui protège cette thèse. $\mathrm{Ni}$ la thèse ni des extraits substantiels de celle-ci ne doivent être imprimés ou autrement reproduits sans son autorisation.
In compliance with the Canadian

Privacy Act some supporting forms may have been removed from this thesis.

While these forms may be included in the document page count, their removal does not represent any loss of content from the thesis.
Conformément à la loi canadienne sur la protection de la vie privée, quelques formulaires secondaires ont été enlevés de cette thèse.

Bien que ces formulaires aient inclus dans la pagination, il n'y aura aucun contenu manquant.

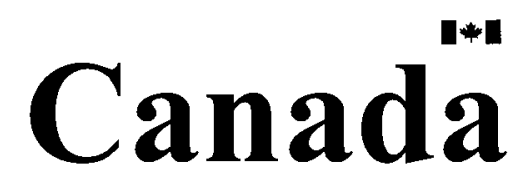




\section{Abstract}

While less developed countries (LDCs) now have significant presence in the global economy, LDCs are rarely associated with products other than commodities and their products are largely undifferentiated on world markets. The purpose of the research is to identify both the characteristics of consumers who might be more responsive to appeals from LDCs and the type of appeals that may be more effective for these consumers. The study examines consumer responses to different types of motivationbased appeals and how these responses are related to consumer characteristics, particularly the inner-other directedness personality trait.

This research makes a contribution through the exploration of justice as an otheroriented, motivation-based appeal type. It builds on the interaction of personality with appeal effectiveness research to investigate the justice appeal for LDCs as distinguished from hedonism, utilitarianism, and altruism. Further, the research makes a contribution by investigating the mechanism by which the justice appeal and images of LDCs are related to promotion effectiveness within the context of the inner-other directedness personality trait and product type (hedonic and utility).

This research was conducted using an experimental methodology. The experiment was designed to incorporate four appeal types with replication across two countries and two products. Participants were asked to respond to one promotional tag providing one of four different appeal types for a country and product. The sample was comprised of undergraduate students drawn from three Ontario universities.

The results include three key findings for the effectiveness of promotions. First, the justice promotion can have broad appeal, especially when compared against the alternative other-oriented promotion (altruism). Second, there is empirical support for congruency effects. Those respondents who were high on the other-directedness personality trait gave more favourable outcome ratings to other-oriented promotional appeals. Those who were more inner-directed gave cognitively emphasized appeals better outcome ratings than promotions that are emotion-based. Third, results indicate 
that LDC images mediate the relationship of appeal type to promotion effectiveness through two dimensions: country and people competence and country character. 


\section{Acknowledgements}

I would like to thank my committee for applying their expertise to this study and supplying comments on my efforts. In particular, I wish to thank my supervisor, Dr. Louise Heslop, for her dedication to excellence and quick turnaround on earlier versions of the dissertation. She sets professional standards as a teacher and researcher that I can only hope to come close to in my academic career.

I would also like to thank my wife, Rosemary, for understanding the primacy of a dissertation for this period in my life and for taking care of our son when I was working on it during those evenings, weekends and cancelled vacations.

Thank you, Griffin. You give new meaning to life. This dissertation is two weeks younger than you. 


\section{Table of Contents}

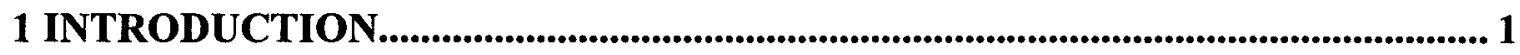

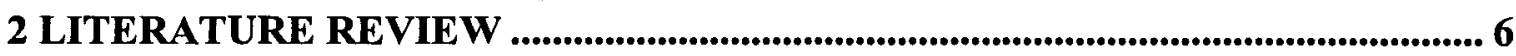

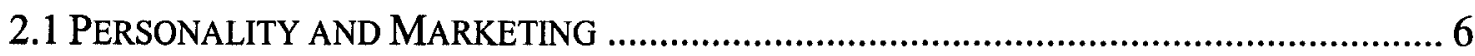

2.1.1 Personality Theory.................................................................................. 7

2.1.2 Personality Traits............................................................................... 12

2.1.3 Personality's Influence on Consumer Behaviour ......................................... 17

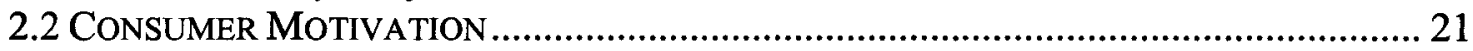

2.2.1 Theories of Motivation.......................................................................... 22

2.2.2 Categorization of Motives ........................................................................... 25

2.2.3 Motivation Influence on Consumer Behaviour ............................................. 45

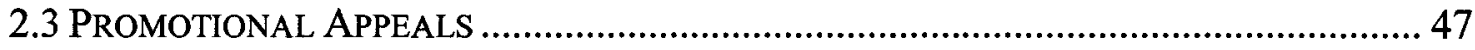

2.3.1 Types of Appeals .................................................................................. 48

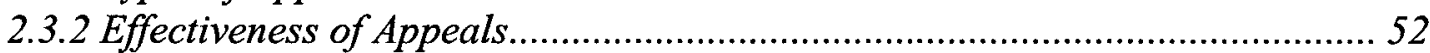

2.3.3 Assessing Appeal Effectiveness ................................................................. 61

2.3.4 Importance of Appeal Context ...................................................................... 66

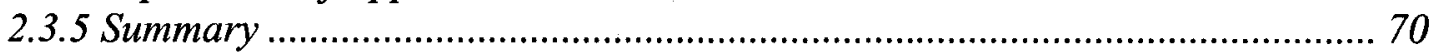

2.4 LESS DEVELOPED CoUNTRIES AND BRANDING ......................................................... 71

2.4.1 Image of Less Developed Countries and Their Products .............................. 76

2.4.2 Country Image and Individual Differences................................................... 83

2.4.3 Summary of Less Developed Countries and Country Branding ...................... 85

2.5 SUMMARY OF LITERATURE ............................................................................. 86

3 RESEARCH OBJECTIVES AND HYPOTHESES .................................................90

4 RESEARCH METHODOLOGY ................................................................... 104

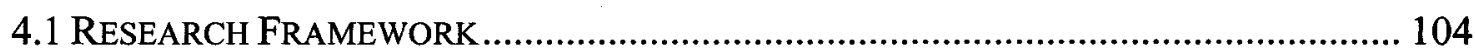

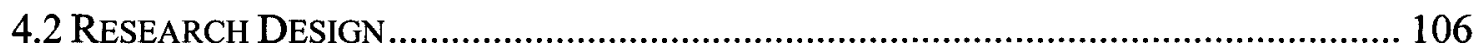

4.2.1 Stimulus Country Selection Process ......................................................... 106

4.2.2 Stimulus Product Selection .................................................................... 110

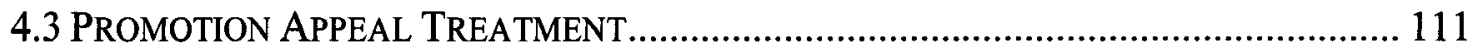

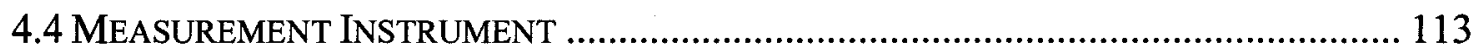

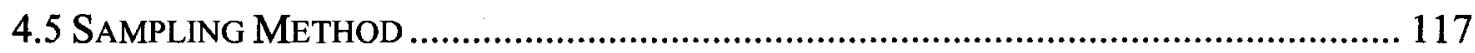

4.6 PRETESTING THE RESEARCH INSTRUMENT ........................................................ 118

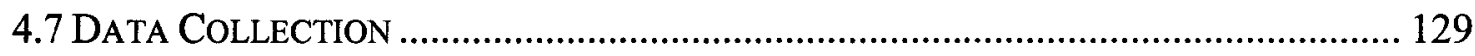

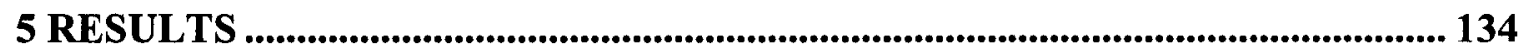

5.1 CounTRY IMAGE DESCRIPTIVE RESUlTS......................................................... 134

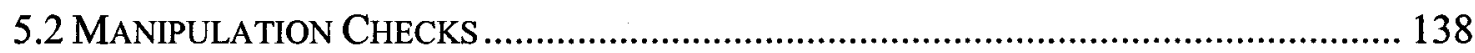

5.3 HYPOTHESIS TESTING ................................................................................. 142

5.3.1 Testing Hypothesis 1 Series - Appeal Type to Promotion Effectiveness........ 142

5.3.2 Testing of Hypothesis 2 Series - Country Image to Promotion Effectiveness 157 
5.3.3 Testing Hypothesis 3 Series - Appeal Type to Country Image ...................... 170

5.3.4 Testing Hypothesis 4 - Country Image as an Intervening Variable............. 179

5.3.5 Discussion of Results ........................................................................... 182

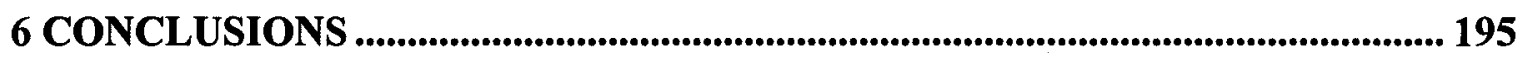

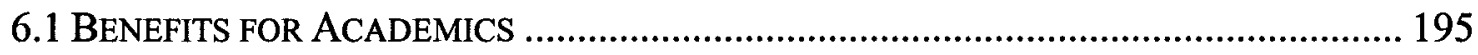

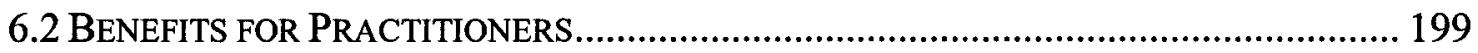

6.3 BENEFITS FOR POLICY MAKERS .................................................................. 202

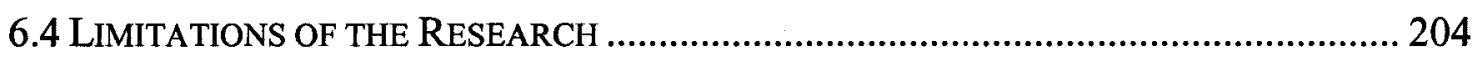

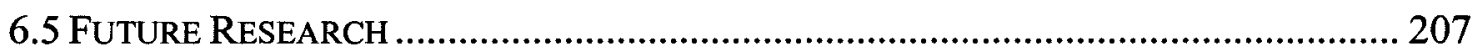

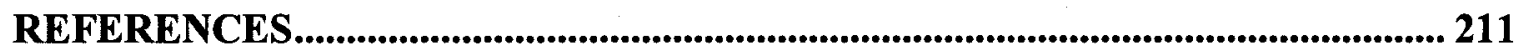

APPENDIX A - MEASUREMENT INSTRUMENT ........................................ 226

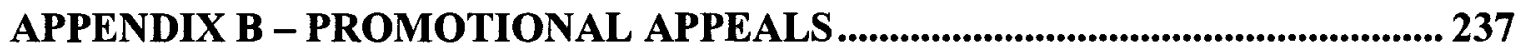




\section{List of Tables}

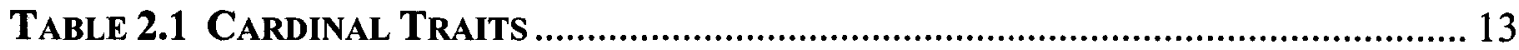

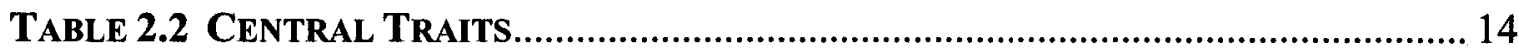

TABLE 2.3 EXAMPLES OF SURFACE TRAITS ......................................................... 16

TABLE 2.4 HEDONISM MEASUREMENT EXAMPLES..................................................... 29

TABLE 2.5 UTILITARIAN MEASUREMENT EXAMPLES............................................... 31

TABLE 2.6 TYPES OF PROMOTION APPEALS …………….............................................. 49

TABLE 2.7 MEASUREMENT OF APPEAL EFFECTIVENESS ................................................6 63

TABLE 2.8 MEASUREMENT OF ADVERTISEMENT EVALUATION .....................................64

Table 2.9 Measurement of Product and Brand Evaluations...........................6 65

TABLE 2.10 PCI MEASURES FOR COUNTRY COGNITIONS ………................................ 74

TABLE 2.11 PCI MEASURES For PRoduct Cognitions …………………………....... 74

TABLE 2.12 PCI MEASURES FOR AFFECT AND EVALUATION ........................................ 75

Table 2.13 Examples of Product Brands from Less DeVeloped Countries .. 81

TABle 4.1 Central Messages by ApPeal and Product TyPe ............................. 113

TABLE 4.2 QUESTIONNAIRE SCALES AND MEASURES............................................... 115

Table 4.3 Pretest Manova Results for Product Complexity and Purchase

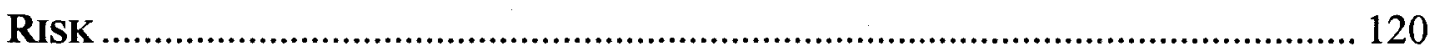

TAble 4.4 Pretest MANOVA Results for Product Representations ............ 122

TABle 4.5 Pretest MANOVA Results for APPEAl Representations................ 126

TABLe 4.6 PRetest Representation MEANS for the Justice APPEAL.................. 127

Table 5.1 Mean Responses for Country and People Measures.......................... 135

TABLE 5.2 LOADINGS OF COUNTRY IMAGE VARIABLES FOR COLOMBIA AND

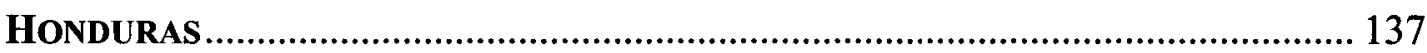

TABLE 5.3 MEAN RESPONSES for APPEAL REPRESENTATION MEASURES.................. 139

TABLE 5.4 MEAN RESPONSES FOR AGGREgATED APPEAL REPRESENTATION MEASURES

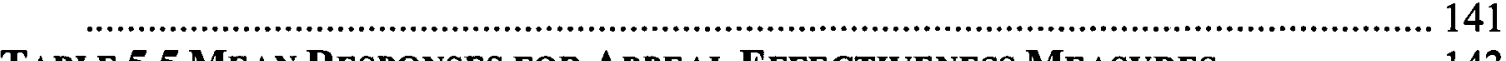

TABLE 5.5 MEAN ReSPONSES for APPEAL EFFeCtIVENESS MEASURES ..................... 143

TABLE 5.6 MANOVA RESULTS FOR HYPOTHESES 1 B-1C TESTING ………................. 146

TABLE 5.7 MEAN SCORES fOR THE APPEAL AND PERSONALITY INTERACTION........... 148

TABLE 5.8 MANOVA RESULTS FOR HYPOTHESES 1D-1G TESTING ............................ 155

TABLE 5.9 MEAN SCORES FOR PRODUCT EFFECTS ............................................... 155

TABLE 5.10 MANOVA RESULTS FOR TESTING HYPOTHESIS 2A ……....................... 158

TABLE 5.11 MANOVA RESULTS FOR TESTING HYPOTHESES 2B-2C …………............ 164

TABLE 5.12 MANOVA RESULTS FOR TESTING HYPOTHESES 2D-2G........................... 169

TABLE 5.13 MANOVA RESULTS FOR TESTING HYPOTHESIS 3A ……...................... 172

TABLE 5.14 MEAN SCORES FOR THE APPEAL MAIN EFFECTS ……........................... 173

TABLE 5.15 MANOVA RESULTS FOR HYPOTHESES 3B-3C TESTING …..................... 175

TABLE 5.16 MANOVA RESULTS FOR HYPOTHESES 3D-3G TESTING........................... 176

TABle 5.17 Mean SCORes for the InTeraction OF Appeal, Personality and

PRODUCT ON CoUNTRY CHARACTER............................................................... 176

TABLE 5.18 MANOVA RESULTS FOR APPEAL TYPE AND COUNTRY IMAGE

Dimensions to Promotional Appeal EfFectiveness 
TABLe 5.19 Summary OF HyPotheses Testing Results

viii 


\section{List of Figures}

Figure 2.1 Evolution Of Motivation Models (From Pincus 2004).................... 24

Figure 2.2 Motivation-Based APPeal Types in the CONTEXt Of Personality

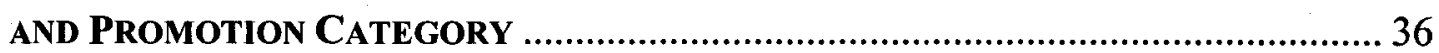

FIGURE 2.3 INTERSECTION OF BRAND AND COUNTRY IMAGES FOR LDCS ................. 78

FIGURE 2.4 GENERALIZED RESEARCH FRAMEWORK ......................................... 87

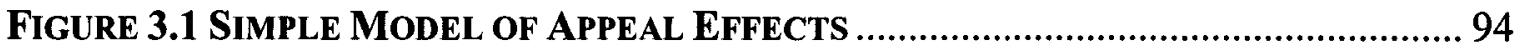

FIGURE 3.2 MODEL OF COUNTRY IMAGE EFFECTS ..................................................... 96

FIGURE 3.3 APPEAL EFFECTS ON COUNTRY IMAGE ........................................... 99

FIGURE 3.4 BIfURCATED MODEL OF APPEAL EFFECTS .......................................... 102

Figure 3.5 A Chain MOdel of Appeal EfFects - Country IMAge as AN

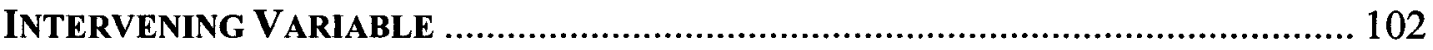

FigURE 4.1 RESEARCH FRAMEWORK FOR LDC PROMOTIONAL APPEAL

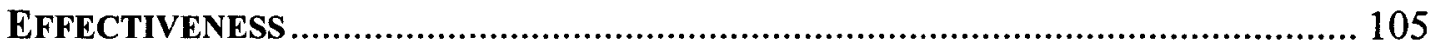

Figure 4.2 Framework fOr Selecting Proposed Stimulus Countries

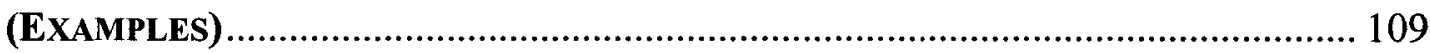

Figure 4.3 EXPERimental Treatment Stimulus (Promotional TAgS) ............. 112

Figure 4.4 Inner-Other Directedness Pretest SCree Plot ........................... 119

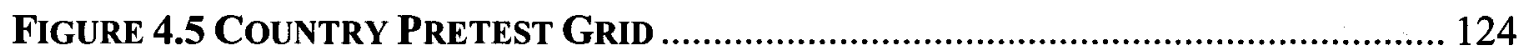

Figure 5.1 HyPothesis 1 SERIES - Simple Model of APPEAL EFFECTS................ 145

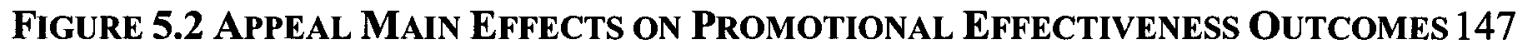

Figure 5.3 PERSONALITY ANd APPEAL INTERACTION EFFECTS ON PROMOTION

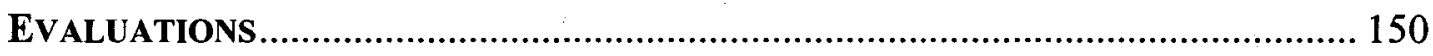

Figure 5.4 Personality and APPEAL Interaction EFfects ON ProduCt

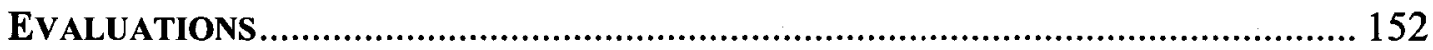

Figure 5.5 Personality and ApPeal InTERACtion EfFects on Purchase

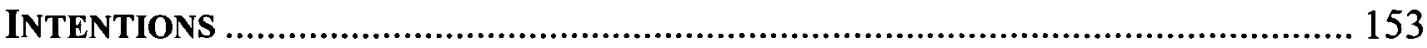

FIGURE 5.6 HYPOTHESIS 2 SERIES - SiMPLE MODEL OF COUNTRY IMAGE EFFECTS 158

Figure 5.7 MAIn EFFects for CoUnTRY AND PEOPle CoMpetence ON APPEAL

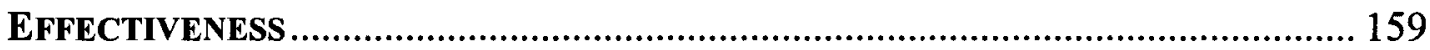

Figure 5.8 Main EFFects for Country ChaRACTER ON APPEAL EFFeCTIVENESS

Figure 5.9 Main EfFects for People CharaCter on APPEal EfFectiveness.. 162

FIGURE 5.10 INTERACTION EFFECTS FOR INNER-OTHER DIRECTEDNESS AND COUNTRY

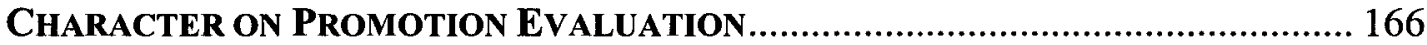

FIGURE 5.11 INTERACTION EFFECTS FOR INNER-OTHER DIRECTEDNESS AND COUNTRY

CHARACTER ON PRODUCT EVALUATION ...................................................... 167

FIGURE 5.12 APPEAL EFFECTS ON COUNTY IMAGE .......................................... 171

FIGURE 5.13 MAIN EFFECTS FOR APPEAL TYPE TO COUNTRY IMAGE DIMENSIONS.. 174

Figure 5.14 InTERACTION EFFECTS FOR APPEAL, PERSONAlity AND PRODUCT ON

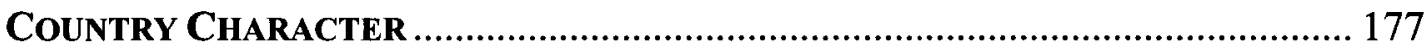

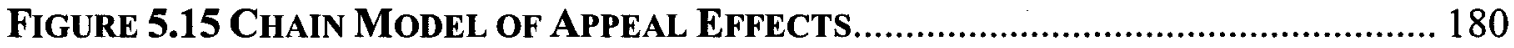

FIGURE 5.16 BIfURCATEd MOdEL OF APPEAL EFFECTS ....................................... 192 
Figure 5.17 Final Chain Model of Appeal Effects 193

FIGURE 6.1 MODIFIED INTERSECTION OF BRAND AND COUNTRY IMAGES FOR LDCS 201 


\section{INTRODUCTION}

Ideals, rooted in religion or morality, are becoming more important to consumers striving to meet their needs. The term 'metrospiritual' has recently been coined to describe consumers who "want to treat the earth and native cultures with respect, connect with their inner source and inspiration, test their bodies and expand their minds with ancient physical practices" (Speyer 2005). Virtuous consumption and the related shopping process can be very important. People are "shopping (their) way to salvation" (Harris 2005, D1). However, it would be a mistake to regard this phenomenon as constrained to those with strong religious views. This trend is broader and can affect many, as people seek out fair trade products, organically grown vegetables, or other virtuous products on the basis of creating a "just planet".

Global economic integration has deepened in recent years, developing through a quest for cheap labour and available raw materials. The result is that 'Less Developed Countries' (LDCs) play a more important role in the global economy. "There is no established convention for the designation of "developed" and "developing" countries or areas in the United Nations system. In common practice, Japan in Asia, Canada and the United States in northern America, Australia and New Zealand in Oceania and Europe are considered "developed" regions or areas" (OECD 2006).

Anholt (2005) presents some world trade facts that demonstrate an overall increase of LDC global manufacturing export share from $17 \%$ in 1990 to $27 \%$ in 2000 . 
However, he also directs attention to an economic counter current where the poorest countries have not participated in growth. For instance, countries like Nepal that experienced recent political instability tend not to have the ability to participate in global economic upswings.

While LDCs now have significant presence in the global economy, marketing knowledge may assist them in strengthening their position. Country-based brands can be an important lever for LDCs as a means to distinguish one country from another and a basis for appealing to consumers. Distinguishing countries from one another may be particularly useful for LDCs with commodity-based country images where there is little opportunity to set value-added prices. Brand identity is defined as "a unique set of brand associations that the brand strategist aspires to create or maintain. These associations represent what the brand stands for and imply a promise to customers from the organization members". (Aaker 1996, p.68). Commodity-based country brands are common for LDCs (e.g. Colombia and coffee; Venezuela and oil). LDCs are rarely associated with products other than commodities and their products are largely undifferentiated on world markets (Anholt 2005). Therefore, LDCs are less able to command value-added prices. From a practitioner and policy maker perspective, research exploring country-based branding of LDC's products is desirable because it may identify an avenue of promotion that is not reliant upon existing commodity-based country images. 
This study is particularly concerned with LDCs that have credible development needs but have the capacity for credibility in development of value-added, branded products. This capacity is not found in countries that are severely dysfunctional so as to be perceived as hopeless cases by consumers. The purpose of the research is to identify both the characteristics of consumers who might be more responsive to appeals from LDCs and the type of appeals that may be more effective for these consumers. Therefore, the study examines consumer responses to different types of motivation-based appeals and how these responses are related to consumer characteristics, particularly the inner-other directedness personality trait. This study represents an extension of previous research on social orientation and promotion effectiveness (Brunel and Nelson 2000; Aaker and Williams 1998; Zhang and Gelb 1996) into the sphere of product branding for LDCs.

Within this general purpose, the research builds on the interaction of personality with appeal effectiveness research to investigate a major motivation appeal type for LDCs distinct from hedonism, utilitarianism, and altruism. This proposed fourth appeal type exists within the intersection of the social orientation personality trait and the feeling-thinking appeal effectiveness continuum. While Anholt (2005) suggests that other-oriented appeals for LDC's products are detrimental to their value assessment, this study will explore the possibility that a cognitive based, other-oriented appeal may positively contribute to perceptions of the promotion, the brand and purchase intentions. 
This dissertation presents a literature review in four parts. Each part addresses relevant streams of personality, motivation, appeal effectiveness and developing country images. Trait theory is the most commonly used approach to personality in the marketing literature. Inner-other directedness, self-monitoring and the 'Big Five' factor model (extroversion/introversion, agreeableness, conscientiousness, neuroticism/emotional stability, and openness to experience/creativity) are among the most researched traits in the literature.

The literature review continues with a presentation of research on consumer motivation. Motivation involves the arousal and direction of behaviour to achieve a certain goal. Motivation influences the decision-making process by enhancing or limiting consumer engagement, aiding attention and comprehension, and directing the selection of information to be used and the brands included in the consideration set. Therefore, motivation is highly relevant to the study of appeal effectiveness.

The literature review also examines research on promotional appeals. While there are several different types of appeals, they can generally be classified into cognitive (information or belief-based) and affective (feelings or emotion-based) categories. The discussion of research results highlights the mixed findings present in the literature but emphasizes the need to be aware of potential moderating influences on appeal effectiveness. 
The literature review concludes with an examination of LDC images. Despite weak images typically associated with LDCs, some LDC manufacturers have employed strategies to succeed in developed country markets. A literature gap is identified where research on LDC marketing strategies seems to exclude an assessment of promotional appeal effectiveness for products from these countries. While some products from LDCs move upwards from a low price position toward one of prestige, many remain positioned in a commodity space with little ability to command premium prices. The influence of country images on consumer decision-making is an important consideration for marketers and recent research strives to better understand the creation of successful country brands derived from country images. Research on country images and personality demonstrates that some traits can influence country image effects on consumers.

Following the discussion of literature, two research gaps emerge that are delineated. These gaps provide the basis for articulating the main research hypotheses. The research framework, experimental research design and the results and analysis of the survey are presented. Finally, the major conclusions of the research as well as the anticipated benefits and limitations of the research are discussed. 


\section{LITERATURE REVIEW}

This dissertation presents a literature review in four parts: personality, motivation, appeal effectiveness and developing country images. The review of these areas will demonstrate that two research gaps exist. The first gap is found where research about social orientation personality traits (inner-other directedness) intersects with motivationbased promotional appeals. The second gap is identified in the area of LDC images, country branding, and the effectiveness of promotional appeals.

\subsection{Personality and Marketing}

A pioneering personality psychologist, Allport, defined personality as "the dynamic organization within the individual of those psychophysical systems that determine his characteristic behaviour and thought" (Allport in Lester 1995, p.2). The emphasis of this definition is on providing an explanation of why people differ based on consistent behaviours and thought over time. More recently, Maddi (1996) defined personality as "a stable set of tendencies and characteristics that determine those commonalities and differences in people's psychological behaviour (thoughts, feelings, and actions) that have continuity in time and that may not be easily understood as the sole result of the social and biological pressures of the moment" (p.8). The recent definition echoes the first by stating personality is about stable behaviour and thoughts. However, an important distinction between these definitions is the acknowledgement by Maddi (1996) that common behaviour among people can be as important as differences. This reflects a more holistic viewpoint of the individual in the study of personality. Maddi 
(1996) also contributed to the definition of personality by separating behaviour associated with personality from other situational determinants and includes feelings among thoughts and actions as outcomes.

Marketing definitions of personality tend to reflect the earlier personality definition from psychology. Plummer (2000) provides a definition in the marketing literature that presents personality as "the way individuals react fairly consistently to a variety of environmental situations" (p.79). The key aspects of this definition include individual persons, their environment, and consistent behavioural outcomes. Similarly, Hawkins, Best and Coney (2004) in their consumer behaviour textbook present a definition of personality as "the common responses (behaviours) that individuals make to a variety of recurring situations" (p. 354).

Therefore, the critical requirements of personality are identified. First, personality is observed in characteristically consistent behaviours, thoughts and feelings sourced within the individual. Second, there are common responses shared among groups of people. Third, there is a reference to the requirement of stability in responses over time.

\subsubsection{Personality Theory}

Ryckman (1989) notes that, "no one theorist can ever hope to construct a completely adequate theory of personality. The task is clearly too complex and difficult" (p.1). Despite the complexity of the task, people have put forward different theories to 
explain how personality works. There are two contrasting approaches to describing multiple posited personality theories: study of the individual versus individual differences (Winter and Barenbaum 1999).

The study of the individual examines people "as unique, integrated wholes" (Winter and Barenbaum 1999, p.6). For example, psychiatry "treats personality from a functional, historical-genetic standpoint" (ibid). A qualitative approach to examining personality dominated psychology in the early 1900's although researchers in North America generally retained a focus on quantitative studies during that time. Winter and Barenbaum (1999) point to a leading personality psychologist, Henry Murray, as a developer of theory around the holistic perspective of the individual. Murray was particularly concerned with underlying needs that drive a person and criticized the trait concept as pre-occupied with consistency (Pervin 1989). While trait theory dominates personality discourse, Pervin (1989) suggests that Murray's thinking may help to describe "the complex interplay among the determinants of behaviour" (p.323), an aspect of personality where trait theory is weak.

The study of individual differences is considered quantitative and explores people through "cross sectional treatment of personality in terms of traits, attitudes and habits" (Winter and Barenbaum 1999, p.6). This approach to personality theory contains different models classified as conflict, fulfillment, and consistency models (Maddi 1996). 
The conflict model presents personality as the result of powerful forces that are "continually acting, necessarily opposed, and unchangeable" (Maddi 1996, p.18). Freud's psychoanalytic theory of personality is an example of a conflict model because he described personality resulting from negotiation among internal forces identified as the id, ego and superego. The id is the unconscious pleasure center and is considered the original aspect of personality (Ryckman 1989). The superego is described as "the individual's internalization of societal moral values" (Ryckman 1989, p.34). While the id is in conflict with the superego, the ego becomes the mediator between the two forces (Ryckman 1989). In a marketing example, Smith et al. (1995) demonstrate personality has an important influence on the effectiveness of appeals. Using partial nudity in advertisements Smith et al. (1995) found those with high sex guilt rated advertisements with female nudity significantly lower than people with low sex guilt. Sex guilt was defined as "the extent to which people are comfortable with sexual matters, and more specifically, with sexual arousal" (Smith et al. 1995, p. 736). The individual differences found responsible in the Smith et al. (1995) study may be explained through variations in subconscious biological needs that are central to psychoanalytic theory.

Describing personality theory using the fulfillment model "assumes, at the core level, only one great force and locates it within the individual" (Maddi 1996, p.20). For instance, Adler viewed personality resulting from people coping with feelings of inferiority and the compensatory strivings to diminish these feelings (Pervin 1989). These feelings and strivings become "a part of his or her style of life - a distinctive aspect of his or her personality functioning" (Pervin 1989, p.147). 
Trait theory reflects the fulfillment approach to personality. Trait theory refers to the characterization of "individuals in terms of a comprehensive but finite and preferably small set of stable dispositions" (Tan Tsu Wee 2003, p.318). A key aspect of this approach is the stability of traits in any situation. This stability results from the great force at a core level of the individual. Trait theory is the most widely accepted approach to studying the influence of personality on consumer behaviour (Cowley and Caldwell 2001).

The environment can also affect the personality of the individual. While the conflict and fulfillment models emphasize internal forces, the consistency model "emphasizes the formative influence of feedback from the external world on the individual" (Maddi 1996, p.22). This approach is reflected by Tan Tsu Wee (2003) questioning whether the "main causes of behaviour were rooted internally in the person's personality system, or externally in the characteristics of the environmental situation ... the role of culture, socialisation, language and the individual definition of the situation that help to make sense of intra-individual variability across situations" (p.318). While the importance of societal influence distinguishes this theoretical approach from psychoanalytic theory, Freud's psychoanalytic theory of personality, for example, also includes society influences through the superego and its norms that guide behaviour.

A social cognition approach represents a consistency model because it describes the interaction of personality traits and the environment. Social cognition prescribes that 
"individual differences, such as personality traits, influence one's perception of the world. Individuals possess schemas that are activated upon receipt of incoming information, and these schemas influence perceptions of environmental stimuli" (Mowen, Harris and Bone, 2004, p.931). In other words, personality can shape our view of the world so one person's interpretation of an environmental stimuli may be distinct from the interpretation of another person. For example, Mowen, Harris and Bone (2004) found different advertisement appeals led to varying levels of emotional response depending on the individual as represented through personality characteristics.

While the consistency of behaviour is a requirement of trait theory, some scholars now use an interactionist approach to acknowledge that environmental or situational stimuli can impact trait influence. Cowley and Caldwell (2001) claim researchers now view personality traits as "the conditional probability of a category of behaviours given a category of contexts" (p.24).

As marketers have extended personality theory to products (e.g. Aaker 1999), the socio-psychological approach views products purchased and used in a social context as having symbolic significance for the individual (Hunt, Kernan and Mitchell 1996; Govers and Schoormans 2005). The symbolic significance is based on congruence theory that posits people will seek products with images that exhibit personality characteristics similar to themselves rather than dissimilar (Aaker 1999). Further, there is some evidence to show that personality can influence attraction to products (Govers and Schoormans 2005). A major criticism of this approach resides with the tendency of the 
perspective to omit consistent individual differences, a critical element of personality (Tan Tsu Wee 2003).

While different approaches exist to explain how personality affects consumer behaviour, trait theory tends to be the most common perspective applied in marketing research. Within this approach, an interactionist viewpoint acknowledging situational or environmental factors has gained recent attention.

\subsubsection{Personality Traits}

Research into personality traits is rooted in the assumption "that individuals are born with a preference for some functions over others and together with their environments, preferences are established" (LaBarbera, Weingard and Yorkston 1998). Several different traits may be included in research on personality (Baumgartner 2002). However, Harris and Morris (2001) cite the three main categories of personality traits: cardinal, central and surface traits. This categorization is considered a hierarchy as each level increases the intensity of influence on behaviour (Mowen, Harris and Bone 2004).

Cardinal traits refer to those underlying dispositions that exist at a very deep level and define the individual (Harris and Morris 2001). The Big Five factor model is a common set of cardinal traits that are believed to constitute a personality and is comprised of extroversion/introversion, agreeableness, conscientiousness, neuroticism/emotional stability, and openness to experience/creativity (see Table 2.1). 
While there are other approaches to describing personality at a very deep level (e.g. Cowley and Caldwell 2001; LaBarbera, Weingard and Yorkston 1998), the Big Five factor model is generally the most used approach (Harris and Morris 2001). Further, some of these additional approaches to deep level traits can be traced directly back to the Big Five factor model. For instance, the competence trait is considered a sub facet of conscientiousness while anxiety is a sub facet of neuroticism and compliance is a sub facet of agreeableness (Cowley and Caldwell 2001).

\section{Table 2.1 Cardinal Traits}

\begin{tabular}{|c|c|c|}
\hline Traits & Example Measures & Sources \\
\hline Extroversion & $\begin{array}{l}\text { Prefer to be alone, } \\
\text { uncomfortable in a group, } \\
\text { bashful, bold, extroverted } \\
\text { with people, quiet with } \\
\text { other people, shy, } \\
\text { talkative with others, } \\
\text { withdrawn }\end{array}$ & $\begin{array}{l}\text { Mowen, Harris and Bone } 2004 \\
\text { Hunthausen, Truxillo, Bauer and } \\
\text { Hammer } 2003 \\
\text { Chang } 2001 \\
\text { Harris and Mowen } 2001 \\
\text { LaBarbera, Weingard and } \\
\text { Yorkston } 1998\end{array}$ \\
\hline Agreeableness & $\begin{array}{l}\text { rude, harsh when others } \\
\text { make a mistake, tender } \\
\text { hearted, cold to others, } \\
\text { kindness, warmth, } \\
\text { sympathy and sensitivity }\end{array}$ & $\begin{array}{l}\text { Mowen, Harris and Bone } 2004 \\
\text { Hoon Tan, Der Foo and Hui Kwek } \\
2004 \\
\text { Hunthausen, Truxillo, Bauer and } \\
\text { Hammer } 2003 \\
\text { Harris and Mowen } 2001\end{array}$ \\
\hline Conscientiousness & $\begin{array}{l}\text { careless, precise, efficient, } \\
\text { organized, sloppy, orderly }\end{array}$ & $\begin{array}{l}\text { Mowen, Harris and Bone } 2004 \\
\text { Hunthausen, Truxillo, Bauer and } \\
\text { Hammer } 2003 \\
\text { Harris and Mowen } 2001\end{array}$ \\
\hline $\begin{array}{l}\text { Neuroticism/emotional } \\
\text { stability }\end{array}$ & $\begin{array}{l}\text { moody, temperamental, } \\
\text { touchy, envious, emotions } \\
\text { go way up and down, } \\
\text { testy, jealous }\end{array}$ & $\begin{array}{l}\text { Mowen, Harris and Bone, } 2004 \\
\text { Hunthausen, Truxillo, Bauer and } \\
\text { Hammer } 2003 \\
\text { Harris and Mowen } 2001\end{array}$ \\
\hline $\begin{array}{l}\text { Openness to } \\
\text { experience/creativity }\end{array}$ & $\begin{array}{l}\text { highly creative, } \\
\text { imaginative, appreciative } \\
\text { of art, enjoy beauty, find } \\
\text { novel situations, more } \\
\text { original than others }\end{array}$ & $\begin{array}{l}\text { Mowen, Harris and Bone } 2004 \\
\text { Hunthausen, Truxillo, Bauer and } \\
\text { Hammer 2003 } \\
\text { Harris and Mowen } 2001\end{array}$ \\
\hline
\end{tabular}


Central traits represent the second layer in the hierarchy and refer to the dispositions that "act to guide individuals through numerous situations" (Harris and Morris 2001, p.1159). These traits also exist at a deep level in the individual directing behaviour over many different contexts yet they are not as directly and specifically observable in action as surface traits. Within the level of central traits, these traits can be classified as orientation, view of the self and needs-based. Table 2.2 displays several examples of the many possible central traits that can be used to categorize personalities.

Table 2.2 Central Traits

\begin{tabular}{|l|l|l|}
\hline Type & Traits & Sources \\
\hline Orientations & $\begin{array}{l}\text { Inner-other directedness } \\
\text { (idio/allocentrism) }\end{array}$ & $\begin{array}{l}\text { Gregory, Munch and Peterson 2002 } \\
\text { Dutta and Vanacker 2000 } \\
\text { Mcdonald and Jacobs 1992 }\end{array}$ \\
\cline { 2 - 3 } & Maximizers vs satisficers & $\begin{array}{l}\text { Schwartz, Ward, Monterosso, } \\
\text { Lyubomirsky, White and Lehman 2002 }\end{array}$ \\
\cline { 2 - 3 } & Competitiveness & Mowen, Harris and Bone 2004 \\
\cline { 2 - 3 } & Impulsivity & Jones and Lejuez 2005 \\
\cline { 2 - 3 } & Risk taking propensity & Jones and Lejuez 2005 \\
\hline View of Self & Self-monitoring & $\begin{array}{l}\text { Dutta and Vanacker 2000 } \\
\text { Aaker 1999 } \\
\text { Shavitt 1989 }\end{array}$ \\
\hline \multirow{5}{*}{ Needs-Based } & Need for cognition & Mourali, Laroche and Pons 2005 \\
\cline { 2 - 3 } & Self-confidence & Mourali, Laroche and Pons 2005 \\
\cline { 2 - 3 } & General self-efficacy & Mowen, Harris and Bone 2004 \\
\cline { 2 - 3 } & Need for material resources & Mowen, Harris and Bone 2004 \\
\cline { 2 - 3 } & Need for arousal & Mowen, Harris and Bone 2004 \\
\cline { 2 - 3 } & Need for body resources & Jones and Lejuez 2005 \\
\cline { 2 - 3 } & Sensation seeking &
\end{tabular}

The orientation group of traits guide behaviour across different situations by providing a general outlook or perspective. For instance, the inner-other directedness is 
representative of the propensity to place themselves versus a group as priority. Kassarjian (1962) described the inner-other directedness trait as the extent a person places emphasis on him/herself versus others to reference values and standards that guide their behaviour.

In the 1930's, Allport "called attention to the importance of the self for personality integration and functioning" (Winter and Barenbaum 1999, p.17). Therefore, the view of one's self provides a basis for individual differences that can influence behaviour over multiple situations. For instance, the self-monitoring trait "conveys the extent to which an individual is likely to monitor and control his/her expression in situations which contain reliable cues to social appropriateness" (Dutta and Vanacker 2000, p.120). Those who are high self-monitors will be guided to fulfill public identity goals using a solution that is congruent to their image of self (Aaker 1999).

Need-based traits are a third type of central traits that guide an individual's behaviour. These refer to the categorization of individuals based on their perception of unmet needs. For instance, the sensation-seeking trait captures the extent a person is looking for "varied, novel, complex, and intense situations and experiences, and the willingness to take physical, social, and financial risks for the sake of such experience" (Jones and Lejuez 2005, p.260). These needs-based traits are important because those who strongly perceive a certain need will behave in a manner that is different from those who are low in the need. In the case of sensation seeking, the trait may be positively 
related to consumer behaviour that selects products providing stimulation (Jones and Lejuez 2005).

Surface traits are considered to be the third tier of the hierarchy and refer to the "individual differences that influence behaviour within specific consumption situations" (Harris and Morris 2001, p.1160). This level of traits accommodates the interactionist theoretical position that argues for flexible traits adjusting to the environment with leniency applied to the consistency requirement of personality. There are many surface traits. Table 2.3 presents a few examples discussed in the literature. As the definition suggests, these traits are typically oriented around activities or situations. For example, a person's likelihood of being influenced by interpersonal information sources is dependent upon the knowledge they have about a product class (Mourali, Laroche and Pons 2005).

\section{TABLe 2.3 EXAMPLes OF SURface Traits}

\begin{tabular}{|l|l|}
\hline Traits & Source \\
\hline Susceptibility to interpersonal influence & Mourali, Laroche and Pons 2005 \\
\hline Coping responses & Arthur and Quester, 2004 \\
\hline Coupon proneness & Harris and Morris 2001 \\
\hline Consumer ethnocentrism & Harris and Morris 2001 \\
\hline Consumer innovativeness & Harris and Morris 2001 \\
\hline Complaint propensity & Harris and Morris 2001 \\
\hline Bargaining proneness & Harris and Morris 2001 \\
\hline
\end{tabular}

In summary, personality has the potential to effect and has been linked to consumer decision-making. Of the three theoretical approaches, trait theory appears to be 
the most popular among consumer marketing scholars. However, echoes of the other approaches exist within trait theory.

\subsubsection{Personality's Influence on Consumer Behaviour}

The nature of personality is important to the field of marketing because differences in behaviours, thoughts and feelings of individuals may be stable over time and situations. Therefore, it can influence how people make purchase decisions and the type of products selected. Previous research indicates that personality can influence several stages of the decision-making process including response to promotion appeals, information search, product evaluations, purchase decision, outcomes of the purchase, and satisfaction.

As previously mentioned, personality can shape our view of the world and our response to environmental stimuli. The same promotional appeal can be interpreted differently depending on the personality of the individual. Mowen, Harris and Bone (2004) examined personality traits and two different advertisement appeals for driver safety behaviour (aggressive driving and inattentive driving). They found that a fear response was more likely for people that are high versus low introversion when presented with these advertisements. Therefore, personality traits can help explain differences in responses to promotional appeals.

Once a need is recognized, consumers conduct internal and external information search to enable assessments of the available options (Hawkins, Best and Coney 2004). 
Consumer personality research provides evidence that personality can have an influence in this stage. For instance, Mourali, Laroche and Pons (2005) found that personality traits (i.e. individual's susceptibility to interpersonal influence, their need for cognition, and their self confidence) influenced a person's engagement in interpersonal information search.

Further, research suggests that personality can influence the type of information a consumer uses in the decision-making process. Evidence suggests that an information preference exists when matching the personality portrayal of a promotional message and the personality of the consumer. Moon (2002) found that participants characterized as extroverts preferred extrovert-styled messages while those categorized as introverted preferred introvert-styled messages. In another example, Dutta and Vanaker (2000) found that people who tended not to monitor or control their behaviour for social appropriateness preferred utilitarian appeals over social appeals.

Evaluating the promotion of a product and the product itself is part of the evaluative stage. In this stage, consumers use information to evaluate the different purchase alternatives available to them (Hawkins, Best and Coney 2004). Research suggests that personality can help explain differences in emotional responses to advertisements. Mowen, Harris and Bone (2004) found people were more likely to have a fear response to a promotional appeal if they are characterized as introverted and with a need to protect and enhance their physical resources. In addition, Chang (2001) found that extroverts give more positive ratings to products than introverts indicating that some 
personality traits may lead to consistent levels of evaluations regardless of the appeal type used by the advertiser (Chang 2001).

Consumer personality traits can also affect the evaluation stage of the decisionmaking process through the evaluation of advertisements (LaBarbera, Weingard and Yorkston 1998) and products (Govers and Schoormans 2005; Aaker 1999). In addition, Chang (2001) also found more negative evaluations of a brand when a large difference exists in how people view themselves and the typical user of the product on introversion/extroversion scales.

Research suggests that personality can influence the decision to purchase a product through past consumption, behaviour intentions and product choice. Jones and Lejuez (2005) found a positive relationship between the extent of identification with the personality traits of sensation seeking and impulsivity and past caffeine consumption. Intended behaviour is also affected by personality as different traits can influence whether a consumer is likely to engage in bargaining behaviour (Harris and Mowen 2001). Further, purchase intentions may be influenced when a personality trait (i.e., sensing vs. intuition) matches the visual imagery in advertisements (LaBarbera, Weingard and Yorkston 1998). Laboratory evidence demonstrates that personality can directly influence product choice. Shiv and Fedorikhin (1999) found those with high impulsiveness were more likely to select a decadent dessert than the healthy one. Therefore, personality has been shown to directly influence consumer behaviour through studies of past consumption, behaviour intentions and product choice. 
The decision to purchase a product does not complete the process for the consumer. The consumer is motivated to fulfill a need and their evaluation of the outcomes of the action assist to determine if their needs have been satisfied. Personality can influence this stage of the decision-making process through satisfaction and memory of consumption. For instance, Hoon Tan, Der Foo and Hui Kwek (2004) highlighted the personality trait of agreeableness as being positively related to customer's display of positive emotions and satisfaction with the service provider. In addition, Harris and Mowen (2001) demonstrate that the propensity of a consumer to complain is positively related to certain personality traits (i.e. extraversion, conscientiousness).

Although personality has provided insight into the behaviour of consumers, not all personality research has found associations between personality traits and behaviours. For instance, among their significant results, Mowen, Harris and Bone (2004) did not find support for their hypotheses that competitiveness and self-efficacy traits would be related to responses to a fear appeal advertisement. However, the authors offer the explanation that competitiveness and self-efficacy traits may be too cognitively oriented to predict a fear response (Mowen, Harris and Bone 2004). In a broad review of personality and consumer behaviour research, Kassarjian and Sheffet (1991) show that mostly weak relationships are found between personality and consumer behaviour while only a few studies indicate that a strong or no relationship exists. They argue that the weak findings result from poorly adapted scales, applying the scales out of the intended context, and an absence of hypothesis or theoretical justification. 
The discussion about personality above reveals that it can influence consumers throughout the decision-making process. Overall, a matching of one's personality aspects to that of the product or advertisement tends to be supported by multiple publications. This relationship demonstrates that personality can influence consumer behaviour through the decision-making process, including information search, alternative evaluation and purchase intentions. That being said, congruity between consumers and the product/advertisement is not a requirement for the salience of personality in the consumption context. While there is empirical support for personality influencing consumers, some research suggests that the link does not always exist.

\subsection{Consumer Motivation}

Consumption motives have strong implications for marketers as they can exert influence on the types of products or appeals that are successful. Motivation is defined in marketing research as "a state that directs behaviour toward some goal ... and is generated through a process of comparing and assessing the relationship between the perception of one's current situation with the perception of a desired situation" (Jewell and Kidwell 2005, p.753). Hawkins, Best and Coney (2004) describe motivation as "the reason for behavior" while a motive is described as "a construct representing an unobservable inner force that stimulates and compels a behavioral response and provides specific direction to that response" (p.355). These definitions are consistent with a modern social-psychology perspective that describes motivation as "goal-directed forces within the individual" (Batson 1991, p.5). The definitions recognize the core meaning of 
motivation as a stimulus for action that is geared toward the attainment of some goal. Motivation occurs when consumers become aware of unmet needs (Pincus 2004). The first definition offers an explanation about the occurrence of motivation by referring to a perceptual difference between a desired state and a perceived current state. A large perceived gap between desired and actual states is the strength or motivational drive that will activate or stimulate a motivational state (Jewell and Kidwell 2005). Therefore, the motivation is the direction of behaviour while the motivational drive refers to its strength.

Motivation is important to understanding consumer behaviour because it can influence the processing of information in decision making. This influence can affect the comprehension of information (Celuch and Salma 1995; Van Osselaer et al. 2001), the type of information used (Yang, Allenby and Fennel 2002), and the brands or products considered in the purchase situation (Paulssen and Bagozzi 2005; Chernev 2004).

\subsubsection{Theories of Motivation}

Pincus (2004) argues that motivational theories have evolved from lower-order theories rooted in biology to higher order theories that acknowledge more complex conditions (see Figure 2.1). Lower-order theories explain motivation primarily through physical need fulfillment using constructs such as instinct and drive. Theories concerning the value of instinct reflect Darwin's view of evolution that the strongest or behaviour best suited to environmental conditions leads to survival of the species (Pincus 2004). Drive explains behaviour through the psychological desire to reach a goal (Pincus 2004). Freud's psychoanalytic theories are considered lower-order motivational theories 
that argue negative mental states motivate people into action (Pincus 2004). These lower order theories also provide a linkage between the study of motivation and personality. Pervin (1989) argues that Murray's perspective on personality was based on needs that drive a person. Similarly, the study of motivation explores behaviours directed at the fulfillment of a person's needs.

The evolved theories, or higher-order theories, acknowledge motivations that exist beyond physiological needs and recognize inherent curiosity and individual differences (Pincus 2004). Within this grouping there are the social-cognitive balance theories evolving from the biological bases including balance, field, cognitive dissonance and reactance theories (Pincus 2004). From the psychoanalytic base, effectance motivation theory evolved to account for human interaction with the environment (Pincus 2004). Of these higher-order theories, Maslow's hierarchy of human motivation has been one of the more popularized theories of motivation as evidenced through discussion in marketing textbooks (e.g. Hawkins, Best and Coney 2004). Despite major criticisms pointed directly at the temporal requirement of the hierarchy, recent literature continues to embrace the theory citing that Maslow recognizes fulfillment of needs simultaneously across levels (Huneke 2005). Higher-order theories also include need-based theories that explain individual differences in motivation, namely, need for achievement, need for cognition, need for affiliation and need for power (Pincus 2004). 
Figure 2.1 Evolution Of Motivation Models (From Pincus 2004)

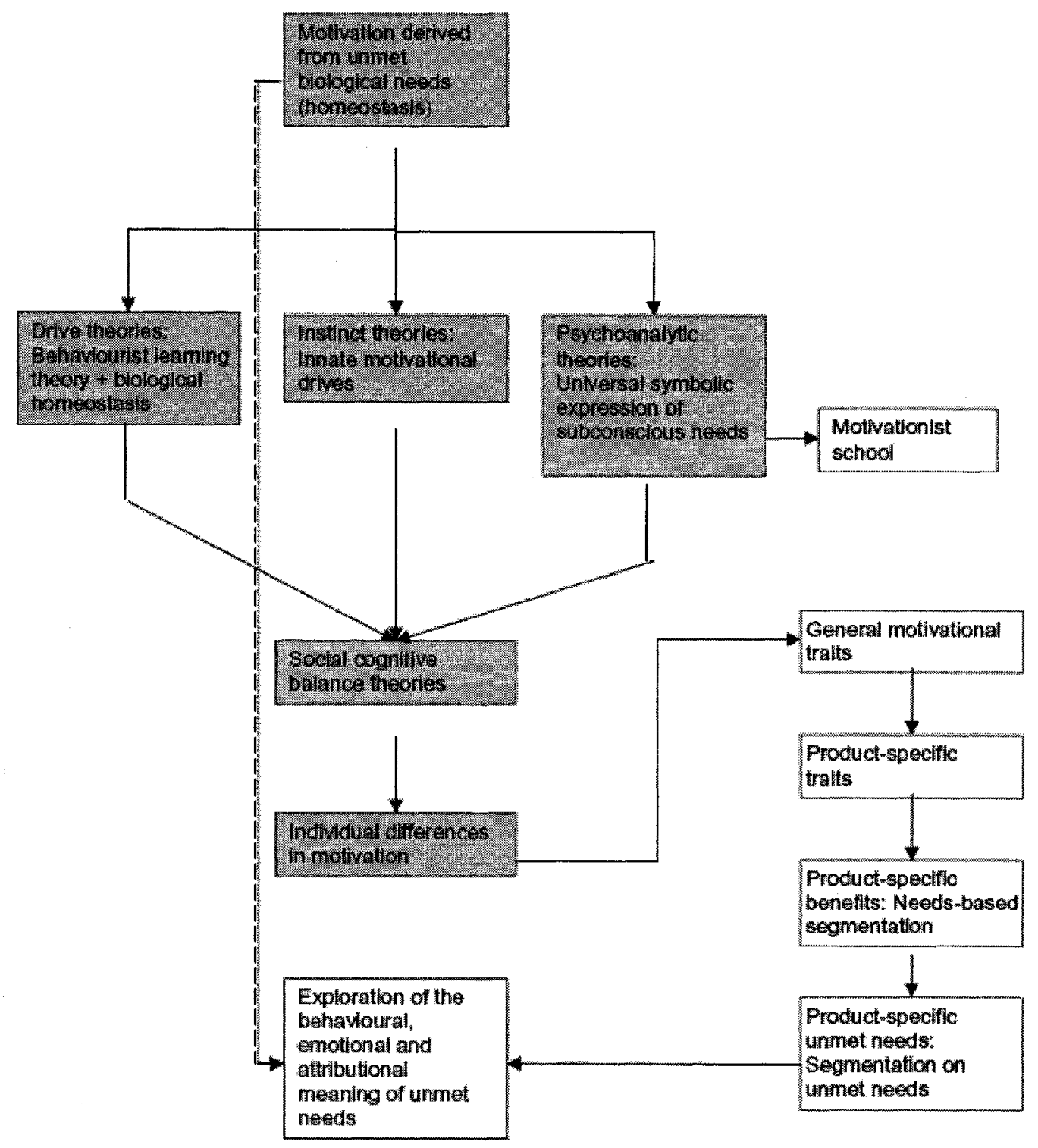

Additional theories are used in consumer motivation research that are not explicitly discussed in the Pincus (2004) paper. However, these theories fit within the author's general discussion. For instance, Cline, Altsech and Kellaris (2003) present a 'need for humour' as a motivational basis to explain differences in individual responses to advertisements. This 'need for humour' motivation is closely aligned with the need- 
based theories articulated by Pincus (2004). In another example, Paulssen and Bagozzi (2005) discuss the theory of self-regulation to help explain what brands consumers select into their consideration set for the purchase decision process through the minimization of a gap between present behaviour and behavioural standards. This theory may be most closely aligned with homeostasis, which posits behavioural motivation results from a state of disequilibrium and a desire to re-establish a balance (Pincus 2004).

In summary, there are several theories to explain motivation and its role in human behaviour. The biological and psychoanalytic theoretical bases have evolved into more sophisticated explanations that account for environmental and individual factors. Above all, motivation theories are based on the shared underlying theme that motivation results from unmet needs (Pincus 2004).

\subsubsection{Categorization of Motives}

While there are many typologies of motivations, Hetsroni (2000) represents a particularly useful one because it identifies three motivation-based promotional appeal types that are commonly used in the advertising effectiveness literature (e.g. Brunel and Nelson 2000; Olney, Holbrook and Batra 1991). These three types are hedonism, utilitarian/functionalism, and altruism.

\subsubsection{Hedonism}

Pleasure is central to the definition of hedonism. Definitions of the term hedonism often refer to fun and/or pleasure (Fitzmaurice 2005; Hetroni 2000; 
O'Shaughnessy and O'Shaughnessy 2002; Olney, Holbrook and Batra 1991). Additionally, Hirschman and Holbrook (1982) use hedonism to refer to "facets of consumer behaviour that relate to the multi-sensory, fantasy and emotive aspects of one's experience with products" (p.92). Psychologists exploring hedonism write that it is "concerned with feelings of pleasure and pain, of interest and boredom, of joy and sorrow, and of satisfaction and dissatisfaction" (Kahneman, Diener and Schwarz 1999, p.ix). In this case, the authors acknowledge that hedonism refers to not only the positive aspect of experience but the unpleasant as well. Therefore, hedonism appears to be about objects and experiences that create pleasure or displeasure. From a motivational perspective, hedonic motives are oriented toward the fulfillment of unmet needs through the acquisition of objects and experiences or through the avoidance of those that are deemed unpleasant.

With pleasure central to the construct, hedonism is considered to be individually oriented (Gregory, Munch and Peterson 2002). Hedonism represents a self-focused orientation where personal goals are of primary concern despite possible conflict with the standards of society (Lepkowska-White, Brashear and Weinberger 2003). From another perspective, Hirschman and Holbrook (1982) identify the importance of emotional arousal to hedonic consumption inferring that hedonism is more affective in nature than cognitive. The importance of emotion to hedonism is echoed by Kahneman, Diener and Schwarz (1999) who wrote that hedonism is primarily "concerned with feelings of pleasure and pain, of interest and boredom, of joy and sorrow, and of satisfaction and dissatisfaction" (p.ix). 
Hedonism provides a basis for understanding differences in the behaviour of individuals. For instance, Puri (1996) finds that those high in hedonism responded to promotional appeals that promise to meet hedonistic desires where costs were presented as probable but not certain. In other words, hedonic responses toward the immediate satisfaction of needs existed under some conditions of risk. This propensity toward impulsive and risk-taking behaviour was not exhibited by those identified as prudents (Puri 1996). Further, individual differences in motive-based values can influence the image people have of countries and their products. Balabanis, Mueller and Melewar (2002) examined hedonism among other motive-based values that were found to predict country images better than demographic variables. In this study, the total variance explained by ten motive-based values (including hedonism) was greater than the total variance explained from demographic variables (including gender, age, and education) when regressed onto perceived country characteristics of two countries. However, the difference between the variance explained by the two types of predictors is small and the study failed to find consistent patterns in the relationship of motive-based values to perceived country characteristics.

Descriptions of product types may also be termed hedonic where the primary characteristics of the product fulfill needs that are identified as pleasure-oriented. For instance, an automobile described as a hedonic product will be perceived as more valuable when compared to a utilitarian option (Dhar and Wertenbroch 2000). Dhar and Wertenbroch (2000) found that people are less likely to give up a hedonic product when 
choosing between it and a utilitarian counterpart. However, Okada (2005) provides evidence to suggest that people may spend more time choosing hedonic products but more money on utilitarian products. Further, in a winning versus purchase scenario, people may prefer to have hedonic products as prizes than as a purchase items ( $\mathrm{O}^{\prime} \mathrm{Curry}$ and Strahilevitz 2001).

While there are mixed results on the preference and value of hedonic products, the situational context can influence the evaluation of products. In this case, presentation order seems to affect product evaluations. Okada (2005) demonstrated that consumers will rate hedonic products more favourably than a comparable utilitarian product when the products are presented independently. Alternatively, Okada (2005) showed that joint presentation results in a better evaluation of the utilitarian product compared to the hedonic option.

Hedonism, with regards to products or promotion appeals, has been measured in the literature using different scales. However, the core concept of pleasure is represented in these measures (Gregory, Munch and Peterson 2002; Olney, Holbrook and Batra 1991). Table 2.4 presents this central notion and other measures used in previous research. Enjoyable seems to be the most common measure to reflect hedonism followed by pleasure, fun, and exciting. Within the list is the recent Voss, Spangenberg, Grohmann (2003) five 7-point semantic differential items that were distilled from a larger inventory and tested successfully for reliability and validity. Their measures include: not 
fun/fun, dull/exciting, not delightful/delightful, not thrilling/thrilling, and enjoyable/unenjoyable.

TABLE 2.4 HEDONISM MEASUREMENT EXAMPLES

\begin{tabular}{|c|c|c|c|c|}
\hline Measure & 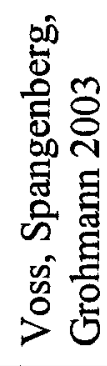 & 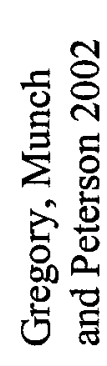 & 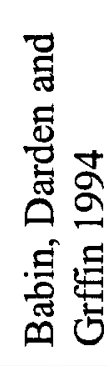 & 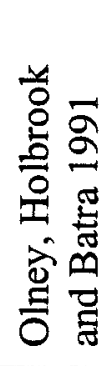 \\
\hline Enjoyable & $\sqrt{ }$ & & $\sqrt{ }$ & $\sqrt{ }$ \\
\hline Pleasure & & $\sqrt{ }$ & & $\sqrt{ }$ \\
\hline Fun & $\sqrt{ }$ & & & $\sqrt{ }$ \\
\hline Exciting & $\sqrt{ }$ & & $\sqrt{ }$ & \\
\hline Delightful & $\sqrt{ }$ & & & \\
\hline Thrilling & $\sqrt{ }$ & & & \\
\hline Comfortable & & $\sqrt{ }$ & & \\
\hline Cheerful & & $\sqrt{ }$ & & \\
\hline Happiness & & $\sqrt{ }$ & & \\
\hline Captivation & & & $\sqrt{ }$ & \\
\hline Escapism & & & $\sqrt{ }$ & \\
\hline Spontaneity & & & $\sqrt{ }$ & \\
\hline Entertaining & & & & $\sqrt{ }$ \\
\hline
\end{tabular}

\subsubsection{Functionalism/Utilitarianism}

Utility is another motive type and is often referred to in conjunction with hedonism. While hedonism is about pleasure associated with a product or the pleasureseeking nature of an individual, utilitarianism refers to the "requirements for products that remove or avoid problems" (Lepkowska-White, Brashear and Weinberger 2003). Functional or utilitarian consumers are most concerned with "the product's main 
(functional) use and the outcome of such use" (Hetsroni 2000, p.57). Product specific information, such as price, quality, size and style, are important considerations for consumers with functional values (Lepkowska-White, Brashear and Weinberger 2003).

Similar to hedonism, utilitarianism can be considered to be individually oriented as consumers seek benefits to enhance the self or personal experience. However, while hedonism has an emotional dimension, utilitarianism is more aligned with a thinking dimension. "Utilitarian goods are ones whose consumption is more cognitively driven, instrumental, and goal oriented and accomplishes a functional or practical task" (Dhar and Wertenbroch 2000, p.61). Therefore, utilitarianism is described as both an individually oriented and a cognition-based construct.

There are mixed results for the perceived value of utilitarian products. Dhar and Wertenbroch (2000) found that a utilitarian product was perceived as less valuable than a hedonic product. However, Okada (2005) showed that consumers will spend more money on utilitarian products compared to hedonic products. Further, consumers preferred utilitarian products in a purchase scenario compared to a prize scenario where hedonic products are preferred (O'Curry and Strahilevitz 2001).

Several measures are used to assess the level of utilitarianism in people and product images. Table 2.5 presents some examples of measures used in recent marketing studies. The most common measures appear to include helpful and accomplishing. The evaluation of several measures by Voss, Spangenberg, Grohmann (2003) resulted in five 
reliable and valid 7-point semantic differential scales to represent utilitarianism: effective/ineffective, helpful/unhelpful, functional/not functional, necessary/unnecessary, and practical/impractical.

TABLE 2.5 UtiLITARIAN MEASUREMENT EXAMPLES

\begin{tabular}{|c|c|c|c|c|}
\hline Measure & 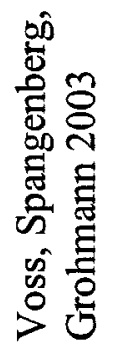 & 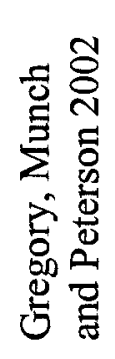 & 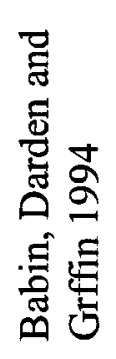 & 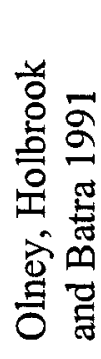 \\
\hline Helpful & $\sqrt{ }$ & & & $\sqrt{ }$ \\
\hline Accomplishing & & $\sqrt{ }$ & $\sqrt{ }$ & \\
\hline Effective & $\sqrt{ }$ & & & \\
\hline Functional & $\sqrt{ }$ & & & \\
\hline Necessary & $\sqrt{ }$ & & & \\
\hline Practical & $\sqrt{ }$ & & & \\
\hline Successful & & $\sqrt{ }$ & & \\
\hline Ambitious & & $\sqrt{ }$ & & \\
\hline Capable & & $\sqrt{ }$ & & \\
\hline Important & & & & $\sqrt{ }$ \\
\hline Informative & & & & $\sqrt{ }$ \\
\hline Useful & & & & $\sqrt{ }$ \\
\hline
\end{tabular}

\subsubsection{Altruism}

While hedonism and functionalism/utilitarianism represent egoistic motivations steeped in the primacy of the self, altruism represents motivations centred on fulfilling the needs of others. Auguste Compte (1798-1857) is recognized as the first person to use the term altruism to describe an unselfish desire to 'live for others' (Batson 1991). Batson (1991) offers three requirements for the existence of altruistic motivations - a 
perception of another's need, a desire to reduce the need of another, and the person's ultimate goal must be the reduction of the need.

In marketing literature, the notion of altruism is applied in a similar manner. For example, Brunel and Nelson (2000) view altruism as an other-oriented perspective. Consumers with altruistic motivations are interested in "the product's capability to help members of the society without obtaining any materialistic benefit for this aid" (Hetsroni 2000, p.57). This is an important distinction because it demonstrates that altruistic motivations differ from hedonic and utilitarian motivations through the orientation that emphasizes others over the self. This perspective implies that altruistically motivated individuals are interested in the rules and benefits of a group even when they conflict with personal goals (Lepkowska-White, Brashear and Weinberger 2003).

Emotion plays a significant role in altruistic motivation. Social psychologists have long recognized the importance of positive moods in the encouragement of altruistic behaviour (Rosenhan et al. 1981). Altruistic emotions have been identified, including sympathy, concern and compassion (Eisenberg 1986). In marketing research, Hibbert, Hogg and Quinn (2005) refer to sympathy and guilt as emotions that stimulate the drive for charitable giving. Further, Goodwin, Smith and Spiggle (1990) provide support for the salience of emotions to altruism as several respondents in the study of consumer gift giving indicated emotional responses were expected when giving gifts. However, emotional responses are associated with several motivations and are not exclusive to altruism. People may have an emotional reaction to the fulfillment of needs associated 
with utilitarian motivations. It is the emotional content of the stimulation for a motivation and the lack of personal gain that helps distinguish altruism from other motivations.

Altruism can be a very important motivator for explaining behaviour. Indeed, Guy and Patton (1989) propose "by far the strongest motive is the basic, deep-seated need to help others without expectation of reward other than the joy or pleasure of helping" (p.21). Further, in the context of purchase exchanges, other values motivating the transactions may be combined with a helping dimension (Hibbert, Hogg and Quinn 2005). This is an important point because purchase behaviour can include multiple motivations. For example, commercials for complex and expensive durables, such as automobiles, often provide a mixture of hedonic and utilitarian appeals. The strength of altruistic promotional appeals may be influenced by the "intensity of the need and the salience of the consequences of help being withheld ... urgency and immediacy ... (and) appeals that are tailored to an individual"' (Guy and Patton 1989, p.24)

There is some evidence to suggest that organizations engaging in other-oriented activities may receive economic benefits when perceived by consumers as socially legitimate (Handleman and Arnold 1999). Handleman and Arnold (1999) demonstrate a minimum level of other-oriented behaviour can improve the relationship between the evaluation of the retailer and consumers' support. 
An orientation towards others can influence consumers' view of the world. For instance, Balabanis, Mueller and Melewar (2002) demonstrated that those with collectivist tendencies of benevolence and tradition perceived the image of Germany to be less favourable than those who are more individualistic. Further, they showed the influence can extend to a country's products.

Of particular interest to this research in the relationship between altruism and personality is the argument about whether altruism is a personality trait or is correlated to other personality traits. Some researchers have explored the possible existence of an altruistic personality. Rushton (1981) argues that altruism is a personality trait by demonstrating consistency of individuals' behaviour across situations. Other researchers have examined possible personality correlates of altruism. For instance, Eisenberg (1986) argues that altruism is related to personality traits identified as empathy/sympathy, role taking, political orientation, scholastic aptitude and social desirability. However, Guy and Patton (1989) report that studies exploring altruistic behaviour and personality have generally yielded mixed results. Although, they report that some studies have shown other-directed people and those who value intrinsic rewards are more likely to help others.

The measurement of altruism in marketing research is inconsistent. One approach uses measurement items, such as, helpful, social justice, equality, friendship and love (Verplanken and Holland 2002). However, in another approach, Hetsroni's (2000) uses courtesy, patriotism, charity and collectivism to assess altruism. Nonetheless, the 
relevant emotions have been more consistently identified as sympathy, concern and compassion (Eisenberg 1986).

\subsubsection{Justice - A Fourth Type of Motivation?}

Motivations have been described in terms of two dichotomies: cognitive- versus affective-based and self- versus other-oriented. Hedonism, utilitarianism and altruism may all be described through the orientation or priority people place on themselves or others in a society during their goal achieving behaviour. In personality research, this dimension of an individual involving the focus on personal versus group motives is referred to as the inner-other directed trait. As previously discussed, hedonism and utilitarian motivations are associated with self-interested goals steeped in pleasure and function, while altruism is associated with motivations involving goals centred on helping others.

Also, hedonism, utilitarianism and altruism may be described using the feelingthinking continuum. As previously discussed, both hedonism and altruism emphasize the presence of emotions in motivating a person toward achieving a goal. In comparison, utilitarianism is primarily cognition driven. This difference is represented in the grid in Figure 2.2 by the placement of hedonism and altruism on the left side of the continuum while utilitarianism is placed on the right side.

The figure graphically displays the intersection of the inner-other directedness personality type and the feeling-thinking promotional appeal dimension and the 
relationship of these characteristics with motivation-based appeal types. Personality type is represented on the vertical axis of the grid through the social orientation trait of individuals while the feeling-thinking dimension is represented through the horizontal axis of affect and cognition. The placement of the three motivation-based appeal types, hedonism, utilitarianism and altruism, raises the possibility that a fourth type should be considered.

\section{Figure 2.2 Motivation-Based Appeal Types in the Context of Personality AND Promotion CATEgory}

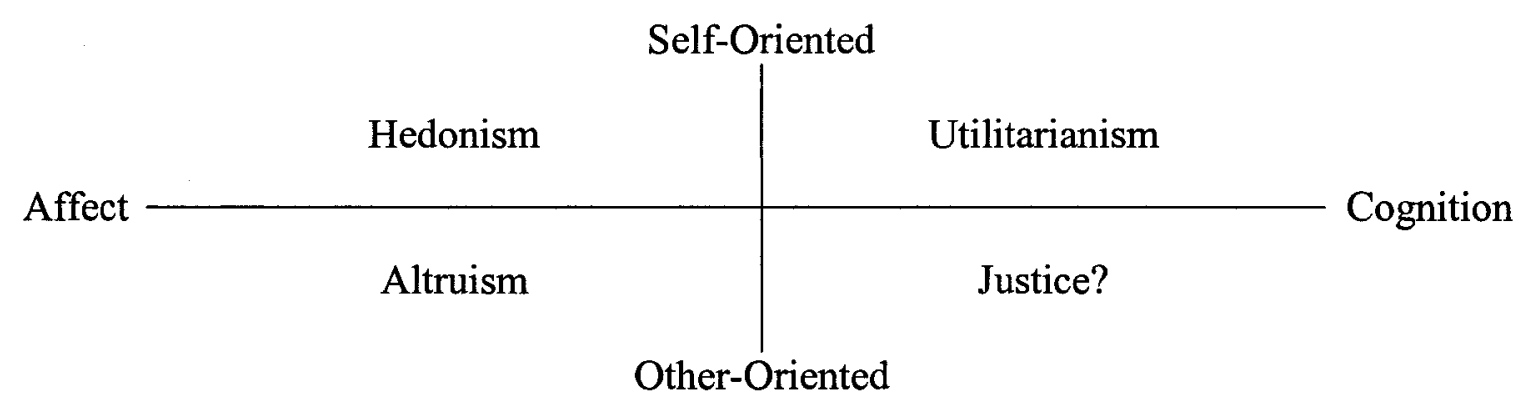

It is proposed that a salient motivation-based appeal type exists that is represented in the bottom right quadrant. The quadrant of the grid is described as other-oriented on the social orientation personality trait and as cognitively oriented on the feeling-thinking continuum for promotion categorization. Justice is suggested as this motivation-based appeal type.

In social psychology, the examination of justice as a motivation is not new (e.g., Lerner and Meind1 1981). The justice motive is viewed as "an ought, a moral imperative for social life ... people are obliged to observe the norms of justice ... they are entitled to 
claim justice from other actors, organizations, state institutions, and so forth, not only for themselves but also for others" (Montada 2002). Justice may be described as a duty to act rather than an option of acting charitably (Montada 2002).

Equality has a longstanding relationship with the concept of justice. An early thinker on justice argues "equality for those who are equal, and not for all" (Aristotle 1995, p.103). A modern thinker describes the concept of 'justice as fairness' and as "the fundamental charter of a well-ordered human association" (Rawls 1971, p.5). Indeed, as a motivation type, justice is relevant, as "people prefer fairness even in situations where it decreases their own outcomes" (Blader and Tyler 2002, p.229). While these perspectives of justice clearly focus on others in a society using fairness and equality as evaluative criteria, the importance of cognition in theories of justice may be less apparent.

With respect to this point, Rawls (1971) pursues the Enlightenment tradition of rationality in determining what is just and argues "each person must decide by rational reflection what constitutes his good, that is, the system of ends which it is rational for him to pursue, so a group of persons must decide once and for all what is to count among them as just and unjust." (p. 11). Although Rawls (1971) writes about group decisions to define justice, he highlights the salience of cognitive reflection in the process. Management scholars also acknowledge the importance of the thinking dimension in justice research (Tuan Pham and Avnet 2004, Schoefer and Ennew 2005). In the behavioural context, the role of cognition or rational thought with justice-oriented 
behaviour is an important distinction from altruistic behaviour that is motivated through an emotional process.

Rawls (1971) acknowledges that agreement on defining justice is not the only issue when he writes, "some measure of agreement in conceptions of justice is, however, not the only prerequisite for a viable human community. There are other fundamental social problems, in particular those of coordination, efficiency, and stability" (p.6). Following this, a link between social problems and the types of justice becomes apparent: distributive (i.e., coordination of outcomes), procedural (i.e., efficient means of distribution) and interactional (i.e., stability in the willingness of people to act on agreed rules).

To facilitate the distributive justice discussion about differences in perceptions of what is fair and unfair, Rawls (1971) provides substantive guidance through two principles that argue for equal rights to basic liberties and a distribution of inequalities structured so they can be to the advantage of everyone. From a procedural perspective, Rawls (1971) offers the veil of ignorance as a just process for determining a fair distribution of duties and benefits within a society. The process encourages the evaluation of ideas using only general considerations because people negotiate without knowledge of their place in society (Rawls 1971). The result is a negotiated contract that is broadly supported. While not identified as such, the interactional perspective of justice is highlighted as instrumental in Rawls' (1971) theory of justice through the duties and obligations of individuals "to support and to further just institutions" (p.334). 
Management research embracing the theory of justice finds the three types of justice deepen our understanding of complaint handling (e.g., Tax, Brown and Chandtashekaran 1998; Maxham and Netemeyer 2003; Mattila and Cranage 2005), consumer privacy (e.g., Culnan and Bies 2003), negotiation (e.g., Pilluta and Murnighan 1995), organizational composition (e.g., Richard and Kirby 1999), international subsidiary strategies (e.g., Taggert 1997), and entrepreneur-investor relationships (e.g., Sapienza and Korsgaard 1996). In addition, other studies explore aspects related to the notion of justice and provide evidence to show influences on sponsorship decisions (e.g., Apostolopoulou and Papadimitriou 2004) and gift purchases (e.g., Goodwin, Smith and Spiggle 1990, Rugimbana et al. 2003).

With respect to justice types, management research on distributive justice indicates it can play a role in various settings. For instance, research about distributive justice and complaint handling "focuses on the perceived fairness of the outcome of the service encounter" (Schoefer and Ennew 2005, p.262). Additionally, compensation and apology can have a direct influence on perceptions of what is fair in recovering from a customer service failure (Mattila and Cranage 2005). In another field, distributive justice plays a vital role by influencing the behaviour of negotiators through their perceptions of fairness.

For consumer goods, fair trade coffee provides a good example of distributive justice because the product represents a redistribution of outcomes. Linton, Chiayuan 
Liou and Shaw (2004) argue that fair trade efforts are geared to having consumers consider the welfare of coffee workers in their consumption decisions. Therefore, products can represent fairness or draw attention to unfair distributions of commercial exchange benefits. In the case of fair trade coffee, consumers are being asked to pay a premium compared to other products as a means of addressing a distributive injustice.

Anholt (2005) disagrees with the basic premise behind fair trade coffee and suggests that the fair trade premium is representative of altruism. Anholt (2005) refers to the price differential as "a voluntary, 'conscience' tax" (p.151). Further, Anholt (2005) argues companies should move away from what he refers to as charity-based fair trade appeals into ones that emphasize added value. This perspective assumes consumers are purchasing fair trade coffee solely on the more emotional basis of charity and ignores or significantly underestimates the perceived value to consumers of exercising just behaviour. In the case of fair trade coffee, while consumers are asked to exhibit 'just' behaviour, they are also asked to purchase a product positioned on the cognitive side as better tasting through organic and shade grown beans that are selected, grown and processed with greater care. Therefore, the issue of altruism versus justice as a positioning and motivation is important to appeals related to products from LDCs.

Management research on procedural justice demonstrates the importance of process in the consumer or organizational context. For instance, Sapienza and Korsgaard (1996) show the relationship of entrepreneurs and investors can be influenced through a fair exchange of information. Alternatively, procedural justice is used to help describe 
different subsidiary strategies (Taggert 1997). Procedural justice in a management context refers "to fairness of policies and procedures, and fairness in the process or application of procedures" (Brashear, Brooks and Boles 2004, p.87). It is important for management scholars to make a distinction between procedural and distributive justice because there is evidence to show that consumers make this distinction (Saxby, Tat and Johansen 2000). The fair trade coffee example may be utilized again to illustrate that procedural justice, or the process behind the product, may be an important consideration to the consumer. In this case, the fair trade designation on coffee indicates that purchases are direct from small farmers, there are guaranteed price floors, credit is available to growers and the relationship between importers and growers is supported (Linton, Chiayuan Liou and Shaw 2004).

Interactional justice in the broader management literature refers to the way consumers are treated in exchanges (e.g., Schoefer and Ennew 2005). Some researchers have even separated the concept of justice into two components to reflect the roles of interpersonal and informational exchanges (Mattila and Cranage 2005). Extending Rawls' (1971) theory of justice to interactional justice would broaden this understanding to include willingness or obligations to act. Indeed, Kim, Junyean Moon, and Tikoo (2004) examine the willingness of employees to engage in customer-oriented behaviour within a hospital environment. In this study, employees were more likely to engage in customer-oriented behaviour when there was a perceived distributional injustice (Kim, Junyean Moon, and Tikoo 2004). Similarly, obligations to act can also influence organizational decision making as evidenced by the reasoning offered by some corporate 
sponsors for their participation in a national sporting program (Apostolopoulou and Papadimitriou 2004). Therefore, obligation to a belief of what is fair or willingness to act in support of these beliefs can represent a significant motivation.

In the consumer context, authors demonstrate that a sense of obligation can influence the decision to purchase in gift giving situations (Goodwin, Smith, and Spiggle 1990, Rugimbana et al., 2003). Service relationship scholars have also examined the influence of normative commitment in diminishing the switching behaviour of consumers (Fullerton 2006; Bansal, Irving, and Taylor 2004). Normative commitment represents the extent to which a consumer feels an obligation to remain a customer of a particular company (Bansal, Irving, and Taylor 2004). While normative commitment has not received much attention in the literature (Fullerton 2006), its exploration has been limited to customer loyalty scenarios. Further, although normative commitment is not the same as justice, it demonstrates that obligation influences consumer behaviour.

Management literature has also provided evidence to suggest that justice can motivate people through a cognitive process. Schoefer and Ennew (2005) found that a cognitive process used to assess justice may be followed by an emotional reaction. However, it is important to note that an emotional response is distinct from an emotional stimulus. While altruistic behaviour relies on an emotional stimulus, justice based actions, feelings or thoughts require a cognitive stimulus. Further, Tuan Pham and Avnet (2004) investigated differences between those motivated by what they ought to do (i.e. obligations, duties and responsibilities) versus those motivated by their ideal (i.e., 
aspirations, hope and wishes). In this study, the authors illustrate that a relationship exists between ought goals and substantive, rather than affective, message evaluations (Tuan Pham and Avnet 2004). Both studies support distinguishing altruism from justice in a consumer context on the basis of a cognitive emphasis.

While the feeling-thinking distinction between hedonism and utilitarian was discussed previously, this difference appears to have been ignored in the marketing literature. Recently, Hetsroni (2000) provides insight into three main types of promotional appeals by assessing the themes of advertisements aired in Israel from 19951997. Smallest space analysis, a statistical clustering technique, revealed three distinct classes, namely, hedonism, functionalism/utilitarianism, and altruism. Each of these groups contained several characteristics of the advertisements that were aired. However, the researcher did not assess characteristics that reflect justice in the advertisements. Perhaps, by incorporating the central notions of justice as fairness and equality, Hetsroni (2000) may have uncovered justice as an additional approach.

Questions about what constitutes a justice appeal may be answered by examining the necessary criteria required for justice as a motivator. Batson (2002) describes the essential conditions to uncover evidence of justice motivation, specifically, (1) the clear identification of an injustice, (2) a response that is obviously about justice, and (3) existence of deliberation and the potential for public scrutiny. The three criteria are reflected in the preceding discussion and a justice appeal should do all three. 
To illustrate a justice appeal in practice, the following example is offered. TerraPass provides an annual pass to consumers who wish to offset the pollution they create through the use of an automobile. First, consumers are confronted with an injustice where detrimental environmental effects are occurring due to the use of their automobiles, yet there is no financial cost associated with these negative effects to manufacturers or users. Perhaps TerraPass's appeal would be more clearly identified as a justice appeal by using the terms 'equality' or 'fairness'. Second, consumers are asked to act justly by purchasing a pass that provides no other benefit than to offset their pollution generation. TerraPass requests a fee payment depending on the vehicle owned and usage. In exchange, the business invests the payment in non-fossil fuel power sources. However, purchasing a pass does not entitle the purchaser to an equity stake in these investments. To the consumer, the TerraPass is an expense associated with driving their car on the basis that it is the right thing to do and is fair to society. Third, the appeal encourages deliberation and social scrutiny. Cognition is emphasized in the overall appeal as the website does not rely on emotional stimulation to persuade buyers. The website provides potential customers with information and reasoning to support taking responsible action. Consumers also come under public scrutiny by placing a window decal and bumper sticker on their vehicle to communicate to others that they have taken action.

While measuring perceptions of justice appeals is desirable, the operationalization of this task may be quite difficult. It may be difficult because there are few studies exploring justice in the context of the purchase decision process. Broadening the search 
criteria to management literature yields little more with respect to measurement items disclosed in published papers. However, studies provide measures for procedural justice in the context of salesforce management (Brashear, Brooks and Boles 2004) and customer service (Saxby, Tat and Thompson 2000, Kim, Junyean Moon and Tikoo 2004). Overall, the design of a measurement instrument should account for the central ideas of justice as fairness and equality. In addition, Kim, Junyean Moon and Tikoo (2004) draw attention to the need to measure willingness of individuals to engage in action.

\subsubsection{Summary}

Motivations may be categorized into various types identified as hedonism, functionalism/utilitarianism and altruism. While there tends to be a distinction between individually oriented value sets into hedonism and functionalism/utilitarianism on the emotion/cognition aspect, there appears to be only one motivational state referring to the collectively minded (i.e. altruism), and it is an emotional one. This paper proposes that justice may represent a second other-oriented value set that is more appropriately aligned with cognitive processes. Drawing a distinction between justice and altruism in marketing literature seems not to have been done. This is particularly noticeable as some key aspects of justice have been included among the measures used to estimate altruism (e.g., Verplanken and Holland 2002).

\subsubsection{Motivation Influence on Consumer Behaviour}

Motivation may influence several aspects of consumer behaviour including the type of information used and the brands or products considered in the purchase situation. 
Motivation experienced by a consumer can also influence the type of information used in the decision-making process. Yang, Allenby and Fennel (2002) show that the selection of relevant information to consumers is based on their motivation state. This motivational state directs the consumer towards matching attributes of the product (Yang, Allenby and Fennel 2002). For example, a thirsty consumer will seek out a product that advertises its thirst quenching abilities.

Beyond assisting the selection of information types, motivation can impact the types of products or brands that are considered for purchase. Paulssen and Bagozzi (2005) demonstrate that motivational goals can influence purchase decisions through the selection of product and related information. Consumers with a hedonistic goal in the fulfillment of purchase will consider very different brands from those considered by people with a utilitarian goal (Paulssen and Bagozzi 2005). Verplanken and Holland (2002) provide additional support demonstrating that products are more likely to be selected when they are perceived to be congruent with an individual's central set of values (as motivators) and they are cognitively activated. Further, currently used products of a consumer are preferred by those concerned with safety and security rather than those focused on growth and development (Chernev 2004). Therefore, these findings are important to this study because products or brands considered in a purchase situation are partly determined by the resonance of the brand image with the consumer's motivation. 


\subsection{Promotional Appeals}

The salience of motivation to understanding consumer behaviour has made it an important part of promotion appeals evaluation. Promotional appeals have been studied almost exclusively within the context of advertising. Appeals have been defined as the main idea or theme of a promotional message (Solomon et al., 2003). An alternative definition based on promotional goals states that an "appeal is a conscious attempt to motivate potential consumers toward some form of activity (such as gathering further information or purchasing) or to influence them to change their attitude or conception" (Hetsroni, 2000, p.58). The key aspects of these appeal definitions include message centrality, a purposeful existence, and attempts to stimulate a behavioural, attitudinal or perceptual outcome.

Appeals are found in all promotional media including print (Arthur and Quester, 2004), Internet (Lohtia, Donthu and Hershberger 2003) and television (Olney, Holbrook and Batra 1991). Some media may be more effective than others for different types of appeals. For example, Royne Stafford and Day (1995) found radio advertisements influenced purchase intentions better than print advertisements for emotional and rational appeals. Appeals are important in marketing because they directly assist the advertiser with gaining attention, holding interest, stimulating desire and encouraging action. To be successful, an appeal should be relevant to the target audience. 


\subsubsection{Types of Appeals}

There are several different types of appeals utilized in promotional campaigns and some may result in better outcomes than others. For example, Royne Stafford and Day (1995) found that a cognitive appeal had a stronger influence on attitudes toward the promotion when compared to an emotional appeal. Olney, Holbrook and Batra (1991) generated a list of 35 appeals in their analysis of promotion effectiveness on television program viewing times. However, a more recent article summarizes the listing of appeals into 25 characteristics of advertisements based on nine previous studies (Hetsroni 2000). Hetsroni's (2000) purpose was to aggregate appeals to the major themes presented in advertisements.

Table 2.6 contains general promotion appeals as summarized by Hetsroni (2000). The appeals are presented in three columns, namely, affective, neutral and cognitive. The general split of appeals into affect and cognition is found in the literature, for example, as either 'feeling' - 'thinking' (Vaughan, 1980) or 'emotional' - 'rational' (Royne Stafford and Day 1995). As a cautionary note, Vaughan (1980) suggests that 'feeling' and 'thinking' exist on a continuum rather than being a dichotomous classification structure. Therefore, the placement of an appeal in the 'affective' or 'feeling' column should not lead to the inference that the appeal involves the same amount of emotion or feeling as another appeal in the same column. However, placement into this tabular format allows for grouping of appeals based on the accentuation of a key similarity. 
The separation of appeals in Table 2.6 into affective, cognitive and neutral categories reflects the frequencies with which the appeals appeared in 861 rational or emotional advertisements (Hetsroni, 2000). The classification is made by comparing appeal appearances in either emotional or cognitive advertisements to their total appearances in all advertisements. This classification indicates the fit of the appeal with an affect or cognitive emphasis. While not utilized in the Hetsroni (2000) study, the neutral category captures those appeals that are equally found in rational and emotional advertisements.

TABLE 2.6 TyPeS OF Promotion APPEALS

\begin{tabular}{|l|l|l|}
\hline Affective (Feeling) & Neutral & Cognitive (Thinking) \\
\hline Adventure & Courtesy & Convenience \\
Beauty & Competition & Efficiency \\
Charity & Family & Excellence \\
Collectivism & Health & Modernization \\
Joy/happiness & Individualistic & Quality \\
Leisure & & Safety \\
Patriotism & & Saving \\
Popularity & & Wealth \\
Sex & & Wisdom \\
Tradition & & \\
Youthful Spirit & & \\
\hline
\end{tabular}

Source: Hetsroni, 2000

For a feelings example, adventure appeals are primarily affect appeals because they rely on emotional stimuli. Hetsroni (2000) describes adventure appeals as those when "the product is clearly associated with the exceptional boldness, bravery or taking risks more than in everyday life" (p.60). These types of appeals are more emotion-based because they tend to rely on messages of pleasure, arousal of feelings or the creation of 
moods (Albers-Miller and Stafford 1999; Olney, Holbrook and Batra 1991). An adventure appeal may be used in promoting white water rafting in a local river system or encouraging the viewer to trek in the Himalayas by using powerful imagery that helps create a sense of excitement (emotional stimulation).

For a cognitive example, saving appeals represents an example of a thinking oriented appeal because they offer cognitive stimuli. These appeals are described as "stressing the low price of the product, mentioning discounts, free bonuses, gifts or special paying arrangements" (Hetsroni 2000). These appeals tend to be more cognitive in nature because the messages tend to rely on a rational stimulation using information in the message. In the case of saving appeals, the viewer must consider the price information in an assessment of product value.

An appeal was included in Hetsroni's (2000) list based on the decision rule that the characteristic was studied in at least two of the reviewed publications. The author argues that this is a fair approach as it avoids undue influence of specific agendas in individual papers and provides a general list of promotional appeals. However, the aggregation seems to ignore several appeals that have garnered attention in the literature. Shock, fear, and guilt appeals are surprisingly absent from the Hetsroni (2000) summary of appeals.

A shock appeal is "one that deliberately, rather than inadvertently, startles and offends its audience" (Dahl, Frankenberger and Manchanda, 2003, p.268). Shock appeals 
differ from other appeals due to their extreme nature. For instance, sex appeals are described as those that contain nudity (Smith et al., 1995) but not all sex appeals would be classified as a shock appeal. By its very nature, shock appeals likely represent a small proportion of all advertisements. Otherwise, the ability of the appeal to shock the viewer would diminish.

While Hetsroni (2000) accounts for safety appeals, the study does not include fear appeals. Safety appeals portray a product as "safe to use and using it does not carry any harmful short-term or long-term effects" (Hetsroni 2000, p.60). A key aspect of the appeal is the demonstration of safety benefits from using the product. However, "a threat is an appeal to fear, a communication stimulus that attempts to evoke a fear response by showing some type of outcome that the audience (it is hoped) wants to avoid." (LaTour and Rotfeld 1997, p.46). Fear appeals may be classified as affective appeals while a safety appeal is more cognitively oriented. "Fear is an emotional response to a threat that expresses, or at least implies, some sort of danger." (Tanner, Hunt and Eppright 1991, p.36).

Guilt appeals are intended to make viewers of the advertisement feel guilty with "some feeling of failing at their own ideals or ethical principles" (Higie Coulter, Cotte and Lunt Moore 1999, p.288). Guilt is related to justice motivation as feelings of guilt may result from a discrepancy between the well-being of a person and the others in a society (Higie Coulter, Cotte and Lunt Moore 1999). These appeals are used regularly as evidenced in a survey of print advertisements that demonstrated guilt usage at around 5\% 
(Huhmann and Brotherton 1997). On the feeling-thinking continuum, guilt appeals would be placed on the cognitive side despite the elicitation of an emotional response (Higie Coulter, Cotte and Lunt Moore 1999). Guilt appeals would first require a cognitive process to assess how current behaviour fails or passes in meeting a set of principles.

In summary, there are many appeals used by advertisers to persuade members of a target group into a particular action. Promotions may incorporate feeling, thinking or both approaches to encourage the desired behaviour.

\subsubsection{Effectiveness of Appeals}

The effectiveness of a promotional appeal is often determined by the extent to which it persuades individuals. This is merely a reflection of the definition of appeals offered earlier in this paper. Peter and Olsen (1994) define persuasion as referring "to changes in beliefs, attitudes and behavioural intentions caused by a promotional communication" (p.195). This description of persuasion refers to the multi-component theory of attitudes that views attitude as having three components, namely, the cognitive component that "refers to the beliefs, judgments, or thoughts associated with an attitude object" (Drolet and Aaker 2002, p.60), the affective component that "refers to the feelings, emotions, or drives associated with an object"' (Drolet and Aaker 2002, p.60) and the conative component, which "refers to the primary motivational or behavioural consequences of attitudes" (Drolet and Aaker 2002; p.60). Drolet and Aaker (2002) argue that when all three components are used simultaneously, the prediction of 
persuasion effectiveness will be better. Therefore, from an attitude perspective, theories of affect and cognition represent two distinct approaches to explain the influence of promotional appeals on consumer behaviour.

\subsubsection{Emotion Theory}

The effectiveness of emotional appeals is based on the notion that promotions containing an affective central characteristic are likely to evoke an emotional response (Aaker and Williams, 1998). Affect is a "central element in emotion theory; several theories view it as the process that mediates between stimulus perception and further emotional response" (Frijda 1999, p.194). In promotion, Brown, Homer and Inman (1998) cite several papers to demonstrate emotions stimulated by advertisements can directly influence brand attitudes bypassing attribute beliefs. Further, ad-evoked emotion is more effective for stimulating hedonistic attitudes toward the advertisement while fact-based appeals are related to utilitarian attitudes (Olney, Holbrook and Batra 1991). The emotional response and the emotionally influenced brand attitude are important because they are believed to influence a purchase decision or other consumer behaviour outcome.

A distinction can be drawn between the emotional stimulation of an advertisement and the emotion that is felt by the viewer (Aaker and Williams 1998). This distinction is important because an emotional response to an advertisement can occur with a cognitive appeal. The distinction between cognitive and emotional appeals seems to rest with the type of stimulus used. An emotional appeal should have both an emotional stimulus and 
an elicited emotional response. In addition, this distinction raises questions about salient measures for emotional appeals.

The emotional content is only one dimension important to the effectiveness of affective persuasion. Generally, emotion is seen as containing two dimensions: valence (degree) and action disposition (direction) (Frijda 1999). However, in the context of effective promotional appeals, Aaker and Williams (1998) suggest that message content, valence, level of arousal and the referent of focus are four salient dimensions. The content represents the type of emotion depicted in the promotion, the valence of the promotion refers to the extent that a viewer perceives the emotion as positive or negative, and the levels of arousal refer to the intensity of the emotion. Aaker and Williams (1998) argue for the inclusion of the fourth dimension - referent of focus. They argue that people differ in their referral of emotion toward either internal attributes or towards other people's feelings or attributes. Aaker and Williams (1998) tested the relevance of referent of focus from a cross-cultural perspective demonstrating ego-focused appeals influenced more positive attitudes for people in a collective culture while other-focused emotional appeals influenced more positive attitudes for people in an individualistic culture. While the results were counter to their expectations, the authors suggested the contrast between appeals and the culture led to a novelty effect that influenced results. Previous research has demonstrated new products can strengthen the positive relationship between the affective response and attitudes toward the product (Brown, Homer and Inman 1998). 
Emotion theory proposes that emotions are central to understanding how reactions are stimulated from promotional appeals. However, social psychologists acknowledge a significant role of cognitions in emotion centred theory. As a primary function, emotions can deepen a person's attention and increase cognitions (Rosenhan et al. 1981). For instance, despite altruistic behaviour being viewed as emotion centric, the emotions associated with the behaviour "are often based, at least in part, on cognitions" (Eisenberg 1986, p.4). In addition, appraisals (one aspect of emotion) involve some cognitive processing as a person considers something to be either positive or negative, determines what can be done about a situation/object and assesses the resources that can be employed (Frijda 1999). Further, "emotions may give rise to intense cognitive activities such as rumination ... intrusive thoughts ... and fantasy ... (extending) the duration of the processes, causing appraisals to extend and the emotions to feed on themselves" (Frijda 1999, p.198). Therefore, while emotional content is the focus of emotion theory in promotional effectiveness, cognitions are also involved.

The existence of a theoretical overlap of cognition and emotion provides a basis for describing an appeal specific theory. The Protection Motivation Theory is an explanation for the effectiveness of promotional appeals. This theory relates in particular to the effectiveness of fear appeals. Fear appeals rely on a threatening message to invoke a fear response (LaTour and Rotfeld 1997). While this response is an emotional one (Arthur and Quester 2004; Laroche, Toffoli, Zhang and Pons 2001; Tanner, Hunt and Eppright 1991), the Protection Motivation Theory "states that cognitive appraisal processes, rather than emotion, mediate the choice of coping behaviour" (Arthur and 
Quester, 2004, 674). Rogers (1975) introduced the Protection Motivation Theory with three key components: severity of threat, probability of occurrence, and efficacy of response. However, a fourth component, self-efficacy, was recently added to the theory representing consumers' capability of performing the coping response (Arthur and Quester 2004).

The Protection Motivation Theory offers an explanation for how fear appeals affect consumer behaviour. Consumers are likely to follow an ordered process where the emotional response of fear "leads to processing of coping response and self-efficacy" (Tanner, Hunt and Eppright 1991, p.43). The theory is based on an expectancy-value formulation (means-ends) where " the tendency to act in a particular fashion is said to be a function of the expectancy that the given act will be followed by some consequence and the value of the consequence" (Rogers 1975, p.96).

\subsubsection{Cognitive Theories}

While emotion theory incorporates some cognition into the explanation of promotional appeal effectiveness, some theories rely more heavily on cognition for their explanations. The discussion of cognitive theories for appeal effectiveness includes situational theories and theories that account for both enduring and situational conditions. This distinction in the theories was made because this study is interested in those theories that explain consumer behaviour in the enduring context. 


\section{Situational Theories}

Situational theories rely on conditions in the environment to explain the effectiveness of promotional appeals. The explanation offered by the RelevanceAccessibility Model for promotional appeal effectiveness is that promotional messages are most persuasive when they are relevant and available to the consumer (Baker and Lutz 2000). The theory employs two motivational constructs based on the Principle of Optimal Advertising Contribution, namely message involvement and brand response involvement. The message involvement refers to an individual's motivation "to process information at the time of message exposure" (Baker and Lutz 2000, p.2) while brand response involvement refers to "consumers' motivation to process information at the time of brand choice" (Baker and Lutz 2000, p.2).

There is some evidence to suggest that affect appeals work better when consumers' motivation to deliberate during message exposure and brand choice is low (Baker and Lutz 2000). The effectiveness of affect appeals declines as the motivation to deliberate increases (Baker and Lutz 2000). Therefore, cognitions dominate when the motivation to deliberate during message exposure and brand choice is high. Additionally, comparative product information may be more effective when motivation to deliberate is high (Baker and Lutz 2000).

\section{Enduring and Situational Theories}

Few theories seem to rely solely on situation factors to explain promotional appeal effectiveness. Instead, appeal theories tend to embrace both situational and 
enduring conditions. There are three main theories found in the literature, namely, the Elaboration Likelihood Model, Congruence Theory and the Persuasion Knowledge Model.

\section{Elaboration Likelihood Model}

The main cognitive theory that has been adopted in consumer behaviour textbooks as the leading explanation for persuasion of communication is articulated through the Elaboration Likelihood Model (e.g., Hawkins, Best and Coney 2004). The Model uses dual mode cognitive processes that are employed by consumers where the selection of mode depends upon the level of involvement a consumer has with a product (Hawkins, Best and Coney 2004) or the product's message (Lohtia, Donthu and Hershberger 2003). For a simple example, the cognitive process used in the purchase of an automobile should differ from the process employed for the purchase of a soft drink.

Higher levels of product involvement occur when the consumer believes significant consequences or outcomes will occur as a result of the consumption decision (Cacioppo and Petty 1984). Under a condition of high involvement, "people use "central route' processing, meaning that they make a cognitive effort to evaluate statements or attend to claims or other message stimuli" (Lohtia, Donthu and Hershberger 2003, p.411). Alternatively, lower levels of product involvement occur when the consequences or outcomes of the consumption decision are perceived to be minimal (Cacioppo and Petty 1984). Under a condition of low involvement, "people tend to use 'peripheral route' processing, meaning that they are engaged in more subconscious processing where they 
do not make an effort to attend to any specific message elements" (Lohtia, Donthu and Hershberger 2003, p.411).

Shavitt (1992) asserts that promotional appeals should be matched to product type in order to maximize the effectiveness of the promotional effort. Indeed, this assertion supports the formation of the FCB (Foote, Cone and Belding) Grid. This grid builds upon the role of involvement in consumer behaviour and includes a thinking-feeling axis and a high-low involvement axis (Vaughan 1980). The FCB Grid presents a match of high involvement products with thinking issues as informative appeals and with feeling importance as affective appeals. A match is also considered for low involvement products with thinking as habit-forming appeals and with feeling as self-satisfaction appeals.

\section{Congruency Theory}

The explanation of congruency theory also utilizes a matching principle to explain appeal effectiveness. The explanation resides with the relationship of the self-concept to brands and products (Hogg, Cox and Keeling 2000; Gifford 1997). The self-concept has many definitions but the term generally refers to the "ideas and feelings that [someone] has about [themselves] in relation to others in a socially determined frame of reference" (Onkvisit and Shaw 1987 p.14).

Congruency theory's role in describing appeal effectiveness uses a matching principle between the nature of the product and the appeal type. Congruency theory 
explains this relationship by the application of cues to match aspects of the product image to the image of the self (Johar and Sirgy 1991). Research has found evidence to support the importance of self-congruity for appeal effectiveness (Celuch and Slama 1995; Hong and Zinkhan 1995; Johar and Sirgy 1991).

In addition, another match is explained through functional congruity with a "match between the beliefs of product utilitarian attributes (performance related) and the audience's referent attributes. The referent (e.g., ideal) attributes are the criteria used to evaluate the actual performance characteristics of the product" (Johar and Sirgy 1991, p.26). Indeed, Johar and Sirgy (1991) suggest a link exists between congruity and the Elaboration Likelihood Model where functional congruence represents the central route and self-congruity represents a peripheral route for promotional persuasion.

\section{Persuasion Knowledge Model}

The Persuasion Knowledge Model for understanding the effectiveness of promotional appeals takes an active reader perspective where the viewer of the advertisement plays an active role in the creation of meaning. "The Persuasion Knowledge Model ... outlines a theory of persuasion that acknowledges an active, thinking consumer whose overall goal is not necessarily to reject ads, or accept them, but to maintain control of the choice of how to respond to persuasion attempts" (Higie Coulter, Cotte and Lunt Moore 1999, p.290). There are three key components to this model, namely, topic knowledge, agent knowledge and persuasion knowledge. Topic knowledge refers to what the consumer knows or infers about the product in an 
advertisement, agent knowledge refers to the advertisement sponsor, and persuasion knowledge refers to tactics employed in the advertisement (Higie Coulter et al. 1999).

To explain consumer behaviour, this model demonstrates that consumers use their persuasion knowledge to form a perception of advertisement credibility and draw inferences about the manipulative intent of the sponsor (Higie Coulter et al. 1999). This is important in the context of a justice appeal because the product's country must be seen as a credible source. Beliefs about credibility are modelled to influence emotions, attitude toward the advertisement and behavioural intentions (Higie Coulter et al. 1999). In other words, the model examines congruency between the representations made in advertisements and the responses of consumers. In the context of guilt appeals, the guilty feeling necessitates behaviour to relieve the sensation of guilt (Higie Coulter et al. 1999).

In summary, the Elaboration Likelihood Model appears to be a major cognitive theory for explaining the persuasion effectiveness of promotional appeals. However, there are other theories, models and frameworks that provide insight into situational influences and specific appeals. Further, emotional appeals may have a direct impact on consumer behaviour or indirectly through a cognitive process where the emotional response to an affect appeal is treated as a piece of information.

\subsubsection{Assessing Appeal Effectiveness}

Promotional appeals are generally intended to persuade individuals toward a perceptual, attitudinal or behavioural outcome. Appeals are the central message 
employed to bring about a behavioural action (or inaction in some cases). While studies examining the effectiveness of appeals may take different approaches to assessing performance in the context of persuasion (Frazer, Bartel Sheehan and Patti, 2002) many examine the behavioural intentions and attitudes reported by respondents.

Twenty-three recent articles on advertising appeal effectiveness were used to assess the measures used. Table 2.7 shows that 10 of 23 articles on appeal effectiveness utilized purchase (or action) intention to evaluate the persuasion effectiveness of the appeals. Purchase intentions are captured using different measures including likely/unlikely, probable/improbable and possible/impossible to purchase (Vincent and Dubinsky 2005; Ruiz and Sicilia 2004; Royne Stafford and Day 1995). Intentions to take other actions were measured with agree/disagree with taking an action (Arthur and Quester 2004). Intentions to purchase/action can be recorded as present intentions or projected intentions for some time in the future (Laroche et al. 2001).

Eleven studies explored appeal effectiveness through the evaluations that individuals made toward the advertisement (see Table 2.8). Within the content of these studies, there appears to be much variability in the measurement of attitudes toward the advertisement. There are 17 different items to record these attitudes reflecting beliefs about effectiveness and memorability to evaluative criteria including informative and positive. Liking/disliking the advertisement is the leading measure and is the only item found in five of the six publications that disclose measurement information. Evaluating the advertisement as good/bad is utilized in four publications while 
interesting/uninteresting is employed in three studies. Three measures are found in two articles including effective/ineffective, favourable/unfavourable and not irritating/irritating.

TAble 2.7 Measurement OF APPEAL EfFectiveness

\begin{tabular}{|l|c|c|l|}
\hline & & & \\
& & &
\end{tabular}


TABLE 2.8 MEASUREMENT OF AdVERTISEMENT EVAluAtion

\begin{tabular}{|c|c|c|c|c|c|c|}
\hline $\begin{array}{l}\text { Advertisement Response } \\
\text { Measures }\end{array}$ & 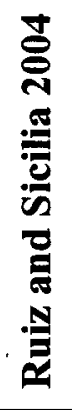 & 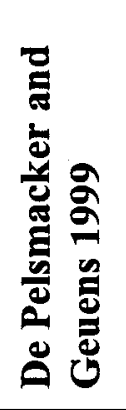 & 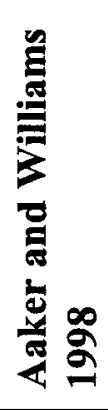 & 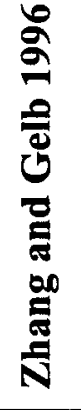 & 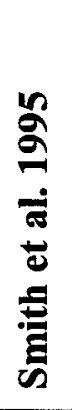 & 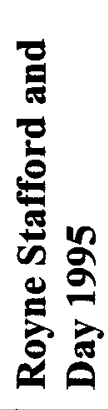 \\
\hline like & $\sqrt{ }$ & $\sqrt{ }$ & $\sqrt{ }$ & $\sqrt{ }$ & & $\sqrt{ }$ \\
\hline good & $\sqrt{ }$ & & $\sqrt{ }$ & & $\sqrt{ }$ & $\sqrt{ }$ \\
\hline interesting & & & & $\sqrt{ }$ & $\sqrt{ }$ & $\sqrt{ }$ \\
\hline effective & & $\sqrt{ }$ & & & $\sqrt{ }$ & \\
\hline favourable & $\sqrt{ }$ & & $\sqrt{ }$ & & & \\
\hline irritating & & & & $\sqrt{ }$ & & $\sqrt{ }$ \\
\hline positive & $\sqrt{ }$ & & & & & \\
\hline pleasant & & & & $\sqrt{ }$ & & \\
\hline nice & $\sqrt{ }$ & & & & & \\
\hline uplifting & & & & & $\sqrt{ }$ & \\
\hline relevant & & & & & $\sqrt{ }$ & \\
\hline persuasiveness & & $\sqrt{ }$ & & & & \\
\hline appealing & & $\sqrt{ }$ & & & & \\
\hline easy to forget & & $\sqrt{ }$ & & & & \\
\hline believable & & $\sqrt{ }$ & & & & \\
\hline informative & & $\sqrt{ }$ & & & & \\
\hline original & & $\sqrt{ }$ & & & & \\
\hline
\end{tabular}

The evaluations made by individuals about the product or brand in advertisements was included in research by scholars somewhat more often than toward the advertisements themselves, as evidenced in the 12 of 23 studies from the last ten years (see Table 2.9). There are ten different measures used in recent publications that present information about the measurement methodology used to gather respondent attitudes towards the advertised product or brand. The leading measurement item is a good/bad evaluation of the product or brand, and the scale is found in all six articles. Additionally, 
the like/dislike item is present in four studies while favourable/unfavourable scale is found in three papers. Nice/not nice is used in two studies with the other measures used in only a single instance.

Table 2.9 Measurement of Product and Brand Evaluations

\begin{tabular}{|c|c|c|c|c|c|c|}
\hline $\begin{array}{l}\text { Product/Brand Evaluation } \\
\text { Measures }\end{array}$ & 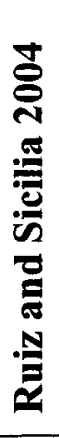 & 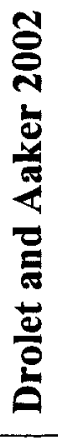 & 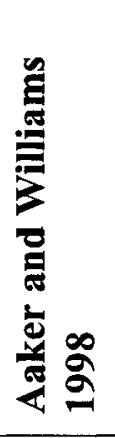 & 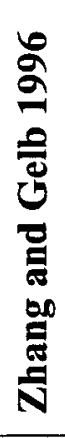 & 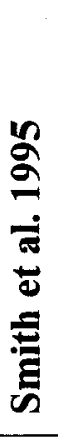 & 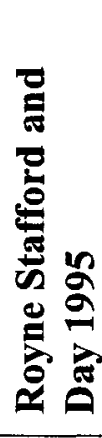 \\
\hline good & $\sqrt{ }$ & $\sqrt{ }$ & $\sqrt{ }$ & $\sqrt{ }$ & $\sqrt{ }$ & $\sqrt{ }$ \\
\hline like & $\sqrt{ }$ & $\sqrt{ }$ & $\sqrt{ }$ & $\sqrt{ }$ & & \\
\hline favourable & & $\sqrt{ }$ & $\sqrt{ }$ & & & $\sqrt{ }$ \\
\hline nice & $\sqrt{ }$ & & & $\sqrt{ }$ & & \\
\hline attractive & $\sqrt{ }$ & & & & & \\
\hline better than competing brands & $\sqrt{ }$ & & & & & \\
\hline worthy & $\sqrt{ }$ & & & & & \\
\hline desirable & & & & & $\sqrt{ }$ & \\
\hline useful & & & & & $\sqrt{ }$ & \\
\hline positive & & & & & & $\sqrt{ }$ \\
\hline
\end{tabular}

Besides using attitudes and behavioural intentions, other studies use particular measures to explore additional aspects of appeals and their effectiveness of communication or persuasion. In three recent articles, brand choice was included as a measure. This approach can be beneficial by improving the accuracy of self-reporting research through taking measurement closer to the actual behaviour. For example, Ruiz and Sicilia (2004) asked respondents to select one of three brands based on the 
assumption that they would purchase immediately. Alternatively, Zhang and Gelb (1996) provided respondents with the two coupons providing a discount toward the purchase of their selected product.

Advertisement preference is another dependent variable used recently for an appeal assessment, not for a product/outcomes assessment. Brunel and Nelson (2003) asked respondents to identify which of two appeals were perceived to be the most persuasive. Brunel and Nelson (2000) also inquired about which of two appeals were better, appeals more to the respondent, will be more successful, will have better recall, is more traditional for the product type, is most persuasive, and would create a better image for the organization.

In summary, the primary dependent variables present in research on appeal effectiveness appear to include attitude toward the advertisement (likeable, good, interesting), attitude toward the product/brand (good, likeable, favourable, nice) and the intention to make a purchase (intend to purchase).

\subsubsection{Importance of Appeal Context}

The effectiveness of promotional appeals is dependent upon the context of their viewing. A variety of contextual reasons can affect the persuasion effectiveness by limiting or enhancing the appeal to the viewer. There are four main issues of contextual importance, namely, advertisement, product, individual and group contexts. 
Promotional appeal effectiveness can be moderated by the advertisement context including media, message order and message involvement. The media used by advertisers is believed to have a moderating effect on cognitive and affective outcomes to the message in the promotion (see Brown, Homer and Inman 1998). For instance, Chaiken and Eagly (1983) found that print advertisement appeal effectiveness is based on information in the message and product cognitions while the effectiveness of television advertising appeals is based on the communicator's likeability. Despite the belief that medium can be a moderator on appeal effectiveness, Brown, Homer and Inman (1998) did not find support in their meta-analysis for this belief. The results do "not support the prediction of stronger feeling effects for television advertisements than for print advertisements" (Homer and Inman 1998, p.120). Therefore, differences in appeal effectiveness over various media may be limited.

There is evidence to support that the order of a message in a group of promotions will impact the receipt of the message. The effects of order are referred to as primacy or recency effects. "Primacy is characterized by a greater persuasion consequence of the initial communication ... (while) recency effect occurs when the final communication has the greater consequence on persuasion" (Brunel and Nelson 2003, p.331). Many advertisers like to have the first spot in a string of commercials with the belief that primacy effects are stronger because viewer attention and memory are higher than later in the commercial run (Zhao 1997). 
Message involvement from a consumer behaviour perspective refers to the extent that a person engages in the decision-making process and considers information; it is typically discussed on a scale from high to low (e.g. Lohtia, Donthu and Hershberger 2003). Involvement and promotional appeals are related through the ability of the appeal to garner attention or provide information, for instance, under conditions of high involvement, consumers are more likely to engage in information processing (MacInnis, Moorman and Jaworski 1991). Involvement may also be viewed as either enduring or situational where enduring involvement refers to ongoing potential arousal for the individual while situational involvement refers to arousal in a given scenario (Fitzmaurice 2005).

Another view of promotion involvement presents two different types that engage the opposing sides of the human brain. This perspective of involvement is directly linked to the main types of promotional appeals. Cognitive involvement refers to the left side of the brain that is "induced by utilitarian or cognitive motives" (Putrevu and Lord 1994, p.79). Affective involvement refers to the right side of the brain and is "derived from value-expressive or affective motives" (Putrevu and Lord 1994, p.79). Cline, Altsech and Kellaris (2003) provide some evidence to support this involvement by showing those with a need for cognition focus engage a thinking process oriented to the central message of the promotion while those with a high need for humour utilize a more emotional process and form favourable attitudes towards the promotion. 
Another possible moderating influence exists within the product context. Novelty and familiarity with the promoted product may also influence the effectiveness of promotional messages. Previous research provides evidence that affective appeals are likely to have stronger emotional reactions associated with novel brands or products (see Brown, Homer and Inman 1998). However, a meta-analysis by Brown, Homer and Inman (1998) found contrary results where a positive relationship between the feeling response and the attitude toward the promotion is stronger when the products are familiar. The authors suggest the promotions with familiar products are cueing affective memory from experience with previous promotions (Brown, Homer and Inman 1998). The metaanalysis also found the positive relationship between the feeling response and attitudes toward the brand is stronger when the product is novel rather than familiar (Brown, Homer and Inman 1998). Despite some mixed results, the authors seem to suggest that affective appeals are more effective for novel products than those that are familiar to the viewers. Further, the novelty of the appeal can bring a higher state of motivation for processing the promotional message.

The individual context can also moderate the promotion appeal effectiveness. In particular, gender represents a possibly important moderating issue. A study by Brunel and Nelson (2003) showed that females displayed the effects of primacy across appeal types while males exhibited more recency effects. However, the recency effects found for males decreases when they are exposed to a help-others oriented appeal (Brunel and Nelson 2003). Brunel and Nelson (2003) believe the gender differences to be based on distinct orientations to the world where females are more concerned with others than 
males. Within the context of the individual, gender may be an important moderator for appeal effectiveness. While personality can also influence the effectiveness of promotional appeals at the individual level, this construct was discussed previously in the paper.

Examining the effectiveness of appeals from a group context raises the potential influence of culture (e.g., Vincent and Dubinsky 2005; Frazer, Bartel Sheehan, and Patti 2002; Laroche et al. 2001; Aaker and Williams 1998; Zhang and Gelb 1996) and social norms (e.g., Albers-Miller and Stafford 1999). This is important for this research because the results could be confounded by unanticipated cultural differences. Therefore, this research will exercise controls over large differences in culture among respondents.

In summary, the context of the appeal can influence the effectiveness of the persuasion attempt. While there are mixed results in many circumstances, researchers and practitioners need to acknowledge the possibility that some of these factors can affect their research or promotional outcomes.

\subsubsection{Summary}

Appeals refer to the central message of the promotion that is intended to persuade consumers toward some activity (perceptual, attitudinal or behavioural). Appeals are important because they assist marketers in gaining the attention of consumers. While there are several appeal types used in practice, they can be classified into those that emphasize emotional versus cognitive content. Indeed, theories have evolved to explain 
the effectiveness of appeals using both emotion and cognition. Several measures have been utilized in the literature to assess promotional appeal effectiveness, but they measure attitudes toward the promotion, attitudes toward the product/brand and purchase intentions/preference. The context of a promotional appeal may influence its effectiveness with consumers including variables in the context of the advertisement (i.e. media, message order, message involvement), product (i.e. novelty), individual (i.e. gender) and group (i.e. culture and norms).

\subsection{Less Developed Countries and Branding}

An exploration of country-based branding appeals requires a general understanding of country images. Country images are mental maps or knowledge structures related to countries (Jaffe and Nebenzahl 2001). Country images are "defined as the total of all descriptive, inferential and informational beliefs one has about a particular country" (Martin and Eroglu 1993, p.193). Country image research originated in the study of countries but has branched out to explore the images associated with regions (e.g., Schweiger, Haubl and Friederes 1995) and cities (e.g., Mossberg and Kleppe 2005). Research on country image and product image has found that the image of any place may influence the image of a product.

There is a difference between image and identity. Brand identity is defined by as "a unique set of brand associations that the brand strategist aspires to create or maintain. These associations represent what the brand stands for and imply a promise to customers from the organization members" (Aaker 1996, p.68). The brand identity is viewed as the 
ideas that represent the product or service to the marketer while the brand image is held by consumers based upon their past experience with the product and marketers' promotions (Meenaghan and Shipley 1999). A key distinction that is inferred from the definitions of brand and country images is that brands are managed images for products while country images exist even when ignored by a country's marketers. However, the converse may also be true as country images can be managed to some degree while product images can exist beyond the intentions of marketers (e.g. Nike and unfair labour practices).

In a way similar to their use of brands, people use country images to assist in the processing of information and to aid in the formulation of purchase decisions (Kotler and Gertner 2002). Country image effects are described as the "impact that generalizations and perceptions about a country have on a person's evaluations of the country's products and/or brands." (Nebenzahl, Jaffe and Lambert 1997 p.28). While the effects of country image are stronger in single cue research settings compared to multiple cue studies, country images remain important in multiple cue environments (Peterson and Jolibert 1995). In the context of point of sale promotions, the country cue has been found to influence product judgements (Kiecker and Duhan 1992; Wall, Liefeld and Heslop 1991).

Beyond examining the influence of consumer decision-making, country image research has also explored the influence of these images on decisions relating to organizational buying (e.g. Heslop et al. 2004) and locations for investment (e.g. Wee, Lim and Tan 1993). Due to the importance of country images in the marketplace, policy 
makers must consider the images held by foreigners about their country and be cognizant of how the products they associate with their country impact those perceptions.

Country image is a maturing research area in the marketing discipline with current research efforts shifting from associative and descriptive efforts to ones aimed at confirming the modeling of theoretical concepts. Although early research conceived the country image construct as uni-dimensional (e.g. Erickson, Johansson, and Chao 1984) and product-centric (e.g. Han 1988), more recent publications generally embrace the construct's distinctiveness and multi-dimensional nature. A key aim of country image theory is to explain the effect of these images through an understanding of attitudes. The cognitive, affective and conative aspects of attitude formation are represented through the beliefs about a country and its products (cognitive), the feelings towards the country and its products (affective), and behavioural intentions to purchase the country's products, to visit the country, or to invest in the country (conative) (Heslop et al. 2004).

The cognitive component of attitude formation is present in country image literature as reflecting the beliefs of a country and its people. As in Table 2.10, these beliefs may be best represented using two groups - descriptive beliefs and competency beliefs (Heslop et al. 2004). 
TABle 2.10 PCI MeAsures for Country Cognitions

\begin{tabular}{|l|l|l|l|}
\hline \multicolumn{2}{|c|}{ Beliefs About Country } & \multicolumn{2}{c|}{ Beliefs About People } \\
\hline Descriptive & Competence & Descriptive & Competence \\
\hline Active in world affairs & Technically advanced & Friendliness & Creative \\
Admirable in world affairs & Economic development & Proud & Well educated \\
Environmental protection & Stability of economy & Trustworthy & Industriousness \\
Individualistic & $\begin{array}{l}\text { Technically } \\
\text { skilled } \\
\text { Alignment with home }\end{array}$ & Wealth & Work ethic \\
country & & & \\
Quality of life & & \\
Individual rights and & & \\
freedoms & & \\
Political stability & & \\
Standard of living & & & \\
\hline Sources include: Manrai et al. 1998; Lee and Ganesh 1999; Knight and Calantone 2000; Parameswaran and \\
Pisharodi 2002; Olsen and Olsson 2002; Orbaiz and Papadopoulos 2003; Heslop et al. 2004
\end{tabular}

Cognitions about products also appear in the PCI literature and are measured through several measures (see Table 2.11). The table presents the measurement items used in the literature as perceptions about inherent features, peripheral features, and evaluations of a country's products.

\section{Table 2.11 PCI Measures for Product Cognitions}

\begin{tabular}{|l|l|l|}
\hline Performance Descriptors & Peripheral Features & Evaluative Terms \\
\hline Defects & Advertised & Attractive \\
Durable & Availability & Inexpensive \\
Innovative & Easy to service & Luxurious \\
Need repairs & Features & Original \\
Quality & Informative ads & Prestigious \\
Reliable & Range of styles & \\
Safety & Sold worldwide & \\
Technical & Stylish & \\
Workmanship & Variety & \\
\hline
\end{tabular}

Sources include: Lee and Ganesh 1999; Knight and Calantone 2000; Parameswaran and Pisharodi 2002; Olsen and Olsson 2002; Orbaiz and Papadopoulos 2003; Heslop et al. 2004 
The affective component of attitudes is represented in the PCI literature through two main constructs, which often include both affect and evaluative measures in their estimation (see Table 2.12). The evaluation of the country is modelled as related to the beliefs about the country and its people while the product evaluation construct is modelled as related to the competency beliefs about a country and its people (e.g. Heslop et al. 2004).

TABLE 2.12 PCI Measures for AfFect AND Evaluation

\begin{tabular}{|l|l|l|l|}
\hline \multicolumn{2}{|c|}{ Country } & \multicolumn{2}{c|}{ Products } \\
\hline Evaluation & Affect & Evaluation & Affect \\
\hline Culturally similar & Likeable & Other people like & Like \\
Economically similar \\
$\begin{array}{l}\text { Politically similar } \\
\text { Ideal country }\end{array}$ & & Value & Proud \\
Satisfied \\
Overall rating & Happy to buy \\
\hline
\end{tabular}

Sources include: Lee and Ganesh 1999; Parameswaran and Pisharodi 2002; Olsen and Olsson 2002; Orbaiz and Papadopoulos 2003; Heslop et al. 2004; Laroche et al. 2005

Two constructs also generally represent the conative component of attitude in PCI research - desired country associations and product buying. The former include desire for closer ties with and more investment from the country (Laroche et al. 2005). While the desired country associations is a conative component of attitude, the terminal dependent variable tends to be related to the buying decision. Here, measures include intention to purchase (Parameswaran and Pisharodi 2002), willingness to buy (Orbaiz and Papadopoulos 2003; Heslop et al. 2004), and recommend to others (Lee and Ganesh 1999). 


\subsubsection{Image of Less Developed Countries and Their Products}

Generally, developed countries (DCs) have more positive country images than countries with lower levels of economic development (Tse and Gorn 1992; Cordell 1992; Ahmed and d'Astous 1993; Chao 1993; Mohamad et al. 2000; Kaynak, Kucukemiroglu and Hyder 2000). Although some LDCs may have positive images for specific characteristics (e.g. tourism), they have less positive images as desirable sources for products and as high functioning countries, politically, economically and socially. Indeed, there is evidence to suggest that a developed country preference exists for both consumers and retail buyers (Heslop et al. 2004).

While a hierarchy of country images likely exists, the order and place of specific countries is undetermined. A complex order may be made with groups of countries (Manrai, Lascu and Manrai 1998) or individual countries (Gaedeke 1973). For instance, a recent study of Ghanaian consumers determined that country images influenced consumer perceptions of brands and their purchase preferences in favour of foreign brands (Yamoah 2005). In this recent study, Ghanaian consumers were asked about their perceptions and purchase preferences for rice from Ghana, Thailand, Japan and the United States. While Thai rice was preferred over the local Ghanaian rice despite the relatively poor status of both countries, Thailand has a higher level of national income compared to Ghana (World Bank 2006). However, differences in the alignment of images may also be rooted in cultural diversity, political climate and perceived similarity with the source country's belief system (Bilkey and Nes 1982). 
Although less developed countries (LDCs) typically face the issue of having a negative country image in DC markets, LDCs are not without options for marketing success. Building on a grid developed by Jaffe and Nebenzahl (2001) examining strategic options for companies based on contrasting country and brand images, Figure 2.3 presents possible marketing actions related to the country image situations facing LDCs. The two-by-two matrix is based on the axes of weak-to-strong product brand image and a negative-to-positive country image. The juncture of product brand image and country image is an important one because the perceptions of a product brand may be more malleable than the image of a country in the short term (Tse and Gorn 1992).

The possibility of a positive country image for a LDC appears to be very low given the literature. However, a LDC may have positive aspects of its country image as a point of leverage. For instance, an opportunity exists for a LDC to export goods that utilize a positive raw material reputation (Bilkey and Nes 1982). Such a practice is found in the promotion of Colombian coffee in DC markets. In addition, positive country image aspects may yield initial positive impressions for a new brand (see Tse and Gorn 1992). 
Figure 2.3 INTERSECTION OF BRAND AND COUNTRY IMAGES FOR LDCS

Positive Country Image

- LDCs have an opportunity to export manufactured goods that are aligned with a current raw material reputation (Bilkey and Nes 1982)

- Positive initial impressions are associated with a new brand from a favourable country image (Tse and Gorn 1992)

- Leverage country image through a government certification program (Choi 1992)
- Emphasize positive aspects of country image (Bilkey and Nes 1982; Tse and Gorn 1992)
- $\quad$ Provide warranties (Bilkey and Nes 1982; Thorelli, Lim and Ye 1989; Cordell 1992; Jo, Nakamoto and Nelson 2003)

- Leverage DCs retailer image (Bilkey and Nes 1982; Thorelli, Lim and Ye 1989)

- Offer after sales service (Jo, Nakamoto and Nelson 2003)

- Encourage product experience (Tse and Gorn 1992)

- Set lower prices (Tse and Gorn 1992)

- Focus production on lower risk goods (Cordell 1992)

- Produce components in an LDC and assemble in a DC (Cordell 1992)

\section{Negative Country Image}

Source: adapted from Jaffe and Nebenzahl 2001

The bottom half of the matrix is the most relevant to LDCs as they face challenges associated with poor country images. The bottom right section represents a scenario where the country image is poor but the LDC possesses strong brands. For example, South Korea would currently fit in this quadrant as an LDC with a weak country image but a strong brand in the high technology brand LG. This is an advantageous situation because the development and maintenance of a strong brand can 
offset poor country images (Gaedeke 1973; Ahmed and d'Astous 1993; Jo, Nakamoto and Nelson 2003). However, this may be a difficult situation to realize because brand building can be very expensive. The approach may be more successful if little is known about other products from the country, thereby reducing any potential negative halo effects. In addition, an option may exist to decompose the origin of manufacture into subgroups (e.g., country of design, assembly or components) with the opportunity to emphasize the contributions to the product from LDCs and build the country image over time. A decomposed negative country image with a strong global brand can lead to perceptions of good purchase value (Tse and Lee 1993).

Another dominant situation for LDCs is the perception that their brands are weak in the markets of DCs. The two options frequently mentioned in the literature suggest that offering a warranty or performance guarantee (Bilkey and Nes 1982); Thorelli, Lim, and Ye 1989; Cordell 1992; Jo, Nakamoto and Nelson 2003) and the leveraging of a prestigious/strong retail image (Bilkey and Nes 1982; Thorelli, Lim and Ye 1989). Research suggests negative images can be offset through post-purchase service (Jo, Nakamoto and Nelson 2003), product experience (Tse and Gorn 1992), lower prices (Tse and Gorn 1992), and a production emphasis (Cordell 1992). These options emphasize the enhancement of brand image, reduced risk, improved value, or better product experience.

Of the research summarized in Figure 2.3, LDC literature on branding appears to be missing an investigation into the effectiveness of different promotional appeals on consumers in developed countries. This information would deepen understanding of how 
companies from LDCs can succeed in developed markets. Anholt (2005) argues that developing countries need to create their own brands and migrate their economic base from resource extraction to manufacturing and ultimately design. Indeed, success for some LDC brands in foreign markets has occurred and is documented in the literature. The success stories are representative of points across the product value spectrum from the low-end value segment (Dawar and Frost 1999) to the high-end prestigious segment (Anholt 2002; Irwin 2003).

Table 2.13 presents examples of LDC brands that are flourishing beyond their domestic boundaries and the strategies that propelled the brands to success. The typical path for LDC brands in DC markets is to begin by offering a low-end value product by exporting from its domestic manufacturing base and progressing towards a higher-end brand (Humphrey 2001). Some Korean firms, including, Samsung, Hyundai and LG, exemplify this brand building process. However, Choi (1992) argues this migration is the result of the Korean government's intervention by providing a national certification and selection program that placed the country's reputation in support of the products. The Korean government selected specific firms as 'General Trading Companies' and inspected their export products for quality. While the attractiveness of this option increases with the strength of the reputation or image of the country, a country with a very weak image may encourage its companies to focus on brand development in lowend segments of DC markets (Kim 1995). 
TABle 2.13 EXamples of Product BRANDS From Less DeVeloped Countries

\begin{tabular}{|c|c|c|}
\hline Approach & Authors & Branding Activity \\
\hline $\begin{array}{l}\text { Low-end emphasis } \\
\text { Skoda (Czech Republic) }\end{array}$ & Dawar and Frost 1999 & $\begin{array}{l}\text { Value position in } \\
\text { Volkswagen line }\end{array}$ \\
\hline $\begin{array}{l}\text { Migration toward high-end } \\
\text { Acer (Taiwan) } \\
\text { Samsung (Korea) } \\
\text { Hyundai (Korea) } \\
\text { LG (Korea) } \\
\text { Bebe Bushh (Thailand) }\end{array}$ & $\begin{array}{l}\text { Amine and Chao } 2004 \\
\text { Humphrey } 2001 \\
\text { Humphrey } 2001 \\
\text { Humphrey } 2001 \\
\text { Anholt } 2002\end{array}$ & $\begin{array}{l}\text { Brand building } \\
\text { Brand building } \\
\text { Brand building } \\
\text { Brand building } \\
\text { Previously manufactured } \\
\text { unbranded clothing for } \\
\text { GAP and Calvin Klein }\end{array}$ \\
\hline $\begin{array}{l}\text { High-end penetration } \\
\text { Acer computers (Taiwan) } \\
\text { DeBeers (South Africa) } \\
\text { Urvashi perfume (India) }\end{array}$ & $\begin{array}{l}\text { Amine and Chao } 2004 \\
\text { Irwin } 2003 \\
\text { Anholt } 2002\end{array}$ & $\begin{array}{l}\text { Premium position in China } \\
\text { Leading diamond provider } \\
\text { Exotic image and sold } \\
\text { through prestigious Paris } \\
\text { retailers }\end{array}$ \\
\hline $\begin{array}{l}\text { Other } \\
\text { Jollibee Foods (Philippines) }\end{array}$ & Dawar and Frost 1999 & Cultural affiliation \\
\hline
\end{tabular}

While not all LDC brands change market position, the typical path for those that do migrate is an upward evolution from a low-end value product to high-end prestigious item. However, some brands can be successful by entering a DC market near the top of the product spectrum. For example, DeBeers from South Africa is very successful in the global diamond market (Irwin 2003) and Urvashi perfumes from India are sold exclusively through expensive Parisian shops (Anholt 2002). In both cases, the success of the premium positioning is rooted in the raw materials typically associated with the 
country (i.e., diamonds from South Africa and exotic spices from India). LDC companies must be cognizant of the influence of country images on their brands.

Indeed, Amine and Chao (2004) demonstrate that a company can exercise flexibility in its approach to foreign markets based on the perceived image of the company or the country. Acer entered the North American, Japanese and European markets with their products positioned at the lower end of the spectrum matching the country's slogan "Taiwan: Your source for innovalue" (Amine and Chao 2004, p.196). However, the company was able to position its products at the higher end of the spectrum when more recently entering the Chinese computer market because "Chinese consumers typically regard Acer's products as having much better quality and great added value than those of domestic makers" (Amine and Chao 2004, p.202). Therefore, evolution of a company's or country's image may provide some flexibility in positioning strategies.

The interaction of images of products and countries is certainly important, perhaps never more important than in the context of agricultural products. Unfortunately, Papadopoulos (2004) points out that producers often perceive agricultural products as commodity products and marketing knowledge is less frequently applied when compared to industrial goods. Indeed, it can be quite difficult to hold share or position in the food market without actively branding in association with the producing country (Anholt 2005). Despite the major challenges, some agricultural producers from developing countries have successfully branded their products, distinguishing them from other offerings in a previously perceived commodity market. For example, Colombian Coffee 
represents an exceptional success story of an agricultural commodity that is distinguished from its competition.

Research on appeal effectiveness and LDC appears to be absent from the

literature. Despite promotional appeal effectiveness research exploring the influence of culture and studies exploring cross-national differences, few studies explore appeal effectiveness in the context of developing countries. Further, these studies (e.g., Laroche et al. 2001; Aaker and Williams 1998; Zhang and Gelb 1996) focus on cross-cultural influences on appeal effectiveness. An investigation of appeal effectiveness for products from LDCs is needed because their role in the global economy has increased in recent years and it may provide a basis for attracting consumers in developed countries to their products. However, they are still limited with providing low value, commodity products and this study may assist them in finding a way to offer higher value products.

\subsubsection{Country Image and Individual Differences}

The intersection of country image and individual differences includes studies on the influence of personality and the familiarity on the images of products and countries. Research on personality and country images is limited and tends to examine a few central and surface level traits. Few papers explore the impact of cardinal traits on the role of country images in consumer behaviour. Central traits provide individuals with guidance to act in multiple situations but are not equivalent to the underlying cardinal traits. Selfand other-directed traits are among the central personality traits explored in country image literature. 
Self-oriented traits include self-monitoring, excellence, self-esteem and harm avoidance. In country image research, the evaluation process of a product can be affected by differences in self-monitoring. Self-monitoring refers to the extent an individual observes and regulates their behaviour in social situations (Dutta and Vanacker 2000). High self-monitors may use a country of origin cue while low self-monitors may not use the information (DeBono and Rubin 1995). Further, Ahmed, d'Astous and Zouiten (1993) demonstrate that excellence (motivation toward a perfect outcome), self-esteem (self-confidence and concern about social risks) and harm avoidance (concern about risks) can all influence the effects of country images on brand and price perceptions.

Value orthodoxy represents an other-directed trait that is investigated in country image literature. Value orthodoxy refers to the conservative nature of individuals (Ahmed, d'Astous and Zouiten 1993). Ahmed, d'Astous and Zouiten (1993) found only weak evidence that value orthodoxy influences the effects of country images. However, Nes (1981) discusses a related concept of dogmatism that is inversely related to a person's preference for foreign products. While Ahmed, d'Astous and Zouiten (1993) included ethnocentrism in the definition of value orthodoxy, ethnocentrism is only one facet of value orthodoxy.

Familiarity is another consideration that can impact product beliefs directly and positively (Heslop et al. 2004) or moderate the influence of country images on the buying behaviour of consumers (Han 1989). There are different ways to view familiarity, 
specifically, familiarity with a product category (Knight \& Calantone 2000), with brands or products of the country (Heslop et al. 2004) and with the country itself (Erickson, Johansson and Chao 1984, Heslop et al. 2004). Evidence suggests that differences in country familiarity can influence the salience of country images where low country familiarity consumers are more likely to utilize country-of-origin cues (Lee and Ganesh 1999). Further, consumers with moderate product or brand familiarity are less likely to use country information than high or low familiarity consumers (Lee and Ganesh 1999). Despite familiarity being a basis for drawing individual differences among consumers in the role of country images, familiarity is perhaps more rooted in situational differences among individuals than representing individual differences associated with personality.

\subsubsection{Summary of Less Developed Countries and Country Branding}

The images of countries affect the evaluation of products and the decisions consumers make. Despite the fact that images of less developed countries are generally less positive than developed countries, some brands from less developed countries have employed strategies to succeed in developed country markets. It appears that research on less developed country strategies excludes an assessment of promotional appeal effectiveness for products from these countries. A typical path for LDC brand equity building is by moving upwards from a value position toward a more prestigious position. The influence of country images on consumer decision-making is an important consideration for marketers, and recent efforts strive to better understand the creation of successful country brands. However, these efforts have been focused mainly on 
developed country brands. Research on country images and personality demonstrates that some traits can help explain country image effects on consumers.

\subsection{Summary of Literature}

Extensive research exists in the areas of personality, motivation and appeal effectiveness. The review of literature outlines major themes of relevance to this study. Figure 2.4 displays the research framework along with a list of supporting sources. The core of the framework indicates the link of personality and motivation to promotional appeal effectiveness. Motivations are derived, at least in part, from personality while appeal effectiveness is derived from the appeals tie with motivations needing fulfillment.

Personality research in marketing is generally based on trait theory and argues personality may be described through sets of traits described as cardinal, central and surface traits. The linkage of personality to motivation and through to appeal effectiveness implies that some traits may influence the relevance of certain motivational appeals. The two chevrons placed in parallel to the direction of this main pathway indicate that emotional or cognitive theories may be employed to explain the influence of personality and motivation on appeal effectiveness. To the left in the figure of the core framework rest two blocks representing factors that can influence the main linkage. The top block refers to country image and the bottom block refers to situational considerations. It is necessary to be aware of these factors in order to control on them in the study of the main linkage. 
Figure 2.4 GENERALIZED RESEARCH FRAMEWORK

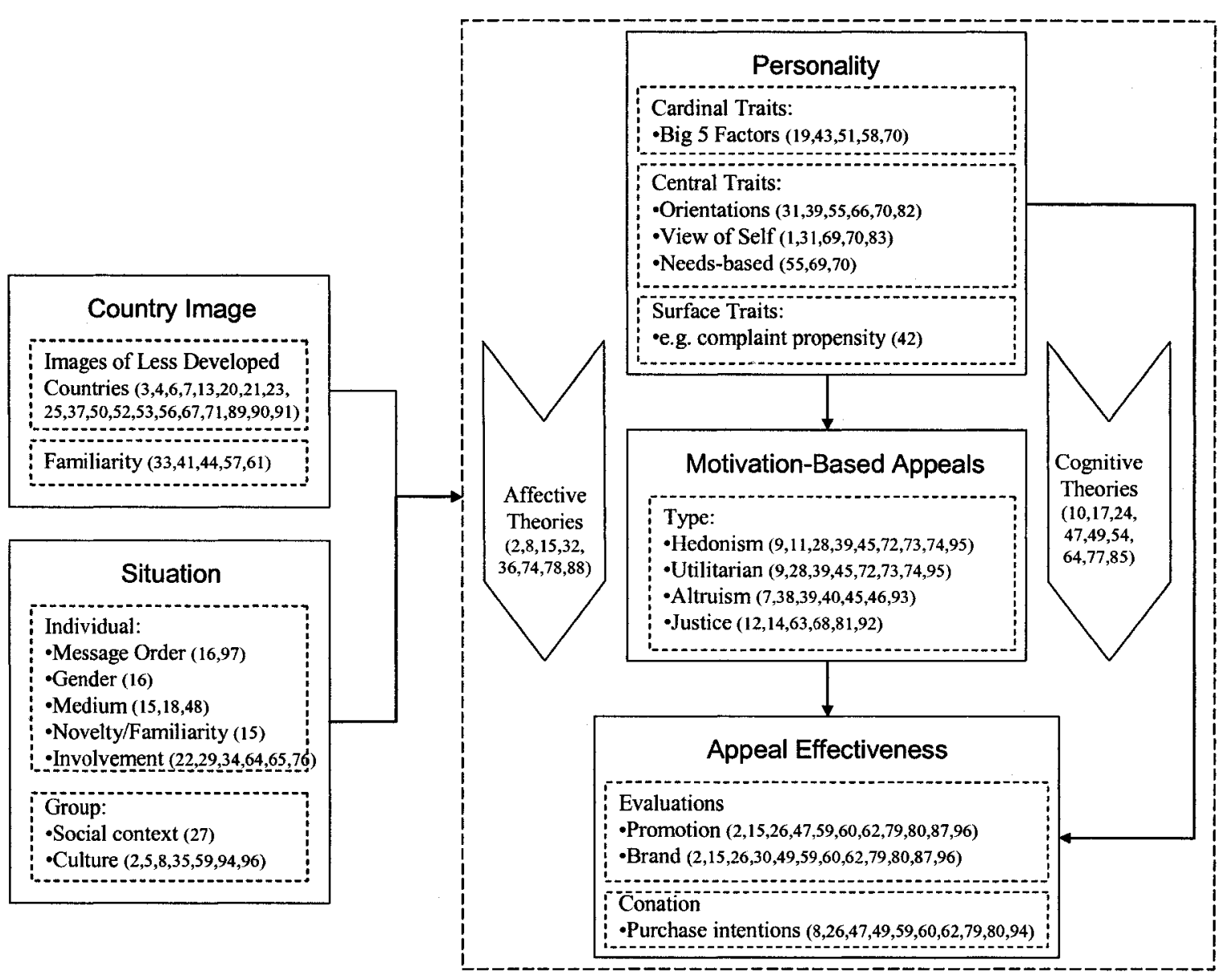


Note to Figure 2.4: Some Supporting Publications for the Research Framework

\begin{tabular}{|c|c|c|c|c|c|}
\hline$\#$ & Source & $\#$ & Source & $\#$ & Source \\
\hline 1 & Aaker 1999 & 34 & Fitsmaurice 2005 & 67 & Mohamad et al. 2000 \\
\hline 2 & Aaker and Williams 1998 & 35 & Frazer, Bartel Sheehan and Patti 2002 & 68 & Montada 2002 \\
\hline 3 & Ahmed and d'Astous 1993 & 36 & Frijda 1999 & 69 & Mourali et al. 2005 \\
\hline 4 & Ahmed, d'Astous and Zouiten 1993 & 37 & Gaedeke 1973 & 70 & Mowen et al. 2004 \\
\hline 5 & Albers-Miller and Stafford 1999 & 38 & Goodwin, Smith and Spiggle 1990 & 71 & Nes 1981 \\
\hline 6 & Amine and Chao 2004 & 39 & Gregory, Munch and Peterson 2002 & 72 & O'Curry et al. 2001 \\
\hline 7 & Anholt 2002 & 40 & Guy and Patton 1989 & 73 & Okada 2005 \\
\hline 8 & Arthur and Quester 2004 & 41 & Han 1989 & 74 & Olney et al. 1991 \\
\hline 9 & Babin, Darden and Grffin 1994 & 42 & Harris and Morris 2001 & 75 & Puri 1996 \\
\hline 10 & Baker and Lutz 2000 & 43 & Harris and Mowen 2001 & 76 & Putrevu and Lord 1994 \\
\hline 11 & Balabanis, Mueller and Melewar 2002 & 44 & Heslop et al. 2004 & 77 & Rogers 1975 \\
\hline 12 & Batson 2002 & 45 & Hetsroni 2000 & 78 & Rosenhan et al., 1981 \\
\hline 13 & Bilkey and Nes 1982 & 46 & Hibbert, Hogg and Quinn 2005 & 79 & Royne Stafford et al. 1995 \\
\hline 14 & Blader and Tyler 2002 & 47 & Higie Coulter, Cotte and Lunt Moore 1999 & 80 & Ruiz and Sicilia 2004 \\
\hline 15 & Brown, Homer and Inman 1998 & 48 & Homer and Inman 1998 & 81 & Schoefer and Ennew 2005 \\
\hline 16 & Brunel and Nelson 2003 & 49 & Hong and Zinkhan 1995 & 82 & Schwartz et al. 2002 \\
\hline 17 & Celuch and Slama 1995 & 50 & Humphrey 2001 & 83 & Shavitt 1989 \\
\hline 18 & Chaiken and Eagly 1983 & 51 & Hunthausen et al. 2003 & 84 & Shavitt 1992 \\
\hline 19 & Chang 2001 & 52 & Irwin 2003 & 85 & Sirgy and Johar 1992 \\
\hline 20 & Chao 1993 & 53 & Jo, Nakamoto and Nelson 2003 & 86 & Slama and Singley 1996 \\
\hline 21 & Choi 1992 & 54 & Johar and Sirgy 1991 & 87 & Smith et al. 1995 \\
\hline 22 & Cline, Altsech and Kellaris 2003 & 55 & Jones and Lejuez 2005 & 88 & Tanner et al. 1991 \\
\hline 23 & Cordell 1992 & 56 & Kaynak, Kucukemiroglu and Hyder 2000 & 89 & Thorelliet al. 1989 \\
\hline 24 & Dahl et al. 2003 & 57 & Knight \& Calantone 2000 & 90 & Tse and Gorn 1992 \\
\hline 25 & Dawar and Frost 1999 & 58 & LaBarbera, Weingard and Yorkston 1998 & 91 & Tse and Lee 1993 \\
\hline 26 & De Pelsmacker and Geuens 1999 & 59 & Laroche et al. 2001 & 92 & Tuan Pham et al. 2004 \\
\hline 27 & DeBono and Rubin 1995 & 60 & LaTour and Rotfeld 1997 & 93 & Verplanken et al. 2002 \\
\hline 28 & Dhar and Wertenbroch 2000 & 61 & Lee and Ganesh 1999 & 94 & Vincent and Dubinsky 2005 \\
\hline 29 & Dholakia 2001 & 62 & Lepkowska-White and Weinberger 2003 & 95 & Voss et al. 2003 \\
\hline 30 & Drolet and Aaker 2002 & 63 & Lerner and Meindl 1981 & 96 & Zhang and Gelb 1996 \\
\hline 31 & Dutta and Vanacker 2000 & 64 & Lohtia, Donthu and Hershberger 2003 & 97 & Zhao 1997 \\
\hline 32 & Eisenberg 1986 & 65 & Macinnis, Moorman and Jaworski 1991 & & \\
\hline 33 & Erickson, Johansson and Chao 1984 & 66 & Mcdonald and Jacobs 1992 & & \\
\hline
\end{tabular}

The figure illustrates points of interaction among the research areas. The literature review highlights two major gaps that do not appear to be addressed. First, marketing literature does not make a distinction in other-oriented motivational appeals along the feeling-thinking continuum. Despite discussion in the psychology literature of 
a cognitive, other-oriented justice motivation, the motivation type does not appear to have captured the attention of marketing scholars. Second, research on country images and the effectiveness of promotional appeals has ignored the context of images of LDC. In the limited research on promotional appeal effectiveness of products from LDCs, the studies do not explore the influence of the country cue on consumer perceptions and outcomes. 


\section{RESEARCH OBJECTIVES AND HYPOTHESES}

The identification of gaps in the literature highlights opportunities for research. The research explores two gaps in knowledge: (1) a possible distinction between otheroriented appeals using the feeling-thinking continuum and (2) the role of developing country images in the effectiveness of motivation-based promotional appeals. These gaps are addressed within the context of personality type (inner-other directedness) and product type (hedonic and utilitarian).

Gap 1: A distinction in other-oriented motivational appeals along the feeling-thinking continuum

As illustrated in the literature review, a gap in knowledge becomes apparent at the intersection of personality and motivation. In motivational appeal research, Hetsroni (2000) demonstrates that major themes used in promotions may be categorized into hedonic, utilitarian and altruism appeals types. However, the current conception of altruism as the sole representation of other-oriented motivations ignores the possibility that the distinction found between hedonic and utilitarian motivations based on the feeling-thinking continuum can also be applied to other-oriented appeals. The feelingthinking continuum is a relevant consideration for this study because it is often applied to the assessments of appeal effectiveness (e.g. Vaughan 1980; Royne Stafford and Day 1995). 
While Anholt (2005) argues other-oriented appeals diminish consumer perceptions of product value because marketers rely on charity appeals, an other-oriented appeal rooted in cognitive reasoning may enhance the perceived value of the product. Product value perceptions may be augmented by the additional benefits that accrue through the purchase of a product using a cognitive based, other-oriented justice appeal (i.e. fairness, equity) by fulfilling a consumer's sense of social obligation. In addition, higher perceived value may also be associated with higher evaluations of products.

A relationship between the type of appeal and its effectiveness in persuading consumers is expected based on emotion and cognition theories. Emotion theory predicts that emotion-based promotions work better for hedonic than for utilitarian motivations (Olney, Holbrook and Batra 1991) whereas cognition appeals work better for utilitarian motivations. From a cognitive theory perspective, the Elaboration Likelihood Model suggests that a cognition-based promotional appeal would be more suitable in situations where higher levels of involvement exist. In this study, the level of involvement is being held constant through the selection of product types to control for this effect. It is expected that the four appeal types will result in different levels of appeal effectiveness. Therefore,

Hypothesis 1a: Outcomes (i.e. overall evaluations of products and promotions and purchase intentions) will be different for the four appeal types (hedonism, utilitarianism, altruism and justice).

In marketing research exploring personality, social orientation can be a means to assess individual differences in behaviour (Gregory, Munch and Peterson 2002; Dutta 
and Vanacker 2000; McDonald and Jacobs 1992). Specifically, the inner-other directedness trait refers to the propensity of people to emphasize themselves and their interests versus society and societal interests. Research has already determined that a person's social orientation is relevant to an assessment of promotional appeal effectiveness (Brunel and Nelson 2000; Aaker and Williams 1998; Zhang and Gelb 1996).

Further, the feeling-thinking continuum may also be relevant to product perceptions, particularly when considering the inner-other directedness trait of individuals and its relationship to the persuasion of motivation-based appeals. In general, a match between the central message of a promotion representing the motivation driving the consumer toward fulfillment of their unmet needs and the social orientation of the consumer is expected to improve the effectiveness of promotions. The proposed hypothesis $1 \mathrm{~b}$ is intended to test the validity of the position that justice is an effective promotional appeal type for LDCs' products for other-oriented individuals. In addition, hypothesis $1 \mathrm{c}$ is intended to test that inner-oriented appeals lead to higher outcomes for inner-directed individuals compared to other-directed people. Therefore,

\section{Appeal and Personality Match:}

Hypothesis 1b: Outcomes (i.e. overall evaluations of products and promotions and purchase intentions) for other-directed subjects will be higher for other-oriented appeals (i.e. altruism and justice appeals) than for self-oriented appeals (i.e. hedonism and utilitarianism appeals).

Hypothesis 1c: Outcomes (i.e. overall evaluations of products and promotions and purchase intentions) for inner-directed subjects will be 
higher for self-oriented appeals (i.e. hedonism and utilitarianism appeals) than for other-oriented appeals (i.e. altruism and justice appeals).

Additionally, a match of product type and the feeling-thinking continuum may predict differences in response outcomes. For other-directed individuals, the influence may result from a matching of the cognitive versus emotion emphasis. The informative and thinking-based other-oriented justice appeal may lead to higher response outcomes with products that are more utilitarian oriented for other-directed individuals. Similarly, the more emotion-based altruistic appeal may lead to higher response outcomes with products that are more hedonic for other directed individuals. For inner-directed individuals, the influence of appeal type, personality and product type on promotional effectiveness outcomes may result from a match between appeal type and product type. The utilitarian appeal will resonate better with the utilitarian product rather than the hedonic product for inner-directed individuals. Similarly, the hedonic appeal will lead to higher outcomes for the hedonic product for inner-directed individuals. Therefore,

Appeal, Personality and Product Type Match:

Hypothesis 1d: Outcomes (i.e. overall evaluations of products and promotions and purchase intentions) for other-directed subjects with utilitarian products will be higher for justice appeals than for altruism appeals.

Hypothesis 1e: Outcomes (i.e. overall evaluations of products and promotions and purchase intentions) for other-directed subjects with hedonic products will be higher for altruistic appeals than for justice appeals.

Hypothesis 1f: Outcomes (i.e. overall evaluations of products and promotions and purchase intentions) for inner-directed subjects with 
utilitarian products will be higher for utilitarian appeals than for hedonic appeals.

Hypothesis 1g: Outcomes (i.e. overall evaluations of products and promotions and purchase intentions) for inner-directed subjects with hedonic products will be higher for hedonic appeals than for utilitarian appeals.

This series of hypotheses is graphically represented in a simple model of appeal effects shown in Figure 3.1. The figure presents only the relationship between appeal type and promotional effectiveness in the context of personality and product type. Further development of the model will be presented to address the second research gap.

Figure 3.1 Simple Model of APPEAL EFFects

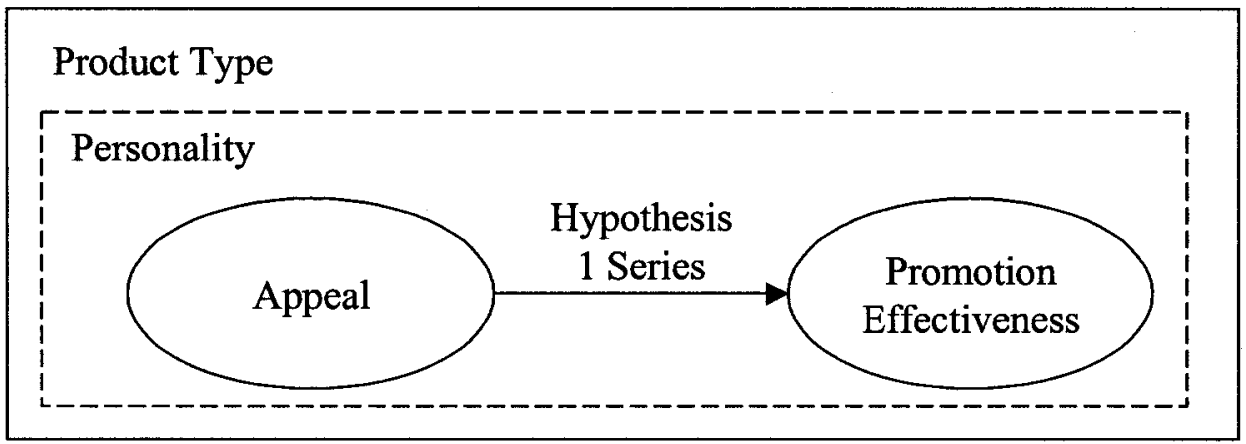

Gap 2: Relationship of Less Developed Country (LDC) images with motivation-based promotional appeals

In order to study the role of country images in promotional appeal effectiveness, two additional relationships need to be established besides hypothesis 1 series (linking 
appeal to promotional effectiveness outcomes). First, the relationship of country image to promotional appeal effectiveness outcomes needs to be assessed. Earlier research has noted the relationship of country image to purchase intentions and product evaluations. In the context of this study of promotional appeals, the relationship of country image to promotional appeal evaluation is also postulated. Second, the relationship of promotional appeal to country image is also required. The hypothesis concerns whether the appeal type affects country image.

The direct linkage of the images of LDC's to the effectiveness of promotional appeals has been largely ignored by the literature. To date, exploration of appeal effectiveness has focused on research in developed countries. LDCs with the desire to manage the image of their countries and their products have little guidance on which to base their policy or branding decisions. The country image literature suggests that the image of countries can influence the evaluation of the country's products and purchase intentions (Heslop et al. 2004). However, there does not appear to be any country image research that explores the image of a country in the context of promotional appeals and the evaluation of the promotional appeal. It is expected that differences in country image will be associated with different levels of product and promotion evaluation.

Hypothesis 2a: Outcomes (i.e. overall evaluations of products and promotions and purchase intentions) will differ based on differences in country image perceptions (character and competence). 
Country images have been found to include beliefs about the competencies of the country and people as producers of products and also general images about the character of the people and the political and social character of the country (Heslop et al. 2004). Therefore, Figure 3.2 presents a model of country image effects on promotional effectiveness outcomes indicating the two main dimensions of country image. This model is situated in the context of the inner-other-directedness personality trait and product type.

Figure 3.2 Model of COUNTRY IMAGe EFFECTS

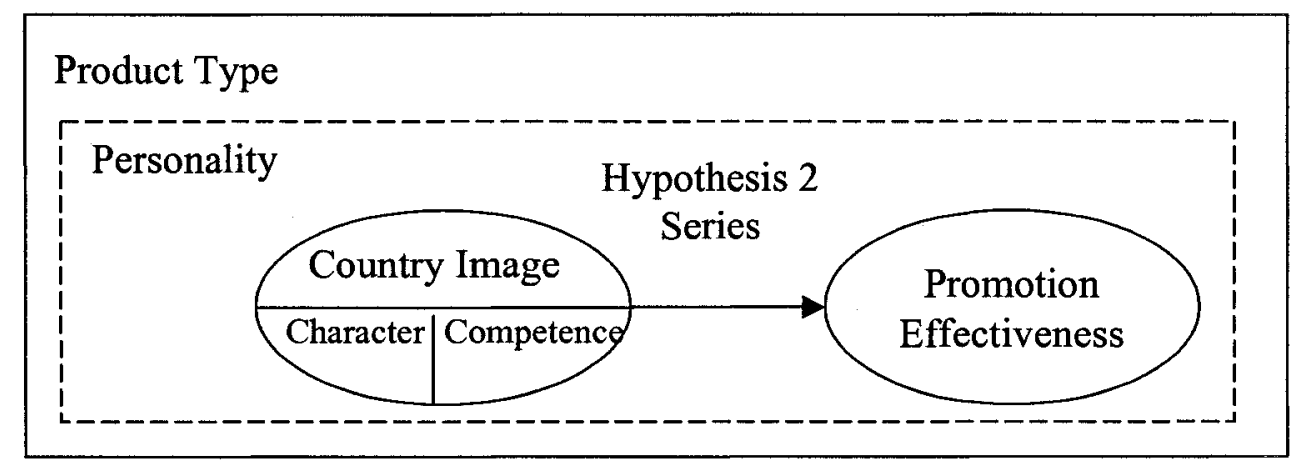

Similar to the hypothesis 1 series, a match between country image dimensions, product type and personality trait is expected to result in more favourable promotional effectiveness outcome ratings. For instance, inner-directed individuals with higher perceptions of country and people competence will have higher promotional effectiveness outcome responses. This is expected because those who are high in inner-directedness will value competency beliefs of the country and people for what they can deliver in products for themselves. Although other-directed individuals will also perceive country and people competencies to be important, they will assess character perceptions of the 
country and people to be more important because they are concerned about others as individuals distinct from their productive capabilities. Therefore,

\section{Personality and Country Image Match:}

Hypothesis 2b: Outcomes (i.e. overall evaluations of products and promotions and purchase intentions) for inner-directed subjects will be higher when perceptions of country and people competencies are higher.

Hypothesis 2c: Outcomes (i.e. overall evaluations of products and promotions and purchase intentions) for other-directed subjects will be higher when perceptions of country and people character are higher.

Additionally, Using the feeling-thinking continuum may help to explain potential differences in promotional effectiveness outcomes between inner- and other-directed individuals, product type and country image. Utilitarian products align with the cognition side of the continuum while hedonic products align with the emotion side. This distinction would guide the application of country and people competence beliefs with a utilitarian product while the use of country and people character beliefs may fit better with a hedonic product. In addition, inner-directed individuals may be more likely to utilize country and people competency perceptions, while other-directed individuals may find country and people character perceptions to be more important. Therefore,

\section{Personality, Country Image and Product Type Match:}

Hypothesis 2d: Outcomes (i.e. overall evaluations of products and promotions and purchase intentions) for other-directed subjects with utilitarian products will be higher when country and people competencies are perceived to be high. 
Hypothesis 2e: Outcomes (i.e. overall evaluations of products and promotions and purchase intentions) for other-directed subjects with hedonic products will be higher when country or people character is perceived to be high.

Hypothesis 2f: Outcomes (i.e. overall evaluations of products and promotions and purchase intentions) for inner-directed subjects with utilitarian products will be higher when country and people competencies are perceived to be high.

Hypothesis 2g: Outcomes (i.e. overall evaluations of products and promotions and purchase intentions) for inner-directed subjects with hedonic products will be higher when country or people character is perceived to be high.

Images of a country are complex and are based upon several sources of information and experiences. It is conceivable that country images can be influenced by the message presented in a promotion particularly when familiarity with the country, its people and its products is low. This low consumer familiarity is likely in the situation for LDCs in a developed market. Therefore, promotion appeal types may result in differential perceptions of the stimulus countries. Figure 3.3 present the graphical representation of the relationship between appeal type and country image. While hypothesis 1 series examines the relationship of appeal type to promotion effectiveness in the context of personality and product type, the relationship between appeal type and country image need to be considered. It is expected that the four appeals will result in differences in country image.

Hypothesis 3a: Country image perceptions (character and competence) will be different for the four appeal types (hedonism, utilitarianism, altruism and justice). 
FigURE 3.3 APPEAL EFFECTS ON COUNTRY IMAGE

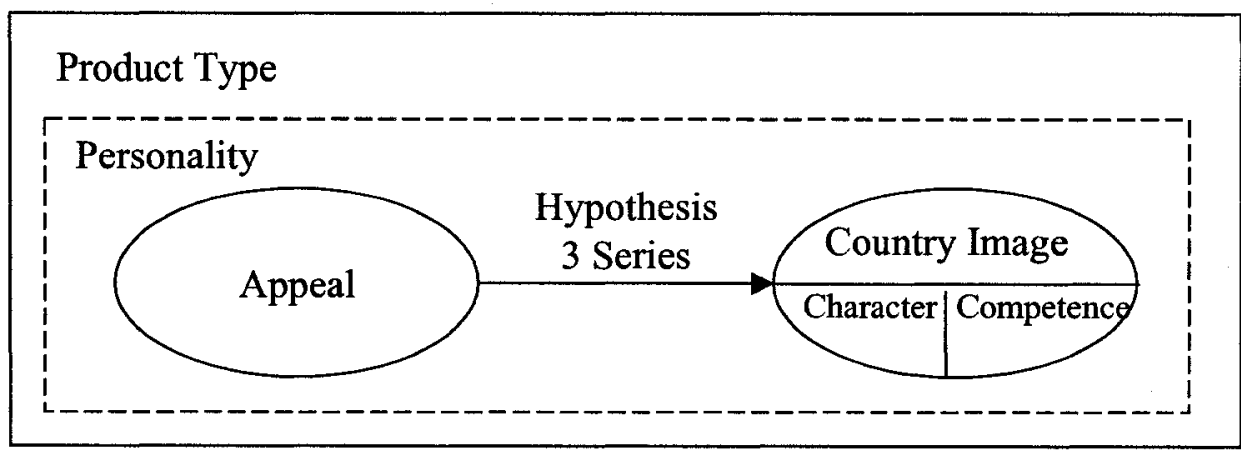

The personality of consumers may help explain differential responses to various motivational appeals. Social orientation was previously discussed as a means to assess individual differences in behaviour through inner-other directedness (Gregory, Munch and Peterson 2002; Dutta and Vanacker 2000; MacDonald and Jacobs 1992). In general, a match between the central message of a promotion and the social orientation of the consumer is expected to improve the country image dimensions. Therefore,

\section{Appeal and Personality Match:}

Hypothesis 3b: Country image dimensions for other-directed subjects will be higher for other-oriented appeals (i.e. altruism and justice appeals) than for selforiented appeals (i.e. hedonism and utilitarianism appeals).

Hypothesis 3c: Country image dimensions for inner-directed subjects will be higher for self-oriented appeals (i.e. hedonism and utilitarianism appeals) than for otheroriented appeals (i.e. altruism and justice appeals).

Similar to the hypothesis 1 series, a match of the product type with the feelingthinking continuum may influence country images. For other-directed individuals, the influence is expected to be stronger when there is a match between the appeal type and 
product type based on cognition versus emotion emphasis. The informative and thinkingbased, other-oriented justice appeal may lead to higher country image dimension responses with products that are more cognition-based for those who are more otherdirected. Similarly, the emotion-based, other-oriented altruism appeal may lead to higher country image dimension responses with the more emotional product for other-directed individuals. For inner-directed individuals, a match between the appeal type and product type is expected to influence the country image dimension responses. Utilitarian appeals are expected to resonate better with the utilitarian product type for those who are more inner-directed. Similarly, hedonic appeals with hedonic products may lead to better country image dimension responses for inner-directed individuals. Therefore, four possible matching situations emerge as outlined below.

\section{Appeal, Personality and Product Type Match:}

Hypothesis 3d: Country image dimensions for other-directed subjects with utilitarian products will be higher for justice appeals than for altruism appeals.

Hypothesis 3e: Country image dimensions for other-directed subjects with hedonic products will be higher for altruistic appeals than for justice appeals.

Hypothesis 3f: Country image dimensions for inner-directed subjects with utilitarian products will be higher for utilitarian appeals than for hedonic appeals.

Hypothesis 3g: Country image dimensions for inner-directed subjects with hedonic products will be higher for hedonic appeals than for utilitarian appeals. 
Testing of Two Models for Appeal, Country Image, and Promotion Effectiveness:

Hypotheses 1,2 and 3 series outline postulated binary relationships in the investigation of appeal type, country image and promotion effectiveness in the context of personality and product type. Once these relationships are established, the form of these relationships needs to be explored. The following discussion presents two alternative models of these relationships.

If the relationships are established as postulated in hypotheses 1 and 3 series, then there is evidence to suggest that the appeal effects can be represented with a bifurcated model (see Figure 3.4). This model of appeal effects shows that appeals have a direct influence on the promotional appeal effectiveness outcomes (hypothesis 1 series). The model also displays a parallel direct influence of appeal type on country image (hypothesis 3 series). While the model shows direct appeal effects on two variables, these effects are considered separate in this model.

However, the bifurcated model may not provide a holistic explanation. The investigation of hypothesis 2 series may provide evidence that an alternative explanation is required (see Figure 3.5). The model is an alternative approach to the bifurcated model that integrates the country image effects on promotion effectiveness (hypothesis 2 series). It presents an indirect relationship of appeal type to promotion effectiveness, mediated by country image within the context of personality and product type. 
Figure 3.4 BifurCATEd MOdEL OF APPEAL EFFECTS

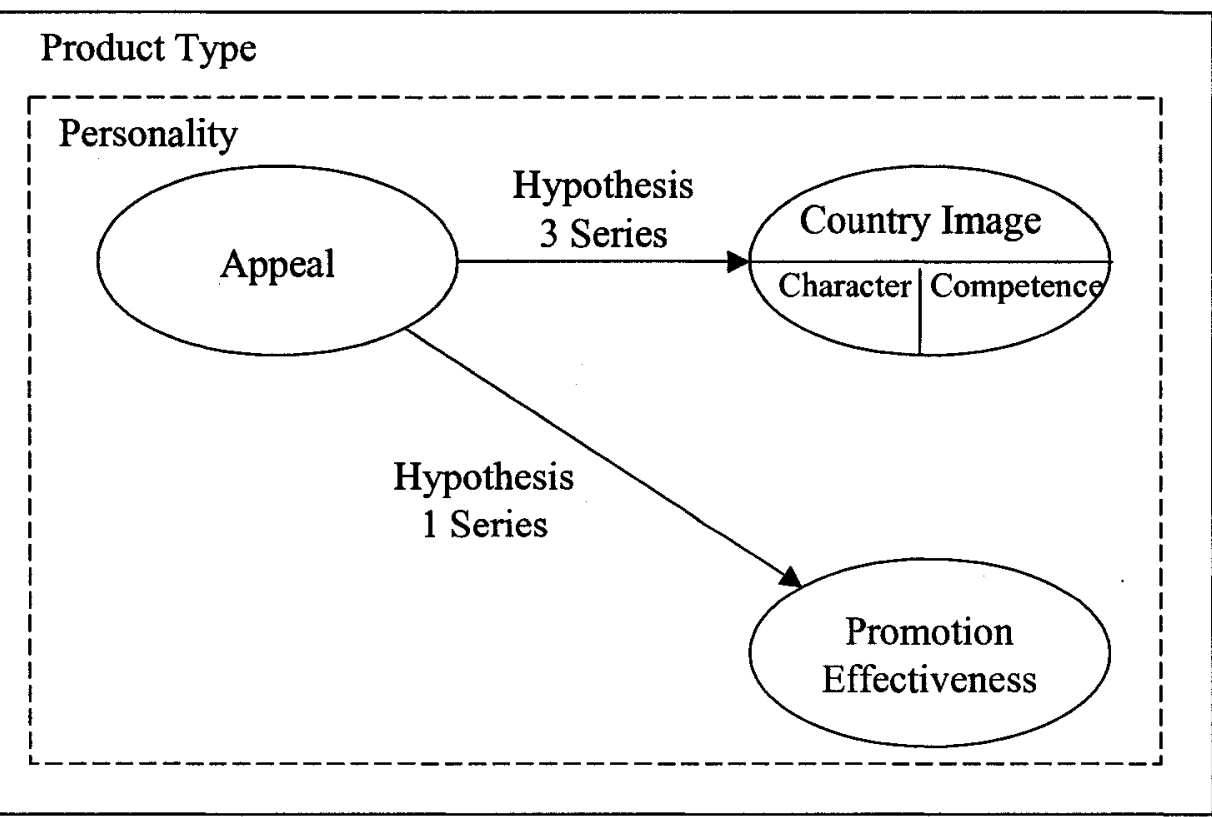

Figure 3.5 A Chain Model of APpeal EfFects - Country IMAge AS AN INTERVENING VARIABLE

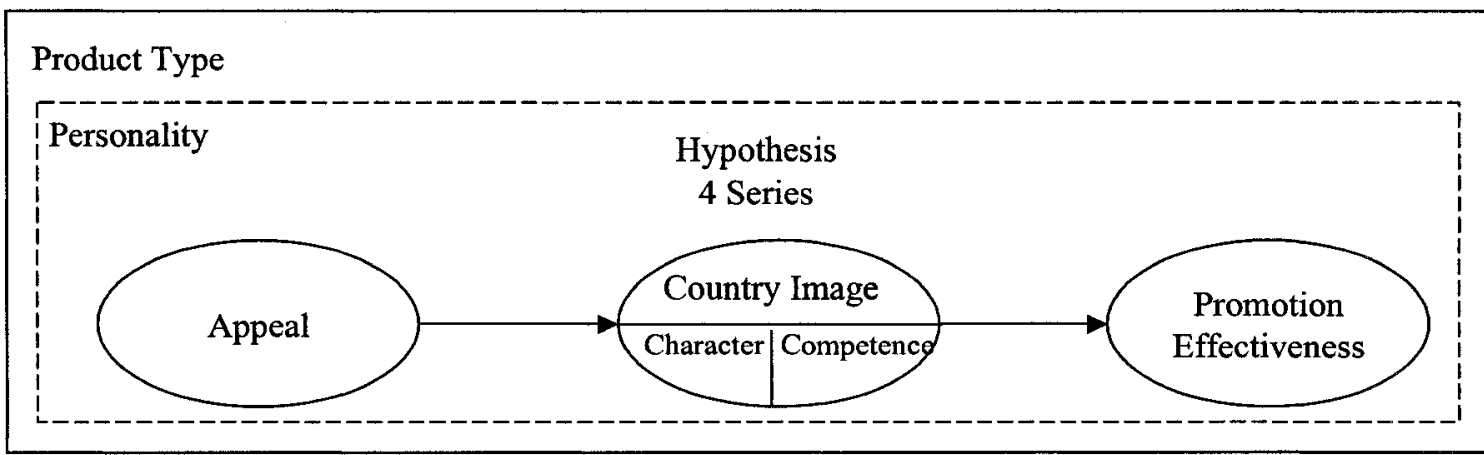

While the bifurcated model is tested using hypotheses 1 and 3 series, the chain model necessitates an additional hypothesis that considers the integrated relationship. Hypothesis 2 series examines only a piece of the chain model from country image to promotion effectiveness. However, the previous hypotheses provide for a base of 
knowledge. Hypothesis 2 series will test whether a relationship exists between country image and promotion effectiveness and hypothesis 3 series will establish whether a relationship exists between appeal type and country image. Therefore, the final hypothesis is stated to reflect the possible intervening role of country image as the only remaining piece in the model.

Hypothesis 4: The relationship between appeal type and promotional appeal effectiveness outcomes (i.e. overall evaluations of products and promotions and purchase intentions) is mediated by country image (i.e. country and people competencies and country and people character) 


\section{RESEARCH METHODOLOGY}

The research methodology chapter outlines the approach of the project including the research framework, research design, the measurement instrument, sampling methodology and data collection, and data analysis.

\subsection{Research Framework}

While the research is designed to explore two gaps in the literature, Figure 4.1 illustrates the interaction of all relevant areas for this study. It is based on the summary of literature previously discussed but contains only those aspects that will be measured or controlled for in the study. The hypotheses include all but four variables indicated in the framework. The four variables not discussed in the hypotheses are variables of interest to the research but do not represent the primary directive. For instance, familiarity of respondents with the stimulus country is another variable that was recorded but did not receive discussion in the hypothesis section. This information was gathered to assist, if necessary, in understanding potential differences in response to the stimulus countries. Different levels of country familiarity are known to affect the use of country information in the decision making process. Similarly, the gender of the subject was recorded to explore the possibility that gender differences are associated with differences in responses. 
Figure 4.1 ReSEarch Framework for LDC Promotional APPEAL EFFECTIVENESS

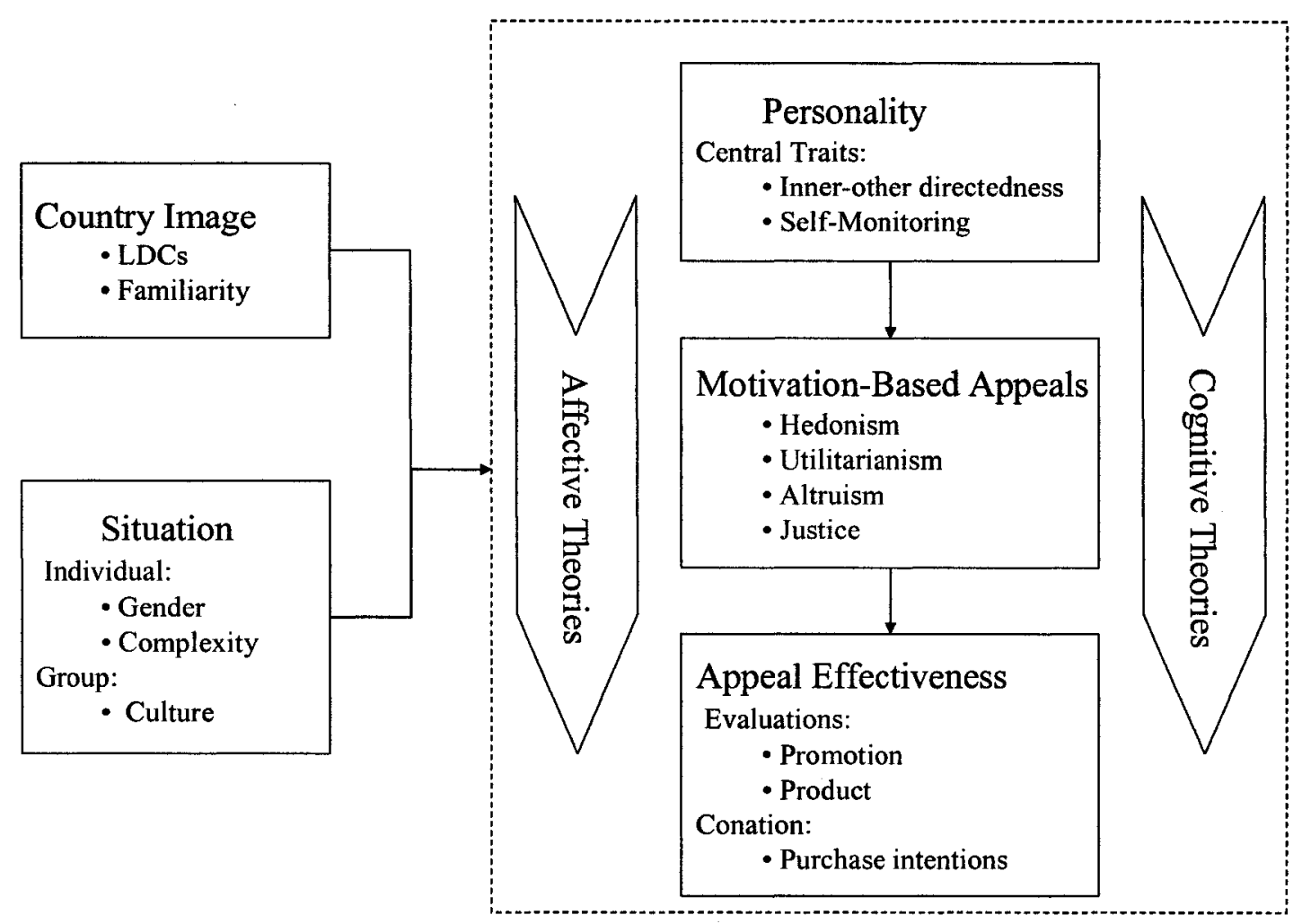

In addition, product complexity may influence the effectiveness of appeals but is not explored in this study. Instead, product complexity is controlled in the design. Products with medium complexity were used in the study. The selection of these products is discussed in the research design section. Finally, research on appeal effectiveness has demonstrated that culture of consumers can affect responses. There is a concern that a large number of respondents who are international visitors, especially from LDC's, could unknowingly confound the research. In addition, they are not considered the target market for this research. Therefore, international students were not included in the sample to provide some limitation to the effects of culture. 


\subsection{Research Design}

In order to study the interaction of appeal types and personality on country image and appeal effectiveness, an experimental design was chosen. The experiment was designed to incorporate the four appeal types with replication across two countries and two products as a $2 \times 2 \times 4$ design (two stimulus countries, two products, and four promotional appeal types). Participants were asked to respond to one promotional tag that provided one of four different appeal types containing only one of the two countries and products. The inner-other directedness personality trait is a between-subjects covariate. The data collection included a questionnaire that had four parts: (1) a personality measure, (2) measures about country, people and product beliefs, feelings/evaluations, and receptivity, (3) response measures to the experimental appeal, and (4) demographic questions. The following sections detail the design including the country selection, product selection, promotional appeal design and questionnaire design.

\subsubsection{Stimulus Country Selection Process}

The framework for selecting the stimulus countries was guided by two principles of country characteristics - need and capability. The countries selected in the study must have an underlying economic need that is not too great or too little. Each extreme situation carries its own risk to the perception of credible need. While a need for help must exist, selected countries must also have the capabilities to benefit from consumer support of their products and the capacity to produce some consumer products of value. 
These capabilities are rooted in the economic, social and political foundations of the country.

Although a country's capabilities may be useful for classifying a country as developing or developed, the United Nations acknowledges that there is no established process for designating which countries are developed and which are developing. However, it argues "in common practice, Japan in Asia, Canada and the United Sates in northern America, Australia and New Zealand in Oceania and Europe are considered developed regions" (United Nations 2006). Additionally, the OECD (2006) refers to international trade statistics that tend to categorize Southern African Customs Union countries (including South Africa, Botswana, Lesotho, Namibia and Swaziland) and Israel as developed, while Eastern European countries are not classified as either developed or developing.

The criteria applied in the selection of stimulus countries coincides with the desire to study appeal effectiveness in the context of developing countries while excluding those countries identified as the poorest in the world. Arguably, these latter countries may need the most assistance in bettering their global position. However, issues facing these countries (i.e. political and economic instability; social infrastructure) will severely impact the effectiveness of promotional appeals. Anholt (2005) argues that branding appeals will not work for least developed countries because certain conditions are required to deliver on the promises made by major exporting brands (e.g., manufacturing standards, legal and financial systems, information infrastructure, stable government). In 
addition, countries chosen for inclusion in the study must not have experienced a major recent event (such as armed conflict or serious epidemics) that would contribute an overwhelming association of negativity to the country. Finally, stimulus countries must be perceived by consumers as having a credible need that can be addressed through the purchase of products.

Therefore, two methods of classifying countries were used to identify proposed stimulus countries among the numerous remaining non-developed countries. The first method focused on the wealth of the country using a measure of gross national income (GNI) per capita as recorded and published by the World Bank (2006). GNI per capita is the primary measure used by the organization to guide its operations and analysis. The second method, the Human Development Index (United Nations 2005) is more broadly representative of the well-being of a country's people, including measures for life expectancy, literacy, education, and other items. The United Nations (2005) classifies countries as having high, medium and low human development levels. For both these country classification methods, this study is particularly interested in the middle class of countries.

The combination of human and wealth characteristics of developing countries provide guidance for selecting the proposed stimulus countries indicated in Figure 4.2. Several countries can be found to fit into each of the cells in the above grid. The selection of countries to represent each quadrant was determined by identifying where countries are placed on the Human Development Index. For the selection of counties in 
the top half of the grid, for instance, Colombia and Mexico represent developing countries with good levels of human development while Egypt and Venezuela represent developing countries with poor levels of human development.

\section{Figure 4.2 Framework for Selecting Proposed Stimulus Countries}

(EXAMPLES)

\section{U.N. Human Development Index}

\begin{tabular}{|c|c|c|c|c|}
\hline \multirow{3}{*}{$\begin{array}{l}\text { World Bank } \\
\text { Income } \\
\text { Groups } \\
\text { (GNI/p) }\end{array}$} & \multicolumn{4}{|c|}{ High-Medium } \\
\hline & & $\begin{array}{c}\text { Colombia } \\
\text { Tonga } \\
\text { Brazil }\end{array}$ & $\begin{array}{l}\text { Mexico } \\
\text { Chile } \\
\text { Argentina }\end{array}$ & \\
\hline & Middle & $\begin{array}{c}\text { Egypt } \\
\text { Morocco } \\
\text { Honduras }\end{array}$ & $\begin{array}{l}\text { Venezuela } \\
\text { Belize } \\
\text { Oman }\end{array}$ & Middle \\
\hline
\end{tabular}

The horizontal axis represents the location of countries in the middle income categories as identified by the World Bank (2006). However, only the countries in the lower-middle level are believed to represent countries with both a perceived credible need and the ability to deliver major branded products. The upper-middle group represents countries that are more self-sufficient and hence may not be seen as requiring assistance. They are also more likely to be actively trading and have products that are already widely exposed and accepted. Therefore, only countries from the left half of the grid were considered as candidates for the research. Pretests were conducted to examine 
perceptions about wealth, neediness, urgency of need, competencies, familiarity, and liking. The results of the pretests and selection of the stimulus countries are reported on in the pretest discussion.

\subsubsection{Stimulus Product Selection}

Products were chosen for the research based on the criteria of being familiar to respondents, varying on the dimension of utility-hedonism, being credibly sourced from the stimulus countries and previous research use in advertising effectiveness literature. Two stimulus products were chosen for the research - designer jeans and athletic shoes. Designer jeans may be considered a hedonistic product as consumers seek different styles or designs. This is particularly true with respect to undergraduate students, the study population group. Also, jeans have been used previously in promotion effectiveness research (Lepkowska-White and Weinberger 2003). Athletic shoes may be considered utilitarian products because people are more likely to evaluate the products on the basis of technical details. Athletic shoes have also been used in previous promotional effectiveness research (Smith et al. 1995). In addition, university students are highly familiar with the product categories (e.g., Kapoor 2005). This varied approach provides the opportunity to test appeal effectiveness with more than one type of product.

The complexity of the product is controlled to hold the anticipated level of involvement in the decision making process fairly constant. The two products are moderately complex to capture products that are more than the typical commodity, low value-added goods that dominate the exports of developing countries. Therefore, the 
products can impact country image perceptions as the products require some manufacturing skill and leverage the production methods in the country. However, the selection of stimulus products is also guided by the necessary requirement that the countries be credible or possible sources of the products in that they are not overly complex with very high levels of technological sophistication.

While stimulus products are referred to as primarily either hedonic or utilitarian types, it is important to note that several different promotional appeal types may be used. The products were pretested to determine subject familiarity and the results of these pretests are reported in the pretest discussion later in this chapter.

\subsection{Promotion Appeal Treatment}

Subjects were exposed to a promotional stimulus presented on an $8 \frac{1}{2}$ × 11 sheet of paper. They were told that the information would be found on a promotional tag attached to the item. Then, they were asked to report their reactions to the promotion and the product. The promotional stimulus presented information in a standardized format over the different treatments of the study (see Figure 4.3).

The template for the promotional tag treatments contains three parts. First, the tag conveys the central message along the top portion of the page. The central message for each appeal type and product type is summarized in Table 4.1. Second, supporting text is provided to reinforce the central message in the middle of the promotional tag. For the hedonic appeal, the supporting text accentuates the pleasurable and fun aspects of the 
product while the supporting text for the utilitarian appeal explores the functional offerings. For the altruistic appeal, the supporting text provides biographic information of young family in their struggle to survive and notes that a portion of the purchase price goes to support them. The supporting text for the justice appeal informs the reader about economic/social inequities and how purchasing the product addresses these issues. Finally, the central message is reinforced at the bottom of the promotion. The promotional tag appeals used in the study are presented in Appendix B. A pretest was conducted on the promotional appeals for compatibility and effectiveness. The results of the pretests are reported in the pretest discussion later in this chapter.

Figure 4.3 Experimental Treatment Stimulus (Promotional Tags)

Central Message with country cue

Supporting text for central message

Tie-in to central message 
Table 4.1 Central Messages by Appeal and Product Type

\begin{tabular}{|c|c|c|c|c|}
\hline & \multicolumn{4}{|c|}{ Appeal Type } \\
\hline Product Type & Hedonic & Utilitarian & Altruistic & Justice \\
\hline Designer Jeans & $\begin{array}{l}\text { Look good and } \\
\text { feel great in } \\
\text { exotic } \\
\text { Colombian } \\
\text { designer jeans }\end{array}$ & $\begin{array}{l}\text { Comfortable, } \\
\text { rugged and } \\
\text { long wearing } \\
\text { Colombian } \\
\text { designer jeans }\end{array}$ & $\begin{array}{l}\text { Support a poor } \\
\text { young } \\
\text { Colombian } \\
\text { family now } \\
\text { with every } \\
\text { stride you make }\end{array}$ & $\begin{array}{l}\text { Ensure hard } \\
\text { working } \\
\text { Colombians are } \\
\text { fairly rewarded }\end{array}$ \\
\hline Athletic Shoes & $\begin{array}{l}\text { Indulge your } \\
\text { feet in exotic } \\
\text { Colombian } \\
\text { athletic shoes }\end{array}$ & $\begin{array}{l}\text { Comfort and } \\
\text { effective } \\
\text { performance } \\
\text { with Colombian } \\
\text { athletic shoes }\end{array}$ & $\begin{array}{l}\text { Support a poor } \\
\text { young } \\
\text { Colombian } \\
\text { family now } \\
\text { with every step } \\
\text { you take }\end{array}$ & $\begin{array}{l}\text { Ensure hard } \\
\text { working } \\
\text { Colombians are } \\
\text { fairly rewarded }\end{array}$ \\
\hline
\end{tabular}

\subsection{Measurement Instrument}

The measurement instrument was a questionnaire with five parts comprised of a section of basic information about the target country and four sets of questions: (1) a personality measure, (2) measures about country, people and product beliefs, feelings/evaluations, and receptivity, (3) response measures to the experimental appeal, and (4) demographic questions (see Appendix A). This represents a typical approach to advertising effectiveness studies that present an advertising stimulus and then measure responses (e.g. Aaker and Williams 1998; Ruiz and Sicilia 2004).

Prior to personality measurement and promotion exposure, subjects were presented with some basic country information. The intention of this information was to provide a common base of knowledge of the stimulus country to avoid possible serious errors in country identification and to reduce possible variance in levels of familiarity 
with the developing countries used in the experiment. Subjects were exposed to information relevant to the classification schemes, i.e., geographic location, political system, population, and per capita income level (see Appendix A). However, no information pertaining to exports and main products was disclosed to subjects.

Table 4.2 presents the construct being estimated with the instrument measures and indicates supporting research. The questionnaire contains three response sections. First, there are personality measures to capture the extent of inner-other directedness (Kassarjian 1962) of subjects. Inner-other directedness measures the extent a person emphasizes him/herself versus others in reference to values and standards to guide their behaviour (Kassarjian 1962). The MacDonald and Jacobs (1992) study of personality influence on innovative product acceptance is an application example of the Kassarjian (1962) scale. The scale contains 36 items.

Second, country image was measured using the Heslop et al. (2004) items to capture beliefs about characteristics and competencies of the country, as well as, the characteristics and competencies of the country's people. While the evaluation of the country is also based on Heslop et al. (2004), there are four new measures in this study intended to fill the country and people affect deficiency highlighted in the literature review for less developed countries and branding (i.e., fascinating people, appealing culture) and to assess perceptions of need (i.e., in need of assistance, urgency of need). In particular, the fascinating people and appealing culture items are meant to reflect the importance of culture on the positioning of LDC products that Anholt (2005) 
recommends. An overall measure for country evaluation was also included. Additionally, receptivity to products from the country was captured (i.e., have products I'd like to buy, would like to help support, and willingness to buy their products).

TABLe 4.2 Questionnaire SCALES AND Measures

\begin{tabular}{|l|l|c|l|}
\hline Construct & Measure/Scale & \# of Items & Supporting Studies \\
\hline Inner-other directedness & Forced-choice items & 36 & Kassarjian 1962 \\
\hline Attitude toward the ad & 7-point Likert type & 4 & Royne Stafford and Day 1995 \\
\hline Attitude toward the product & 7-point Likert type & 6 & Ruiz and Sicilia 2004 \\
\hline Purchase intentions & 7-point Likert type & 4 & $\begin{array}{l}\text { (1) Lee and Ganesh 1999; (1) } \\
\text { Parameswaran and Pisharodi } \\
\text { 2002; (1) Heslop et al. 2004; } \\
\text { (1) Nadeau et al. 2006 }\end{array}$ \\
\hline Country description & 7-point Likert type & 6 & Heslop et al. 2004 \\
\hline Country competence & 7-point Likert type & 3 & Heslop et al. 2004 \\
\hline People description & 7-point Likert type & 3 & Heslop et al. 2004 \\
\hline People competence & 7-point Likert type & 3 & Heslop et al. 2004 \\
\hline $\begin{array}{l}\text { Country evaluation } \\
\text { Receptivity to country's } \\
\text { products }\end{array}$ & 7-point Likert type & 7 & $\begin{array}{l}\text { (2) Heslop et al. 2004; (5) } \\
\text { New }\end{array}$ \\
\hline
\end{tabular}

Second, country image was measured using the Heslop et al. (2004) items to capture beliefs about characteristics and competencies of the country, as well as, the characteristics and competencies of the country's people. While the evaluation of the country is also based on Heslop et al. (2004), there are four new measures in this study intended to fill the country and people affect deficiency highlighted in the literature review for less developed countries and branding (i.e., fascinating people, appealing culture) and to assess perceptions of need (i.e., in need of assistance, urgency of need). In particular, the fascinating people and appealing culture items are meant to reflect the 
importance of culture on the positioning of LDC products that Anholt (2005) recommends. An overall measure for country evaluation was also included. Additionally, receptivity to products from the country was captured (i.e., have products I'd like to buy, would like to help support, and willingness to buy their products).

Third, responses to the promotional stimulus were gathered. Respondents were asked about the advertisement representations, their ratings of the advertisement, their ratings of the product and their purchase intentions. Note that they are asked about attitudes towards the advertisement rather than promotional tag. Although the subjects were exposed to a promotional tag, this is an industry term and referring to the stimulus as an advertisement was not expected to cause any problem. There was no indication about any confusion during the pretesting of the instrument.

The representation of the promotion was recorded to assess whether the promotion represented what was intended. The measures for representation of the four appeal types were sourced or developed from the literature on hedonism (Olney, Holbrooke and Batra 1991; Voss, Spangenberg and Grohmann 2003), utility (Voss, Spangenberg and Grohmann 2003), altruism (Eisenberg 1986; Hetsroni 2000), and justice (Goodwin, Smith and Spiggle 1990; Rawls 1971; Tuan Pham and Avnet 2004). The attitudes held by subjects toward the promotions were measured using the Royne Stafford and Day (1995) items (i.e. like, good, interesting, irritating). These scales are among the leading measures used in other research and records attitudes in both directions using multiple measures. Royne Stafford and Day (1995) used an average of the items to 
represent respondent attitudes. Ruiz and Sicilia (2004) items (i.e., good, like, nice, attractive, better than competing brands, worthy) were employed to measure attitudes held toward the product. These items contain the leading measures in the reviewed literature and provide an additional item (i.e. worthy) relevant to the proposed research. Ruiz and Sicilia (2004) checked their reliability and averaged the multiple item scales in their research. Purchase intentions were measured through items from two studies to ensure that multiple items measured different aspects of purchase intentions. The items are from PCI research including, intend to purchase (Parameswaran and Psiharodi 2002), would recommend to others (Lee and Ganesh 1999), would like to purchase (Nadeau et al., 2006) and willingness to buy (Heslop et al. 2004).

Finally, another section of the instrument requested demographic information about the subject (birth in Canada, length of time in Canada, extended stay in other countries, gender, and age).

\subsection{Sampling Method}

Given this study is exploring new concepts, such as justice, and requires a very large sample size, the study uses undergraduate university students. Students provide ease of access and a relatively homogeneous basis for this study. Products for the study were chosen so as to be familiar to the students and represent purchases that they make in the marketplace. The sampling frame included university classrooms and the sample 
selection relied on a convenience process depending upon access to classes at multiple universities.

\subsection{Pretesting the Research Instrument}

Prior to conducting the data collection, several pretests were carried out to develop an appropriately useful personality measure, determine that the measurement instrument recorded what was intended and that the products and promotional messages used were suitable.

The objective of the first pretest was to reduce the number of items in the innerother directedness scale without compromising the ability of the scale to assess the personality trait. A sample of 192 undergraduate students responded to Kassarjian's (1962) complete 36-item inner-other directedness scale. Principle components factor analysis with varimax rotation was used to determine which items load together and identify the leading items for the personality trait. The analysis revealed a three-factor solution using the Cattell (1966) decision rule of drawing the number of factors from where the scree plot line breaks into a smooth decrease of eigen values (see Figure 4.4). All three factors had eigenvalues over 1 . The 11 items in the three factor solution achieved a Cronbach's alpha of .620. The smaller subset of 11 items were retained for further pretesting. Using a subsequent sample of 43 students, the Cronbach's alpha for the 11 items was determined and it achieved a reasonable .609 value (Nunnally 1978 ; Usunier 1999). Further factor analysis, with a forced single factor solution, resulted in all 11 items loaded on that single factor. Therefore, the 11 items were used in the study. 


\section{Figure 4.4 Inner-Other Directedness Pretest SCRee Plot}

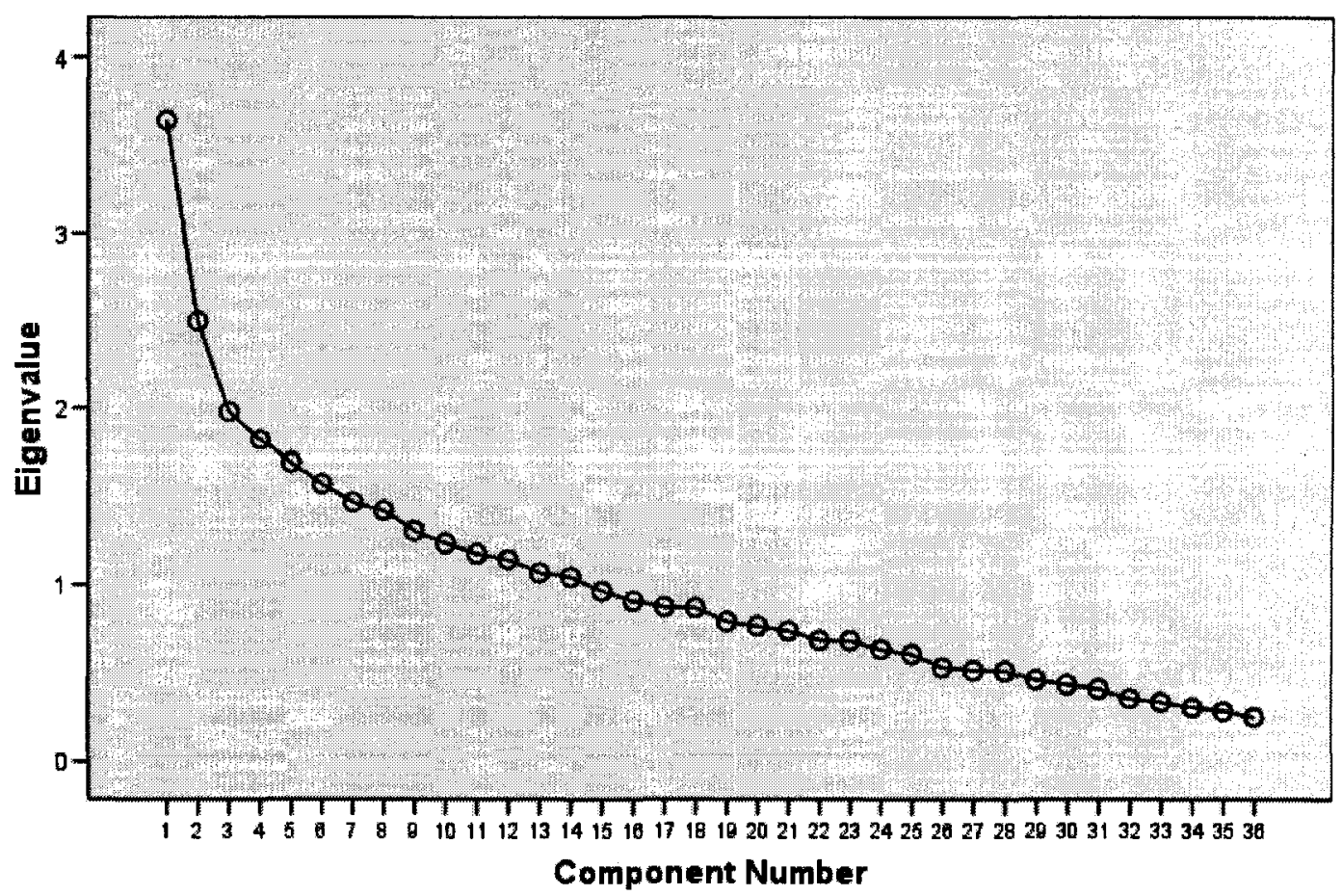

Next, the stimulus product types (designer jeans and athletic shoes) were tested to determine their level of complexity and purchase risk. This was done by assessing responses on five measures, including, product complexity, time needed to consider the purchase, price, impact of poor quality and overall purchase risk. Responses for a sample of 18 students demonstrated that both products were perceived as moderately complex and having moderate risk associated with them (i.e. ratings of 3 to 5 on a 1 to 7 scale). Table 4.3 presents the results from the MANOVA analysis indicating a significant 
difference of product complexity and purchase risk $(F=5.2$, sig. $=.001)$. Note that the $F$ statistics referred to in the dissertation are for Wilks' Lambda.

\section{Table 4.3 Pretest ManOVa Results for Product Complexity and Purchase RISK}

\begin{tabular}{|l|c|c|r|r|}
\hline \multicolumn{5}{|c|}{ Between Subjects Effects for Product } \\
\hline & \multicolumn{2}{|c|}{ Means Scores } & & \\
\hline Measure & Jeans & Shoes & \multicolumn{1}{|c|}{ F } & Sig. \\
\hline Product complexity & 3.7 & 5.4 & 10.5 & $\mathbf{. 0 0 3}$ \\
\hline $\begin{array}{l}\text { Time needed to consider } \\
\text { purchase }\end{array}$ & 4.8 & 4.9 & 0.1 & .799 \\
\hline Price & & & & \\
\hline Impact of poor quality & 6.5 & 5.5 & 7.1 & $\mathbf{. 0 1 2}$ \\
\hline Overall purchase risk & 5.3 & 6.2 & 3.7 & $\mathbf{. 0 6 2}$ \\
\hline
\end{tabular}

Note: Bold indicates significance $<0.1$

$\mathrm{F}=5.2$, sig. $=.001$, d.f. $=5$

$\mathrm{N}=18$

The overall different product perceptions are rooted in significant differences in product complexity, price and impact of poor quality. Athletic shoes are viewed as more complex (jeans $\bar{X}=3.7$ and shoes $\bar{X}=5.4$ ), having higher risks of poor quality (jeans $\bar{X}$ $=5.3$ and shoes $\overline{\mathrm{X}}=6.2$ ) yet lower prices and financial risk (jeans $\overline{\mathrm{X}}=6.5$ and shoes $\overline{\mathrm{X}}$ $=5.5$ ) than designer jeans. While price and quality risks attained relatively higher mean scores than the other measures, the average responses for the complexity, time needed to consider purchase (jeans $\bar{X}=4.8$ and shoes $\bar{X}=4.9$ ) and overall risk (jeans $\bar{X}=4.0$ and shoes $\overline{\mathrm{X}}=4.9$ ) are closer to the midpoint of the 7-point scale. Therefore, while shoes may be seen as slightly more complex, higher physical risk but lower financial risk than jeans, both products are seen to have an overall moderate risk assessment. In addition, the significantly higher rating for product complexity for athletic shoes compared to 
designer jeans supports the selection of athletic shoes as a more utilitarian product type (i.e., more features for the consumer to consider). Also, the higher price rating given to designer jeans compared to athletic shoes indicates that the designer jeans are a more hedonic product.

The products were also tested to determine the dominant representation that each product has with respondents. The intention in the research design was that designer jeans would represent a more hedonic product while athletic shoes would be more utilitarian in nature. The measures used to assess hedonic product representation were drawn from Olney, Holbrook and Batra (1991) and Voss, Spangenberg and Grohmann (2003) while the measures used to assess utility product representation were drawn from Voss, Spangenberg and Grohmann (2003). The results from a MANOVA analysis support this intention, and the results of the analysis are summarized in Table 4.4. While there is an overall significance in perceptions of product representations $(F=4.6$, sig. $=.001$ ), this difference is derived from perceptions of utility. The utility measures of helpful (jeans $\bar{X}=2.8$ and shoes $\bar{X}=4.6$ ), effective (jeans $\bar{X}=3.6$ and shoes $\bar{X}=5.6$ ), functional (jeans $\bar{X}=4.7$ and shoes $\bar{X}=6.2$ ), necessary (jeans $\bar{X}=3.9$ and shoes $\bar{X}=5.8$ ) and practical (jeans $\overline{\mathrm{X}}=3.8$ and shoes $\overline{\mathrm{X}}=6.2$ ) are higher for athletic shoes compared to designer jeans.

Although there is no significant difference in the average responses to hedonic scale items, the direction of all but one item are in favour of the designer jeans being perceived as more hedonic. Designer jeans received higher mean scores compared to 
athletic shoes for enjoyment (jeans $\bar{X}=5.2$ and shoes $\bar{X}=4.8$ ), pleasure (jeans $\bar{X}=5.2$ and shoes $\bar{X}=4.2$ ), delightful (jeans $\bar{X}=4.2$ and shoes $\bar{X}=3.5$ ), exciting (jeans $\bar{X}=4.1$ and shoes $\overline{\mathrm{X}}=3.9$ ), entertaining (jeans $\overline{\mathrm{X}}=3.7$ and shoes $\overline{\mathrm{X}}=3.4$ ), and thrilling (jeans $\overline{\mathrm{X}}=3.7$ and shoes $\overline{\mathrm{X}}=3.0$ ). The products achieved the same mean score on only one hedonic scale - fun (jeans $\bar{X}=4.2$ and shoes $\bar{X}=4.2$ ). Together, this indicates that athletic shoes are clearly more utility oriented while designer jeans are viewed as more hedonic oriented. It is also worth highlighting that the possibility of either product coming from a developing country is viewed equally.

\section{TABle 4.4 Pretest Manova Results for Product Representations}

\begin{tabular}{|l|c|c|r|r|}
\hline \multicolumn{5}{|c|}{ Between Subjects Effects for Product } \\
\hline & \multicolumn{1}{|c|}{ Mean Scores } & & \\
\hline Dependent Variable & Jeans & \multicolumn{1}{|c|}{ Shoes } & \multicolumn{1}{c|}{ F } & \multicolumn{1}{c|}{ Sig. } \\
\hline Enjoyment & 5.2 & 4.8 & 0.2 & .676 \\
\hline Pleasure & 5.2 & 4.2 & 1.1 & .314 \\
\hline Fun & 4.2 & 4.2 & 0.3 & .595 \\
\hline Exciting & 4.1 & 3.9 & 0.0 & .916 \\
\hline Delightful & 4.2 & 3.5 & 0.3 & .590 \\
\hline Thrilling & 3.7 & 3.0 & 0.5 & .495 \\
\hline Entertaining & 3.7 & 3.4 & 0.1 & .708 \\
\hline Helpful & 2.8 & 4.6 & 12.8 & $\mathbf{. 0 0 1}$ \\
\hline Effective & 3.6 & 5.6 & 14.7 & $\mathbf{. 0 0 1}$ \\
\hline Functional & 4.7 & 6.2 & 11.0 & $\mathbf{. 0 0 2}$ \\
\hline Necessary & 3.9 & 5.8 & 9.4 & $\mathbf{. 0 0 4}$ \\
\hline Practical & 3.8 & 6.2 & 21.1 & $\mathbf{. 0 0 0}$ \\
\hline $\begin{array}{l}\text { Possibility of being from a } \\
\text { developing country? }\end{array}$ & 4.3 & 4.6 & 0.0 & .978 \\
\hline $\begin{array}{l}\text { Note: Bold indicates significance }<0.1 \\
\text { F=4.6, sig.=.001, d.f.=13 }\end{array}$ & & & & \\
\hline N=328
\end{tabular}


Pretests were also conducted on the stimulus countries to determine if they represent each of the quadrants in the country selection grid (i.e. axis = World Bank income group and UN Human Development Index). Fourteen undergraduate respondents considered sixteen countries generally on the basis of human and economic development without any additional information and placed them on a grid (see Figure 4.5). The figure indicates where the countries were expected to be located and the number of times respondents perceived them to be in those quadrants. The higher human and higher economic quadrant countries of Mexico and Argentina were seen to be wealthier than Colombia and Thailand. They were also perceived to have higher levels of human development than lower human development countries of not only Venezuela and Belize but also Honduras and El Salvador. The higher human and lower economic countries (e.g. Colombia and Thailand) were seen to have higher human development than Honduras and El Salvador. Colombia and Thailand were also perceived to have higher levels of human development than Venezuela and Belize. The lower human and lower economic quadrant is represented as expected by Honduras and El Salvador. The higher economic and lower human quadrant (e.g. Venezuela and Belize) were seen to be lower in human development when compared to Mexico and Argentina but more economically developed than Honduras and El Salvador.

From this process, Colombia and Honduras were selected as stimulus countries for two main reasons. First, the two countries seem to represent the desired quadrants. Although the frequency of correct placement in the grid appears low for Colombia, it should be noted that the off-diagonal represents fewer countries as there is a positive 
relationship between income and human development. In other words, there are fewer countries that fit into its quadrant compared to the lower left and upper right quadrants of the grid. Further, Colombia was placed in the lower left of the grid more often than the other quadrants and ahead of Honduras. This indicates that Colombia is perceived to have a low-middle level of income and a better level of human development than Honduras.

\section{Figure 4.5 Country Pretest Grid}

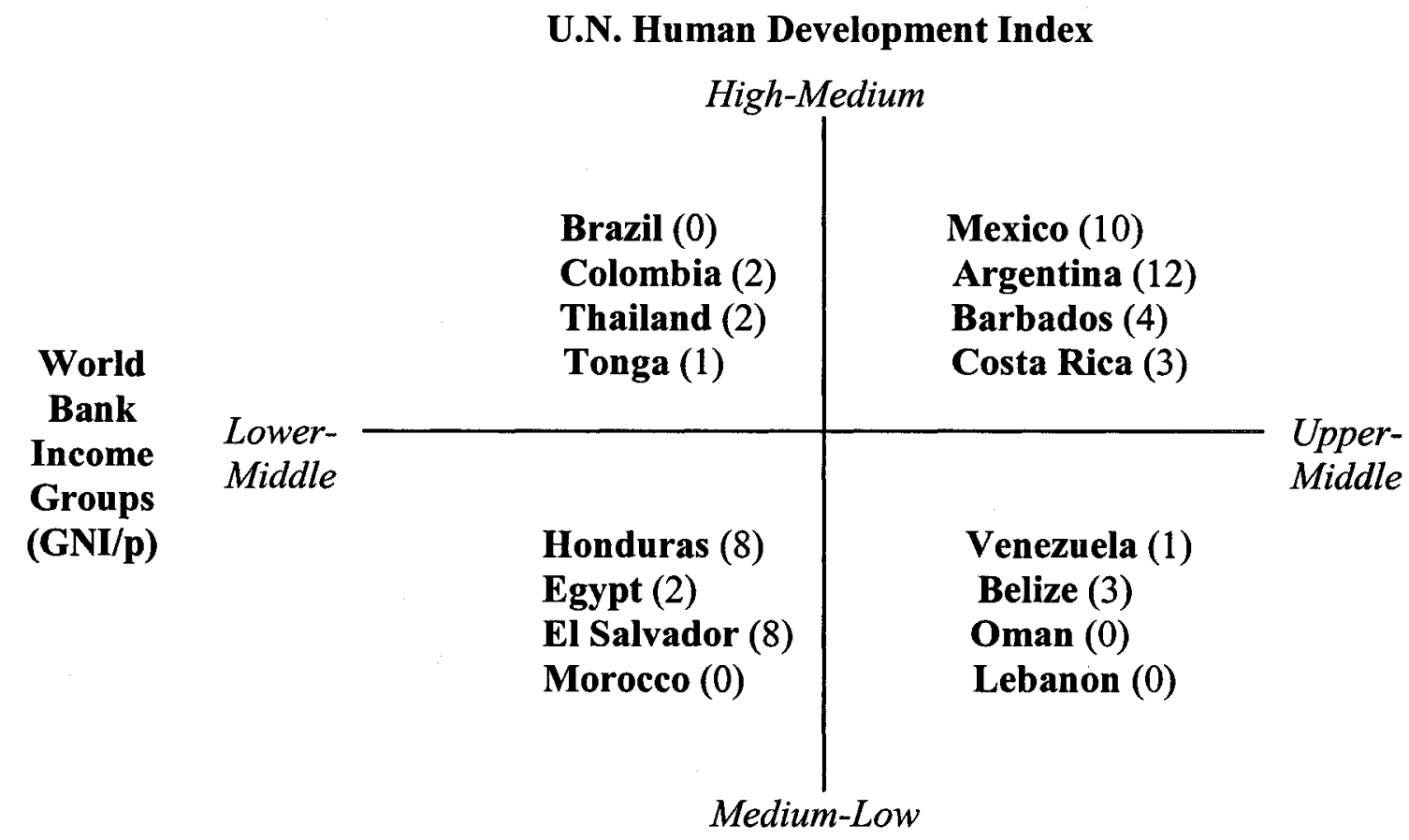

Note: (indicates the number of times the country was correctly placed in the grid)

Second, the selection of stimulus countries was also guided by the desire to reduce the potential impact of variance in geographic proximity. Therefore, countries from the Americas were emphasized. The selection of Colombia and Honduras ensures 
that one country is from South America while another is from Central America. This minimizes a possible regional impact of the stimulus countries on the study design while also maintaining geographic proximity to the respondent's location.

Finally, the promotional appeals were tested to ensure that they represent what is intended. Using responses from a pretest sample of 328 undergraduate students drawn from nine classrooms, a MANOVA analysis was used to determine how the appeals were being interpreted (see Table 4.5). The table indicates that, overall and at the measurement item level, the appeal types are viewed as significantly different.

An assessment of the mean scores recorded for the appeal types provides support for the assumption that the promotional messages represent what was intended. While significant differences for the measures among the appeal types do not always exist for the highest mean score, the highest mean scores are found with the appropriate promotional appeal type.

An assessment of the mean scores recorded for the appeal types provides support for the assumption that the promotional messages represent what was intended. While significant differences for the measures among the appeal types do not always exist for the highest mean score, the highest mean scores are found with the appropriate promotional appeal type. 
TABle 4.5 Pretest MANOVA Results for APPEAl REPRESENTAtions

\begin{tabular}{|c|c|c|c|c|c|c|}
\hline \multicolumn{7}{|c|}{ Between Subjects Effects for Product } \\
\hline & \multicolumn{4}{|c|}{ Mean Scores } & \multirow[b]{2}{*}{$\mathbf{F}$} & \multirow[b]{2}{*}{ Sig. } \\
\hline Dependent Variable & Hedonic & Utility & Altruism & Justice & & \\
\hline Enjoyment & $4.43^{\mathrm{a}}$ & $4.01^{\mathrm{a}}$ & $2.75^{\mathrm{b}}$ & $3.16^{\mathrm{b}}$ & 16.6 & .000 \\
\hline Pleasure & $4.51^{\mathrm{a}}$ & $4.03^{\mathrm{a}}$ & $2.80^{b}$ & $3.05^{b}$ & 19.2 & .000 \\
\hline Fun & $4.44^{\mathrm{a}}$ & $3.86^{b}$ & $2.57^{\mathrm{c}}$ & $2.88^{\mathrm{c}}$ & 22.4 & .000 \\
\hline Exciting & $4.47^{\mathrm{a}}$ & $3.75^{b}$ & $2.73^{\mathrm{c}}$ & $2.87^{\mathrm{c}}$ & 19.1 & .000 \\
\hline Delightful & $3.90^{\mathrm{a}}$ & $3.64^{\mathrm{a}}$ & $2.79^{b}$ & $2.73^{b}$ & 10.8 & .000 \\
\hline Thrilling & $3.89^{2}$ & $3.30^{b}$ & $2.51^{\mathrm{c}}$ & $2.61^{\mathrm{c}}$ & 13.4 & .000 \\
\hline Entertaining & $3.97^{a}$ & $3.33^{b}$ & $2.38^{\mathrm{c}}$ & $2.93^{b}$ & 14.2 & .000 \\
\hline Helpful & $3.14^{\mathrm{c}}$ & $4.54^{a}$ & $4.01^{b}$ & $3.83^{b}$ & 8.6 & .000 \\
\hline Effective & $3.45^{\mathrm{c}}$ & $4.74^{\mathrm{a}}$ & $4.11^{b}$ & $3.70^{b}$ & 9.5 & .000 \\
\hline Functional & $3.22^{\mathrm{C}}$ & $5.13^{\mathrm{a}}$ & $3.89^{b}$ & $3.67^{6}$ & 23.5 & .000 \\
\hline Necessary & $2.71^{\mathrm{c}}$ & $4.21^{\mathrm{a}}$ & $3.80^{b}$ & $3.63^{b}$ & 12.6 & .000 \\
\hline Practical & $2.86^{c}$ & $4.84^{a}$ & $3.60^{b}$ & $3.85^{b}$ & 23.1 & .000 \\
\hline Equality & $2.14^{\mathrm{c}}$ & $2.67^{b}$ & $4.46^{\mathrm{a}}$ & $4.94^{a}$ & 53.9 & .000 \\
\hline Fairness & $2.16^{c}$ & $2.81^{b}$ & $4.39^{\mathrm{a}}$ & $4.83^{a}$ & 43.1 & .000 \\
\hline Obligation & $2.16^{6}$ & $2.52^{b}$ & $4.29^{\mathrm{a}}$ & $4.37^{a}$ & 40.4 & .000 \\
\hline Duty & $2.07^{b}$ & $2.43^{b}$ & $4.20^{\mathrm{a}}$ & $4.25^{\mathrm{a}}$ & 37.2 & .000 \\
\hline Sympathy & $2.06^{b}$ & $2.36^{\mathrm{b}}$ & $5.23^{\mathrm{a}}$ & $5.04^{\mathrm{a}}$ & 92.5 & .000 \\
\hline Concern & $2.26^{b}$ & $2.74^{b}$ & $5.33^{\mathrm{a}}$ & $4.88^{\mathrm{a}}$ & 66.7 & .000 \\
\hline Compassion & $2.23^{\mathrm{c}}$ & $2.53^{c}$ & $5.43^{\mathrm{a}}$ & $4.81^{b}$ & 80.0 & .000 \\
\hline Charity & $2.11^{c}$ & $2.68^{b}$ & $5.18^{\mathrm{a}}$ & $4.96^{\mathrm{a}}$ & 71.1 & .000 \\
\hline
\end{tabular}

Note: Bold $=$ highest mean

Means with the same superscript are not significantly different at $<.05$

$\mathrm{F}=8.6$, sig. $=.000$, d.f. $=60$

$\mathrm{N}=328$

The hedonic appeal mean scores are highest and significantly different for four of the seven hedonic measures. All the utilitarian measures are significantly highest for the utility appeal. For the other-oriented appeals, the altruism measures are higher for altruism appeals than for justice appeals but only compassion is significantly different. However, concern (sig.=.083) also approaches significance at $p<0.1$. Similarly, the four justice measures are higher for the justice appeal. However, there are no significant 
differences between the altruism and justice appeals at the $\mathrm{p}<0.05$ significance threshold. Although, equality (sig.=.064) and fairness (sig.=.099) mean score differences approach significance. Justice appeals are viewed similar to altruism in this pretest on the basis of obligation and duty. However, this analysis does not account for differences in personality of respondents that may affect their responses.

Therefore, an additional pretest was conducted to evaluate differences in interpretation of the promotional appeal types based on the inner-other directedness personality trait. Based on responses of 43 undergraduate students, a MANOVA analysis for all the representation measures showed that the inner-other directedness personality trait approaches a significant main effect $(\mathrm{F}=2.12$; sig.=.071) with perceptions of the promotional appeal. The sample was separated into two groups: those who are more other-directed and those who are more inner-directed. This separation was done by taking the mean of the inner-other directedness personality measures. Table 4.6 presents the mean scores of the promotional appeal representation measures sorted by the largest difference in the mean scores between inner- and other-directed individuals.

While the overall main effect approaches significance, there was no significance found at the individual measure level. However, the direction of mean differences was in the expected direction for most cases. It was expected that the other-oriented justice appeal would resonate better with other-directed versus inner-directed individuals. Of particular note are the large differences in perceptions of the justice appeal as an obligation (other-directed $\overline{\mathrm{X}}=5.0$; inner-directed $\overline{\mathrm{X}}=4.2$ ) and duty (other-directed $\overline{\mathrm{X}}=$ 
4.7; inner-directed $\overline{\mathrm{X}}=4.1$ ). Further, a MANOVA analysis of the personality trait on only the justice measures reveals that differences in viewing obligation approaches significance in the between-subjects tests $(F=3.27$, sig.=.078). Therefore, the appeals seem to represent what was intended in the research design. The intended motivationbased appeal is reflected back through the measures associated with each appeal type. While all respondents can make the distinction between hedonic and utilitarian appeal types, perceiving the difference between altruism and justice is more sensitive to personality. Those who are more other-directed tend to recognize the justice appeal more distinctly from altruism.

Table 4.6 Pretest Representation Means for the Justice Appeal

\begin{tabular}{|l|c|c|c|}
\hline & \multicolumn{3}{|c|}{ Mean Score } \\
\hline Item & Difference & Other-Directed & Inner-Directed \\
\hline Obligation & -0.78 & 5.00 & 4.22 \\
\hline Duty & -0.61 & 4.74 & 4.13 \\
\hline Concern & -0.48 & 5.05 & 4.57 \\
\hline Fun & -0.48 & 3.05 & 2.57 \\
\hline Thrilling & -0.37 & 2.85 & 2.48 \\
\hline Fairness & -0.30 & 4.60 & 4.30 \\
\hline Equality & -0.29 & 4.55 & 4.26 \\
\hline Sympathy & -0.28 & 4.84 & 4.57 \\
\hline Enjoyment & -0.27 & 3.05 & 2.78 \\
\hline Exciting & -0.24 & 2.85 & 2.61 \\
\hline Practical & -0.24 & 4.15 & 3.91 \\
\hline Pleasure & -0.22 & 3.05 & 2.83 \\
\hline Delight & -0.22 & 2.74 & 2.52 \\
\hline Entertaining & -0.19 & 3.10 & 2.91 \\
\hline Charity & -0.07 & 4.90 & 4.83 \\
\hline Effectiveness & -0.01 & 4.40 & 4.39 \\
\hline Helpful & 0.01 & 4.47 & 4.48 \\
\hline Compassion & 0.05 & 4.60 & 4.65 \\
\hline Functional & 0.06 & 4.63 & 4.70 \\
\hline Necessary & 0.72 & 3.80 & 4.52 \\
\hline
\end{tabular}

Note: Overall MANOVA $F=2.12$, sig. $=.071$, d.f. $=20, N=43$ 


\subsection{Data Collection}

On the basis of the pretests, the final questionnaire with all its scales was developed (see Appendix A), the product, country and appeal stimuli were selected. The sample was also identified. Undergraduate student responses were collected through classrooms where the instructor granted access. Twelve classrooms in three universities were used in this study, including Carleton University, Laurentian University and Ryerson University. The data were collected from November 2006 to January 2007 . A quota sampling approach was employed to help ensure there are equal cell sizes in the analysis, meaning that each treatment has a comparable number of responses. In total, 840 questionnaires were gathered from the classrooms. However, 15 could not be used in the analysis because they were received as incomplete. This represents a non-response rate of less than two percent.

Prior to analyzing the responses, the impact of possible confounding variables on the dependent variables of promotional effectiveness (promotion evaluation, product evaluation and purchase intentions) and the images of the stimulus countries was assessed. The literature review highlighted several aspects that could influence the results. Some of these aspects were controlled for in the research design but others needed to be measured and their associations assessed after the responses were gathered. This measurement and assessment process is required for gender, age and culture prior to exploring the relationship of personality to promotional appeal effectiveness. In addition, the measurement for the inner-other directedness personality scale is assessed. 
Gender is an important factor to consider in this study because previous research found there were gender differences in the orientations people have toward the world. For instance, Brunel and Nelson (2003) found that females were more concerned than males with the welfare of others. In this study, the sample is comprised of $58 \%$ males. Using MANOVA to examine differences in responses, there are no significant differences found in the overall gender-based responses for the effectiveness of the promotion $(\mathrm{F}=0.11, \mathrm{p}=.953)$ or the image of the stimulus country $(\mathrm{F}=1.58, \mathrm{p}=.162)$. Therefore, further gender-based analysis of promotional appeal effectiveness and country image was not done.

Age is another possible unintended influencer of responses that requires assessment in this study. The vast majority of the sample is less than 20 years of age $(80 \%)$. Much variation in the age of respondents is minimized through the sampling design that draws responses from undergraduate classrooms. Therefore, within the relatively tight range of ages, the assessment of the influence of age on response differences was done by comparing those 20 years and below and those older. Using MANOVA, there are no overall significant differences found in the responses of the two age groups for promotion effectiveness $(\mathrm{F}=0.06, \mathrm{p}=.980)$ or the country image $(\mathrm{F}=1.59$, $\mathrm{p}=.160$ ). Therefore, further age-based analysis on promotional appeal effectiveness and country image was not done. 
Culture can influence consumers and the effectiveness of promotional appeals (Vincent and Dubinsky 2005). Therefore, it is important to assess whether recent arrivals to Canada have different responses about the effectiveness of the promotional appeal or the image of the stimulus countries. Differences in promotion effectiveness and country image responses were compared on the basis of those who have been in Canada for less than five years and those who have been in Canada for five years or longer. Using MANOVA, there were significant differences found between the two groups for promotion effectiveness $(\mathrm{F}=5.34, \mathrm{p}=.001)$ and image of the stimulus country $(\mathrm{F}=6.54$, $\mathrm{p}=.000)$.

In the pairwise comparison of promotion effectiveness measures, it is worth noting that there were significant differences for the evaluation of the promotion $(F=9.46$, $\mathrm{p}=.002)$ and the intention to purchase $(\mathrm{F}=10.18, \mathrm{p}=.001)$. Those who have been in Canada for less than five years evaluated the promotions more positively and had higher intentions to purchase than those who had been in Canada longer. In the pairwise comparison of country image measures, there were significant differences for country and people competence $(F=22.89, p=.000)$, people characteristics $(F=5.37, p=.021)$, and need and urgency $(F=2.75, \mathrm{p}=.098)$. Those who had been in Canada less than five years view country and people competencies and people character of the developing countries higher while need and urgency was lower when compared to those who had been in Canada for five years or more. Therefore, because they had different views than the larger group, 83 respondents who had been in Canada less than five years were excluded from further analysis. Therefore, this study reports on the analysis of 742 usable questionnaires and 
represents approximately 46 responses for each treatment cell. The majority of respondents were born in Canada (i.e. 65\%) and the remaining respondents had been in Canada for at least the last five years.

The hypothesis testing involves the investigation of the inner-other directedness personality trait and its association to outcomes of promotional appeals. To accomplish this task, the personality measures were assessed for their ability to represent the underlying personality trait. In the pretesting process of this study, Kassarjian's (1962) scale was abridged to 11 items that achieved a Cronbach's alpha value of .620 in one sample and a .609 value in another sample. In this study, the Cronbach's alpha value of the 11 items was .466 . However, when two poorly loaded items are dropped from the scale, the remaining nine items achieve an adequate Cronbach's alpha value of .503 . While Nunnally (1978) suggests that applied research should have a reliability of greater than .80 , Nunnally (1978) acknowledges that exploratory research can be more flexible and use more modest reliability values. Further, Cronbach's Alpha values in the .50 range have been judged as acceptable (e.g. Usunier 1999). In addition, scales with more items tend to have higher reliabilities. Therefore, the smaller scale (i.e. 11 items) would be expected to have a lower Cronbach's alpha.

Confidence in applying the inner-other directedness scale in this research is enhanced further through the method of analysis. First, the mean of the nine items generated a summary measure of the underlying personality trait. This is appropriate because Kassarjian (1962) indicates that the personality trait is unidimensional. Second, 
to maximize understanding of the differences for people who are inner- or other-directed, those with mid-range scores (i.e. neither clearly inner- or other-directed) were eliminated from this analysis. The mean score of the inner-other directedness scale was 3.47 with the mid-third defined by a bottom value of 3.22 and a top value of 3.78 . The removal of responses reduces the sample to 450 responses. This enables the research to confidently compare two groups of people with clear differences on the personality trait. 


\section{RESULTS}

The data analysis is conducted in three main parts. First, the descriptive results of the study are presented to provide a general overview of the responses collected. Second, a manipulation check is reported to assess the impact of the appeal treatment. Third, the hypotheses testing results are reported and discussed.

Prior to analyzing the responses, the data were screened for non-normality, outliers and other data problems. This screening revealed no areas of concern. The subsequent analysis of data involves two procedures to evaluate the hypotheses. The approach is modeled on the Aaker and Williams (1998) study that explores the effect of emotional appeals on people of different cultures. According to the approach in this study, manipulation checks are first conducted to determine the extent to which the appeals represent what is intended.

\subsection{Country Image Descriptive Results}

The following discussion of descriptive results provides a broad overview of the responses received for this study. In particular, these results demonstrate differences in responses to the country and people scales for the stimulus countries. Table 5.1 presents the country image mean scores for the stimulus countries of Colombia and Honduras. With overall direct effects $(F=3.65, p=.000)$ in a MANOVA analysis, the two countries are perceived as significantly different. 
Table 5.1 Mean Responses for Country and People Measures

\begin{tabular}{|l|c|c|c|}
\hline Variable & Colombia & Honduras & Sig. \\
\hline Likeability of people & 4.52 & 4.61 & $\mathrm{~ns}$ \\
\hline Industriousness & 4.10 & 4.16 & $\mathrm{~ns}$ \\
\hline Education level & 3.13 & 3.00 & $\mathrm{~ns}$ \\
\hline Fascinating people & 4.30 & 4.22 & $\mathrm{~ns}$ \\
\hline Wealth & $\mathbf{3 . 0 1}$ & 2.73 & .006 \\
\hline Friendliness & 4.65 & $\mathbf{5 . 0 1}$ & .000 \\
\hline Trustworthiness & 3.85 & 4.25 & .000 \\
\hline Work ethic & 4.67 & 4.88 & .060 \\
\hline Appealing culture & 4.54 & 4.49 & $\mathrm{~ns}$ \\
\hline Individualism & 3.99 & 3.88 & $\mathrm{~ns}$ \\
\hline Political stability & 2.93 & 3.04 & $\mathrm{~ns}$ \\
\hline Technology level of country & 2.96 & 2.82 & $\mathrm{~ns}$ \\
\hline Stability of economy & 3.06 & 2.94 & $\mathrm{~ns}$ \\
\hline Quality of life & 3.12 & 2.98 & $\mathrm{~ns}$ \\
\hline Admirable in world politics & 2.77 & 2.82 & $\mathrm{~ns}$ \\
\hline Environmental/pollution controls & 3.12 & 3.04 & $\mathrm{~ns}$ \\
\hline Individual rights and freedoms & 3.12 & 3.19 & $\mathrm{~ns}$ \\
\hline In need of assistance & 5.07 & 5.21 & $\mathrm{~ns}$ \\
\hline Urgency of need & 4.57 & 4.87 & .004 \\
\hline Alignment with your home country & 3.21 & 3.30 & $\mathrm{~ns}$ \\
\hline Liking of the country & 4.19 & 4.03 & $\mathrm{~ns}$ \\
\hline Your knowledge of the country & $\mathbf{2 . 7 2}$ & 2.14 & .000 \\
\hline Overall, how would you rate the country? & 3.83 & 3.72 & $\mathrm{~ns}$ \\
\hline
\end{tabular}

Note: Bold indicates the highest mean score for that variable

Overall MANOVA $\mathrm{F}=3.65, \mathrm{p}=.000$, d.f. $=26$

The overall MANOVA difference is attributable mainly to six of the 23 country image measures. Colombia was perceived to be wealthier and respondents believed they knew more about the country compared to Honduras. Honduras was seen more positively for friendliness, trustworthiness, and work ethic of the people. While both countries were seen to be in need of assistance, Honduras was viewed as in more urgent 
need for attention. Therefore, despite some similarities, Honduras was perceived more positively on people character aspects and neediness than Colombia. The two countries are seen as lower-middle advancement as indicated by responses around the mid-point of the scale yet still in need of assistance. Although the wealth measure is significantly different for the two countries and reflects the country's income level, these country image measures are not really a human development index scale as only three of measures reflect the index (i.e. education, quality of life, technology level) and they are not significantly different.

To identify the underlying dimensions of the country image for these two countries, a principal components factor analysis was conducted. A four-factor solution was generated using the Kaiser method (i.e. critical eigenvalue of 1.0) and a minimum loading of 0.4 after a varimax rotation demonstrating consistency with previous research (see Table 5.2). The presence of country and people competence, country character and people character in the factor analysis output is similar to earlier research (Heslop et al. 2004). The combination of country and people competence into one factor may be a result of the stimulus countries. There may be less sophisticated perceptions of competencies for less developed countries or when familiarity with the country is low. The additional neediness factor is comprised of two measures included in this research to capture the perceived level of neediness and urgency of that need for less developed countries. 
TABLE 5.2 LOADINGS OF COUNTRY IMAGE VARIABLES FOR COLOMBIA AND HONDURAS

\begin{tabular}{|c|c|c|c|c|}
\hline Variable & 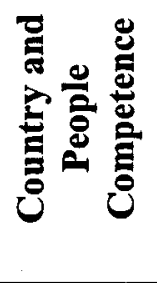 & 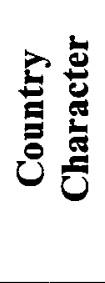 & 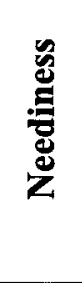 & 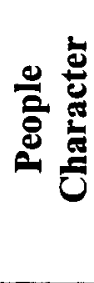 \\
\hline Likeability of people & & .645 & & \\
\hline \multicolumn{5}{|l|}{ Industriousness } \\
\hline Education level & .731 & & & \\
\hline Fascinating people & & .672 & & \\
\hline Wealth & .723 & & & \\
\hline Friendliness & & .590 & & .519 \\
\hline Trustworthiness & & & & .621 \\
\hline Work ethic & & & & .595 \\
\hline Appealing culture & & .713 & & \\
\hline Individualism & & .498 & & \\
\hline Political stability & .797 & & & \\
\hline Technology level of country & .820 & & & \\
\hline Stability of economy & .858 & & & \\
\hline Quality of life & .794 & & & \\
\hline Admirable in world politics & .792 & & & \\
\hline Environmental/pollution controls & .717 & & & \\
\hline Individual rights and freedoms & .727 & & & \\
\hline In need of assistance & & & .837 & \\
\hline Urgency of need & & & .883 & \\
\hline Alignment with your home country & .448 & & & \\
\hline Liking of the country & & .644 & & \\
\hline Your knowledge of the country & & & & -.526 \\
\hline Overall, rate the country? & .456 & .512 & & \\
\hline
\end{tabular}

Note: only loadings greater than 0.4 are presented.

These four factors were used in the assessment of the hypothesized relationship among country image, appeal type, inner-other directedness personality trait, and product type with promotional appeal effectiveness outcome measures. Further analysis was based on these factors as presented with the following three exceptions. First, the overall 
rating of the country was included in only the country character factor because the loading was higher and fits with some of the other evaluative (i.e. liking of the country) and affective (i.e. likeability of people) items in the factor. A calculation of the Cronbach's alpha value confirms the change was beneficial as the country character achieved a value of .783 with no improvement indicated through deletion of any items. Second, friendliness achieved double loadings and was included in only the people character factor. Cronbach's alpha values demonstrate that the factor has higher values with it (.679) than without it (.604). Third, removing the knowledge of the country item from the people character factor improves the Cronbach's alpha from .521 to .710 . Therefore, the item was removed from further analysis.

\subsection{Manipulation Checks}

Beyond assessing the descriptive results, an examination of the promotional appeal representation provides insight into the respondents' interpretations of the appeals. The manipulation check is done to ensure that respondents interpreted the promotional appeal types as intended by the research design. Table 5.3 presents the mean scores for each appeal type representation measure. The responses are significantly different as indicated through an overall MANOVA $(\mathrm{F}=10.17, \mathrm{p}=.000)$. Generally, the highest means were attained for measures intended to represent the appeal types. However, there were four instances where this was not the case. Three instances occur with helpful, effective and necessary measures. These three means were expected to be highest for the utility appeal but they were also high for the justice and altruism appeals. However, it is important to note that the way the appeals are helpful, effective and necessary can be 
quite different for each appeal type. The utility appeal is oriented to fulfil goals about the product for the self, while the justice and altruism appeals are about satisfying the needs of others. Therefore, the utility appeal was interpreted as expected by respondents.

TABLE 5.3 MEAN RESPONSES fOR APPEAL REPRESENTATION MEASURES

\begin{tabular}{|c|c|c|c|c|c|}
\hline & \multirow[b]{2}{*}{ Measure } & \multicolumn{4}{|c|}{ Appeal Type } \\
\hline & & Hedonic & Utility & Altruism & Justice \\
\hline \multirow[t]{7}{*}{ Hedonic } & Enjoy & $3.90^{\mathrm{a}}$ & $3.47^{\mathrm{b}}$ & $2.82^{\mathrm{c}}$ & $2.91^{\mathrm{c}}$ \\
\hline & Pleasure & $4.24^{\mathrm{a}}$ & $3.73^{\mathrm{b}}$ & $3.18^{\mathrm{c}}$ & $3.30^{\mathrm{c}}$ \\
\hline & Fun & $4.25^{\mathrm{a}}$ & $3.58^{\mathrm{b}}$ & $2.58^{\mathrm{c}}$ & $2.80^{c}$ \\
\hline & Exciting & $3.85^{\mathrm{a}}$ & $3.18^{\mathrm{b}}$ & $2.81^{\mathrm{c}}$ & $2.79^{\mathrm{c}}$ \\
\hline & Delight & $\mathbf{3 . 5 5}^{\mathrm{a}}$ & $3.20^{6}$ & $2.68^{\mathrm{c}}$ & $2.88^{\mathrm{b}}$ \\
\hline & Thrilling & $\mathbf{3 . 3 5}^{\mathrm{a}}$ & $2.88^{\mathrm{b}}$ & $2.47^{\mathrm{c}}$ & $2.64^{\mathrm{b}}$ \\
\hline & Entertain & $3.67^{\mathrm{a}}$ & $2.97^{\mathrm{b}}$ & $2.48^{\mathrm{c}}$ & $2.66^{b}$ \\
\hline \multirow[t]{5}{*}{ Utility } & Helpful & $3.18^{\mathrm{c}}$ & $4.00^{b}$ & $4.14^{\mathrm{b}}$ & $4.32^{\mathrm{a}}$ \\
\hline & Effective & $3.69^{b}$ & $4.14^{\mathrm{a}}$ & $4.14^{\mathrm{a}}$ & $4.44^{\mathrm{a}}$ \\
\hline & Function & $3.91^{\mathrm{c}}$ & $4.77^{\mathrm{a}}$ & $3.81^{\mathrm{c}}$ & $4.27^{\mathrm{b}}$ \\
\hline & Necessary & $3.24^{\mathrm{b}}$ & $3.85^{\mathrm{a}}$ & $4.16^{\mathrm{a}}$ & $4.20^{\mathrm{a}}$ \\
\hline & Practical & $3.64^{b}$ & $4.90^{\mathrm{a}}$ & $3.75^{b}$ & $4.01^{\mathrm{b}}$ \\
\hline \multirow{4}{*}{ Altruism } & Charity & $2.98^{\mathrm{c}}$ & $3.07^{\mathrm{c}}$ & $5.14^{\mathrm{a}}$ & $4.75^{\mathrm{b}}$ \\
\hline & Sympathy & $3.26^{\mathrm{b}}$ & $3.16^{6}$ & $5.00^{2}$ & $4.85^{a}$ \\
\hline & Concern & $3.16^{b}$ & $3.25^{6}$ & $4.79^{a}$ & $4.70^{2}$ \\
\hline & Compassion & $3.14^{b}$ & $3.12^{b}$ & $4.48^{\mathrm{a}}$ & $4.52^{\mathrm{a}}$ \\
\hline \multirow[t]{4}{*}{ Justice } & Equality & $3.24^{\mathrm{c}}$ & $3.52^{6}$ & $3.59^{\mathrm{b}}$ & $4.28^{\mathrm{a}}$ \\
\hline & Fairness & $3.37^{6}$ & $3.63^{b}$ & $3.68^{b}$ & $4.28^{\mathrm{a}}$ \\
\hline & Obligation & $3.30^{b}$ & $3.39^{6}$ & $4.07^{a}$ & $4.07^{\mathrm{a}}$ \\
\hline & Duty & $2.98^{\mathrm{b}}$ & $3.28^{\mathrm{b}}$ & $3.84^{\mathrm{a}}$ & $4.10^{a}$ \\
\hline
\end{tabular}

Note: Bold = highest mean;

Means with the same superscript are not significantly different at $<.05$

Overall MANOVA $F=10.17, p=.000$, d.f. $=60$

Also, the mean response for the obligation measure is slightly higher, but not significant, for the altruism appeal compared to the justice appeal. Again, it is worth noting that the source of obligation differs for the two appeal types. A similar insignificant result was found with the measure of duty for altruism and justice appeals. 
Altruism appeals develop a sense of obligation and duty primarily through emotion while justice develops obligation through cognition. In the pretests, obligation and duty were also found to be similar for altruism and justice appeals. However, as previously presented in the pretest discussion, those who were more other-directed made a distinction between the two appeal types on these measures.

An alternative explanation for distinguishing between altruism and justice is rooted in the emotion and cognitive continuum and the underlying mechanisms of the two appeal types. Despite justice's cognitive emphasis, it is also important to note that emotion may play a role in the effectiveness of a justice appeal as presented in this study. This is consistent with the view that cognitions and emotions may interact to explain behaviour (Rosenhan et al. 1981; Eisenberg 1986). The non-significance of differences between altruism and justice appeals for the emotional measures of sympathy, concern and compassion provide some evidence for this importance. Finally, the distinction between these two appeal types may be clearer for other-directed individuals.

Cronbach's alpha statistics are reported to assess the fit of the appeal representation measures in the appeal type that was intended. All four appeal types were representing what was intended as indicated by Cronbach alpha values range from .74 to .94 (hedonic $=.938$, utility $=.792$, altruism $=.856$ and justice $=.740$ ). Therefore, the measures were averaged into their expected groupings to explore the representations of the promotional appeals further. This aggregation is possible because the individual scales were meant to measure the singular, underlying essence of the promotional appeal. 
Table 5.4 presents the aggregated mean scores for the intended measures. The aggregated results indicate that each promotional appeal type was viewed as expected. For example, the highest hedonic mean score was found with the hedonic appeal. It is important to note that the highest mean was significantly different from the next highest mean in all but one case. For example, the hedonic mean for the hedonic appeal is significantly higher than the hedonic mean for the utility appeal. The only case where the highest mean score was not significant from another is with the utility measures mean score for the utility and justice appeals. However, as noted previously, the two appeal types are quite different in the way they are helpful, effective and necessary and both use a cognitive base. The important distinction between the other-oriented appeals of altruism and justice was supported in the results. Overall, these results increase the confidence that the manipulations were as expected.

TABLe 5.4 Mean Responses fOr AgGRegated APPEAL RePresentation Measures

\begin{tabular}{|l|c|c|c|c|}
\hline \multirow{2}{*}{ Measure } & \multicolumn{4}{|c|}{ Appeal Type } \\
\cline { 2 - 5 } & Hedonic & Utility & Altruism & Justice \\
\hline Hedonic & $\mathbf{3 . 8 9}^{\mathrm{a}}$ & $3.26^{\mathrm{b}}$ & $2.76^{\mathrm{c}}$ & $2.89^{\mathrm{c}}$ \\
\hline Utility & $3.58^{\mathrm{c}}$ & $\mathbf{4 . 3 3}^{\mathrm{a}}$ & $4.01^{\mathrm{b}}$ & $\mathbf{4 . 2 3}^{\mathrm{a}}$ \\
\hline Altruism & $3.16^{\mathrm{c}}$ & $3.15^{\mathrm{c}}$ & $\mathbf{4 . 8 7}^{\mathrm{a}}$ & $4.65^{\mathrm{b}}$ \\
\hline Justice & $3.28^{\mathrm{c}}$ & $3.47^{\mathrm{c}}$ & $3.82^{\mathrm{b}}$ & $\mathbf{4 . 1 5}^{\mathrm{a}}$ \\
\hline
\end{tabular}

Note: Bold = highest mean;

Means with the same superscript are not significantly different at $<.05$

Overall MANOVA $\mathrm{F}=41.07, \mathrm{p}=.000$, d.f. $=12$ 


\subsection{Hypothesis Testing}

The third part of the data analysis involves the testing of the hypotheses. Testing the study hypotheses is organized into five sets presented in the hypotheses section. The goal of the first hypothesis is to establish whether the appeal types have different promotional effectiveness outcome responses. The following four hypotheses represent the important relationships among promotional appeal types, country images and promotional appeal effectiveness within the context of personality and product as they were postulated in the hypothesis section.

\subsubsection{Testing Hypothesis 1 Series - Appeal Type to Promotion Effectiveness}

The first hypothesis (1a) examines the four promotional appeal types and the responses on the promotion effectiveness measures of promotion evaluation, product evaluation and purchase intentions. It was postulated that the appeal effectiveness outcome measures would differ for the four appeal types. The promotion effectiveness response scales are presented in Table 5.5. The table presents the overall responses for these effectiveness measures that were found in a MANOVA analysis to be significantly different overall $(\mathrm{F}=4.69, \mathrm{p}=.000)$. 
TABle 5.5 Mean Responses for APPEAL EfFectiveness MeAsures

\begin{tabular}{|c|c|c|c|c|c|}
\hline & \multirow[b]{2}{*}{ Measure } & \multicolumn{4}{|c|}{ Appeal Type } \\
\hline & & Hedonic & Utility & Altruism & Justice \\
\hline \multirow{4}{*}{$\begin{array}{l}\text { Promotion } \\
\text { Evaluation }\end{array}$} & Likeable & $3.66^{\mathrm{a}}$ & $3.63^{\mathrm{a}}$ & $3.41^{\mathrm{a}}$ & $3.59^{\mathrm{a}}$ \\
\hline & Good & $3.50^{6}$ & $3.64^{b}$ & $3.77^{\mathrm{a}}$ & $4.03^{\mathrm{a}}$ \\
\hline & Interesting & $3.49^{c}$ & $3.15^{\mathrm{d}}$ & $3.83^{b}$ & $4.19^{\mathrm{a}}$ \\
\hline & Irritating & $3.88^{\mathrm{a}}$ & $3.63^{\mathrm{a}}$ & $3.97^{\mathrm{a}}$ & $3.60^{\mathrm{a}}$ \\
\hline \multirow{6}{*}{$\begin{array}{l}\text { Product } \\
\text { Evaluation }\end{array}$} & Good & $3.89^{b}$ & $4.55^{\mathrm{a}}$ & $4.06^{b}$ & $4.19^{b}$ \\
\hline & Likeable & $3.88^{b}$ & $4.29^{a}$ & $4.14^{\mathrm{a}}$ & $4.20^{\mathrm{a}}$ \\
\hline & Nice & $3.92^{\mathrm{a}}$ & $4.19^{\mathrm{a}}$ & $4.14^{\mathrm{a}}$ & $4.08^{\mathrm{a}}$ \\
\hline & Attractive & $3.91^{2}$ & $3.98^{\mathrm{a}}$ & $4.02^{\mathrm{a}}$ & $4.07^{\mathrm{a}}$ \\
\hline & Worthy & $3.59^{b}$ & $4.11^{a}$ & $4.19^{a}$ & $4.17^{a}$ \\
\hline & $\begin{array}{l}\text { Compared to } \\
\text { competing products, } \\
\text { how would you rate } \\
\text { the product? }\end{array}$ & $3.60^{b}$ & $3.77^{\mathrm{a}}$ & $3.97^{\mathrm{a}}$ & $4.07^{a}$ \\
\hline \multirow{4}{*}{$\begin{array}{l}\text { Purchase } \\
\text { Intentions }\end{array}$} & Like to purchase & $3.22^{b}$ & $3.51^{b}$ & $4.04^{a}$ & $4.03^{a}$ \\
\hline & Willingness to buy & $3.13^{b}$ & $3.45^{b}$ & $3.96^{\mathrm{a}}$ & $4.04^{a}$ \\
\hline & Intend to purchase & $2.68^{b}$ & $2.99^{b}$ & $3.72^{\mathrm{a}}$ & $3.59^{\mathrm{a}}$ \\
\hline & $\begin{array}{l}\text { Would recommend to } \\
\text { others }\end{array}$ & $2.91^{b}$ & $3.29^{b}$ & $3.88^{\mathrm{a}}$ & $3.77^{\mathrm{a}}$ \\
\hline
\end{tabular}

Note: Bold = highest mean;

Means with the same superscript are not significantly different at $<.05$

Overall MANOVA $F=4.69$, $p=.000$, d.f. $=42$

In four of the fourteen measures, the four appeal types achieved the same overall mean score including two promotion evaluation measures (likeable, irritating) and two product evaluations (nice, attractive). Views of the utility, altruism and justice appeals were significantly different from the hedonic appeal in another three items. These three items pertained to product evaluations and included likeable, worthy and the rating compared to competing products. The altruism and justice appeals reached higher mean scores compared to both the utility and hedonic on five items including one of the promotion evaluation measures (interesting) and the four purchase intention measures 
(like to purchase, willingness to buy, intend to purchase, recommend to others). The utility appeal was viewed most favourably for good as a product evaluation measure whereas the justice appeal was seen as better than other appeal types for interesting as a promotion evaluation measure. Overall, it would appear that the other-oriented appeals achieve higher promotion effectiveness outcomes as only one measure was higher for a self-oriented appeal.

Measures of effectiveness of the altruism and justice appeals were not significantly different for all measures but one. However, this analysis did not examine personality-based individual differences (i.e. inner-other directedness) among respondents. The hypotheses testing will explore the possible influence of the relevant personality trait on these measures.

Further analysis was conducted using the three constructs of promotion effectiveness as specified above. However, one measure was dropped from further analysis due to poor fit with the other promotion effectiveness measures as indicated by a Cronbach's alpha analysis. The Cronbach's alpha was improved from .488 to .852 by removing the irritating measure from the construct. In the context of the different appeal types, this item may have been interpreted differently, perhaps as describing the situation in the appeal rather than the promotion itself. For instance, the situation of the family described in the altruism appeal may have irritated some respondents while others may have been irritated by a functionally focused utility appeal. Therefore, it was removed from further analysis. 
Building upon hypothesis 1a, the remaining hypothesis 1 series investigates the relationship between the appeal type and promotional appeal effectiveness within the context of the inner-other directedness personality trait and the product type (hedonic/utility). Figure 5.1 presents the simple model of appeal effects. It was postulated that better promotion effectiveness outcomes would result when there is a match between the different appeal types and the personality trait. The hypothesis series further postulated that promotion effectiveness results would be better when there is a match among appeal type, personality and product type.

The remaining analysis of Hypothesis 1 series was done in two parts. First, there was a test for differences in promotional appeal effectiveness within the context of the personality trait. This testing explored the relevance of certain appeal types to those who are more inner- or other-directed. Second, the relationship of appeal type to promotion effectiveness was tested taking into account both personality and product type. This testing focused on the relationship under the different product treatment conditions.

\section{FiguRE 5.1 HyPOTHESIS 1 SERIES - SiMPle MODEL OF APPEAL EFFECTS}

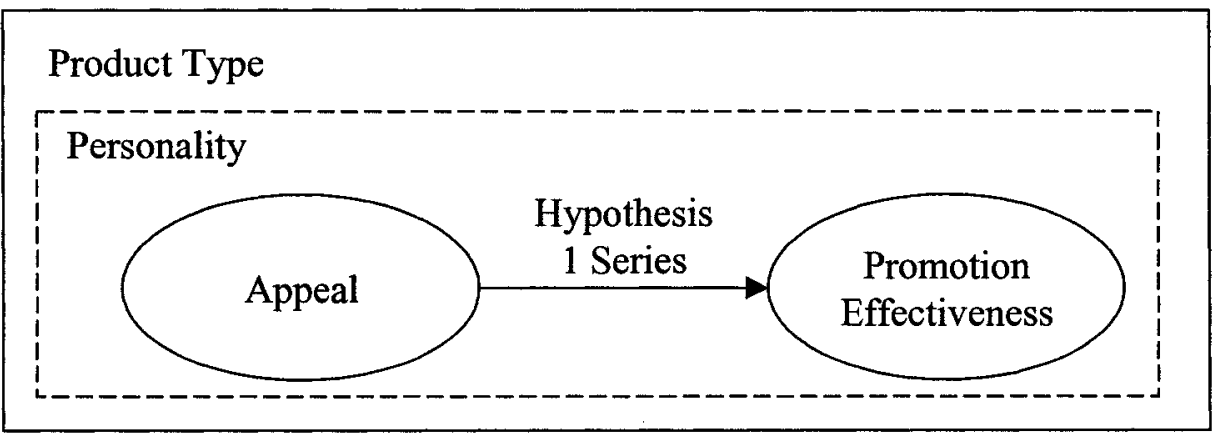




\subsubsection{Appeal and Personality Effects}

A MANOVA was conducted to assess the appeal effects on promotional effectiveness within the context of personality. The results of this test are presented in Table 5.6 and indicate two significant effects. For this analysis, the three aggregated (mean aggregation) promotion effectiveness outcome measures (promotion evaluation, product evaluation and purchase intentions) are the dependent variables. The appeal type and personality trait are the factors. The result of this analysis presents one significant difference as a main effect while the interaction effect is significant.

TABLE 5.6 MANOVA RESUltS FOR HyPOTHESES 1B-1C TESTING

\begin{tabular}{|l|c|c|c|c|}
\hline Effects & F & Hypothesis df & Error df & Sig. \\
\hline Appeal & 4.3 & 9 & 1071 & $\mathbf{. 0 0 0}$ \\
\hline Inner-Other Directedness & 1.9 & 3 & 440 & .124 \\
\hline Appeal x Inner-Other Directedness & 1.9 & 9 & 1071 & $\mathbf{. 0 4 7}$ \\
\hline \multicolumn{4}{|l|}{} \\
\hline Dependent Variables: & $\begin{array}{l}\text { Promotion Evaluation, } \\
\text { Product Evaluation, } \\
\text { Purchase Intentions }\end{array}$ \\
\hline $\mathrm{N}=450$
\end{tabular}

The significant main effect demonstrates that the three promotion effectiveness mean scores are significantly different across promotional appeal types $(F=4.3, p=.000)$. This aligns with the earlier reported manipulation checks that showed the appeal types are perceived as distinctly different promotional approaches. In the tests of betweensubjects effects, the appeal types have different overall mean scores for purchase 
intentions $(\mathrm{F}=7.2, \mathrm{p}=.000)$ while the promotion evaluation $(\mathrm{F}=1.3, \mathrm{p}=.270)$ and product evaluation $(F=1.0, p=.385)$ means are not significantly different.

Figure 5.2 graphically presents this finding by indicating significant differences using a solid line and insignificant results with broken lines. This result means that the appeal type significantly influences the decision to purchase or recommend the advertised product. In this case, altruism and justice appeals attained the higher mean scores than utility and hedonic appeals. While this direct effect demonstrates the influence of the appeal type on the outcome measures, this research is particularly interested in the interaction effects reflected in the hypotheses.

Figure 5.2 Appeal Main Effects on Promotional Effectiveness Outcomes

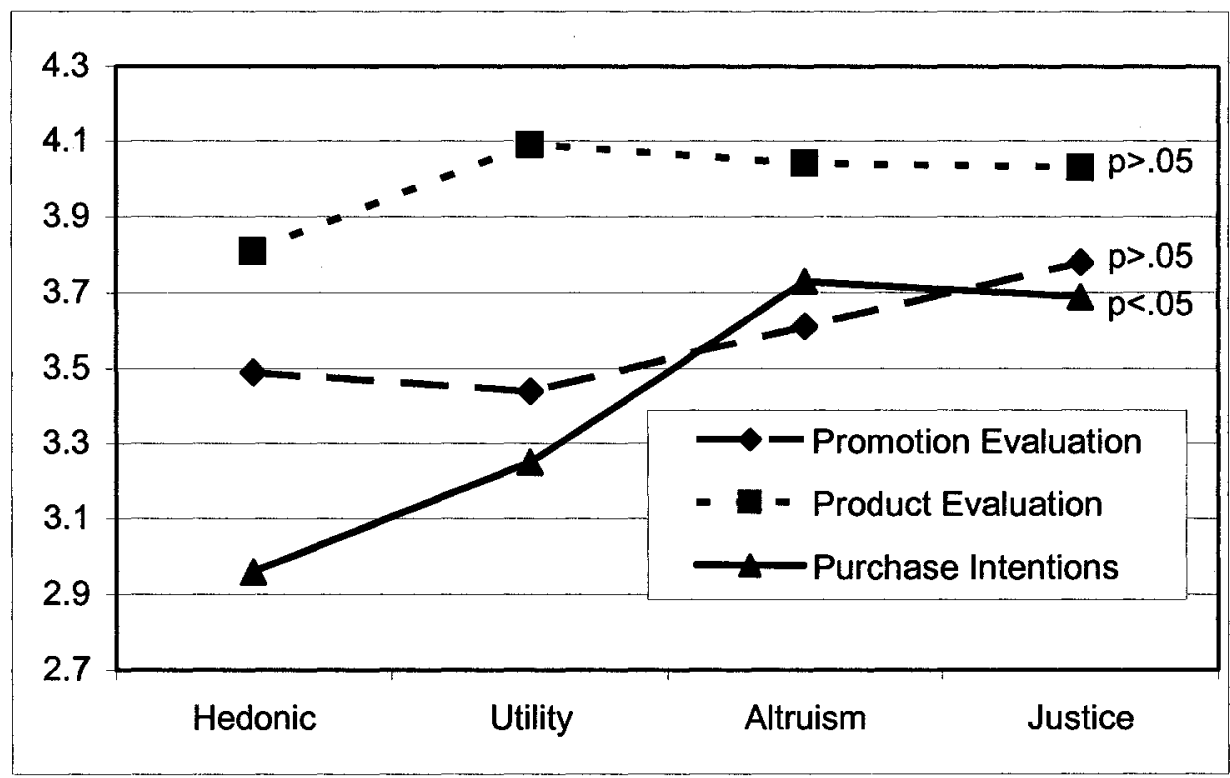

Note: Solid line represents significant differences at $\mathrm{p}<.05$, dotted lines represent non-significant differences at $\mathrm{p}>.05$ 
Another significant result from the MANOVA analysis is the interaction effect of appeal type with the personality trait of inner-other directedness $(F=1.9, p=.047)$. The tests of between-subjects effects reveals that the difference is derived from a significant difference of mean scores for purchase intentions $(F=4.7, p=.003)$. Promotion evaluation $(\mathrm{F}=2.4, \mathrm{p}=.068)$ differences approached significance. Product evaluation $(\mathrm{F}=1.3, \mathrm{p}=.274)$ means were not significantly different. The mean scores for the interaction effect of appeal type and personality on promotional appeal effectiveness are presented in Table 5.7.

TABle 5.7 Mean SCORES FOR THE APPEAl AND PERSONALITy INTERACTION

\begin{tabular}{|l|l|c|c|c|c|c|c|c|c|}
\hline \multirow{2}{*}{} & \multicolumn{9}{|c|}{ Appeal Type } \\
\cline { 2 - 9 } & \multicolumn{2}{|c|}{ Hedonic } & \multicolumn{2}{|c|}{ Utility } & \multicolumn{2}{|c|}{ Altruism } & \multicolumn{2}{|c|}{ Justice } \\
\hline \multicolumn{2}{|c|}{ Personality (Inner-Other) } & $\mathrm{I}$ & $\mathrm{O}$ & $\mathrm{I}$ & $\mathrm{O}$ & $\mathrm{I}$ & $\mathrm{O}$ & $\mathrm{I}$ & $\mathrm{O}$ \\
\hline $\begin{array}{l}\text { Promotion } \\
\text { Evaluation }\end{array}$ & $\begin{array}{l}\mathrm{F}=2.4, \\
\mathrm{p}=.068, \\
\mathrm{~d} . \mathrm{f}=3\end{array}$ & 3.27 & 3.71 & 3.55 & 3.32 & 3.26 & 3.96 & 3.75 & 3.82 \\
\hline $\begin{array}{l}\text { Product } \\
\text { Evaluation }\end{array}$ & $\begin{array}{l}\mathrm{F}=1.3, \\
\mathrm{p}=.274, \\
\text { d.f.=3 }\end{array}$ & 3.59 & 4.04 & 4.12 & 4.06 & 3.77 & 4.30 & 3.95 & 4.11 \\
\hline $\begin{array}{l}\text { Purchase } \\
\text { Intentions }\end{array}$ & $\begin{array}{l}\mathrm{F}=4.7, \\
\mathrm{p}=.003, \\
\text { d.f.=3 }\end{array}$ & 2.74 & 3.18 & 3.43 & 3.07 & 3.22 & 4.24 & 3.66 & 3.72 \\
\hline
\end{tabular}

Overall MANOVA $\mathrm{F}=1.9$, sig. $=.047$, d.f. $=9$

The finding that purchase intentions were significantly different and promotion evaluation approached significance while product evaluation was not significantly different may be explained by the role of emotion in appeal effects. Previous research on promotion effectiveness has argued that emotion-based appeals evoke an emotional response (Aaker and Williams 1998). Further, Brown, Homer and Inman (1998) noted 
that emotional response stimulated by a promotion can directly influence brand attitudes while bypassing attitude beliefs. It is also important to note that purchase intentions are higher for the two other-oriented appeals (altruism and justice) compared to the emotionbased hedonic appeal. Anholt (2005) suggests that the hedonic appeal is the appropriate approach for LDC branding. However, these results suggest that the appeals of altruism and justice may be better suited.

Figure 5.3 graphically presents the moderately significant differences for promotion evaluation mean scores by appeal type and the inner-other directedness personality trait. Although the interaction was only approaching significance for this dependent variable, it is decided that it was important to examine it. A separate MANOVA test was run for each inner- and other-directed groups on the aggregated promotion effectiveness outcomes. The results showed that the appeal types were significantly different for other-directed individuals $(F=2.7, p=.047)$ but were not significantly different for inner-directed individuals $(\mathrm{F}=1.4, \mathrm{p}=.258)$.

The figure shows there is support for hypothesis $1 \mathrm{~b}$ but only directional support for hypothesis 1c. Consistent with hypothesis $1 \mathrm{~b}$, for those who are other-directed, the other-oriented appeals (altruism $\overline{\mathrm{X}}=3.96$, justice $\overline{\mathrm{X}}=3.82$ ) have significantly higher promotion evaluations than the self-oriented appeals (hedonic $\overline{\mathrm{X}}=3.71$, utility $\overline{\mathrm{X}}=3.32$ ). Similarly, for inner-directed people, hypothesis $1 \mathrm{c}$ is directionally supported since the self-oriented appeals of hedonic $(\overline{\mathrm{X}}=3.27)$ and utility $(\overline{\mathrm{X}}=3.55)$ are higher than altruism $(\overline{\mathrm{X}}=3.26)$. However, the other-oriented justice appeal $(\overline{\mathrm{X}}=3.75)$ receives the highest 
promotion evaluation mean score for inner-directed individuals. Another important note is that inner-directed people give cognition-based appeals (utility and justice) higher promotion evaluations than they give to the more emotional appeals. The pattern is also the same for other-directed people but is less pronounced. The justice appeal provides the exception as the promotion evaluation rating is higher than the rating for the more emotion-based hedonic appeal. Overall, it seems that emotion-based appeals (hedonic and altruism) seem to resonate with other-directed individuals but not with inner-directed people. The justice appeal, with its balance of cognition and emotion, seems to work for both personality types.

\section{Figure 5.3 Personality and Appeal Interaction EfFects on Promotion EVALUATIONS}

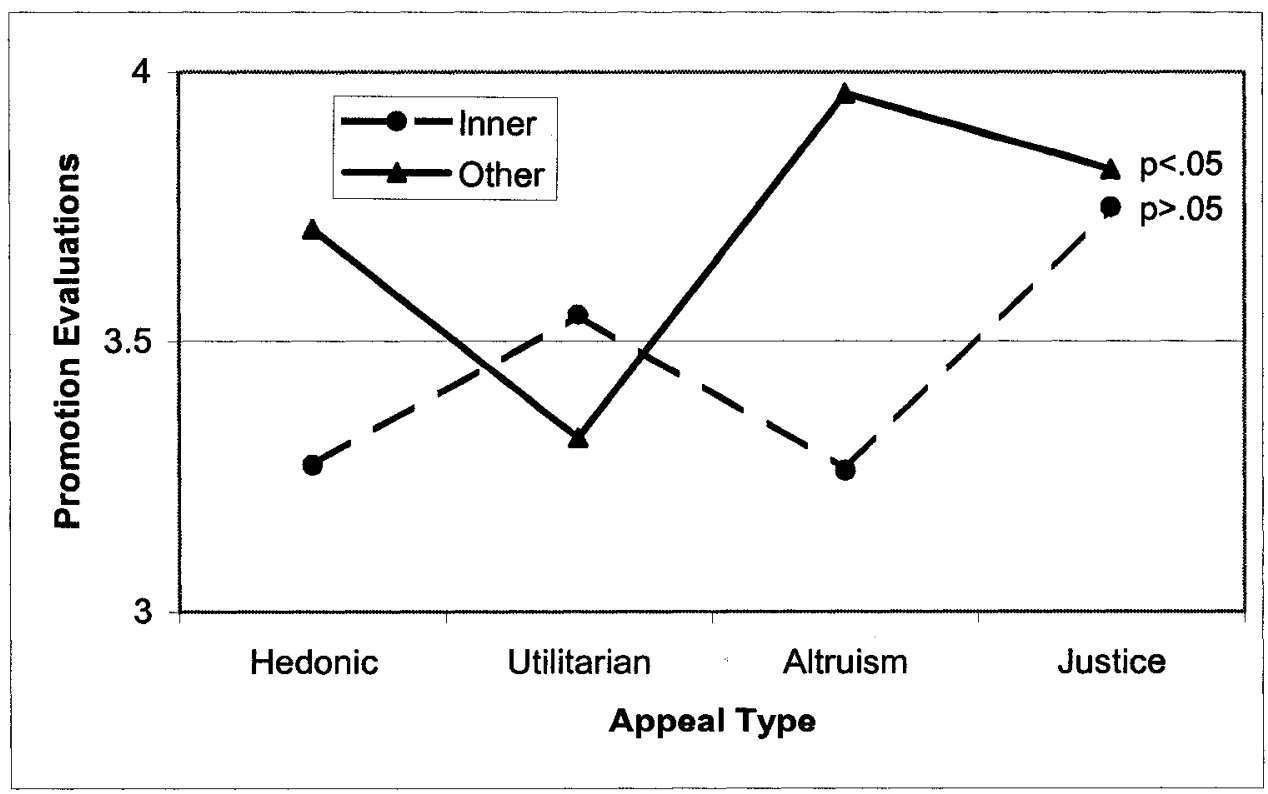

Note: Solid line represents significant differences at $\mathbf{p}<.05$, dotted line represents non-significant differences at $\mathrm{p}>.05$ 
The graphic illustration also draws attention to the gap between promotion evaluations for the altruism appeal for inner-directed and other-directed individuals. For those who are inner-directed, the altruism appeal results in a less favourable evaluation of the promotion. For other-directed individuals, the altruism appeal receives the most favourable promotion evaluation rating. What is most interesting is that these two lines almost converge with the justice appeal where the evaluations of the promotion are most similar. In addition, other-directed people gave the hedonic appeal more positive promotion evaluation ratings compared to those who are more inner-directed. This wasn't expected but other-directed individuals may be more emotionally responsive in general compared to inner-directed people.

The interaction effect of appeal type and the inner-other directedness personality trait is not significant for product evaluations $(\mathrm{F}=1.3, \mathrm{p}=.274)$. Separate MANOVA analyses for inner-directed $(\mathrm{F}=1.4, \mathrm{p}=.250)$ and other-directed people $(\mathrm{F}=0.6, \mathrm{p}=.600)$ also showed differences are not significant. Therefore, there is only directional support for hypothesis $1 \mathrm{~b}$ and partial directional support for $1 \mathrm{c}$. The graphic representation of mean scores is presented in Figure 5.4 to illustrate that there is convergence with the justice appeal for both inner- and other-directed people despite lower values. In addition, there is convergence with the other cognitive-based utilitarian appeal for both personality types. 


\section{Figure 5.4 Personality aNd Appeal Interaction Effects on Product EVALUATIONS}

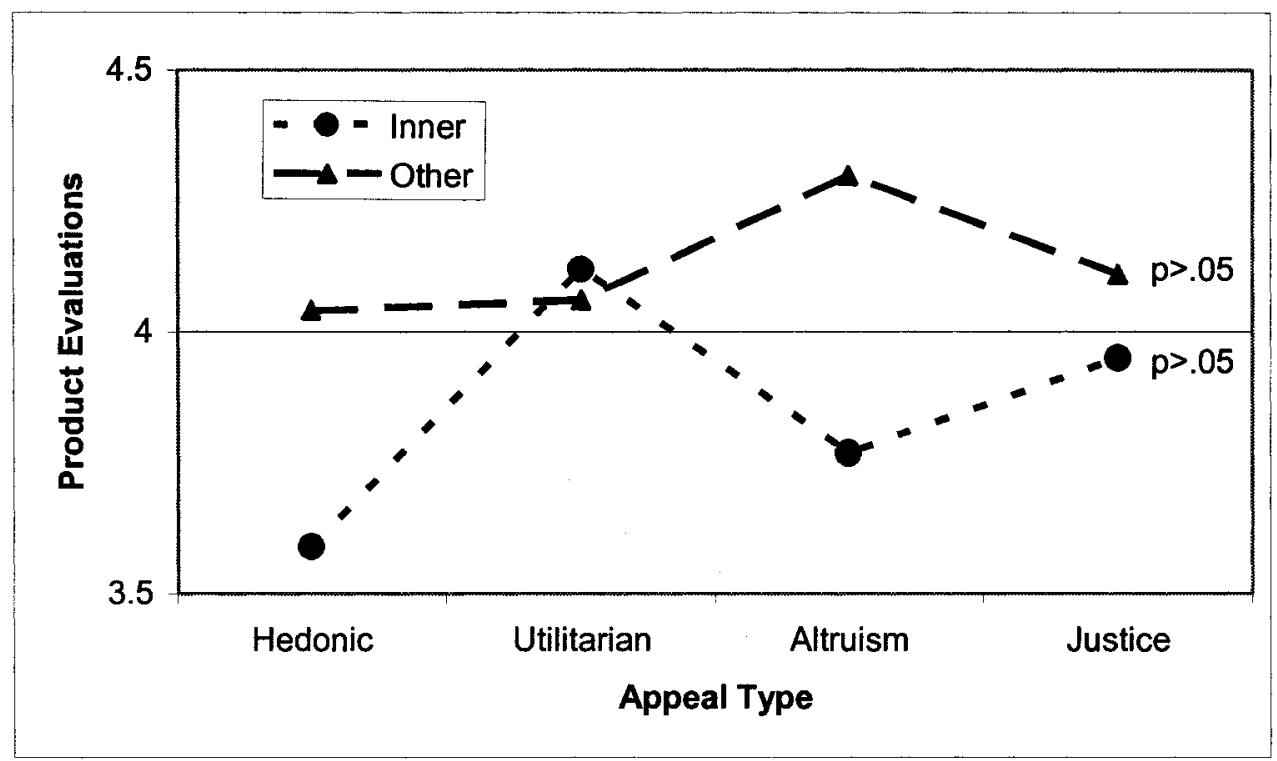

Note: dotted lines represent non-significant differences at $\mathrm{p}>.05$

For other-directed people, the hypotheses are directionally supported as the otheroriented appeals of altruism $(\overline{\mathrm{X}}=4.30)$ and justice $(\overline{\mathrm{X}}=4.11)$ achieved higher mean scores than the self-oriented appeals of hedonism $(\overline{\mathrm{X}}=4.04)$ and utility $(\overline{\mathrm{X}}=4.06)$. For those who are more inner-directed, the hypothesized relationship does not hold. The selforiented appeal of hedonism has the lowest mean product evaluation score. Instead, for inner-directed individuals, the cognition-oriented appeals of utility $(\overline{\mathrm{X}}=4.12)$ and justice $(\overline{\mathrm{X}}=3.95)$ are higher than the emotion-oriented appeals of hedonism $(\overline{\mathrm{X}}=3.59)$ and altruism $(\overline{\mathrm{X}}=3.77)$

The appeal type and the inner-other directedness personality trait significantly influence purchase intentions. The results are graphically illustrated in Figure 5.5 and 
provide support for hypothesis $1 \mathrm{~b}$ but only partial support for hypothesis 1c. Separate MANOVA analysis for inner- and other-directed people shows that appeal types effects on purchase intentions are significantly different for both inner- $(F=3.3, p=.022)$ and other-directed $(\mathrm{F}=9.8, \mathrm{p}=.000)$ individuals.

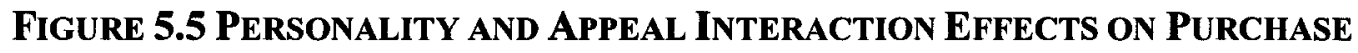 INTENTIONS}

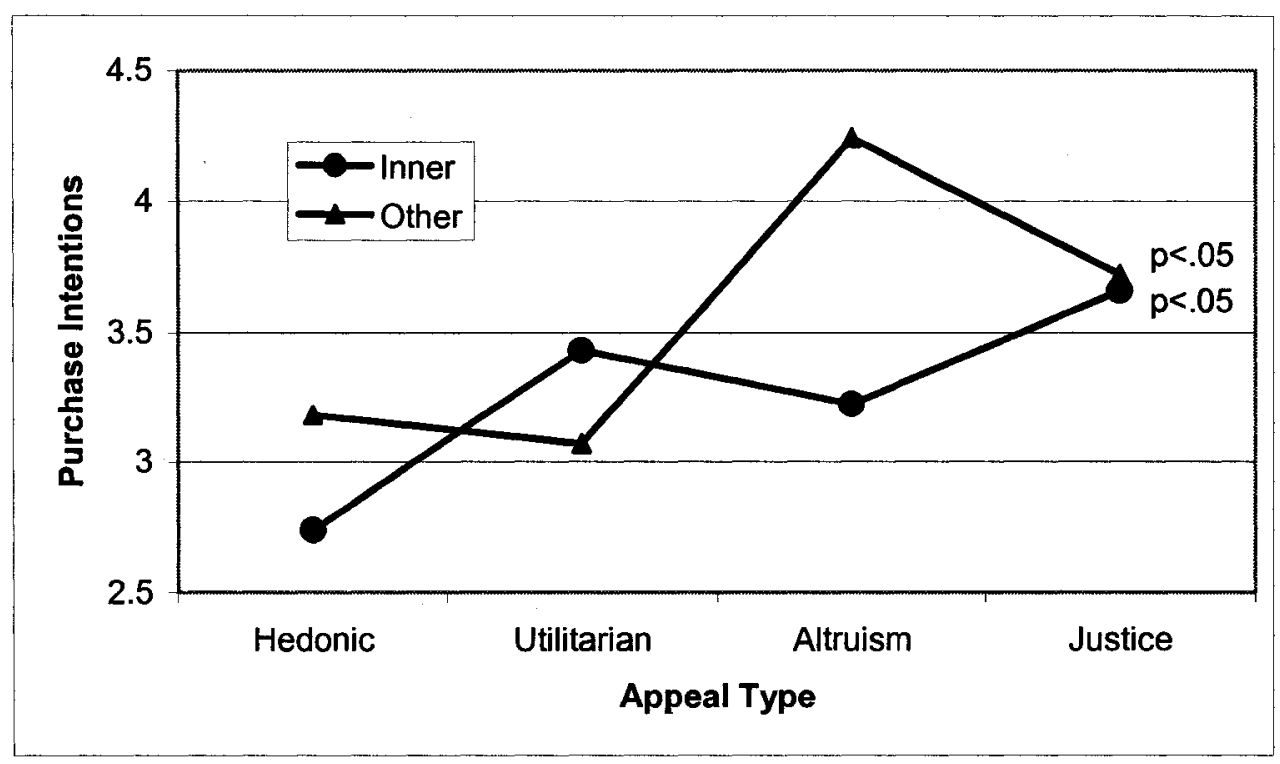

Note: Solid lines represent significant differences at $\mathrm{p}<.05$

Consistent with hypothesis $1 \mathrm{~b}$, for other-directed subjects, purchase intentions are higher with the other-oriented appeals of altruism $(\overline{\mathrm{X}}=4.24)$ and justice $(\overline{\mathrm{X}}=3.72)$ when compared to the self-oriented appeals of hedonism $(\overline{\mathrm{X}}=3.18)$ and utility $(\overline{\mathrm{X}}=3.07)$. For inner-directed subjects, the parallel relationship is not found as the self-oriented hedonic appeal leads to lower purchase intentions compared to the other appeal types. What is interesting here is that the justice appeal has broad resonance for both inner- and other- 
directed people when it comes to purchase intentions. A relationship seems to exist for inner-directed individuals where the more cognition-oriented appeals lead to higher outcomes. This is the case with purchase intentions as the cognition-oriented utility $(\overline{\mathrm{X}}=$ 3.43) and justice $(\overline{\mathrm{X}}=3.66)$ appeals receive higher purchase intention ratings than the emotion-oriented hedonic $(\overline{\mathrm{X}}=2.74)$ and altruism $(\overline{\mathrm{X}}=3.22)$ appeals.

\subsubsection{Product Effects}

The relationship of appeal type and the inner-other directedness personality trait on promotion effectiveness outcomes is tested in the context of two different products to explore its generalizability. The two products used in the study, designer jeans and athletic shoes, represented moderately complex products. Further, the designer jeans were intended to represent a more hedonic product while the athletic shoes were intended to represent a utility product. It was expected that justice appeals would be more effective than altruistic appeals in the promotion of a utility product to other-directed individuals. The results of a MANOVA analysis are presented in Table 5.8 and do not support the hypotheses $1 \mathrm{~d}-1 \mathrm{~g}$. Table 5.9 presents the mean scores for the product effects on the promotion effectiveness outcomes and the level of significance indicated from the MANOVA analysis. The table illustrates that there are no significant differences for the two products with promotion evaluation $(F=0.2, p=.675)$, product evaluation $(F=0.7$, $\mathrm{p}=.407)$, and purchase intentions $(\mathrm{F}=0.2, \mathrm{p}=.639)$. The absence of a main and interaction effects for the stimuli products suggests that the effectiveness of the promotional appeal types have a robust effect over both the hedonic and utility product types for the 
moderately complex level of products tested in this study. This table and others that follow include only those interactions that were represented in the stated hypotheses.

TABLE 5.8 MANOVA RESULTS FOR HYPOTHESES 1D-1G TESTING

\begin{tabular}{|l|c|c|r|r|}
\hline Effects & F & Hypothesis df & Error df & Sig. \\
\hline Intercept & 1553.5 & 3 & 432 & .000 \\
\hline Appeal & 4.1 & 9 & 1052 & .000 \\
\hline Inner-Other Directedness & 1.8 & 3 & 432 & .155 \\
\hline Product & 0.7 & 3 & 432 & .585 \\
\hline $\begin{array}{l}\text { Appeal x Product x Inner-Other } \\
\text { Directedness }\end{array}$ & 1.1 & 30 & 1269 & .280 \\
\hline \multicolumn{4}{|l|}{} \\
\hline Dependent Variables: & $\begin{array}{l}\text { Promotion Evaluation, } \\
\text { Product Evaluation, } \\
\text { Purchase Intentions }\end{array}$ \\
\hline
\end{tabular}

$\mathrm{N}=450$

Table 5.9 Mean SCORES for Product EfFectS

\begin{tabular}{|l|c|c|c|}
\hline \multicolumn{2}{|c|}{} & \multicolumn{2}{c|}{ Product Type } \\
\cline { 3 - 4 } \multicolumn{2}{|c|}{} & Jeans & Shoes \\
\hline Promotion Evaluation & $\mathrm{F}=0.2, \mathrm{p}=.675$, d.f. $=1$ & 3.57 & 3.62 \\
\hline Product Evaluation & $\mathrm{F}=0.7, \mathrm{p}=.407$, d.f. $=1$ & 4.05 & 3.95 \\
\hline Purchase Intentions & $\mathrm{F}=0.2, \mathrm{p}=.639$, d.f. $=1$ & 3.44 & 3.38 \\
\hline
\end{tabular}

Overall MANOVA $F=0.7$, sig. $=.585$, d.f. $=3$

\subsubsection{Summary of Hypothesis 1 Series}

Overall there are three key findings to this part of the analysis. First, the justice appeal appears to be equally effective for both inner- and other-directed individuals as evidenced by the strong ratings on the outcome measures of this appeal type. Second, there are some congruency effects found in the analysis. For instance, for other-directed individuals, other-oriented appeals resulted in better promotion evaluations and purchase 
intentions. There was good support for hypothesis 1b (appeal type to appeal effectiveness for other-directed) for two promotion effectiveness outcomes: promotion evaluation (approaching significance) and purchase intentions. There is no support for hypothesis 1c (appeal type to appeal effectiveness for inner-directed) despite significant differences in the purchase intentions across appeal types. Although there is no support for hypothesis 1c, there is evidence to suggest that people who are inner-directed respond favourably to cognition-based promotional appeals compared to emotion-based appeals. However, the congruency effects are not universal. There is no support for hypotheses $1 \mathrm{~b}$ and $1 \mathrm{c}$ for the product evaluation outcome. Since the effects of congruency are seen only for promotion evaluation and purchase intentions, it suggests that product evaluations are being bypassed by the promotion. This pattern is likely influenced by the presence of an emotional component in three of the four promotional appeal types and their resonance with respondents.

Third, while primarily a cognition-based appeal, the justice appeal also contains a strong emotional dimension. The manipulation check of the appeal treatment provides some evidence of this with no significant differences found on the ratings of emotional measures (sympathy, concern and compassion) between the altruism and justice appeals. This emotional component of justice likely contributes to the limited support for hypothesis 1a with similar main effects for justice and altruism. However, this emotional dimension, within a cognition-based promotional appeal, is likely the basis for the justice appeal resonating with both inner- and other-directed individuals while the altruism 
appeal resonates only with those who are more other-directed. In other words, the combination of emotion and cognition is more powerful than a single dimension of either.

\subsubsection{Testing of Hypothesis 2 Series - Country Image to Promotion Effectiveness}

Understanding the relationships of LDC images with the effectiveness of promotional appeals is the next objective of this research and it is represented through this set of hypotheses. The purpose of this analysis is to explore the relationship of country images and promotion effectiveness outcomes within the context of personality and product type. Figure 5.6 presents a graphical representation of a simple model of country image associations with promotion effectiveness. It was postulated that innerdirected individuals would be more concerned with country and people competencies in evaluating products while other-directed people would be more interested in country and people character. Competency beliefs were thought to be important for those who are more inner-directed because these beliefs would influence how the country's products would meet their self-oriented goals. Character beliefs were thought to be important for those who are more other-directed because these beliefs would influence the desire to help the country's people. Overall, promotion effectiveness outcomes would be more positive for other-oriented respondents with more positive country and people character beliefs. In contrast, promotion effectiveness outcomes would be more positive for innerdirected respondents with more positive country and people competency beliefs. The following analysis explores the relationships in the context of the three hypothesized country image dimensions that were also identified in the factor analysis - country and people competence, country character and people character. 


\section{Figure 5.6 HyPothesis 2 SERIES - Simple MOdeL OF COUNTRY IMAGE EFFECTS}

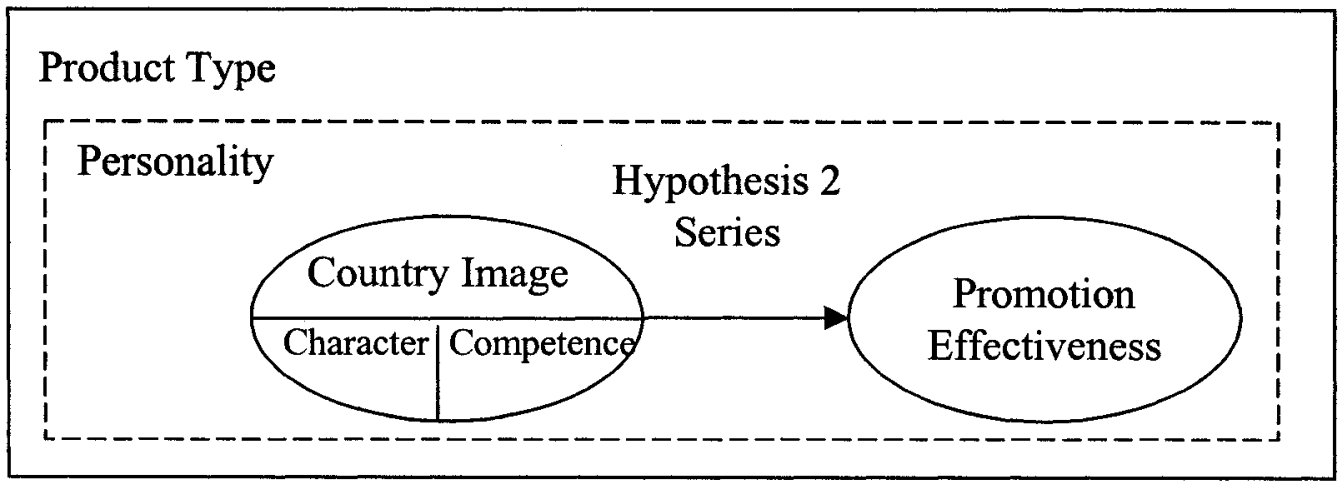

Hypothesis $2 a$ anticipates a relationship between country image and promotion effectiveness outcomes. There is support for this expectation. The MANOVA analysis utilized continuous country image dimension variables. Table 5.10 presents the main effects for the country image dimensions on promotional appeal effectiveness. The three dimensions are all significant, namely, country and people competence $(F=8.1, p=.000)$, country character $(F=7.4, p=.000)$ and people character $(F=7.3, p=.000)$.

TABle 5.10 MANOVA RESUltS FOR TESTING HyPOTHESIS 2A

\begin{tabular}{|l|c|c|c|c|}
\hline Effects & F & Hypothesis df & Error df & Sig. \\
\hline Country and People Competence & 8.1 & 3 & 703 & $\mathbf{. 0 0 0}$ \\
\hline Country Character & 7.4 & 3 & 703 & $\mathbf{. 0 0 0}$ \\
\hline People Character & 7.3 & 3 & 703 & $\mathbf{. 0 0 0}$ \\
\hline \multicolumn{5}{|l|}{} \\
\hline Dependent Variables: & $\begin{array}{l}\text { Promotion Evaluation, } \\
\text { Product Evaluation, } \\
\text { Purchase Intentions }\end{array}$ \\
\hline $\mathrm{N}=437$
\end{tabular}


The main effect for country and people competence is illustrated in Figure 5.7. The significant main effect of country and people competence on promotional appeal effectiveness outcomes is derived from significant differences with all three outcomes promotion evaluation $(\mathrm{F}=18.2, \mathrm{p}=.000)$, product evaluation $(\mathrm{F}=16.9, \mathrm{p}=.000)$ and purchase intentions $(\mathrm{F}=16.8, \mathrm{p}=.000)$.

\section{Figure 5.7 Main Effects for Country and People Competence on APPeal EFFECTIVENESS}

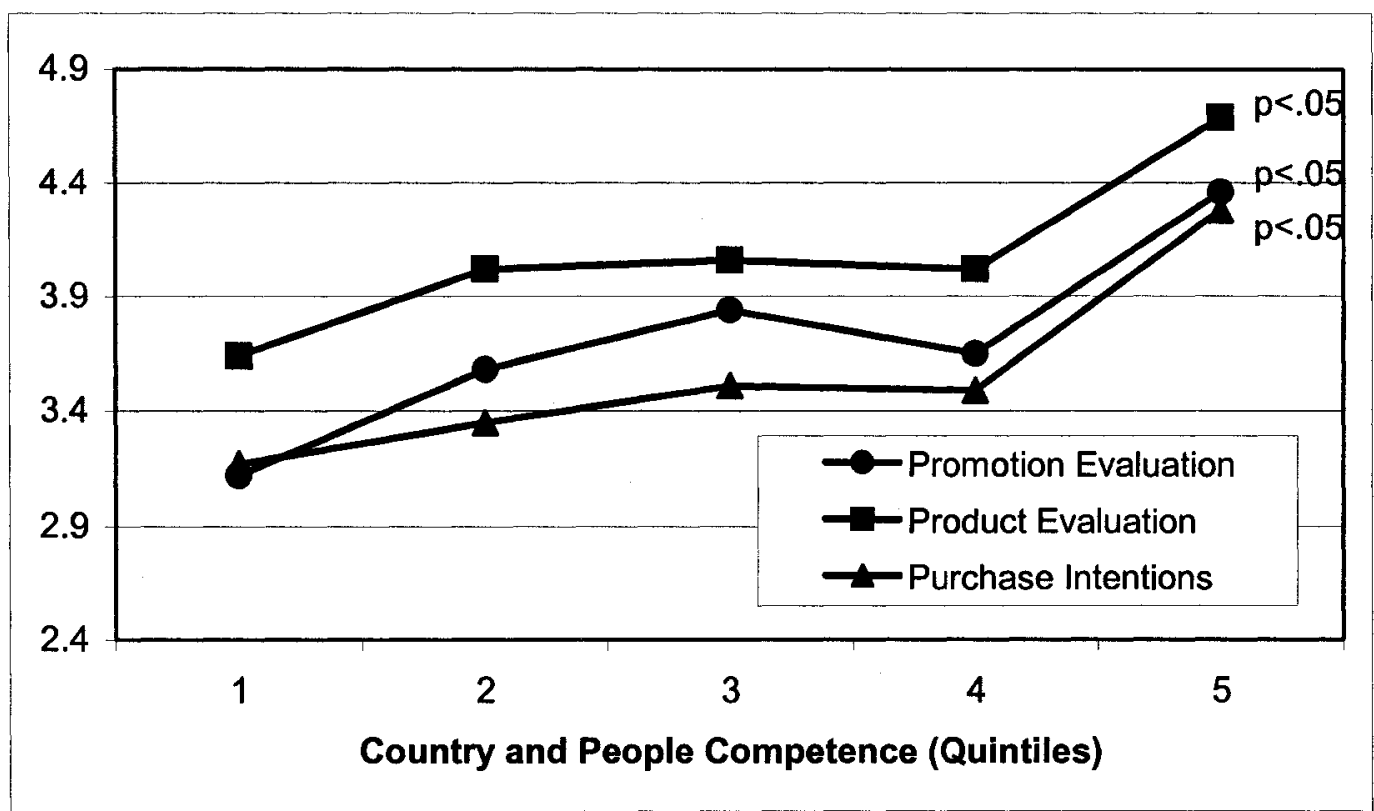

Note: Solid lines represent significant differences at $\mathrm{p}<.05$

The graph demonstrates that a positive linear relationship exists. A separate regression analysis confirms this relationship as the slopes for the three lines are all positive. The slopes are indicated through the respective beta values for promotion evaluation (.264), product evaluation (.268), and purchase intentions (.233). Therefore, country and people competence is an important dimension of country image for LDC 
promotional appeals. This main effect of the country image dimension reflects previous research that found country and people competencies influence evaluations (e.g. Heslop et al. 2004). However, Heslop et al. (2004) only dealt with product evaluations and purchase intentions and did not consider the association of country image dimensions with promotion evaluation or in the promotional appeal context.

Another main effect presented in Figure 5.8 shows perceptions of country character are related to promotional appeal effectiveness outcomes. This significant effect is derived from significant differences found with promotion evaluation $(\mathrm{F}=16.8$, $\mathrm{p}=.000)$, product evaluation $(\mathrm{F}=13.2, \mathrm{p}=.000)$ and purchase intentions $(\mathrm{F}=3.3, \mathrm{p}=0.069)$. The difference with purchase intentions is approaching a strong level of significance.

These results are similar to the main effects with country and people competence as a general positive linear relationship exists for all three outcomes. Generally, better perceptions of country character are associated with higher outcomes. A separate regression analysis confirms this relationship. The slopes are indicated through the respective beta values for promotion evaluation (.282), product evaluation (.327), and purchase intentions (.243). Note, the non-significant relationship of country character and purchase intentions has the lowest slope. Therefore, country characteristics, such as appealing culture, fascinating people and liking the country, have a positive relationship with the evaluations and intentions of purchasing a country's products. This result only partially supports Anholt's (2005) assertion that culture can influence purchases of LDC 
products in the marketplace. It is partially supported because evaluations of country are associated with product response and purchase intentions only approach significance.

\section{Figure 5.8 Main EFFects for Country Character on APPEAL EFFeCtiveness}

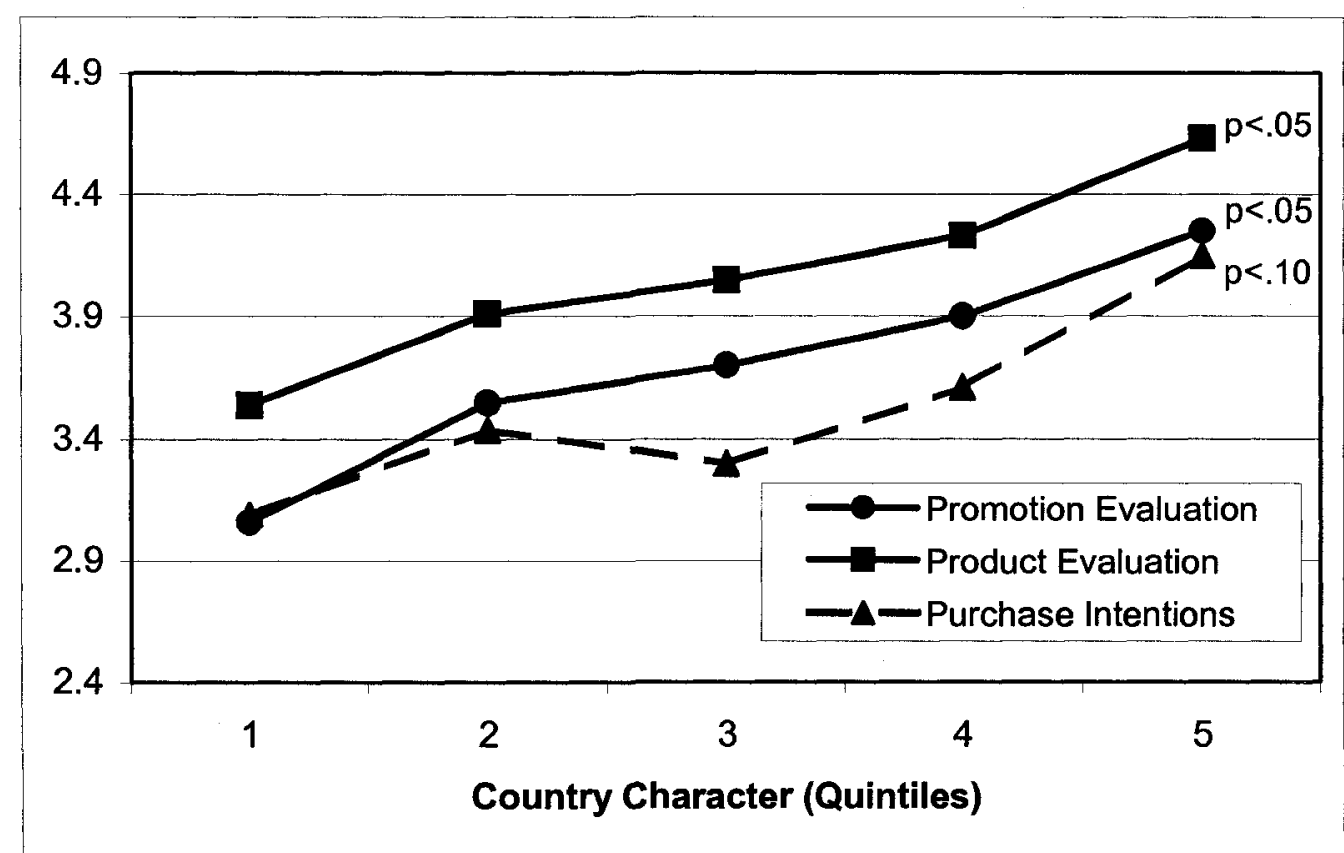

Note: Solid lines represent significant differences at $\mathrm{p}<.05$, dotted line represents non-significant differences at $\mathrm{p}>.05$

Moderate significance was found with the main effect of people character on appeal effectiveness outcomes (Figure 5.9). The significant effects are based on significant differences with product evaluation $(\mathrm{F}=16.1, \mathrm{p}=.000)$ and purchase intentions $(\mathrm{F}=13.2, \mathrm{p}=.000)$ while promotion evaluation $(\mathrm{F}=0.6, \mathrm{p}=.459)$ was not significant. The pattern of relationships for the significant appeal effectiveness outcomes is similar to the other country image dimension main effects. Here, a significant positive linear relationship is evident by the positive slope of lines in the graph. The slopes are 
indicated through the respective beta values for promotion evaluation (.161), product evaluation (.281), and purchase intentions (.228). Better perceptions of a country's people character are associated with higher promotion effectiveness outcomes. Therefore, the people characteristic dimension of country image (i.e. friendliness, trustworthiness and work ethic) is important because it is directly associated with the evaluation of a country's products and the likelihood of purchase. Although Heslop et al (2004) did not examine country images in the context of promotion effectiveness, the study did find a people character dimension can directly influence the evaluation of products and bypass product evaluations to influence purchase intentions.

\section{Figure 5.9 Main Effects for People Character on Appeal Effectiveness}

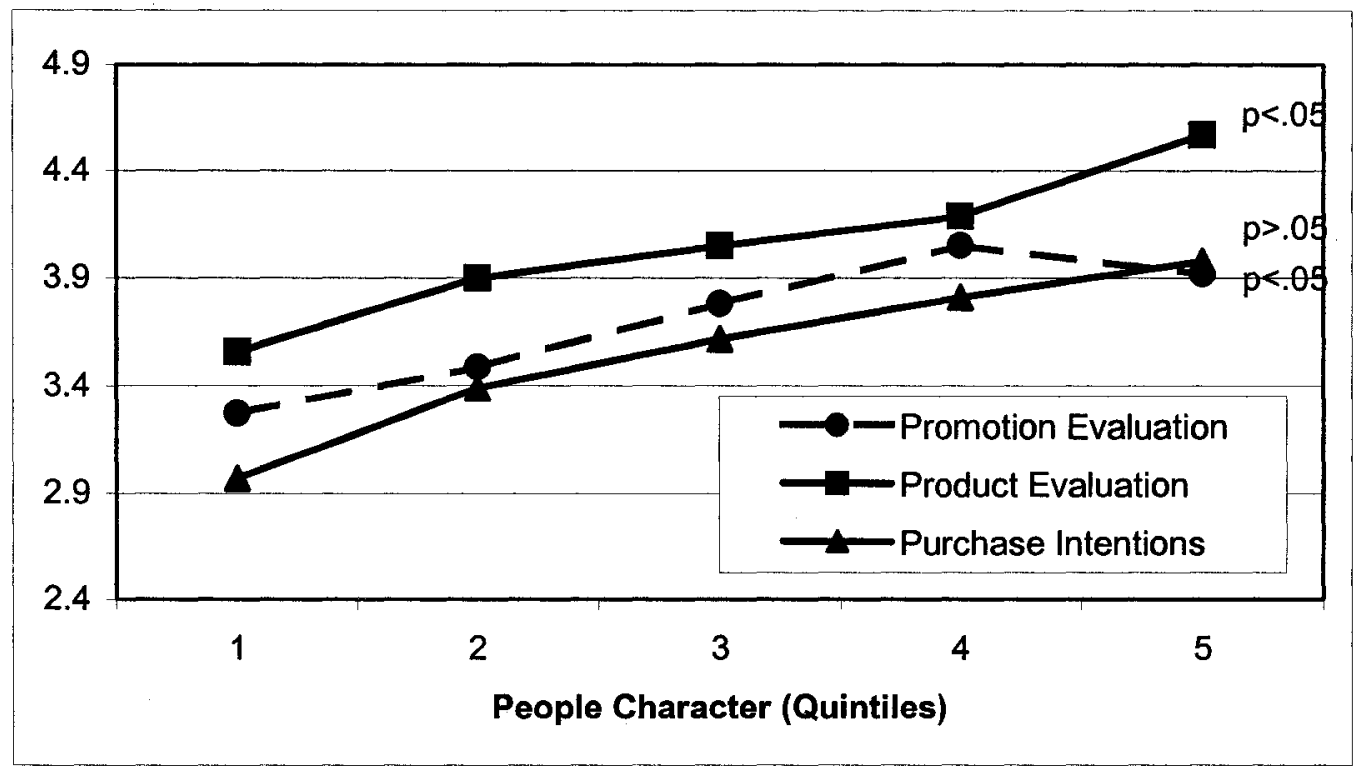

Note: Solid lines represent significant differences at $\mathbf{p}<.05$, dotted line represents non-significant differences at $\mathrm{p}>.05$ 
Overall, there is good support for hypothesis $2 \mathrm{a}$ as evidenced by significant main effects for the three country image dimensions on promotion effectiveness outcomes. While the significance is not derived from all the outcomes (promotion evaluation, product evaluation and purchase intentions) in all cases, most of the outcomes are significant indicating that country image influences promotion effectiveness.

The remainder of the analysis is done in two parts. First, the relationship of country image to promotion effectiveness is assessed in the context of personality only. Second, the country image and promotion effectiveness relationship is examined with the context of both personality and product type to determine the product effects.

\subsubsection{Personality and Country Image Effects}

A MANOVA was conducted to assess the country image and personality effects on promotion effectiveness. To accomplish this, the continuous country image dimension variables of country and people competence, country character and people character are used as covariates. The promotion effectiveness outcomes of promotion evaluation, product evaluation and purchase intentions are the dependent variables while the inner-other-directedness personality trait is a factor variable.

The results presented in Table 5.11 show three main effects and one interaction effect. Main effects are found with the inner-other directedness personality trait $(F=6.5$, $\mathrm{p}=.000)$, country and people competence $(\mathrm{F}=5.5, \mathrm{p}=.001)$, and country character $(\mathrm{F}=4.2$, $\mathrm{p}=.006$ ). In addition, the main effect of people character on promotion effectiveness 
outcomes has moderate significance $(F=2.4, p=.068)$. An interaction effect is found with the inner-other directedness personality trait and country character $(F=2.6, p=.049)$. These results indicate that the effectiveness of promotional appeals is related to the perceptions of the country as well as the inner- and other-directedness of the individual.

TABLE 5.11 MANOVA RESUltS FOR TESTING HYPOTHESES 2B-2C

\begin{tabular}{|c|c|c|c|c|}
\hline Effects & $\mathbf{F}$ & Hypothesis df & Error df & Sig. \\
\hline Inner-Other Directedness & 6.5 & 3 & 427 & .000 \\
\hline Country and People Competence & 5.5 & 3 & 427 & .001 \\
\hline Country Character & 4.2 & 3 & 427 & .006 \\
\hline People Character & 2.4 & 3 & 427 & .068 \\
\hline $\begin{array}{l}\text { Inner-Other Directedness } x \\
\text { Country and People Competence }\end{array}$ & 0.5 & 3 & 427 & .705 \\
\hline $\begin{array}{l}\text { Inner-Other Directedness } \mathrm{x} \\
\text { Country Character }\end{array}$ & 2.6 & 3 & 427 & .049 \\
\hline $\begin{array}{l}\text { Inner-Other Directedness x People } \\
\text { Character }\end{array}$ & 0.3 & 3 & 427 & .834 \\
\hline \multicolumn{5}{|c|}{$\begin{array}{ll}\text { Dependent Variables: } & \text { Promotion Evaluation, } \\
& \text { Product Evaluation, } \\
& \text { Purchase Intentions }\end{array}$} \\
\hline
\end{tabular}

The significant interaction of the inner-other directedness personality trait and perceptions of country character on promotional appeal effectiveness outcomes is presented through two graphs. Figure 5.10 illustrates the significant interaction on promotion evaluation while Figure 5.11 displays the significant interaction on product evaluation. There was no significant interaction with purchase intentions. Although the country image dimensions (i.e. country and people competence) are continuous variables, country image dimensions are presented in the following figures using quintiles to 
illustrate the significant relationships. The quintiles of the country image dimensions are used only for illustrative purposes.

First, Figure 5.10 illustrates the relationship of country character and the personality trait on promotion evaluation $(\mathrm{F}=9.2, \mathrm{p}=.026)$. The relationship appears to be variable. However, despite variability, the overall pattern of the relationship is positive as higher evaluations are associated with higher country character perceptions. Separate regression analyses for inner- and other-directed groups demonstrate the slopes of the lines are different. The beta, or slope of the line, for inner-directed individuals is steeper (beta $=.396)$ compared to other-directed people (beta=.147) indicating a more positive relationship of the country image dimension with promotion evaluations for innerdirected individuals.

Further, the observation that country character has a greater impact for innerdirected people was substantiated through separate MANOVA analyses for inner- and other-directed people on the aggregated promotion effectiveness outcomes. The results showed that inner-directed people had significantly different views of country character $(\mathrm{F}=11.4, \mathrm{p}=.001)$ while the other-directed individuals had no significant difference in their country character beliefs $(\mathrm{F}=0.1, \mathrm{p}=.779)$. 
FIGURE 5.10 INTERACTION EFFECTS FOR INNER-OTHER DIRECTEDNESS AND COUNTRY Character on Promotion Evaluation

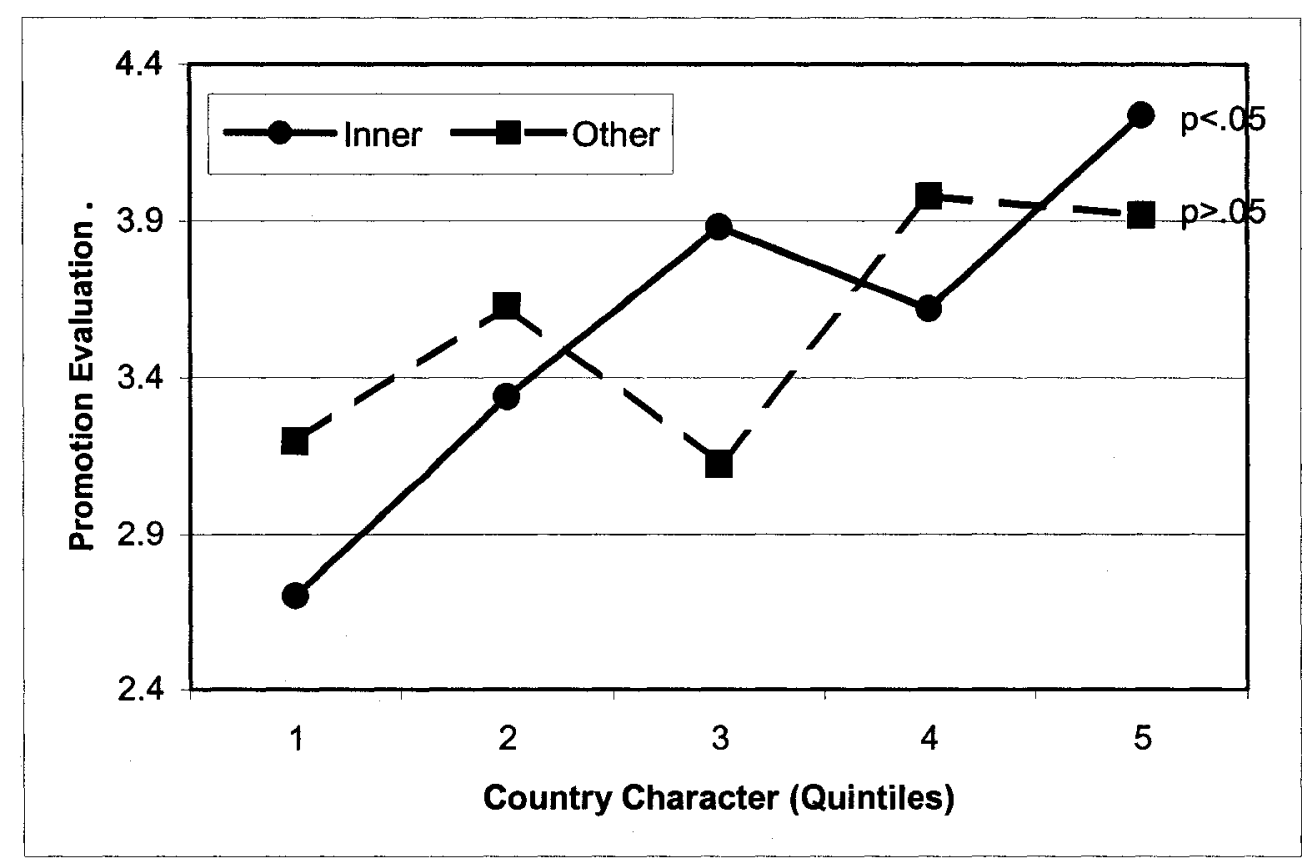

Note: Solid line represents significant differences at $\mathbf{p}<.05$, dotted line represents non-significant differences at $\mathrm{p}>.05$

Second, the interaction of inner-other directedness personality trait and country character on promotional appeal effectiveness is derived from a significant relationship with product evaluation $(\mathrm{F}=6.4, \mathrm{p}=.012)$. This relationship is presented in Figure 5.11. The pattern of the product evaluation lines is similar to the pattern found with promotion evaluation. The lines illustrate a more positive relationship of the country image dimension with product evaluations for those who are inner-directed. Separate regression analysis on inner- and other-directed groups confirms this as the slope of the line for inner-directed individuals is steeper (beta $=.522)$ compared to the line for other-directed individuals (beta $=.197)$. 
To substantiate the observation that country character has a greater influence for inner-directed individuals on product evaluation compared to the effects for otherdirected individuals, separate MANOVA analyses were conducted for inner- and otherdirected people. The results indicate that the slopes of the two lines of best fit are different. For inner-directed individuals, country character has a significantly different effect on product evaluations $(\mathrm{F}=16.5, \mathrm{p}=.000)$. Conversely, for other-directed people, the country character dimension is not related to differences of product evaluations $(\mathrm{F}=0.4$, $\mathrm{p}=.543)$

\section{FIGURE 5.11 INTERACTION EFFECTS FOR INNER-OTHER DIRECTEDNESS AND COUNTRY Character on Product Evaluation}

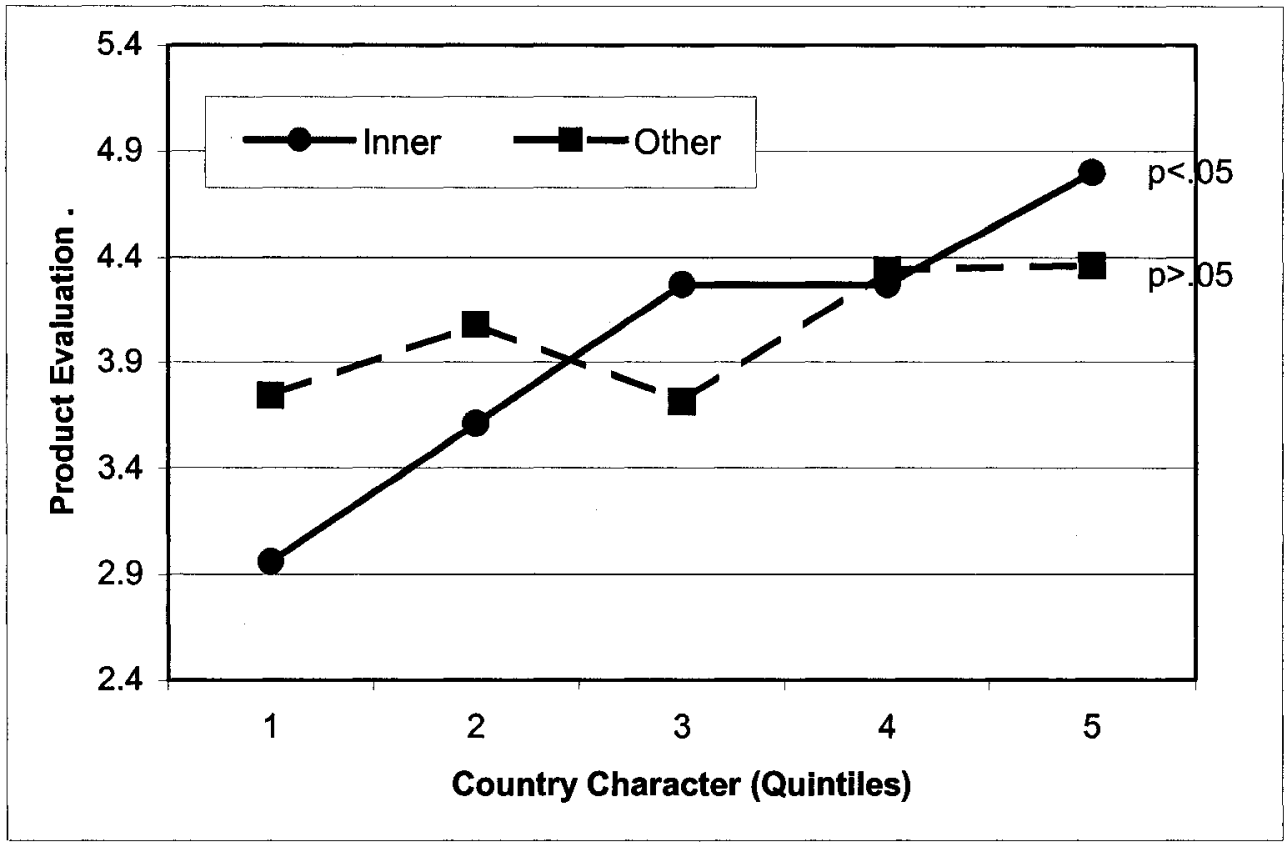

Note: Solid line represents significant differences at $\mathrm{p}<.05$, dotted line represents non-significant differences at $\mathrm{p}>.05$ 
It is worth noting that the inner-other directedness personality trait also has a main effect on outcomes. This main effect is derived from significant differences with promotion evaluation $(\mathrm{F}=5.8, \mathrm{p}=.017)$ and product evaluation $(\mathrm{F}=16.3, \mathrm{p}=.000)$. The effects are not significant for purchase intentions $(F=2.0, p=158)$. For other-directed individuals, promotion evaluations are higher $(\overline{\mathrm{X}}=3.66)$ when compared to those that are more inner-directed $(\overline{\mathrm{X}}=3.45)$. Product evaluations are higher for people who are more other-directed $(\overline{\mathrm{X}}=4.12)$ than those who are more inner-directed $(\overline{\mathrm{X}}=3.87)$. While not significant, the direction of purchase intentions for inner-other directedness is the same with other-directed people $(\overline{\mathrm{X}}=3.50)$ higher than for inner-directed individuals $(\overline{\mathrm{X}}=$ 3.28). Purchase intentions are lowest of the outcomes for all individuals.

\subsubsection{Product Effects}

The relationship of the country image dimensions and the inner-other directedness personality trait on promotional appeal effectiveness is tested under a two product treatment. It was expected that promotional effectiveness outcomes would be higher when country and people competence beliefs are higher for inner-directed with a utilitarian product. Similarly, promotion effectiveness outcomes would be higher when country and people character beliefs are higher for other-directed individuals with a hedonic product. The results of a MANOVA are presented in Table 5.12 and do not support the hypotheses $2 \mathrm{~d}-2 \mathrm{~g}$. There are no main or interaction effects for product type. 
TABLE 5.12 MANOVA RESUlTS FOR TESTING HYPOTHESES 2D-2G

\begin{tabular}{|c|c|c|c|c|}
\hline Effects & $\mathbf{F}$ & Hypothesis df & Error df & Sig. \\
\hline Inner-Other Directedness & 6.7 & 3 & 420 & .000 \\
\hline Product & 0.5 & 3 & 420 & .658 \\
\hline Country and People Competence & 5.4 & 3 & 420 & .001 \\
\hline Country Character & 3.9 & 3 & 420 & .009 \\
\hline People Character & 2.2 & 3 & 420 & .088 \\
\hline $\begin{array}{l}\text { Product } \mathrm{x} \text { Inner-Other Directedness } \mathrm{x} \\
\text { Country and People Competence }\end{array}$ & 0.9 & 9 & 1022 & .514 \\
\hline $\begin{array}{l}\text { Product } \mathrm{x} \text { Inner-Other Directedness } \mathrm{x} \\
\text { Country Character }\end{array}$ & 1.3 & 9 & 1022 & .257 \\
\hline $\begin{array}{l}\text { Product } x \text { Inner-Other Directedness } x \\
\text { People Character }\end{array}$ & 0.3 & 9 & 1022 & .961 \\
\hline $\begin{array}{l}\text { Promotion Evalu } \\
\text { Product Evaluat } \\
\text { Purchase Intenti }\end{array}$ & & & & \\
\hline
\end{tabular}

$\mathrm{N}=437$

\subsubsection{Summary of Hypothesis 2 Series}

Hypothesis 2 series examined the relationship of country image to promotional appeal effectiveness within the context of personality and product type. There is good support for hypothesis $2 \mathrm{a}$ (main effects of country image on appeal effectiveness) as the three country image dimensions are found to have main effects on promotion effectiveness outcomes. There is no support for Hypothesis $2 b$ (appeal effectiveness and competency beliefs) as the interaction effects were not significant. There is also no support for Hypothesis 2c (appeal effectiveness and character beliefs). Despite the significant interaction effects for country character, the direction of effects was not as expected. Similar to the previous hypothesis testing, there was no significant product type effects. Based on the significant results, there are two key findings overall. 
First, a key finding is that country images have a direct relationship with promotional appeal effectiveness. Country and people competence and country character have main effects on the promotion effectiveness outcomes. For country and people competence, more positive views of the country image dimension are associated with higher promotion evaluations, product evaluations and purchase intentions. For country character, more positive perceptions of the dimension are related to better promotion and product evaluations. While the people character country image dimension was only moderately significant, more positive views of this dimension are associated with product evaluations and purchase intentions but not promotion evaluations.

Second, the inner-other directedness personality trait interacted with the country character image dimension on promotion effectiveness. The main result from the analysis is that country character has a significant influence for inner-directed people but not other-directed individuals. For inner-directed people, more positive views of the country's character are related to better promotion and product evaluations. There was only some evidence found to support's Anholt's (2005) assertion that culture can influence purchases of LDC products. Purchase intentions were found to be not significant in the interaction effect but were found to be approaching significance.

\subsubsection{Testing Hypothesis 3 Series - Appeal Type to Country Image}

Hypothesis 3 series represents a continuation of the exploration into the relationship that country image has with promotional appeal types. The objective of this hypothesis series is to examine the influence that appeal types have on the country image 
dimensions (country and people competence, country character and people character) within the context of the inner-other directedness personality trait and the product types (designer jeans and athletic shoes). Figure 5.12 is a graphical representation of this relationship.

FiguRE 5.12 APPEAL EFFECTS ON COUNTY IMAGE

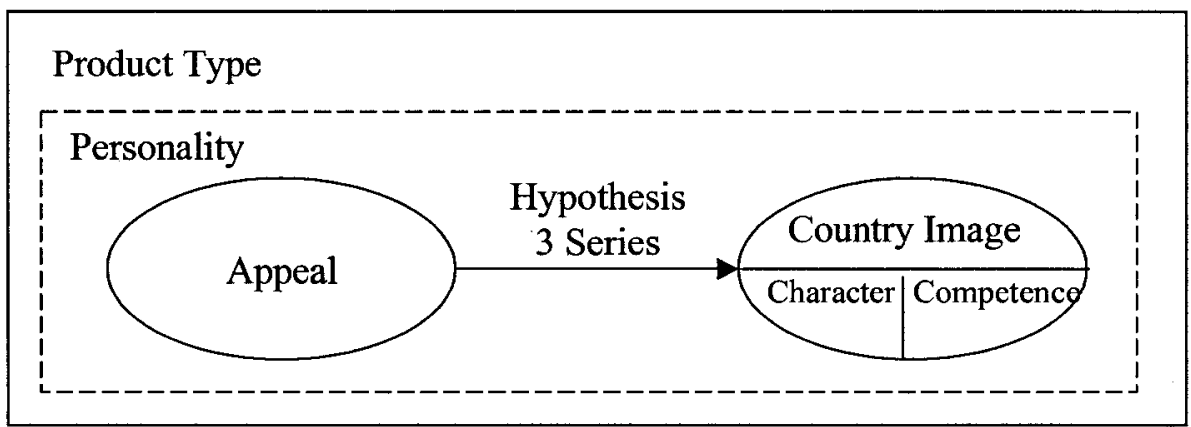

Hypothesis 3a represents the expectation that a main effect relationship exists between appeal type and country image. A MANOVA analysis, as indicated in Table 5.13, demonstrates that main effects exist for the appeal type for the dependent variables of the three country image dimensions of country and people competence, country character, and people character $(\mathrm{F}=11.2, \mathrm{p}=.000)$. Therefore, the promotional appeal type has an influence on how a country is perceived. In particular, there is a significant difference among the appeal types for the mean scores of country and people competence $(\mathrm{F}=23.3, \mathrm{p}=.000)$ and country character $(\mathrm{F}=6.8, \mathrm{p}=.000)$ but not for people character $(\mathrm{F}=1.9, \mathrm{p}=.135)$. 
TABle 5.13 MANOVA RESUlts fOR TESTING HyPOTHESIS 3A

\begin{tabular}{|l|c|c|c|c|}
\hline Effects & F & Hypothesis df & Error df & Sig. \\
\hline Appeal & 11.2 & 9 & 1740 & $\mathbf{. 0 0 0}$ \\
\hline \multicolumn{5}{|l|}{} \\
\hline Dependent Variables: & $\begin{array}{l}\text { Country and People Competence, } \\
\text { Country Character, } \\
\text { People Character }\end{array}$ \\
\hline $\mathrm{N}=437$ &
\end{tabular}

The mean scores for the significant main effect of appeal are presented in Table 5.14. Figure 5.13 provides a graphical representation of the influence of appeal type on country image dimensions. While the people character ratings are highest compared to the other dimensions, there are no significant differences among the mean scores for the different appeal types. The significant differences presented in the graph highlights two key findings. First, the other-oriented appeals of altruism $(\overline{\mathrm{X}}=2.42)$ and justice $(\overline{\mathrm{X}}=$ 2.80) resulted in lower mean scores compared to the self-oriented appeals of hedonic $(\bar{X}$ $=3.10)$ and utility $(\bar{X}=3.19)$ for country and people competence. Second, the cognitionbased appeals (utility and justice) achieve higher scores compared to the emotion-based appeals (hedonic and altruism) for country and people competence. These observations are significantly different for altruism and utility appeals using the Tukey post hoc analysis but the difference between the justice and hedonic appeal is not significant. Therefore, the other-oriented justice appeal results in better country and people competence perceptions than the altruistic appeal. 
TABLE 5.14 Mean SCORES FOR the APPEAl MAIN EFfects

\begin{tabular}{|l|l|c|c|c|c|}
\hline \multicolumn{2}{|c|}{} & \multicolumn{4}{c|}{ Appeal Type } \\
\cline { 3 - 6 } & Hedonic & Utility & Altruism & Justice \\
\hline Country and People & $\begin{array}{l}\mathrm{F}=23.3, \\
\text { sig.=.000, } \\
\text { Competence }\end{array}$ & $3.10^{\mathrm{a}}$ & $3.19^{\mathrm{a}}$ & $2.42^{\mathrm{b}}$ & $2.80^{\mathrm{a}}$ \\
\hline Country Character & $\begin{array}{l}\mathrm{F}=6.8, \\
\text { sig.=.000, } \\
\text { d.f.=3 }\end{array}$ & $4.39^{\mathrm{a}}$ & $4.23^{\mathrm{a}}$ & $3.94^{\mathrm{b}}$ & $4.09^{\mathrm{a}}$ \\
\hline People Character & $\begin{array}{l}\mathrm{F}=1.9, \\
\text { sig.=.135, } \\
\text { d.f.=3 }\end{array}$ & $4.47^{\mathrm{a}}$ & $4.60^{\mathrm{a}}$ & $4.61^{\mathrm{a}}$ & $4.49^{\mathrm{a}}$ \\
\hline
\end{tabular}

Overall MANOVA $\mathrm{F}=11.2$, sig. $=.000$, d.f. $=9$

For country character, the observation may be made where altruism $(\overline{\mathrm{X}}=3.94)$ and justice $(\bar{X}=4.09)$ mean scores are lower than those of hedonic $(\bar{X}=4.39)$ and utility $(\overline{\mathrm{X}}=4.23)$. However, the Tukey post hoc analysis shows that only altruism and hedonic appeals are associated with significantly different country character beliefs. Despite the limited differences in country character perceptions over the appeal type, there is overall significance for two country image dimensions and specific significant differences were found in the perceptions of country and people competence for key appeal types (i.e. justice versus altruism). Therefore, there is partial support for hypothesis $3 \mathrm{a}$.

The examination of the remaining hypotheses in the series is done in two parts. First, the relationship of appeal type to country image is assessed in the context of personality. In the personality context, it was expected that country image perceptions would be better when there is a match between appeal type and personality. Therefore, country image perceptions would be higher when other-oriented appeals are presented to 
other-directed individuals or when self-oriented appeals are presented to inner-directed people. Second, the relationship of appeal type to country image is investigated with the personality and product type context. In the product context, a match between appeal type, personality and product was expected to be related to better country image beliefs. For example, inner-directed individuals would have high country image perceptions when presented with a utilitarian appeal for a utilitarian product.

\section{Figure 5.13 MAIN EFFECTS FOR APPEAL TYPE TO COUNTRY IMAGE Dimensions}

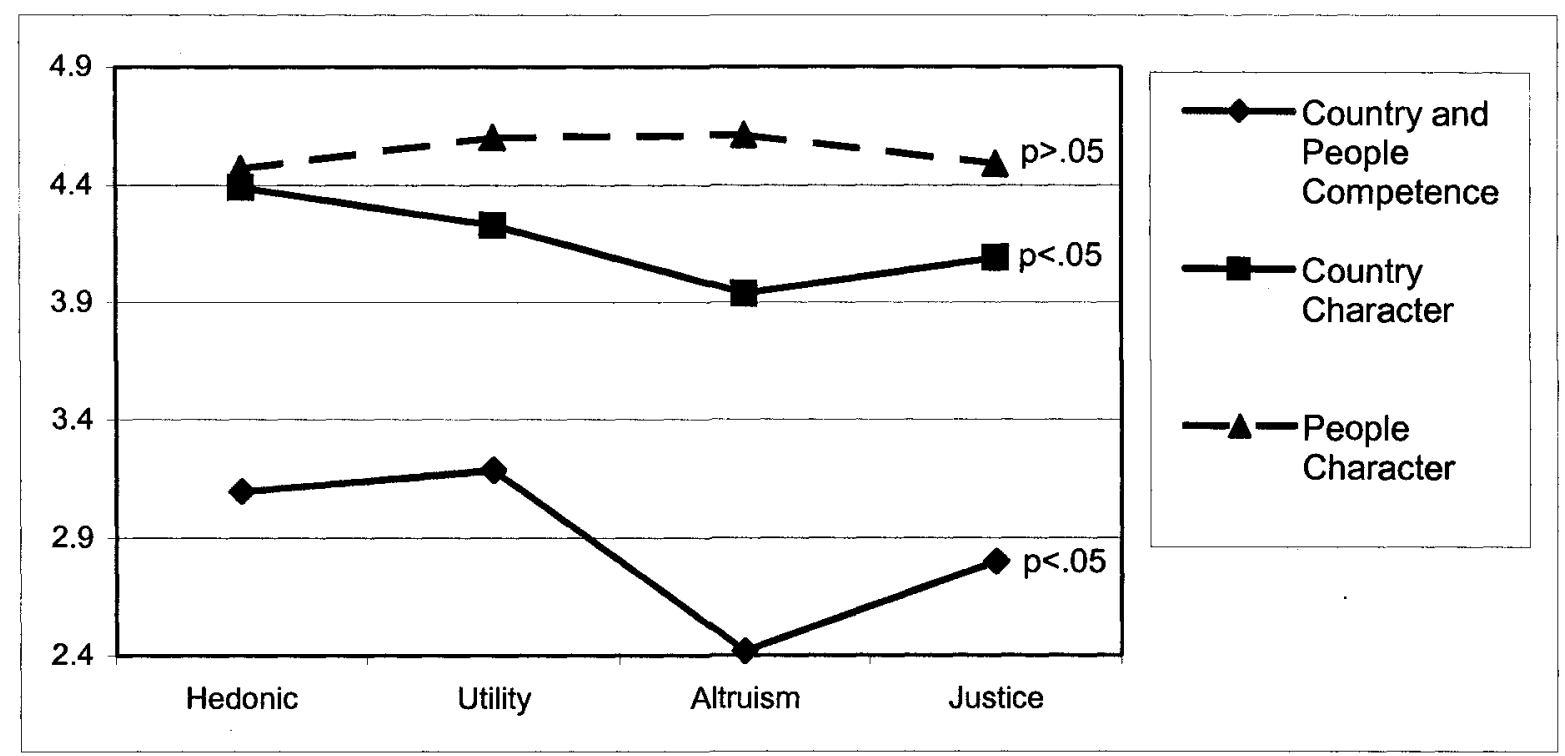

Note: Solid lines represent significant differences at $p<.05$, dotted line represents non-significant differences at $\mathrm{p}>.05$

\subsubsection{Appeal and Personality Effects}

Hypotheses $3 b$ and $3 c$ represent the relationship of appeal type to country image dimensions in the context of the inner-other directedness personality trait. A MANOVA was conducted to assess the influence of personality on the relationship. The results are 
presented in Table 5.15. While the main effects of appeal type on country image remain, there are no main or interaction effects of the personality trait on the relationship. Therefore, there is no support for hypotheses $3 b$ and $3 c$.

TABLe 5.15 MANOVA Results fOR HyPOTHESES 3B-3C TeSTING

\begin{tabular}{|l|c|c|c|c|}
\hline Effects & F & Hypothesis df & Error df & Sig. \\
\hline Appeal & 5.7 & 9 & 1056 & $\mathbf{. 0 0 0}$ \\
\hline Inner-Other Directedness & 0.8 & 3 & 434 & .523 \\
\hline Appeal x Inner-Other Directedness & 1.0 & 9 & 1056 & .482 \\
\hline \multicolumn{4}{|l}{} \\
\hline $\begin{array}{l}\text { Dependent Variables: } \\
\text { Country and People Competence, } \\
\text { Country Character, } \\
\text { People Character }\end{array}$ \\
\hline
\end{tabular}

\subsubsection{Product Effects}

To assess the generalizability of the research, the relationship of appeal type and personality to country image dimensions is investigated with the context of the two different products (designer jeans and athletic shoes). It was postulated that a match between appeal type, personality and product would result in better country image beliefs. A MANOVA analysis was conducted and the results are presented in Table 5.16.

Although there is no main product effect on the relationship of appeal type to country image, there is a significant interaction effect $(F=1.5, p=.041)$. This significant interaction is based on significant differences in perceptions of country character $(F=2.7$, $p=.001$ ) while there is no significant differences with country and people competence 
$(\mathrm{F}=0.7, \mathrm{p}=.763)$ and people character $(\mathrm{F}=1.3, \mathrm{p}=.244)$. Table 5.17 presents the mean scores for the significant interaction for the country character dimension.

TABLE 5.16 MANOVA RESULTS FOR HYPOTHESES 3D-3G TESTING

\begin{tabular}{|l|c|c|c|c|}
\hline Effects & F & Hypothesis df & Error df & Sig. \\
\hline Appeal & 5.8 & 9 & 1037 & $\mathbf{. 0 0 0}$ \\
\hline Inner-Other Directedness & 1.0 & 3 & 426 & .408 \\
\hline Product & 1.0 & 3 & 426 & .410 \\
\hline $\begin{array}{l}\text { Product x Appeal x Inner-Other } \\
\text { Directedness }\end{array}$ & 1.5 & 30 & 1251 & $\mathbf{. 0 4 1}$ \\
\hline \multicolumn{3}{|l|}{} & & \\
\hline Dependent Variables: & $\begin{array}{l}\text { Country and People Competence, } \\
\text { Country Character, } \\
\text { People Character }\end{array}$ \\
\hline
\end{tabular}

Table 5.17 Mean SCORes for the Interaction of APPEal, Personality and Product On COUNTRy Character

\begin{tabular}{|l|c|c|c|c|c|c|c|c|}
\hline & \multicolumn{8}{|c|}{ Appeal Type } \\
\cline { 2 - 9 } & \multicolumn{2}{|c|}{ Hedonic } & \multicolumn{2}{|c|}{ Utility } & \multicolumn{2}{c|}{ Altruism } & \multicolumn{2}{c|}{ Justice } \\
\hline (Inner-Other) & $\mathrm{I}$ & $\mathrm{O}$ & $\mathrm{I}$ & $\mathrm{O}$ & $\mathrm{I}$ & $\mathrm{O}$ & $\mathrm{I}$ & $\mathrm{O}$ \\
\hline Designer Jeans & 4.10 & 4.22 & 4.34 & 4.13 & 3.62 & 3.88 & 4.68 & 4.21 \\
\hline Athletic Shoes & 4.65 & 4.64 & 4.38 & 4.09 & 4.16 & 4.10 & 3.68 & 3.89 \\
\hline
\end{tabular}

Overall MANOVA $F=1.5$, sig. $=.041$, d.f. $=30$

Figure 5.14 provides the illustration of the interaction through two graphs. The top graph presents the country character beliefs means score for designer jeans for both inner- and other-directed individuals across appeal type. The bottom graph presents similar information for athletic shoes. Two additional MANOVA tests that isolate the inner- and other-directed people indicate that the mean scores are significantly different for inner-directed individuals $(\mathrm{F}=6.5, \mathrm{p}=.000)$ but not for other-directed people $(\mathrm{F}=1.8$, 
$\mathrm{p}=.145$ ). Therefore, the lack of significant differences in country character beliefs for other-directed people suggests that there is no support for hypotheses $3 \mathrm{~d}$ and $3 \mathrm{e}$.

\section{Figure 5.14 Interaction Effects for Appeal, Personality and Product on COUNTRY CHARACTER}
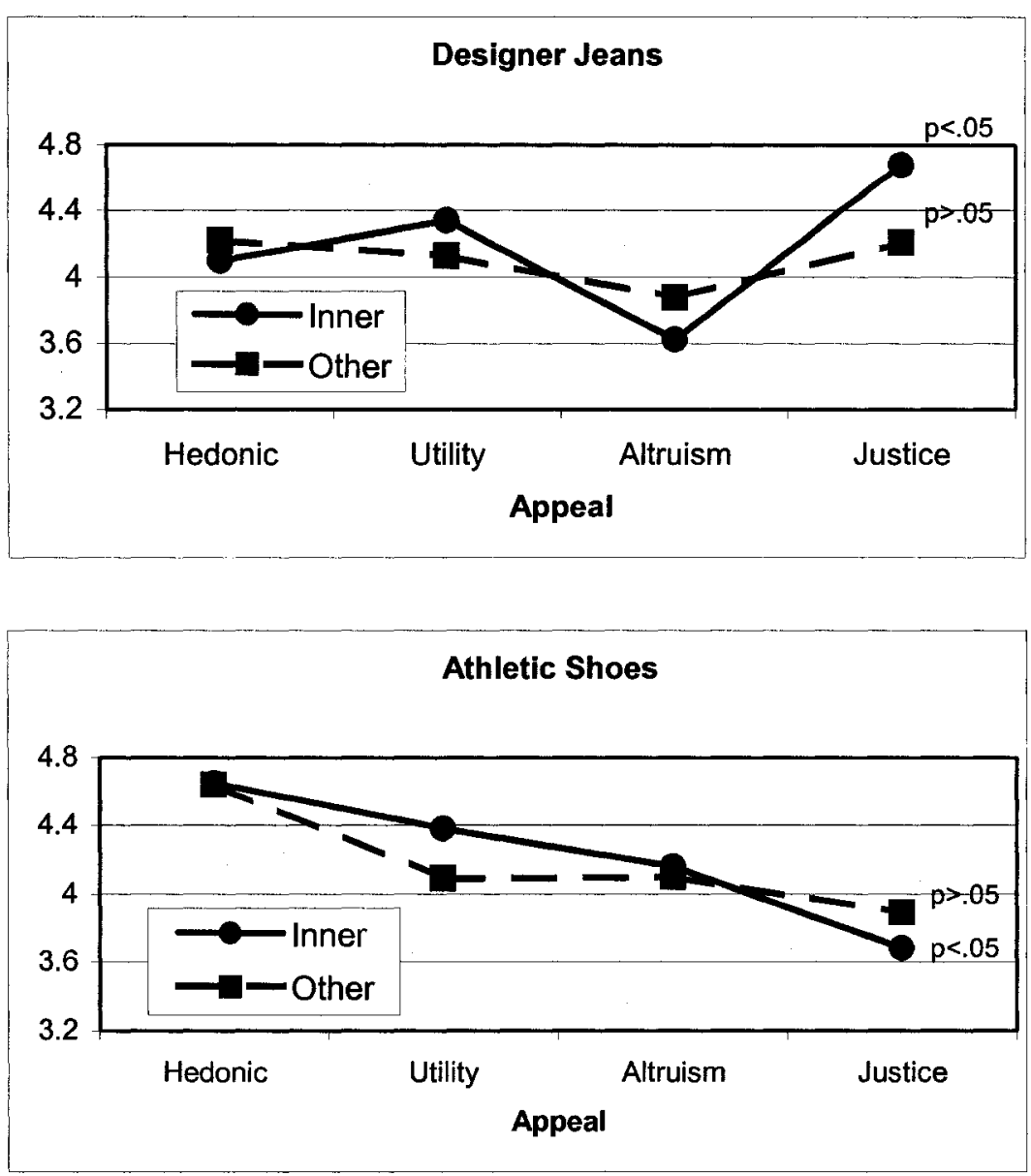

Note: Solid lines represent significant differences at $p<.05$, dotted lines represent non-significant differences at $\mathrm{p}>.05$

Hypotheses $3 \mathrm{f}$ and $3 \mathrm{~g}$ suggested that a match between product and appeal types (i.e. utility product and utilitarian appeal) would be associated with better country image perceptions for inner-directed individuals. There is no support for this expectation. 
Indeed, the opposite seems to occur. For inner-directed people, the utility appeal $(\overline{\mathrm{X}}$ $=4.34)$ has higher country character beliefs compared to the hedonic appeal $(\overrightarrow{\mathrm{X}}=4.10)$ for the hedonic product (designer jeans). Similarly, for inner-directed individuals, the hedonic appeal $(\overline{\mathrm{X}}=4.65)$ has higher country character perceptions compared to the utilitarian appeal $(\overline{\mathrm{X}}=4.38)$ for the utility product (athletic shoes).

A key observation between the two graphs highlights the difference between mean scores of the justice appeal for designer jeans $(\overline{\mathrm{X}}=4.68)$ and athletic shoes $(\overline{\mathrm{X}}=$ 3.68). In other words, the hedonic product has the higher country character mean score than the utility product. There seems to be a congruency effect here as the more emotionbased product fits with the other-oriented justice appeal for inner-directed people. This likely occurred because the cognition-based justice appeal also has an emotional component that seems to resonate with the hedonic product type.

\subsubsection{Summary of Hypothesis 3 Series}

There are three key points to highlight from the results of the hypothesis 3 series testing. First, there is support for hypothesis 3a (main effects of appeal on country image) that a relationship exists between appeal type and country images as evidenced by significant main effects. However, the results provide only partial support as appeal types significantly influence two of three country image dimensions, namely, country and people competence and country character. In addition, country image perceptions differ for key appeal types for only country and people competence. 
Second, the results do not provide support for hypotheses 3b (appeal and country image for other-directed) and $3 c$ (appeal and country image for inner-directed). There was no significant interaction of the inner-other directedness personality trait with appeal type on the country image dimensions.

Third, the results show that there are some product effects on country image through an interaction with appeal type and personality. The analysis showed that the interaction was significant for country character perceptions. Further analysis revealed that this interaction is only significant for inner-directed individuals. The lack of significance for the interaction for other-directed people provides no support for the product context hypotheses of $3 \mathrm{~d}$ and $3 \mathrm{e}$. Further, the direction of inner-directed results does not support the product context hypotheses of $3 f$ and $3 g$. However, the results do indicate that the justice appeal is associated with higher country character perceptions for the hedonic product compared to the utility product for inner-directed people.

\subsubsection{Testing Hypothesis 4 - Country Image as an Intervening Variable}

The previous hypotheses have established a set of two-way relationships (appeal to promotion effectiveness; appeal to country image and country image to promotion effectiveness). The objective of hypothesis 4 is to test the path of relationship of appeal type, country image and promotion effectiveness in a holistic manner within the context of personality and product type. The goal is to assess the possible mediating role of country image in the effect of appeal type on promotion effectiveness. Figure 5.15 presents an illustration of the relationship. The figure shows appeal type as the 
independent variable that has an indirect relationship with promotion effectiveness as the dependent variable with country image as the intervening variable. The relationship is situated within the context of personality and product type.

Figure 5.15 Chain MOdel of APPEAL EfFects

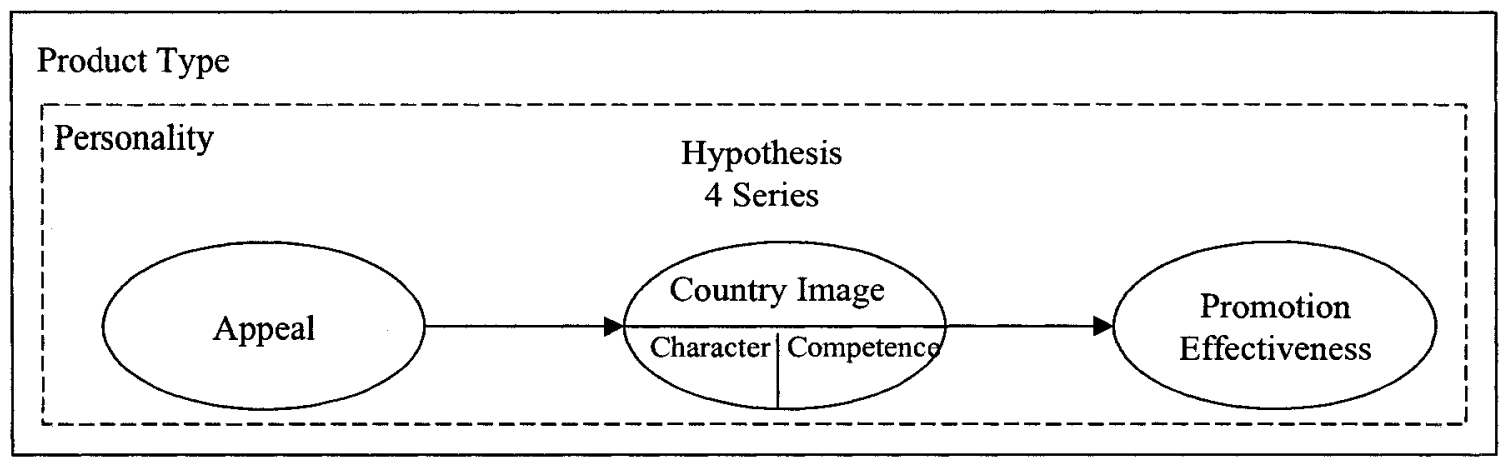

The chain model was tested using a MANOVA analysis that had promotion effectiveness measures (promotion evaluation, product evaluation, and purchase intentions) as the dependent variables. Additionally, appeal type, product type and innerother directedness personality trait were used as factors while the country image dimensions were covariates. The results of a MANOVA analysis of the relationship are presented in Table 5.18. This analysis reveals that main effects of inner-other directedness $(\mathrm{F}=6.8, \mathrm{p}=.000)$, country and people competence $(\mathrm{F}=9.0, \mathrm{p}=.000)$, and country character $(\mathrm{F}=4.2, \mathrm{p}=.006)$. Previous hypotheses testing already found these relationships. The most noteworthy finding is that the appeal effect is no longer significant $(\mathrm{F}=1.6, \mathrm{p}=.107)$. In previous hypotheses testing, the appeal main effect is always present. The results of testing the chain model seem to suggest that country 
image mediates the relationship between appeal type and promotional appeal effectiveness.

\section{TABle 5.18 MANOVA RESUltS FOR APPEAL TYPE AND COUNTRY IMAGE Dimensions to Promotional APPEAL EfFECTIVENESS}

\begin{tabular}{|c|c|c|c|c|}
\hline Effects & $\mathbf{F}$ & Hypothesis df & Error df & Sig. \\
\hline Appeal & 1.6 & 9 & 927 & .107 \\
\hline Inner-Other Directedness & 6.8 & 3 & 381 & .000 \\
\hline Product & 1.1 & 3 & 381 & .339 \\
\hline Country and People Competence & 9.0 & 3 & 381 & .000 \\
\hline Country Character & 4.2 & 3 & 381 & .006 \\
\hline People Character & 0.6 & 3 & 381 & .618 \\
\hline $\begin{array}{l}\text { Appeal x Inner-Other Directedness } \mathrm{x} \\
\text { Product } \mathrm{x} \text { Country and People } \\
\text { Competence }\end{array}$ & 1.1 & 45 & 1133 & .303 \\
\hline $\begin{array}{l}\text { Appeal x Inner-Other Directedness X } \\
\text { Product x Country Character }\end{array}$ & 1.2 & 45 & 1133 & .134 \\
\hline $\begin{array}{l}\text { Appeal x Inner-Other Directedness } \mathrm{x} \\
\text { Product } \times \text { People Character }\end{array}$ & 1.1 & 45 & 1133 & .283 \\
\hline $\begin{array}{l}\text { Promotion E } \\
\text { Product Eval } \\
\text { Purchase Inte }\end{array}$ & \multicolumn{4}{|c|}{$\begin{array}{l}\text { Promotion Evaluation, } \\
\text { Product Evaluation, } \\
\text { Purchase Intentions }\end{array}$} \\
\hline
\end{tabular}

Although previous analysis determined a direct effect of appeal type to promotion effectiveness and appeal type to country image along with a relationship between country image and promotion effectiveness, this model demonstrates that country image performs a mediating role in the relationship of appeal type to promotion effectiveness. Further, the mediating role of country image is concentrated within two dimensions, namely, country and people competence and country character. 


\subsubsection{Discussion of Results}

In summary, this dissertation examined the relationships of appeal type, country images and promotional appeal effectiveness within the context of the inner-other directedness personality trait and product type. The analysis points to some key findings that can be highlighted through a review of the descriptive results and hypotheses testing results.

The descriptive analysis revealed that some differences exist in the country images of the two stimulus countries. The images of Colombia and Honduras are seen to be distinct based on a few key variables. By comparing the two countries, Colombia is viewed as wealthier and respondents believe they know more about the country while Honduras is perceived as having people that are more friendly, more trustworthy, have a stronger work ethic and are in more urgent need of assistance. Consumers do hold differentiated images of different LDCs.

The analysis of the hypotheses provides several key findings. Table 5.19 provides a summary of the hypotheses testing results for the three promotion effectiveness outcomes. Despite the lack of support for some hypotheses, important new findings have emerged from the analysis. 
TABLE 5.19 Summary OF HyPOTHESES Testing Results

\begin{tabular}{|c|c|c|c|c|}
\hline & \multicolumn{3}{|c|}{ Dependent Variables } \\
\hline & & $\begin{array}{l}\text { Promotion } \\
\text { Evaluation }\end{array}$ & \begin{tabular}{c|c} 
Product \\
Evaluation
\end{tabular} & $\begin{array}{c}\text { Purchase } \\
\text { Intentions }\end{array}$ \\
\hline \multirow[t]{4}{*}{1} & $\begin{array}{l}\text { a - Overall appeal } \\
\text { effectiveness differences }\end{array}$ & (sever & $\begin{array}{l}\text { Partial support } \\
\text { appeals viewed s }\end{array}$ & nilarly) \\
\hline & $\begin{array}{l}\mathrm{b}-\text { Appeal and personality } \\
\text { match on appeal effectiveness } \\
\text { for other-directed }\end{array}$ & Supported & No support & Supported \\
\hline & $\begin{array}{l}\text { c - Appeal and personality } \\
\text { match on appeal effectiveness } \\
\text { for inner-directed }\end{array}$ & \multicolumn{3}{|c|}{ No support } \\
\hline & $\begin{array}{l}\text { d-g-Product effects on } \\
\text { appeal to appeal effectiveness }\end{array}$ & \multicolumn{3}{|c|}{ No support } \\
\hline \multirow[t]{4}{*}{2} & $\begin{array}{l}\text { a-Overall country image on } \\
\text { appeal effectiveness }\end{array}$ & $\begin{array}{c}\text { Partial Support } \\
\text { ( } 2 \text { of } 3 \\
\text { dimensions) }\end{array}$ & Supported & $\begin{array}{c}\text { Partial Support } \\
\text { ( } 2 \text { of } 3 \\
\text { dimensions) }\end{array}$ \\
\hline & $\begin{array}{l}\mathrm{b}-\text { Personality and country } \\
\text { image on appeal effectiveness } \\
\text { competencies }\end{array}$ & \multicolumn{3}{|c|}{ No support } \\
\hline & $\begin{array}{l}\text { c - Personality and country } \\
\text { image on appeal effectiveness } \\
\text { for character }\end{array}$ & \multicolumn{3}{|c|}{ No support } \\
\hline & $\begin{array}{l}\mathrm{d}-\mathrm{g} \text { - Product effects on } \\
\text { country image to appeal } \\
\text { effectiveness }\end{array}$ & \multicolumn{3}{|c|}{ No support } \\
\hline & & $\begin{array}{l}\text { Country and } \\
\text { People } \\
\text { Competence }\end{array}$ & $\begin{array}{l}\text { Country } \\
\text { Character }\end{array}$ & $\begin{array}{c}\text { People } \\
\text { Character }\end{array}$ \\
\hline \multirow[t]{4}{*}{3} & $\begin{array}{l}\text { a - Overall appeal on country } \\
\text { image }\end{array}$ & Supported & $\begin{array}{l}\text { Partial support } \\
\text { (limited } \\
\text { differences) }\end{array}$ & No support \\
\hline & $\begin{array}{l}\mathrm{b}-\text { Appeal and personality } \\
\text { match on country image for } \\
\text { other-directed }\end{array}$ & \multicolumn{3}{|c|}{ No support } \\
\hline & $\begin{array}{l}\text { c - Appeal and personality } \\
\text { match on country image for } \\
\text { inner-directed }\end{array}$ & \multicolumn{3}{|c|}{ No support } \\
\hline & $\begin{array}{l}\mathrm{d}-\mathrm{g}-\text { Product effects on } \\
\text { appeal to country image }\end{array}$ & \multicolumn{3}{|c|}{ No support } \\
\hline & & $\begin{array}{l}\text { Promotion } \\
\text { Evaluation } \\
\end{array}$ & $\begin{array}{c}\text { Product } \\
\text { Evaluation } \\
\end{array}$ & $\begin{array}{l}\text { Purchase } \\
\text { Intentions }\end{array}$ \\
\hline 4 & $\begin{array}{l}\text { Country image as an } \\
\text { intervening variable }\end{array}$ & \multicolumn{3}{|c|}{ Supported } \\
\hline
\end{tabular}


Hypothesis 1a examined the relationship of appeal type to promotion effectiveness. This hypothesis was designed to be a foundation for the study of appeal effect and a base for hypotheses testing of personality and product interaction by demonstrating whether differences in the promotion effectiveness outcomes (i.e. promotion evaluation, product evaluation and purchase intentions) exist across appeal type (i.e. hedonic, utilitarian, altruism, justice). The analysis provides partial support for this expectation. While there were several differences found among the appeal types, there were also several measurement items that were viewed as similar for the four different appeal types. In particular, the promotion effectiveness measures for altruism and justice were not significantly different in all but one case. However, these results do not account for respondent variation based on the inner-other directedness personality trait and the two stimulus products. Therefore, it was expected that further differentiation was likely with the context of personality and product type.

Hypothesis 1 series also placed the relationship between appeal type and promotion effectiveness within the context of personality and product type. For hypothesis $1 \mathrm{~b}$, the expectation was that promotion effectiveness outcomes would be higher for other-directed individuals when presented with an other-oriented appeal (altruism and justice) compared to a self-oriented appeal (hedonic and utilitarian). The significant interaction of appeal type with personality on promotion effectiveness suggests that trait theory is helpful in explaining the phenomenon by demonstrating where differences exist relative to personality type. Promotion effectiveness for two 
measures (promotion evaluation and purchase intentions) was higher for other-directed individuals presented with other-oriented appeals. The effect of appeal type on promotion evaluation and purchase intentions combined with the absence of an effect on product evaluations for other-directed people suggests that the stage that is normally expected to provide a link between promotion and product response is being bypassed. This result is similar to previous findings by Higie Coulter and Pinto (1995) who found affective-based guilt appeals influenced purchase intentions through ad-evoked anger.

For hypothesis $1 \mathrm{c}$, the expectation was that promotion effectiveness outcomes would be higher for inner-directed people when presented with a self-oriented appeal compared to an other-oriented appeal. The results do not support this hypothesis despite significantly different responses for purchase intentions. This result runs counter to previous personality and promotion research that demonstrated that matches between personality trait and appeal type can influence promotional preferences (Moon 2002) or purchase intentions (LaBarbera, Weingard and Yorkston 1998). However, there seems to be an alternative congruency effect at work here. For inner-directed individuals, purchase intentions are higher when there is a cognition-based promotional appeal (utilitarian and justice) rather than an emotion-based appeal (hedonic and altruism). While promotion and product evaluations were not significantly different across appeal types for inner-directed respondents, the cognition-based appeals were more effective for purchase intentions with inner-directed respondents. 
For hypothesis $1 \mathrm{~d}-1 \mathrm{~g}$, the expectation was that promotion effectiveness would depend upon appeal type, personality, and product type (designer jeans and athletic shoes). It was thought that the hedonic product (designer jeans) would be associated with higher promotion effectiveness outcomes for the emotion-based appeals (hedonic for inner-directed and altruistic for other-directed individuals). Similarly, it was expected that the utility product (athletic shoes) would have higher promotion effectiveness outcomes for the cognition-based appeals (utilitarian for inner-directed and justice for other-directed people). However, there was no support for hypotheses 1d-1g in the results. This suggests that the effects on promotion effectiveness are more invariant across product types than expected within the moderate range of product complexity.

Hypothesis 2 series testing investigated the relationship of country image to promotion effectiveness situated in the context of inner-other directedness personality trait and product type. First, Hypothesis 2a examined the main association of country image and promotion effectiveness. The results demonstrated support for the relationship with product evaluation but partial support for promotion evaluation and purchase intentions. Although there was overall significance for the three country image dimensions on promotion effectiveness outcomes, the significant differences in promotion evaluation and purchase intentions were associated with only two of three country image dimensions. Country and people competence was found to be significantly related to all three outcomes while country character and people character had an association with two outcomes. Although Heslop et al. (2004) in their study of developing country images did not explore country image influence in the context of 
promotional appeals, in the study here, country and people competencies were related to product and promotion evaluations. Country character was found to be directly related to promotion evaluation and product evaluation implying that purchase intentions are indirectly related through these. Additionally, people character was found to be directly associated with product evaluation and purchase intentions. These findings reflect previous country image research that demonstrated country and people beliefs are related to purchase intentions through product evaluations or by bypassing this evaluation (Heslop et al. 2004).

Hypothesis $2 b$ explored the country image dimensions (country and people competence, country character, people character) and promotion effectiveness with innerdirected people. For inner-directed individuals, it was expected that promotion effectiveness outcomes would be higher when perceptions of country and people competencies are higher. There was no support for this hypothesis in the analysis as there was no significant interaction effect. While there was a positive association of country and people competence on promotion effectiveness for promotion evaluation, product evaluation and purchase intentions, the association did not depend upon the inner-other directedness personality trait. This result is contrary to what was expected based on previous research (Moon 2002; LaBarbera, Weingard and Yorkston 1998).

Hypothesis $2 \mathrm{c}$ investigated the relationship between country image dimensions and promotion effectiveness for other-directed individuals. For other-directed people, it was expected that promotion effectiveness outcomes would be higher when perceptions 
of country and people character are higher. Although the interaction effect of country character on promotion effectiveness with the context of personality was significant, the relationships were not in the anticipated direction. Therefore, there was no support for hypothesis $2 c$. The positive relationship exists between country character and promotion effectiveness for those who are inner-directed rather than other-directed. This provides some support for Anholt's (2005) assertion that culture can play an important role in the purchase of products from LDCs. Those who are more inner-directed may see that they can derive some value from products made in an appealing culture or by fascinating people. However, for other-directed people, their responses were not related to their evaluations of people's character.

The interaction effect of people character with personality on promotion effectiveness was not significant. The moderately significant direct association of people character on promotion effectiveness occurs for product evaluation and purchase intentions but not promotion evaluations. Personality type was not related to the association of country's people character with consumers' product evaluation and purchase intentions. Therefore, hypothesis $2 \mathrm{c}$ is not supported. Again, despite some significant findings relating personality to consumer behaviour (e.g. Moon 2002; LaBarbera, Weingard and Yorkston 1998), Kassarjian and Sheffet (1991) point out that many studies find weak associations with personality traits.

Hypotheses $2 \mathrm{~d}-2 \mathrm{~g}$ examined the relationship between country image dimensions and promotion effectiveness in the context of personality and product. It was expected 
that appeal effectiveness outcomes would be higher with a utilitarian product and when country competencies are perceived to be high. Similarly, it was postulated that promotion effectiveness would be higher with a hedonic product when country or people character is perceived to be high. There were no direct or indirect product effects found in this study. Therefore, the significant relationships are considered robust across product types.

Hypothesis 3 series was designed to investigate the relationship of appeal type to country image within the context of the inner-other directedness personality trait and the two product types. Specifically, hypothesis 3a explored a main effect for appeal type on the country image ratings. The results showed that appeal types influenced country image on two of the three dimensions, namely, country and people competence and country character. Country and people competence beliefs were lowest when an altruism appeal is used. Similarly, country character perceptions were also lowest when the otheroriented altruism appeal is used. This was present despite finding that the inner-other directedness personality trait and its interaction with appeal type was not significant. This finding suggests that trait theory is not helping to describe differences in country image perceptions. Perhaps, Murray's view of personality is apt to describe the role personality plays in influencing country images. Murray's approach of personality is concerned with the underlying needs that drive a person. Therefore, the resonance of the appeal to underlying needs may be the cause for the appeal type's main effects. 
Hypothesis $3 \mathrm{~b}$ explored the relationship of appeal type to the country image dimensions for other-directed individuals. It was expected that country image perceptions would be higher for other-directed people when there was a match with other-oriented appeals (altruism and justice). The results did not support the hypothesis. There was no significant interaction.

Hypothesis $3 \mathrm{c}$ explored the relationship of appeal type to country image dimensions with inner-directed people. It was expected that country image perceptions would be higher for inner-directed individuals when there was a match with inneroriented appeals (hedonism and utilitarian). The results did not support hypothesis $3 \mathrm{c}$.

Hypothesis $3 \mathrm{~d}$ was intended to explore the relationship of appeal type to country image in the context of personality and product. The expectation was that a match between appeal and product types would be associated with higher country image perceptions for inner- and other-directed individuals. While the interaction was significant, the hypothesis was not supported. However, the justice appeal was associated with significantly higher perceptions of country character for designer jeans than for athletic shoes. The hedonic product type matches with emotional component of cognition-based justice appeal for inner-directed individuals.

The findings articulated in hypotheses 1,2 and 3 series provided guidance to determine the nature of relationships among appeal type, country image, appeal effectiveness, personality and product type. The results from that testing also provide 
insight into the form of these relationships. The analysis from testing hypotheses 1 and 3 series provides substantiation that a model of appeal effects with two associations may exist as a bifurcated model presented in Figure 5.16. Hypothesis 1 testing showed a relationship exists between appeal type and promotion effectiveness within the context of personality. Additionally, hypothesis 3 series showed that a relationship exists between appeal type and country image but not in the personality or product context. The main effects found in the analysis of both hypotheses series shows that appeal types may simultaneously influence promotion effectiveness outcomes and country image. These results enable the bifurcated model but do not prove that it is the correct explanation. However, testing hypotheses 2 series revealed that country images can also influence promotion effectiveness. Therefore, two alternative model forms can explain these relationships - a bifurcated model and a chain model. The chain model was developed as an alternative that views the relationships of appeal types, country image and promotion effectiveness in a holistic manner.

Hypothesis 4 represents the alternative chain model that is presented in Figure 5.17. The expectation of the hypothesis was that country image as an intervening variable on the relationship between appeal type and promotion effectiveness. The results of testing support the hypothesis. Country image acts as a mediator in the relationship as the main effect of appeal type is no longer significant on promotion effectiveness when all three components (appeal type, country image and promotion effectiveness) are present i.e., the effect of appeal type on promotion effectiveness is fully mediated by country image. Therefore, it is not enough to consider the influence of 
appeal type in isolation as in the simple model of appeal effects. Nor is it enough to think of country image as a separate dependent variable in its relationship with appeal type as in the bifurcated model. The image of the country plays an important role in determining the effectiveness of promotional appeals. In addition, two of three country image dimensions seem to play an important role in this relationship, namely, country and people competence and country character.

Figure 5.16 BifurCATEd MOdel OF APPEAL EFFECTS

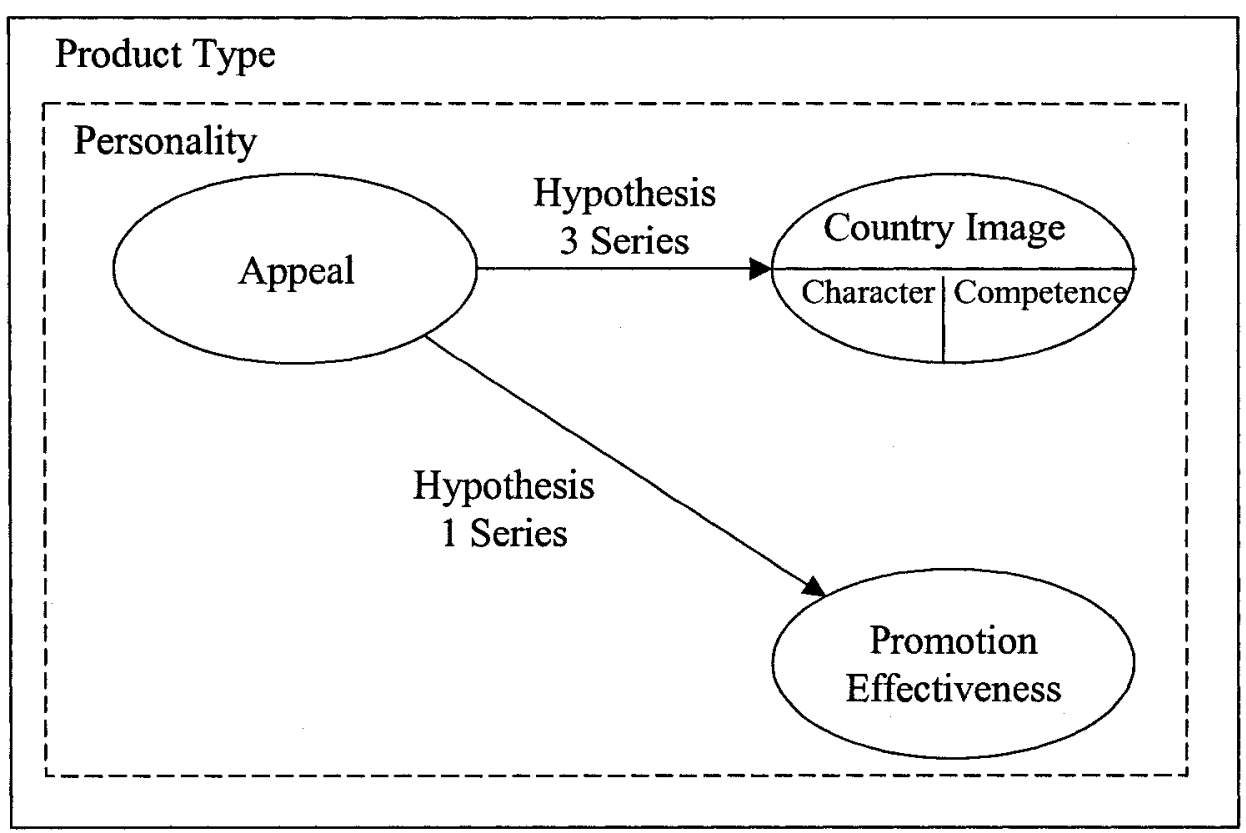

Country and people competencies refer to the abilities of the country and its people to manufacture products or provide services. Previous research demonstrated that beliefs about the competencies of a country and its people influence consumer behaviour by affecting the evaluation of products (Heslop et al. 2004). In this research, perceptions about country and people competencies significantly influence the three promotion 
effectiveness outcomes, namely, promotion evaluation, product evaluation and purchase intentions.

\section{Figure 5.17 Final Chain Model of Appeal Effects}

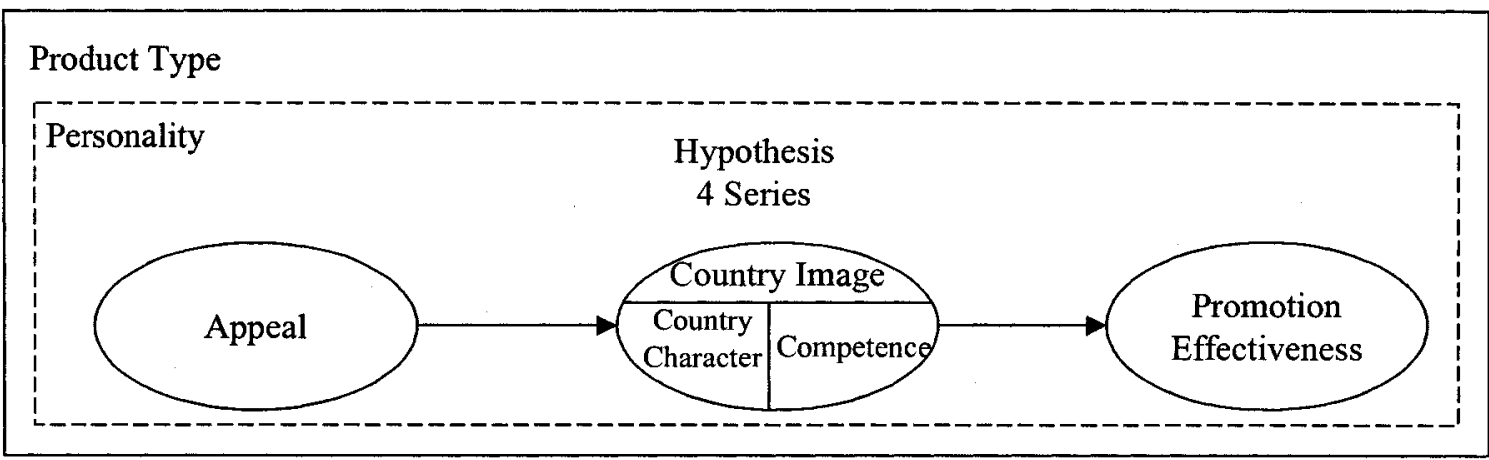

Anholt (2005) argues that other-oriented appeals diminish consumers' perceptions of the LDC products. Country and people competencies seem to act as a mechanism for affecting views of the product. The findings from testing hypothesis 3 series provide evidence to support Anholt's view as altruism results in the lowest country and people competence beliefs. This is in contrast to the higher beliefs associated with the selforiented appeals of hedonism and utilitarianism. However, the competence perceptions associated with the justice appeal are viewed as equal to the self-oriented appeals. Therefore, justice is an effective appeal and does not lead to lower country and people competence beliefs.

Similarly, country character also seems to function as a mechanism for decreasing promotion effectiveness outcomes. However, this relationship offers a weaker explanation. While testing of hypothesis 3 series demonstrated a similar interaction of 
country character and country and people competence with appeal type, only altruism had significantly differential effects. In this study, country character includes perceptions about the country's culture and fascinating people. It is interesting to note that the otheroriented altruism appeal is associated with the lowest country character perceptions. Anholt (2005) suggests that culture can play an important role in positioning products from LDCs. However, cultural aspects of country image do not seem to be as effective for altruism appeals as they are for self-oriented (hedonic and utilitarian) and justice appeals.

Overall, the justice appeal seems to be an effective other-oriented appeal. When the simple appeal effects model were assessed, the justice appeal resulted in strong purchase intentions for both inner- and other-directed individuals. Justice is better for inner-directed individuals but the same as altruism for other-directed individuals. When the relationship of appeal type to country image was examined, the justice appeal resulted in similar country image dimension ratings as the self-oriented appeals. The broad resonance of the justice appeal is likely because it is a more balanced appeal. The manipulation check provides some evidence to suggest that the justice appeal is cognition-based but with an emotional component. This is consistent with the view that cognitions and emotions can interact to explain behaviour (Rosenhan et al. 1981; Eisenberg 1986). Schoefer and Ennew (2005) found that a cognitive process used to assess justice may be followed by an emotional reaction. Further, emotional responses can differ for different appeal types and depending upon how people view the world (Mowen, Harris and Bone 2004). 


\section{CONCLUSIONS}

The dissertation results provide benefits to three primary constituency groups. These benefits are discussed in the following sections pertaining to academics, practitioners, and policy makers.

\subsection{Benefits for Academics}

The purpose of this research is to explore the effectiveness of a justice appeal relative to three conventional categories of promotional appeal types. A second objective was to assess the relevance of country image dimensions to the promotion effectiveness outcomes. To this end, this research presents two key findings for the effectiveness of promotional appeal types plus additional discoveries when the context of country image is considered.

One key finding was that the justice promotion can have broad appeal especially when compared against the alternative other-oriented promotion, altruism. Altruism asks and expects people to help others even when the action would conflict with personal goals (Lepkowska-White, Brashear and Weinberger 2003). This approach only resonates with other-directed individuals and is associated with a weaker country image. Those who are more inner-directed cannot relate to an altruistic appeal. However, the justice appeal is effective for both inner- and other-directed individuals indicating that virtuous consumption may be a broad trend (Harris 2005). Those who are other-directed can relate to the justice appeal on the basis of helping others while those who are more inner- 
directed relate to the appeal because they can help others as well as helping themselves. Inner-directed people may recognize the value of justice appeals that by their nature, benefit everyone, including, themselves. Everyone desires a fair return for fair work. Inner-directed people can "buy into" this appeal because they agree this is what they wish for themselves. In this sense, justice does seem to be blind because it appeals to a broad base of people.

The appeals in this dissertation were crafted to reflect the expectancy-value formulation in the Protection Motivation Theory. Rogers (1975) suggests that action is based on an expectation that the action will lead to some consequence and that the consequence has some value. In particular, the justice promotion clearly has these components as it outlines the current injustice, the action that must be taken to correct the injustice, and the desired outcome. Therefore, the success of the justice appeal may be rooted in the expectancy-value formulation.

While this connection is explicit, the broad appeal of justice is also likely derived from the presence of an emotional component along with its cognitive orientation. The pretests and manipulation checks both confirmed that emotion plays a role in the communication and interpretation of a justice appeal. The presence in the promotion appeal of both thinking and feeling along with an outcome would have led Drolet and Aaker (2002) to predict justice's broad appeal. They argue that simultaneous activation of both thinking and feeling, as well as motivational consequence improves the effectiveness of persuasion attempts. 
The presence of an emotional component in the justice appeal may have influenced other results. The non-significant effects for product evaluation and significant effects for the promotion evaluation and purchase intentions indicate that an alternate route of appeals effects may exist for the justice appeal. Previous research on emotion-based appeals demonstrated that emotional responses to promotions directly affect evaluations without influencing product beliefs (Brown, Homer and Inman 1998) or directly influence purchase intentions (Higie Coulter and Pinto 1995). A similar effect may be occurring here whereby the emotional component of the justice appeal is enabling the respondent to make determinations about purchase intentions directly on the basis of a promotion evaluation without direct reference or inference to product beliefs.

A second key finding in this study is the presence of empirical support for congruency effects. While full support is lacking, there are significant matching effects among the variables that influence promotion effectiveness outcomes. For instance, those who were high on the other-directedness personality trait gave more favourable outcome ratings to other-oriented promotional appeals. While inner-directed individuals did not give higher ratings to self-oriented appeals, an alternative matching pattern exists. Those who were more inner-directed gave cognitively emphasized appeals better outcome ratings than promotions that were emotion-based.

Country images are complex so there is ample opportunity for differentiation among countries. While the country images of LDCs are often seen to be weaker than 
those of developed countries (Tse and Gorn 1992; Cordell 1992; Ahmed and d'Astous 1993; Chao 1993; Mohamad et al. 2000; Kaynak, Kucukemiroglu and Hyder 2000), little research has been done to distinguish among the images of different LDCs, particularly with examinations of promotion effectiveness. In this study, Colombia was perceived to be the wealthier country and respondents reported a higher level of country familiarity. Honduras was viewed as a country with friendly and trustworthy people that have a strong work ethic. Honduras was also viewed as a country in need and requiring urgent assistance compared to Colombia. These aspects are the basis for overall differentiation of the two country images.

There are five country image dimensions revealed in this study, namely, country and people competence, country character, people character, neediness and product receptivity. Four dimensions roughly reflect recent research (Heslop et al. 2004; Orbaiz and Papadopolous 2003) while neediness is an additional dimension introduced in this study suitable to LDC images. The positive influence of higher beliefs about country and people character on promotion effectiveness outcomes is similar to findings by Heslop et al. (2004) that found country images can influence purchase intentions. However, this study explored country images in the context of promotional appeals and with the evaluation of the promotion as an outcome.

A new finding from the country image dimensions includes the role of culture. Anholt (2005) suggests that culture can play a role in enhancing the image of LDC's products in developed country markets. This study provides some empirical support that 
fascinating people and appealing culture beliefs can assist the development of favourable perceptions of the country's characteristics and promotion effectiveness outcomes. However, this effect was not limited to the hedonic appeal and was also important for utilitarian and justice appeals. The results of this dissertation demonstrate that Anholt (2005) does not present a complete picture when discussing the effects of other-oriented promotion appeals. Anholt (2005) argues that other-oriented appeals are altruistic and serve to diminish the image of the country and promotion responses. However, this dissertation showed that justice represents an alternative promotional appeal for LDCs that worked as well as the self-oriented appeals and better than the altruistic appeal. The justice appeal did not lead to lower country and people competence and country character beliefs as the altruistic appeal did. Country beliefs are important to the assessment of appeals because these beliefs were found to mediate the relationship of appeal type and promotion effectiveness.

\subsection{Benefits for Practitioners}

The primary benefit of the research to marketers is the potential to turn a liability into an asset. LDC product manufacturers often face a negative or weak country image when trying to sell their goods in a developed market (Tse and Gorn 1992; Cordell 1992; Ahmed and d'Astous 1993; Chao 1993; Mohamad et al. 2000; Kaynak, Kucukemiroglu and Hyder 2000). The examination of justice as an important appeal type demonstrates that LDC producers can turn their weak position into one of strength. Anholt (2005) argues that other-oriented appeals contribute to diminished perceptions of value. However, his argument points to the application of charity in the central message as the 
root of perceived value erosion. But, this research suggests that the justice appeal can be very effective with both personality types studied.

In addition, this dissertation contributes to the collection of strategic options for LDCs when exporting their products to developed country markets. Figure 6.1 presents the strategic options for LDCs at the intersection of country image and brand image that was adapted from Jaffe and Nebenzahl (2001). This grid was presented earlier in the dissertation. However, the option of using a justice-based promotion approach and monitoring country beliefs have been added to the upper left hand corner of the grid. The justice appeal would be most suited to those producers from countries with relatively positive country images but with weak product brands. A positive country image would be a requirement for the effective deployment of a justice promotion appeal because it is necessary that the country be perceived as a credible source of products and possessing the ability to help themselves. The justice appeal is also more suitable with a weak brand image because the justice message could dilute the image of a strong brand. In addition, the focus of the justice appeal is not necessarily on the product itself, but on the circumstances that surround its production.

The results of this dissertation provide mixed support for Anholt's (2005) view. The key finding here is that product evaluations are not central to the effectiveness of other-oriented appeals. The effectiveness of the justice appeal seems to work based on the promotion evaluation and purchase intentions. Therefore, the evaluation of a product associated with an altruistic or justice appeal is often similar to that of a self-oriented 
appeal. While altruism is very effective with other-oriented individuals for purchase intentions, justice is effective with both inner- and other-directed people.

\title{
FIGURE 6.1 MODIFIED INTERSECTION OF BRAND AND COUNTRY IMAGES FOR LDCS
}

\author{
Positive Country Image \\ - Develop a justice-oriented promotional \\ campaign with strong emotion and \\ cognition components with a clear \\ - Emphasize positive aspects of country \\ image (Bilkey and Nes 1982; Tse and Gorn \\ 1992)
} outcome

- Monitor country competencies and character beliefs because of their mediating role

- LDCs have an opportunity to export manufactured goods that are aligned with a current raw material reputation (Bilkey and Nes 1982)

- Positive initial impressions are associated with a new brand from a favourable country image (Tse and Gorn 1992)

- Leverage country image through a government certification program (Choi 1992)

\section{Weak Brand}

- Provide warranties (Bilkey and Nes 1982; Thorelli, Lim and Ye 1989; Cordell 1992; Jo, Nakamoto and Nelson 2003)

- Leverage DCs retailer image (Bilkey and Nes 1982; Thorelli, Lim and Ye 1989)

- Offer after sales service (Jo, Nakamoto and Nelson 2003)

- Encourage product experience (Tse and Gorn 1992)

- Set lower prices (Tse and Gorn 1992)

- Focus production on lower risk goods (Cordell 1992)

- Produce components in an LDC and assemble in a DC (Cordell 1992)

\section{Negative Country Image}

Source: adapted from Jaffe and Nebenzahl 2001 
A key finding for practitioners is the importance that country images play in mediating the relationship of appeal type to promotion effectiveness. Marketers from LDCs cannot ignore the role of country images because they interact with the central message of their promotions. In particular, marketers should be aware of how their country is perceived by consumers in terms of competencies and country character. These are dimensions of the country image that significantly mediate the relationship of appeal type to promotion effectiveness. A country image that is weak in these areas may make a LDC marketer less effective. Further, the importance of fascinating people and appealing culture beliefs with intentions to purchase products from an LDC supports Anholt's (2005) argument in this area. Therefore, marketers should portray relevant cultural aspects in a way that captures attention in a favourable light. Furthermore, it is important to maintain ongoing monitoring of country and people competence and country character perceptions because they play a mediating role in the relationship between appeal type and promotion effectiveness outcomes.

\subsection{Benefits for Policy Makers}

Policy makers can also benefit from the results of this research. The main contribution for policy makers is the improved understanding in the area of country images for LDCs. Developing countries often have weak or negative country images yet this weakness may be turned into an advantage. However, little research has explored the images associated with LDCs. For policy makers in Colombia and Honduras, this study provided descriptive results that outline how respondents perceived the two countries. 
The areas where the two countries were seen as different are particularly useful. Colombia was seen as having higher levels of competency rooted in beliefs about the country's wealth. Colombia's policy makers may wish to build upon this belief in promotional campaigns using either hedonic, utilitarian or justice appeals as a means to support their exporters.

Honduras was perceived to be a country of people who are friendly, trustworthy and possess a strong work ethic. This provides a good basis for policy makers to continue development of the country's image by encouraging their businesses to provide strong customer service and ensuring that foreigners have positive encounters with various levels of government during their visit. However, the results of this study showed that the people character dimension of country image was not related to promotion effectiveness. Therefore, consumers may be willing to give everyone an opportunity as fellow human beings to be good people. The justice appeal accommodates this conclusion through beliefs about work ethic, as everyone deserves a reward commensurate with their inputs.

Just as practitioners can benefit from applying a justice appeal, LDCs can enhance the appeal's effects through their country images. Despite the hardships faced by its population, a country may wish to profile this reality employing cognitive means to provide fertile ground for justice appeals of its manufacturers and other producers. To assist the effectiveness of LDC marketers, the country should focus on improving country and people competencies beliefs and country character perceptions. Both dimensions of 
country image were shown to influence the effectiveness of promotional appeals so building up the country image in these dimensions would help the LDCs' marketers regardless of the appeal type used. Further, justice appeals may represent a new window of opportunity for LDCs to expand beyond initial successes of a commodity based country image. The promotion appeals should not focus too much on negative aspects of the country's situation because this approach may decrease the country image. Instead, show how "justice" enables and improves life in the country. The emphasis is on the positive outcomes, not on the negative situation.

\subsection{Limitations of the Research}

Limitations in any research project are unavoidable. However, it is important to identify these restrictions when discussing the results. In the case of this research, five main limitations are identified relating to the methodology.

First, the choice of sampling students when the unit of analysis is general consumers carries some risk associated with the generalizability of the results. However, the study design attempted to lessen the effect of a non-traditional sample by choosing products for which the sampling frame is a major consumer. Students are very familiar with the proposed stimulus products and they are likely purchasers of these products. Furthermore, the investigation of justice as an appeal for LDCs may be better suited to younger participants as young people have grown up with the introduction of Fair Trade products and many actively campaign against the forces of globalization. 
Second, some situational influences may have an impact on participants' responses yet not be known to the researcher. However, identifying the major possibilities in the literature and accounting for the factors in the experimental design and collecting associated data in the measurement instrument help alleviate this concern. For instance, the demographic questions allowed for the collection of the subject's gender. While there are mixed results in previous studies, gender was found to be not a significant factor in this study of promotion effectiveness.

Third, the experimental research design raises concern that laboratory stimulation and responses do not directly correspond to behaviour in the marketplace. While the classroom setting is not a precise replication of the marketplace, the research was designed to capture intentions rather than just the beliefs, feelings and evaluations of subjects to provide a better reflection of actual behaviour. This research is an initial exploration intended to determine the general importance of a justice appeal in an LDC context. Further, the point of the study was to explore the basic mechanisms of decision making. Many researchers have argued that such mechanisms operate regardless of whether the subject is a consumer or student. While field trials are a next step, this initial exploration was best done in a controlled environment with a limited range of population variables in play and with less distraction than would occur in a normal marketplace setting. In addition, this study was interested in the form and nature of the basic relationship and not the "effect sizes" so a non-typical respondent group was also acceptable. Furthermore, Liefeld (1993) demonstrates that there is less distortion than might be expected from using student samples. 
Fourth, the order of stimulus and response measures in the questionnaire may raise concerns for some over possible order effects. The order was determined after careful consideration. First, the decision was made to place the personality scale ahead of the promotion stimulus because personality is a critical classification for this study. Therefore, it was important to eliminate the possibility that the promotion stimulus could distort personality item responses. Then, the promotional stimulus was exposed to the subject. Country image measures were provided after exposure to the stimulus to assess the impact on country images. While the images of developed countries are strong and well entrenched in the consumer's mind, the images of LDCs are weakly held. Therefore, it is possible that a promotional tag can influence their conceptions of the country. Indeed, the results show that the country image is influenced by the appeal type. Following the country image measures, response measures to the promotion stimulus were placed after the respondent was exposed to the stimulus as is typically done in advertising effectiveness research (Aaker and Williams 1998; Ruiz and Sicilia 2004). While it might seem ideal to have respondents return a day later to provide responses to the stimulus, this would not be appropriate for an assessment of the effectiveness of a promotional tag. In the case of promotional tags, consumers make immediate evaluations based on the promotional tag and any effects of the tag occur immediately as evidenced by the purchase decision.

Fifth, the difference in word length of the following appeal may provide a possible confounding effect. It is reasonable to argue that the shorter appeals (hedonic 
and utility) would result in poorer ratings than the longer appeals (altruism and justice). Certainly, the results of hypothesis 1 series would substantiate this claim given that some promotion effectiveness measures were lower for hedonic and utility compared to altruism and justice. However, these results were not consistent. This was not the case for product evaluation where the utility appeal receives ratings as high as the longer appeals. Further, this study was particularly interested in the interaction of personality on promotion effectiveness. Within these results, there doesn't seem to be a word length confounding effect as there is no preference for the longer appeals.

\subsection{Future Research}

While providing insight into the relationship of appeal type, country image and promotion effectiveness in the context of personality and product type, this study raises several questions that require further research. First, can justice appeals be effective within a developed country context? Within developed countries there exists economically distressed regions or poverty stricken neighbourhoods. The justice appeal may be a useful tool for marketers associated with efforts to economically stimulate these depressed areas through activities like social enterprise. The justice appeal may resonate if consumers perceive the location or area to be in need and if these areas also have the competencies to help themselves.

Second, what differences may be found in the images of LDCs? This study found that the images of Colombia and Honduras were perceived as different overall and with respect to some specific measures. However, there are many more LDCs than the two 
used in this study and there needs to be a better understanding of the constellation of their images. Specifically, more needs to be known about how the images of LDCs differ and to determine whether a means of categorizing these images is possible.

Third, would a different set of products influence the relationship of appeal type, country image and promotion effectiveness? This study explored the effectiveness of LDC promotional appeals within the context of two products used to represent hedonic (designer jeans) and utility (athletic shoes). However, the two products both represented a moderate range of product complexity. Future research should strive to determine the sensitivity of the results with products that are both high and low in complexity.

Fourth, what is the impact on relationships with promotion effectiveness of products that are more polarized on the hedonic-utility product type range? The results of this research suggest that the effects on promotion effectiveness are more invariant across product type than what was expected. This occurred despite a research design that successfully used two products that were more representative of either hedonic or utility. However, future research should examine the influence of varying product type on the effects of promotion effectiveness by using products with stronger distinctiveness in their representation of hedonic and utility.

Fifth, what is the most effective form of justice in a promotional appeal? Rawls (1971) argued that there are three types of justice, namely, distributive, procedural and interactional. Distributive justice refers to the coordination of outcomes while procedural 
justice refers to the means of distribution and interactional justice refers to stability in the willingness of people to act on agreed rules. This study included the notions of distributive and procedural justice in the promotional appeal for justice. Further research should isolate the different types to test their resonance with promotion effectiveness outcomes.

Sixth, what is the most effective form of promotional type for a justice appeal? The justice appeal is cognition-based but also has a significant emotional component that seems to influence its broad resonance. While emotion-based or cognitive-based promotional appeals can be more effective through certain media (Olney, Holbrook and Batra 1991; Royne Stafford and Day 1995), it is not clear where a more balanced appeal would be most effective. Further research is required to determine the order of effects in advertising (television, radio, print, point of sale and Internet) and other promotional types.

Seventh, what is the influence of brand names on the effectiveness of a justice appeal? The association of a product with a major brand name might diminish the effects of the justice appeal as consumers might view the purchase as having a limited effect on correcting the injustice. Alternatively, there could be a negative relationship for some young consumers as some view global injustices as the result of business practices of the companies behind major brands. 
Although more work is required to answer the questions raised by this study, this dissertation makes a considerable contribution to developing an understanding of the value of the justice appeal and its mechanism of effects on consumers in promoting the products and images of developing countries. 


\section{REFERENCES}

Aaker, Jennifer. 1999. The malleable self: The role of self-expression in persuasion. Journal of Marketing Research 36(February): 45-57.

Aaker, Jennifer and Patti Williams. 1998. Empathy versus pride: The influence of emotional appeals across cultures. Journal of Consumer Research. 25(Dec): 241 61 .

Aaker, David. 1996. Building Strong Brands. The Free Press: New York, New York.

Ahmed, Sadrudin and Alain d'Astous. 1993. Evaluation of country-of-design and country-of-assembly in a multi-cue/multi-national context. European Advances in Consumer Research 1: 214-21.

Ahmed, Sadrudin, Alain d'Astous and Said Zouiten. 1993. Personality variables and the made-in concept, in Product-country images: Impact and role in international marketing, Edited by Nicolas Papadopoulos and Louise Heslop. International Business Press: Binghamtom, NY, 197-222.

Albers-Miller, Nancy and Marla Stafford, 1999. An international analysis of emotional and rational appeals in services vs goods advertising. Journal of Consumer Marketing 16(1), 42-57.

American Marketing Association. 2005. Marketing Glossary Dictionary. http://www.marketingpower.com/mg-dictionary-view329.php? [Accessed February 9, 2005].

Amine, Lyn and Mike Chao. 2005. Managing country image to long-term advantage: The case of Taiwan and Acer. Place Branding 1(2): 187-204.

Anholt, Simon, 2002. Sharing the wealth. Brand Strategy April, 31.

Anholt, Simon. 2005. Brand new justice: How branding places and products can help the developing world. Revised edition. Elsevier Butterworth-Heinemann: Burlington, USA.

Apostolopoulou, Artemisia and Dimitra Papadimitriou. 2004. "Welcome Home": Motivations and objectives of the 2004 Grand National Olympic Sponsors. Sport Marketing Quarterly 13(4): 180-192.

Aristotle. 1995. Politics. Oxford University Press: New York, NY. 
Arthur, Damien and Pascale Quester. 2004. Who's afraid of that ad? Applying segmentation to the protection motivation model. Psychology and Marketing 21(9): 671-696.

Baker, William and Richard Lutz. 2000. An empirical test of an updated RelevanceAccessibility Model of advertising effectiveness. Journal of Advertising 24(1): 114.

Babin, Barry, William Darden and Mitch Griffin. 1994. Work and/or fun: Measuring hedonic and utilitarian shopping value. Journal of Consumer Research 20(4): 644-656.

Balabanis, George, Rene Mueller and T.C. Melewar. 2002. The human values' lenses of country of origin images. International Marketing Review 19(6): 582-610.

Bansal, Harvir, P. Gregory Irving and Shirley Taylor. 2004. A three-component model of customer commitment to service providers. Journal of the Academy of Marketing Science 32(3): 234-250.

Batson, Daniel. Justice motivation and moral motivation. In The justice motive in everyday life. Edited by Michael Ross and Dale Miller. Cambridge University Press: New York, 2002, 91-106.

Batson, C. Daniel. The altruism question: Toward a social-psychological answer. Lawrence Erlbaum Associates, Publishers: Hillsdale, New Jersey, 1991.

Baumgartner, Hans. 2002. Toward a personology of the consumer. Journal of Consumer Research 29(2): 286-292.

Bilkey, W. and E. Nes. 1982. Country-of-origin effects on product evaluations. Journal of International Business Studies 13(1): 89-99.

Blader, Steven and Tom Tyler. Justice and empathy: What motivates people to help others?". In The justice motive in everyday life. Edited by Michael Ross and Dale Miller. Cambridge University Press: New York, 2002, 226-250.

Brashear, Thomas, Charles Brooks and James Boles. 2004. Distributive and procedural justice in a sales force context: Scale development and validation. Journal of Business Research 57(1): 86-93.

Brown, Steven, Pamela Homer and Jeffrey Inman. 1998. A meta-analysis of relationships between ad-evoked feelings and advertising responses. Journal of Marketing Research 35(1): 114-126.

Brunel, Frederic and Michelle Nelson. 2003. Message order effects and gender differences in advertising persuasion. Journal of Advertising Research 43(3): 330 340 . 
Brunel, Frederic and Michelle Nelson. 2000. Explaining gendered responses to "helpself" and "help-others" charity ad appeals: The mediating role of world-views. Journal of Advertising 29(3): 15-27.

Cacioppo, John and Richard Petty. 1984. The elaboration likelihood model of persuasion. Advances in Consumer Research 11(1): 673-675.

Cattell, R.B. (1966), The scree test for the number of factors. Multivariate Behavioral Research 1: 245-276.

Celuch, Kevin and Mark Slama. 1995. 'Getting along' and 'getting ahead' as motives for self-presentation: Their impact on advertising effectiveness. Journal of Applied Social Psychology 25(19): 1700-1713.

Chaiken, Shelly and Alice Eagly. 1983. Communication modality as a determinant of persuasion: The role of communicator salience. Journal of Personality and Social Psychology 45: 241-56.

Chang, Chingching. 2001. The impacts of personality differences on product evaluations. Advances in Consumer Research 28(1): 26-33.

Chao, Paul. 1993. Partitioning country of origin effects: Consumer evaluations of a hybrid product. Journal of International Business Studies 24(2): 291-307.

Chernev, Alexander. 2004. Goal orientation and consumer preference for the status quo. Journal of Consumer Research 31(3): 557-565.

Choi, Chong Ju. 1992. Marketing barriers facing developing country manufactured exporters: A comment. The Journal of Development Studies 29(1): 166-71.

Cline, Thomas, Moses Altsech, and James Kellaris. 2003. When does humour enhance or inhibit ad responses? Journal of Advertising 32(3):31-45.

Cordell, Victor. 1992. Effects of consumer preferences for foreign sourced products. Journal of International Business Studies $2^{\text {nd }}$ Quarter: 251-69.

Cowley, Elizabeth and Marylouise Caldwell. 2001. Truth, lies and videotape: The impact of personality on the memory for a consumption experience. Advances in Consumer Research 28: 20-25.

Culnan, Mary and Robert Bies. 2003. Consumer privacy: Balancing economic and justice considerations. Journal of Social Issues 59(2): 323-342.

Dahl, Darren, Kristina Frankenberger and Rajesh Manchanda. 2003. Does it pay to shock? Reactions to shocking advertising content among university students. Journal of Advertising Research 43(3): 268-280. 
Dhar, Ravi and Klaus Wertenbroch. 2000. Consumer choice between hedonic and utilitarian goods. Journal of Marketing Research 37(1): 60-71.

Dawar, Niraj and Tony Frost. 1999. Competing with giants: survival strategies for local companies in emerging markets. Harvard Business Review 77(2): 119-30.

De Pelsmacker, Patrick and Maggie Geuens. 1999. The advertising effectiveness of different levels of intensity of humour and warmth and the moderating role of top of mind awareness and degree of product use. Journal of Marketing Communications 5(3): 113-129.

DeBono, Kenneth and Karen Rubin. 1995. Country of origin and perceptions of product quality: An individual difference perspective. Basic and Applied Social Psychology 17(1\&2): 239-247.

Dholakia, Utpal. 2001. A motivational process model of product involvement and consumer risk perception. European Journal of Marketing 35(11): 1340-1360.

Drolet, Aimee And Jennifer Aaker. 2002. Off-target? Changing cognitive-based attitudes. Journal of Consumer Psychology 12(1): 59-68.

Dutta, Mohan Jyoti and Bastian Vanacker. 2000. Effects of personality on persuasive appeals in health communication. Advances in Consumer Research 27(1): 119124.

Eisenberg, Nancy. Altruistic emotion, cognition, and behaviour. Lawrence Erlbaum Associates, Publishers: Hillsdale, New Jersey, 1986.

Erickson, Gary, Johny Johansson, and Paul Chao. 1984. "Image variables in multiattribute product evaluations: Country-of-origin effects". Journal of Consumer Research 11(2), 694-699.

Fitzmaurice, Julie. 2005. Incorporating consumers' motivations into the theory of reasoned action. Psychology \& Marketing 22(11): 911-929.

Frazer, Charles, Kim Bartel Sheehan and Charles Patti. 2002. Advertising strategy and effective advertising: Comparing the USA and Australia. Journal of Marketing Communications 8(3): 149-164.

Frijda, Nico, Emotions and hedonic experience, in Well being: The foundations of hedonic psychology, Edited by Daniel Kahneman, Ed Diener, and Norbert Schwarz. Russell Sage Foundation: New York. 1999. 190-210.

Fullerton, Gordon. 2006. The moderating effect of normative commitment in service relationships. Administrative Sciences Association of Canada Conference, Marketing Division: Banff, Alberta. 129-137. 
Gaedeke, Ralph. 1973. Consumer attitudes toward products 'Made-in' developing countries. Journal of Retailing 49(2): 13-24.

Gifford Jr., Dun. 1997. Brand management: Moving beyond loyalty. Harvard Business Review 75(2): 9-10.

Goodstein, Ronald. 1993. Category-based applications and extensions in advertising: Motivating more extensive ad processing. Journal of Consumer Research 20(1): 87-99.

Goodwin, Cathy, Kelly Smith, Susan Spiggle. 1990. Gift giving: consumer motivation and the gift purchase process. Advances in Consumer Research 17: 690-698.

Gregory, Gary, James Munch and Mark Peterson, 2002. Attitude functions in consumer research: Comparing value-attitude relations in individualist and collectivist cultures. Journal of Business Research 55(11): 933-942.

Guy, Bonnie and Wesley Patton. 1989. The marketing of altruistic causes: Understanding why people help. The Journal of Consumer Marketing 6(1): 19-30.

Han, Min. 1989. Country image: Halo or summary construct?, Journal of Marketing Research 26(2): 222-230.

Handleman, Jay and Stephen Arnold. 1999. The role of marketing actions with a social dimension: Appeals to the institutional environment. Journal of Marketing 63(3): 33-48.

Harris, Eric and John Morris. 2001. The influence of cardinal-, central-, and surface-level personality traits on consumers' bargaining and complaint intentions. Psychology \& Marketing 18(11): 1155-1185.

Harris, Misty. 2005. Metrospirituals: They worship at the altar of sustainable excess. Ottawa Citizen, November 16: D1.

Hawkins, Del, Roger Best and Kenneth Coney. 2004. Consumer behavior: Building marketing strategy. McGraw Hill/Irwin: New York.

Helgeson, James and Magne Supphellen. 2004. A conceptual and measurement comparison of self-congruity and brand personality. International Journal of Market Research 46(2): 205-233.

Heslop, Louise, Nicolas Papadopoulos, Melissa Dowdles, Marjorie Wall and Deborah Compeau, 2004. Who Controls the Purse Strings: A study of Consumers' and Retail Buyers' Reactions in an America's FTA Environment, Journal of Business Research 57(10), 1177-1188. 
Hetsroni. Amir. 2000. The relationship between values and appeals in Israeli

Advertising: A smallest space analysis. Journal of Advertising 29(3): 55-68.

Hibbert, Sally, Gillian Hogg and Theresa Quinn. 2005. Social entrepreneurship: Understanding consumer motives for buying The Big Issue. Journal of Consumer Behaviour 4(3): 159-172.

Higie Coulter, Robin, June Cotte and Melissa Lunt Moore. 1999. Believe it or not: Persuasion, manipulation and credibility of guilt appeals. Advances in Consumer Research 26: 288-294.

Higie Coulter, Robin and Mary Beth Pinto. 1995. Guilt appeals in advertising: What are their effects? Journal of Applied Psychology 80(6): 697-705.

Hirschman, Elizabeth and Morris Holbrook. 1982. Hedonic consumption: Emerging concepts, methods and propositions. Journal of Marketing 46(3): 92-101.

Hogg, Margaret, Alastair Cox, Kathy Keeling. 2000. The Impact of Self-Monitoring on Image Congruence and Product/Brand Evaluation. European Journal of Marketing 34(5/6): 641-667.

Hong, Jae and George Zinkhan. 1995. Self-concept and advertising effectiveness: The influence of congruency, conspicuousness, and response mode. Psychology and Marketing 12(1): 38-77.

Hoon Tan, Hwee, Maw Der Foo and Min Hui Kwek. 2004. The effects of customer personality traits on the Display of positive emotions. Academy of Management Journal 47(2): 287-296.

Huhmann, Bruce and Timothy Brotherton. 1997. A content analysis of guilt appeals in popular magazine advertisements. Journal of Advertising 26(2): 35-45.

Humphrey, John. 2001. Opportunities for SMEs in developing countries to upgrade in a global economy. SEED Working Paper, ILO.

Huneke, Mary. 2005. the face of the un-consumer: An empirical examination of the practice of voluntary simplicity in the United States. Psychology \& Marketing 22(7): 527-550.

Hunthausen, John, Donald Truxillo, Tayla Bauer and Leslie Hammer. 2003. A field study of frame-of-reference effects on personality test validity. Journal of Applied Psychology 88(3): 545-551.

Hunt, James, Jerome Kernan and Deborah Mitchell. 1996. Materialism as social cognition: People, possessions, and perception. Journal of Consumer Psychology 5(1): 65-83. 
Irwin, Ron. 2003. Corporate social investment and branding in the new South Africa. Journal of Brand Management 10(4/5): 303-312.

Jaffe, Eugene and Israel Nebenzahl. 2001. National image and competitive advantage: The theory and practice of country-of-origin effect. Copenhagen, Denmark: Copenhagen Business School Press.

Jewell, Robert and Blair Kidwell. 2005. The moderating effect of perceived control on motivation to engage in deliberative processing. Psychology \& Marketing 22(9): 751-769.

Jo, Myung-Soo, Kent Nakamoto, and James E. Nelson. 2003. The shielding effects of brand image against lower quality countries-of-origin in global manufacturing. Journal of Business Research 56(8): 637-646.

Johar, J.S. and Joseph Sirgy. 1991. Value-expressive versus utilitarian advertising appeals: When and why to use which appeal. Journal of Advertising 20(3): 23-33.

Jones, Heather and C.W. Lejuez. 2005. Personality correlates of caffeine dependence: The role of sensation seeking, impulsivity, and risk taking. Experimental and Clinical Psychopharmacology 13(3): 259-266.

Kahneman, Daniel, Ed Diener, and Norbert Schwarz. 1999. Preface, in Well being: The foundations of hedonic psychology, Edited by Daniel Kahneman, Ed Diener, and Norbert Schwarz. Russell Sage Foundation: New York. ix-xii.

Kapoor, Harish. 2005. Competitive effects on the evaluation of brand extensions. Unpublished dissertation. Sprott School of Business, Carleton University.

Kassarjian, Harold and Mary Jane Sheffet. 1991. in Personality and consumer behavior: An update. Edited by Harold Kassarjian and Thomas Robertson, Perspectives in Consumer Behavior. Prentice Hall: Englewood Cliffs, New Jersey. 281-303.

Kassarjian, Waltraud. 1962. A study of Reisman's theory of social character. Sociometry 25: 213-230.

Kaynak, Erdener, Orsay Kucukemiroglu and Akmal Hyder. 2000. Consumer's countryof-origin (COO) perceptions of imported products in a homogenous lessdeveloped country. European Journal of Marketing 34(9/10): 1221-1242.

Kiecker, Pamela and Dale Duhan. 1992. The influence of origin evaluation and origin information on retail sales. American Marketing Association Educators' Proceedings Summer: 27.

Kim, Chung Koo. 1995. Brand popularity and country image in global competition: managerial implications. Journal of Product \& Brand Management 4(5): 21-33. 
Kim, Jae-Young, Junyean Moon, Dongchul and Surinder Tikoo. 2004. Perceptions of justice and employee willingness to engage in customer-oriented behaviour. Journal of Services Marketing 18(4): 267-275.

Knight, Gary and Roger Calantone. 2000. A flexible model of consumer country-oforigin perceptions: A cross-cultural investigation. International Marketing Review 17(2): 127-45.

Kotler, Philip and David Gertner. 2002. Country as brand, product and beyond: A place marketing and brand management perspective. Journal of Brand Management 9(4-5), 249-61.

LaBarbera, Priscilla, Peter Weingard and Eric Yorkston. 1998. Matching the message to the mind: Advertising imagery and consumer processing styles. Journal of Advertising Research 38(5): 29-41.

Laroche, Michel, Nicolas Papadopoulos, Louise Heslop and Mehdi Mourali. 2005. The influence of country image structure on consumer evaluations of foreign products. International Marketing Review 22(1): 96-115.

Laroche, Michel, Roy Toffoli, Quihong Zhang and Frank Pons. 2001. A cross-cultural study of the persuasive effect of fear appeal messages in cigarette advertising: China and Canada. International Journal of Advertising 20(3): 297-317.

LaTour, Michael and Herbert Rotfeld. 1997. There are threats and (maybe) fear-caused arousal: Theory and confusions of appeals to fear and fear arousal itself. Journal of Advertising 26(3): 45-59.

Lerner, Melvin and James Meindl. 1981. Justice and altruism. In Altruism and Helping Behaviour: Social, Personality, and Developmental Perspectives. Edited by J. Philippe Rushton and Richard Sorrentino. Lawrence Erlbaum Associates, Publishers: Hillsdale, New Jersey, 213-232.

Lester, David 1995. Theories of personality: A systems approach, Taylor and Francis: Washington, DC.

Linton, April, Cindy Chiayuan Liou and Kelly Ann Shaw. 2004. A taste of trade justice: Marketing global social responsibility via Fair Trade Coffee. Globalizations 1(2): 223-246.

Lee, Dongdae and Gopala Ganesh. 1999. Effects of partitioned country image in the context of brand image and familiarity. International Marketing Review 16(1): 18-39.

Lepkowska-White, Brashear and Marc Weinberger. 2003. A test of ad appeal effectiveness in Poland and the United States. Journal of Advertising 32(3): 57 67. 
Liefeld, John. 1993. Experiments on country-of-origin effects: Review and meta-analysis of effect size. in Product-country images: Impact and role in international marketing, Edited by Nicolas Papadopoulos and Louise Heslop. International Business Press: Binghamtom, NY, 117-156,

Lohtia, Ritu, Naveen Donthu and Edmund Hershberger. 2003. The impact of content and design elements on banner advertising click-through rates. Journal of Advertising Research 43(4): 410-418.

MacDonald, Colin and Laurence Jacobs. 1992. The importance of inner/other-directed personality factors upon innovative product acceptance. International Journal of Advertising 11(3): 239-247.

MacInnis, Deborah, Christine Moorman and Bernard Jaworski. 1991. Enhancing and measuring consumers' motivation, opportunity, and ability to process brand information from ads. Journal of Marketing 55(4): 32-53.

Maddi, Salvatore 1996. Personality theories: A comparative analysis, Brooks/Cole Publishing Company: Pacific Grove, California.

Manrai, Lalita, Dana-Nicoleta Lascu, and Ajay Manrai. 1998. Interactive effects of country of origin and product category on product evaluations. International Business Review 7(6): 591-615.

Martin, Ingrid and Sevgin Eroglu. 1993. Measuring a multi-dimensional construct: Country image. Journal of Business Research 28(3): 191-211.

Mattila, Anna and David Cranage. 2005. The impact of choice on fairness in the context of service recovery. Journal of Services Marketing 19(5): 271-279.

Maxham, James and Richard Netemeyer. 2003. Firms reap what they sow: The effects of shared values and perceived organizational justice on customers' evaluations of complaint handling. Journal of Marketing 67(1): 46-62.

Meenaghan, Tony and David Shipley. 1999. Media effect in commercial sponsorship. European Journal of Marketing 33(3/4): 328-347.

Mohamad, Osman, Zafar Ahmed Earl Honeycutt, Taizoon Tyebkhan. 2000. Does 'madein ...' matter to consumers? A Malaysian study of country of origin effects. Multinational Business Review 8(2): 69-74.

Montada, Leo. 2002. Doing justice to the justice motive. In The justice motive in everyday life. Edited by Michael Ross and Dale Miller. Cambridge University Press: New York. 41-62. 
Moon, Youngme. 2002. Personalization and personality: Some effects of customizing message style based on consumer personality. Journal of Consumer Psychology 12(4): 313-326.

Mossberg, L. and Kleppe, I. A. 2005. Country and destination image - different or similar image concepts. The Service Industries Journal 25(4): 493-503.

Mowen, John, Eric Harris and Sterling Bone. 2004. Personality traits and fear response to print advertisements: Theory and an empirical study. Psychology and Marketing 21(11): 927-943.

Nadeau, John, Louise Heslop, Norman O'Reilly and Peter Luk. 2006. Climbing to new heights: Lessons from Mount Everest on PCI and TDI Convergence. Administrative Sciences Association of Canada Conference: Banff, Alberta.

Nebenzahl, Israel, Eugene Jaffe and Schlomo Lampert, 1997. Towards a theory of country image effect on product evaluation, Management International Review $37(1), 27-49$.

Nes, Erik. 1981. Consumer perceptions of product risk and quality for goods manufactured in developing versus industrialized nations. Ph.D. Dissertation, The University of Wisconsin-Madison.

Nunnally, Jum. 1978. Psychometric Theory. Second edition. McGraw Hill: New York.

O'Curry, Suzanne and Michal Strahilevitz. 2001. Probability and mode of acquisition effects on choices between hedonic and utilitarian options. Marketing Letters 12(1): 37-49.

Okada, Erica Mina. 2005. Justification effects on consumer choice of hedonic and utilitarian goods. Journal of Marketing Research 42(February): 43-53.

Olney, Thomas, Morris Holbrook and Rajeev Batra. 1991. Consumer responses to advertising: The effects of ad content, emotions, and attitude toward the ad on viewing time. Journal of Consumer Research 17: 440-453.

Olsen, Svein Ottar, Olsson, Ulf. 2002. Multientity scaling and the consistency of country-of-origin attitudes. Journal of International Business Studies 33(1): 149167.

Onkvisit, Sak and John Shaw. 1987. Self-concept and image congruence: Some research and managerial implications. The Journal of Consumer Marketing 4(1): 13-23.

Orbaiz, Luisa Villanueva and Nicolas Papadopoulos. 2003. Toward a Model of Consumer Receptivity of Foreign and Domestic Products. Journal of International Consumer Marketing 15(3): 101-126. 
Organization for Economic Co-operation and Development. 2006. Glossary. http://stats.oecd.org/glossary/detail.asp?ID=6326. [Accessed May 5, 2006].

O'Shaughnessy, John and Nicolas Jackson O'Shaughnessy. 2002. Marketing, the consumer society and hedonism. European Journal of Marketing 36(5/6): 524547.

Papadopoulos, Nicolas. 2004. Place branding: Evolution, meaning and implications. Place Branding 1(1): 36-49.

Parameswaran, Ravi and R. Mohan Pisharodi. 2002. Assimilation effects in country image research. International Marketing Review 19(3): 259-278.

Paulssen, Marcel and Richard Bagozzi. 2005. A self-regulatory model of consideration set formation. Psychology \& Marketing 22(10): 785-812.

Pervin, Lawrence 1989. Personality: Theory and Research, fifth edition, John Wiley \& Sons, Inc.: New York, New York.

Peter, J. Paul and Jerry C. Olson. 1994. Understanding Consumer Behavior. Irwin: Burr Ridge, Illinois.

Peterson, Robert and Alain Jolibert. 1995. A meta-analysis of country-of-origin effects. Journal of International Business Studies 26(4): 883-900.

Pilluta, Madan and J. Keith Murnighan. 1995. Being fair or appearing fair: Strategic behaviour in ultimatum bargaining. Academy of Management Journal 38(5): 1408-1426.

Pincus, Jeremy. 2004. The consequences of unmet needs: The evolving role of motivation in consumer research. Journal of Consumer Behaviour 3(4): 375-387.

Plummer, Joseph. 2000. How personality makes a difference. Journal of Advertising Research (November): 79-83.

Puri, Radhika. 1996. Measuring and modifying consumer impulsiveness: A cost-benefit accessibility framework. Journal of Consumer Psychology 5(2): 87-113.

Putrevu, Sanjay and Kenneth Lord. 1994. Comparative and noncomparative advertising: Attitudinal effects under cognitive and affective involvement conditions". Journal of Advertising 23(2): 77-90.

Rawls, John. 1971. A theory of justice. The Belknap Press of Harvard University Press: Cambridge, MA. 
Richard, Orlando and Susan Kirby. 1999. Organizational justice and the justification of work force diversity programs. Journal of Business and Psychology 14(1): 109118.

Rogers, R. W., 1975. A protection motivation theory of fear appeals and attitude change. Journal of Psychology 91(1), 93-114.

Rosenhan, David, Peter Salovey, Jerzy Karylowski, and Kenneth Hargis. 1981. Emotion and altruism. In Altruism and helping behaviour: Social, personality, and developmental perspectives. Edited by J. Philippe Rushton and Richard Sorrentino. Lawrence Erlbaum Associates, Publishers: Hillsdale, New Jersey, 233-248.

Royne Stafford, Marla and Ellen Day. 1995. Retail services advertising: The effects of appeal, medium and service. Journal of Advertising 24(1): 57-71.

Rugimbana, Robert, Brett Donahay, Christopher Neal, Michael Polonsky. 2003. The role of social power relations in gift giving on Valentine's Day. Journal of Consumer Behaviour 3(1): 63-73.

Ruiz, Salvador and Maria Sicilia. 2004. The impact of cognitive and/or affective processing styles on consumer response to advertising appeals. Journal of Business Research 57(6): 657-664.

Rushton, J. Philippe. 1981. The altruistic personality. In Altruism and helping behaviour: Social, personality, and developmental perspectives. Edited by J. Philippe Rushton and Richard Sorrentino. Lawrence Erlbaum Associates, Publishers: Hillsdale, New Jersey, 251-266.

Ryckman, Richard 1989. Theories of personality, fourth edition, Brooks/Cole Publishing Company: Pacific Grove, California.

Sapienza, Harry and Audrey Korsgaard. 1996. Procedural justice in entrepreneur-investor relations. Academy of Management Journal 39(3): 544-574.

Saxby, Carl, Peter Tat and Jane Thompson Johansen. 2000. Measuring consumer perceptions of procedural justice in a complaint context. The Journal of Consumer Affairs 34(2): 204-216.

Schoefer, Klaus and Christine Ennew. 2005. The impact of perceived justice on consumers' emotional responses to service complaint experiences. Journal of Services Marketing 19(5): 261-270.

Schwartz, Barry, Andrew Ward, John Monterosso, Sonja Lyubomirsky, Katherine White and Darrin Lehman. 2002. Maximizing versus satisficing: Happiness is a matter of choice. Journal of Personality and Social Psychology 83(5): 1178-1197. 
Schweiger, Gunter, Gerald Haubl and Geroen Friederes, 1995. Consumers' evaluations of products labeled 'made in Europe'. Marketing and Research Today February, 2532.

Shavitt, Sharon. 1989. Products, personalities and situations in attitude functions: Implications for consumer behaviour. Advances in Consumer Behaviour 16: 300305.

Shavitt, Sharon. 1992. Evidence for predicting the effectiveness of value-expressive versus utilitarian appeals: A reply to Johar and Sirgy. Journal of Advertising 21(2): 47-49.

Shiv, Baba and Alexander Fedorikhin. 1999. Heart and mind in conflict: The interplay of affect and cognition in consumer decision making. Journal of Consumer Research 26(December): 278-292.

Sirgy, Joseph and J.S. Johar. 1992. Value expressive versus utilitarian appeals: A reply to Shavitt. Journal of Advertising 21(2): 53-54.

Slama, Mark and Rodger Singley. 1996. Self-monitoring and value expressive vs. utilitarian ad effectiveness: Why the mixed findings? Journal of Current Issues and Research in Advertising 18(2): 39-52.

Smith, Stephen, Curtis Haugtvedt, John Jadrich and Mark Anton. 1995. Understanding responses to sex appeals in advertising: An individual difference approach. Advances in Consumer Research 22: 735-739.

Solomon, Michael, Elnora Stuart, Auleen Carson and Brock Smith, 2003. Marketing: Real people, real decision. Updated First Canadian Edition, Prentice Hall: Toronto.

Speyer, Ariana. 2005. Riding the metrospiritual wave: The growing ranks of the hip and holistic are seeking their inner bliss with serious style. BeliefNet.com [Accessed May 5, 2006].

Sutton, Robert and Barry Staw. 1995. What theory is not. Administrative Science Quarterly 40: 371-84.

Taggart, James. 1997. Autonomy and procedural justice: A framework for evaluating subsidiary strategy. Journal of International Business Studies 28(1): 51-76.

Tan Tsu Wee, Thomas. 2003. Extending human personality to brands: The stability factor. Brand Management 11(4): 317-330.

Tanner, John, James Hunt and David Eppright. 1991. The protection motivation model: A normative model of fear appeals. Journal of Marketing 55(3): 36-45. 
Tax, Stephen, Stephen Brown and Murali Chandtashekaran. 1998. Customer evaluations of service complaint experiences: Implications for relationship marketing. Journal of Marketing 62(2): 60-76.

TerraPass. 2005. www.terrapass.com. [Accessed December 6, 2005].

Thorelli, Hans, Jeen-Su Lim, and Jongsuk Ye. 1989. Relative importance of country of origin, warranty and retail store image on product evaluations. International Marketing Review 6(1): 35-46.

Triandis, Harry, Robert Bontempo, Marcelo Villareal, Masaaki Asai and Nydia Lucca. 1988. Individualism and collectivism: Cross-cultural perspectives on self-ingroup relationships. Journal of Personality and Social Psychology 54(2): 323-338.

Tse, David and Gerald Gorn. 1992. An experiment on the salience of country-of-origin in the era of global brands. Journal of International Marketing 1(1): 57-76.

Tse, David and Wei-na Lee. 1993. Removing negative country images: effects of decomposition, branding, and product experience. Journal of International Marketing 1(4): 25-48.

Tuan Pham, Michel and Tamar Avnet. 2004. Ideals and oughts and the reliance on affect versus substance in persuasion. Journal of Consumer Research 30(4): 503-518.

Usunier, Jean-Claude. 1999. Food consumption and the expatriation experience: A study of American expatriates in France, in European Advances in Consumer Research. Volume 4. Edited by Bernard Dubois, Tina Lowry, L.J. Shrum and Marc Vanhuele. Association for Consumer Research: Provo, UT.

Van Osselaer, Stijn, Chris Janiszewski, David Mick and Frank Kardes. 2001. Two ways of learning brand associations. Journal of Consumer Research 28(2): 2002-223.

Vaughan, Richard, 1980. How advertising works: A planning model. Journal of Advertising Research 20(5), 27-33.

Verplanken, Bas and Rob Holland. 2002. Motivated decision making: Effects of activation and self-centrality of values on choices and behaviour. Journal of Personality and Social Psychology 82(3): 434-447.

Vincent, Anne-Marie and Alan Dubinsky. 2005. Impact of Fear Appeals in a CrossCultural Context. Marketing Management Journal 15(1): 17-32.

Voss, Kevin, Eric Spangenberg and Bianca Grohmann. 2003. Measuring the hedonic and utilitarian dimensions of consumer attitude. Journal of Marketing Research 40(3): 310-320. 
Wall, Marjorie, John Liefeld and Louise Heslop. 1991. Impact of country-of-origin cues on consumer judgements in multi-cue situations: A covariance analysis. Journal of the Academy of Marketing Science 19(2): 105-113.

Wee, Chow Hou, David Lim, and Gilbert Tan. 1993. The image of countries as locations for investment, in Product-country images: Impact and role in international marketing, Edited by Nicolas Papadopoulos and Louise Heslop, International Business Press: Binghamtom, NY, 311-38.

Weick, Karl. 1995. What theory is not, theorizing is. Administrative Science Quarterly 40(3): 385-390.

Winter, David and Nicole Barenbaum. 1999. History of modern personality theory and research. In eds. Pervin, Lawrence and Oliver John, Handbook of personality: Theory and research, second edition, The Guilford Press: New York, New York.

World Bank. 2006. Country classification. http://web.worldbank.org [accessed May 4, 2006].

Yamoah, Fred. 2005. Role and impact of product-country image on rice marketing: A developing country perspective. The Journal of American Academy of Business $7(2): 265-276$.

Yang, Sha, Greg Allenby and Geraldine Fennel. 2002. Modeling variation in brand preference: The roles of objective environment and motivating conditions. Marketing Science 21(1): 14-31.

Zhang, Yong and Betsy Gelb. 1996. Matching advertising appeals to culture: The influence of products' use conditions. Journal of Advertising 25(3): 29-46.

Zhao, Xinshu, 1997. Clutter and serial order redefined and retested. Journal of Advertising Research 37(5): 57-73. 


\section{APPENDIX A - MEASUREMENT INSTRUMENT}


Please take a moment to review this basic information about:

\section{Colombia}

Geographic location - Northern South America, bordering the Caribbean Sea, between Panama and Venezuela, and bordering the North Pacific Ocean, between Ecuador and Panama

Political system - republic

Population - 44 Million

GDP per capita (PPP) - $\$ 7,900$

Source: The World Factbook (2006) 
Section 1: A number of statements or questions with two alternative answers are given below. Please answer every item as it applies to you. Indicate your preference by circling the number closest to the statement that reflects you. Some of the alternatives may appear equally attractive or unattractive to you. Nevertheless, please make a real attempt to choose the alternative that is relatively more acceptable to you. 
1. If I had more time I would:

$\begin{array}{lllllll}\text { spend more evenings at home } & 1 & 2 & 3 & 4 & 5 & \text { more often go out with my friends }\end{array}$ doing the things I like to do

2. For physical exercise or as a sport, I would prefer:

softball, basketball, volleyball, or 12

a similar team sport

$\begin{array}{llll}3 & 4 & 5 & \text { skiing, hiking, horseback riding, }\end{array}$

bicycling, or similar individual sport

3. I believe:

$\begin{gathered}\text { being able to make friends is a } \\ \text { great accomplishment in and of } \\ \text { itself }\end{gathered}$

4. It is more desirable:

to be popular and well liked by $\begin{array}{lllllll}1 & 2 & 3 & 4 & 5 & \text { to become famous in the field of one's }\end{array}$ everybody choice or for a particular deed

5. I would consider it more embarrassing:

to be caught loafing on a job for $\begin{array}{lllllll}1 & 2 & 3 & 4 & 5 & \text { losing my temper when a number of }\end{array}$ which I get paid people are around of whom I think a lot

6. In my free time:

I'd like to read an interesting book at home

$\begin{array}{llllll}1 & 2 & 3 & 4 & 5 & \text { l'd rather be with a group of my friends }\end{array}$

7. As leisure-time activity, I would rather choose:

woodcarving, painting, stamp 1

collecting, photography, or a

similar activity

$\begin{array}{lllll}2 & 3 & 4 & 5 & \text { bridge or other card game, or }\end{array}$

discussion groups

8. One of the main things a child should be taught is:

$\begin{array}{lllllll}\text { cooperation } & 1 & 2 & 3 & 4 & 5 & \text { self-discipline }\end{array}$

9. The persons whom I admire most are those who:

are very outstanding in their $\begin{array}{llllll}1 & 2 & 3 & 4 & 5 & \text { have a very pleasant personality }\end{array}$ achievements

10. I prefer listening to a person who:

knows his subject matter real well but is not skilled in

$\begin{array}{llllll}1 & 2 & 3 & 4 & 5 & \text { knows his subject matter not as well }\end{array}$ presenting interestingly but has an interesting way of discussing it

11. As far as I am concerned:

I see real advantages to keeping a diary and would like to keep

$\begin{array}{llllll}1 & 2 & 3 & 4 & 5 & \text { l'd rather discuss my experiences with }\end{array}$ friends than keep a diary 
Section 2: Please circle the appropriate number that indicates to what degree each item is reflective of your behaviour

1. My behaviour is usually an expression of my true inner feelings, attitudes and beliefs

2. At parties and social gatherings, I do not attempt to do or say things that others will like

3. In a group of people I am rarely the center of attention

4. I am not particularly good at making other people like me

5. I would not change my opinions (or the way I do things) in order to please someone else or win their favour

6. At a party, I let others keep the jokes and stories going

7. I feel a bit awkward in company and do not show up quite so well as I should
False $\begin{array}{llllllll}1 & 2 & 3 & 4 & 5 & 6 & 7 & \text { True }\end{array}$

False $\begin{array}{llllllll}1 & 2 & 3 & 4 & 5 & 6 & 7 & \text { True }\end{array}$

False $\begin{array}{llllllll}1 & 2 & 3 & 4 & 5 & 6 & 7 & \text { True }\end{array}$

False $\begin{array}{llllllll}1 & 2 & 3 & 4 & 5 & 6 & 7 & \text { True }\end{array}$

False $\begin{array}{llllllll}1 & 2 & 3 & 4 & 5 & 6 & 7 & \text { True }\end{array}$ False $\begin{array}{llllllll}1 & 2 & 3 & 4 & 5 & 6 & 7 & \text { True }\end{array}$ False $\begin{array}{llllllll}1 & 2 & 3 & 4 & 5 & 6 & 7 & \text { True }\end{array}$ 
Section 3: For each of the characteristics listed below, rate how descriptive each characteristic is of you using the scale from 1 to 5 as shown below.

$\begin{array}{ccccc}\text { Disagree } & \text { Disagree } & \text { Neither agree } & \text { Agree } & \text { Agree } \\ \text { strongly } & \text { a little } & \text { of disagree } & \text { a little } & \text { strongly } \\ 1 & 2 & 3 & 4 & 5\end{array}$

\section{I see myself as someone who...}

Is talkative

Tends to find fault with others

Does a thorough job

Is depressed, blue

Is original, comes up with new ideas

Is reserved

Is helpful and unselfish with others

Can be somewhat careless

Is relaxed, handles stress well

Is curious about many different things

Is full of energy

Starts quarrels with others

Is a reliable worker

Can be tense

Is ingenious, a deep thinker

Generates a lot of enthusiasm

Has a forgiving nature

Tends to be disorganized

Worries a lot

Has an active imagination

Tends to be quiet

Is generally trusting
Tends to be lazy

Is emotionally stable, not easily upset

Is inventive

Has an assertive personality

Can be cold and aloof

Perseveres until the task is finished

Can be moody

Values artistic, aesthetic experiences

Is sometimes shy, inhibited

Is considerate and kind to almost everyone

Does things efficiently

Remains calm in tense situations

Prefers work that is routine

Is outgoing, sociable

Is sometimes rude to others

Makes plans and follows through with them

Gets nervous easily

Likes to reflect, play with ideas

Has few artistic interests

Likes to cooperate with others

Is easily distracted

Is sophisticated in art, music, or literature 
Section 4: Imagine you are at a store where you would normally shop for designer jeans and you saw a pair that you would consider buying. It has the following information on an attached promotional tag. Please read the promotional tag below and provide your opinion on the following pages.

\section{Support a poor young Colombian family now with every stride you make}

Diego and Camila are children living in impoverished conditions and struggle to access clean water and food.

Their parents work hard in their local textile factory and need to keep their jobs.

Every designer jean purchase you choose to make helps families like these live better.

\section{It's up to you. Choose to help Diego and Camila today!}


How would you describe the country and people of Colombia?

Likeability of people

Industriousness

Education level

Fascinating people

Wealth

Friendliness

Trustworthiness

Work ethic

Appealing culture

Individualism

Political stability

Technology level of country

Stability of economy

Quality of life

Admirable in world politics

Environmental/pollution controls

Individual rights and freedoms

In need of assistance

Urgency of need

Alignment with your home country

Liking of the country

Your knowledge of Colombia

Overall, how would you rate Colombia?

Have products l'd like to buy

Would like to help support

Willingness to buy their products

$\begin{array}{lllllllll}\text { Low } & 1 & 2 & 3 & 4 & 5 & 6 & 7 & \text { High } \\ \text { Low } & 1 & 2 & 3 & 4 & 5 & 6 & 7 & \text { High } \\ \text { Low } & 1 & 2 & 3 & 4 & 5 & 6 & 7 & \text { High } \\ \text { Low } & 1 & 2 & 3 & 4 & 5 & 6 & 7 & \text { High } \\ \text { Low } & 1 & 2 & 3 & 4 & 5 & 6 & 7 & \text { High } \\ \text { Low } & 1 & 2 & 3 & 4 & 5 & 6 & 7 & \text { High } \\ \text { Low } & 1 & 2 & 3 & 4 & 5 & 6 & 7 & \text { High } \\ \text { Low } & 1 & 2 & 3 & 4 & 5 & 6 & 7 & \text { High } \\ \text { Low } & 1 & 2 & 3 & 4 & 5 & 6 & 7 & \text { High } \\ \text { Low } & 1 & 2 & 3 & 4 & 5 & 6 & 7 & \text { High } \\ \text { Low } & 1 & 2 & 3 & 4 & 5 & 6 & 7 & \text { High } \\ \text { Low } & 1 & 2 & 3 & 4 & 5 & 6 & 7 & \text { High } \\ \text { Low } & 1 & 2 & 3 & 4 & 5 & 6 & 7 & \text { High } \\ \text { Low } & 1 & 2 & 3 & 4 & 5 & 6 & 7 & \text { High } \\ \text { Low } & 1 & 2 & 3 & 4 & 5 & 6 & 7 & \text { High } \\ \text { Low } & 1 & 2 & 3 & 4 & 5 & 6 & 7 & \text { High } \\ \text { Low } & 1 & 2 & 3 & 4 & 5 & 6 & 7 & \text { High } \\ \text { Low } & 1 & 2 & 3 & 4 & 5 & 6 & 7 & \text { High } \\ \text { Low } & 1 & 2 & 3 & 4 & 5 & 6 & 7 & \text { High } \\ \text { Low } & 1 & 2 & 3 & 4 & 5 & 6 & 7 & \text { High } \\ \text { Low } & 1 & 2 & 3 & 4 & 5 & 6 & 7 & \text { High } \\ \text { Low } & 1 & 2 & 3 & 4 & 5 & 6 & 7 & \text { High }\end{array}$

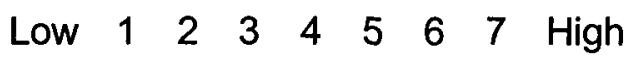
Low $1 \begin{array}{llllllll}1 & 2 & 3 & 4 & 5 & 6 & 7 & \text { High }\end{array}$ Low $1 \begin{array}{llllllll}1 & 2 & 3 & 4 & 5 & 6 & 7 & \text { High }\end{array}$ Low $1 \begin{array}{llllllll}1 & 2 & 3 & 4 & 5 & 6 & 7 & \text { High }\end{array}$ 
What does the advertisement represent to you?

$\begin{array}{llllllllll}\text { Enjoyment } & \text { Low } & 1 & 2 & 3 & 4 & 5 & 6 & 7 & \text { High } \\ \text { Helpful } & \text { Low } & 1 & 2 & 3 & 4 & 5 & 6 & 7 & \text { High } \\ \text { Equality } & \text { Low } & 1 & 2 & 3 & 4 & 5 & 6 & 7 & \text { High } \\ \text { Charity } & \text { Low } & 1 & 2 & 3 & 4 & 5 & 6 & 7 & \text { High } \\ \text { Pleasure } & \text { Low } & 1 & 2 & 3 & 4 & 5 & 6 & 7 & \text { High } \\ \text { Effective } & \text { Low } & 1 & 2 & 3 & 4 & 5 & 6 & 7 & \text { High } \\ \text { Fairness } & \text { Low } & 1 & 2 & 3 & 4 & 5 & 6 & 7 & \text { High } \\ \text { Sympathy } & \text { Low } & 1 & 2 & 3 & 4 & 5 & 6 & 7 & \text { High } \\ \text { Fun } & \text { Low } & 1 & 2 & 3 & 4 & 5 & 6 & 7 & \text { High } \\ \text { Functional } & \text { Low } & 1 & 2 & 3 & 4 & 5 & 6 & 7 & \text { High } \\ \text { Obligation } & \text { Low } & 1 & 2 & 3 & 4 & 5 & 6 & 7 & \text { High } \\ \text { Concern } & \text { Low } & 1 & 2 & 3 & 4 & 5 & 6 & 7 & \text { High } \\ \text { Exciting } & \text { Low } & 1 & 2 & 3 & 4 & 5 & 6 & 7 & \text { High } \\ \text { Necessary } & \text { Low } & 1 & 2 & 3 & 4 & 5 & 6 & 7 & \text { High } \\ \text { Duty } & \text { Low } & 1 & 2 & 3 & 4 & 5 & 6 & 7 & \text { High } \\ \text { Compassion } & \text { Low } & 1 & 2 & 3 & 4 & 5 & 6 & 7 & \text { High } \\ \text { Delightful } & \text { Low } & 1 & 2 & 3 & 4 & 5 & 6 & 7 & \text { High } \\ \text { Practical } & \text { Low } & 1 & 2 & 3 & 4 & 5 & 6 & 7 & \text { High } \\ \text { Thrilling } & \text { Low } & 1 & 2 & 3 & 4 & 5 & 6 & 7 & \text { High } \\ \text { Entertaining } & \text { Low } & 1 & 2 & 3 & 4 & 5 & 6 & 7 & \text { High }\end{array}$

First, I would like to ask you some questions about the advertisement.

How would you rate the advertisement on the following scales:

\begin{tabular}{llllllllll}
\hline Likeable & Low & 1 & 2 & 3 & 4 & 5 & 6 & 7 & High \\
Good & Low & 1 & 2 & 3 & 4 & 5 & 6 & 7 & High \\
Interesting & Low & 1 & 2 & 3 & 4 & 5 & 6 & 7 & High \\
Irritating & Low & 1 & 2 & 3 & 4 & 5 & 6 & 7 & High
\end{tabular}

Now, I would like to ask you some questions about the product in the advertisement.

How would you rate the product on the following scales:

\begin{tabular}{|c|c|c|c|c|c|c|c|c|}
\hline Good & Low & 1 & 2 & 3 & 4 & 5 & 6 & 7 \\
\hline Likeable & Low & 1 & 2 & 3 & 4 & 5 & 6 & 7 \\
\hline Nice & Low & 1 & 2 & 3 & 4 & 5 & 6 & 7 \\
\hline Attractive & Low & 1 & 2 & 3 & 4 & 5 & 6 & 7 \\
\hline Worthy & Low & 1 & 2 & 3 & 4 & 5 & 6 & 7 \\
\hline $\begin{array}{l}\text { Compared to competing products, how } \\
\text { would you rate the product? }\end{array}$ & Low & 1 & 2 & 3 & 4 & 5 & 6 & 7 \\
\hline Like to purchase & Low & 1 & 2 & 3 & 4 & 5 & 6 & 7 \\
\hline Willingness to buy & Low & 1 & 2 & 3 & 4 & 5 & 6 & 7 \\
\hline Intend to purchase & Low & 1 & 2 & 3 & 4 & 5 & 6 & 7 \\
\hline Would recommend to others & Low & 1 & 2 & 3 & 4 & 5 & 6 & 7 \\
\hline
\end{tabular}


Section 5: Finally, please tell me a little about yourself.

5.1 Were you born in Canada? Yes __ No If no, how many years have you lived in Canada?

5.2 What countries, if any, have you lived in for greater than 6 months?

5.3 Please indicate your gender by circling the appropriate response:

$$
\text { Male Female }
$$

5.4 Please indicate your age by circling the appropriate range:

$<20$ years $\quad 21-30 \quad 31-50 \quad 51-65 \quad>65$ years

Thank you for participating in this study! 


\section{APPENDIX B - PROMOTIONAL APPEALS}


The table below presents the content of the promotional stimulus for one country (Honduras) as it varied across the appeal and product types.

\begin{tabular}{|c|c|c|c|}
\hline Appeal & Central Message & Text & Tagline \\
\hline Hedonic - Jeans & $\begin{array}{l}\text { Look good and } \\
\text { feel great in exotic } \\
\text { Honduran designer } \\
\text { jeans }\end{array}$ & $\begin{array}{l}\text { Express yourself. } \\
\text { Have fun beyond the ordinary. } \\
\text { Take yourself to the } \\
\text { extraordinary. }\end{array}$ & $\begin{array}{l}\text { Your } \\
\text { fashionable } \\
\text { choice }\end{array}$ \\
\hline Utility - Jeans & $\begin{array}{l}\text { Comfortable, } \\
\text { rugged and long } \\
\text { wearing Honduran } \\
\text { designer jeans }\end{array}$ & $\begin{array}{l}\text { Designed to fit comfortably for } \\
\text { everyday wear. } \\
\text { Honduran denim is highly } \\
\text { breathable and strong. } \\
\text { Dense fibre weaving delivers a } \\
\text { durable, long lasting product. }\end{array}$ & $\begin{array}{l}\text { Your sensible } \\
\text { choice }\end{array}$ \\
\hline Altruism - Jeans & $\begin{array}{l}\text { Support a poor } \\
\text { young Honduran } \\
\text { family now with } \\
\text { every stride you } \\
\text { make }\end{array}$ & $\begin{array}{l}\text { Diego and Camila are children } \\
\text { living in impoverished } \\
\text { conditions and struggle to } \\
\text { access clean water and food. } \\
\text { Their parents work hard in } \\
\text { their local textile factory and } \\
\text { need to keep their jobs. } \\
\text { Every athletic shoe purchase } \\
\text { you choose to make helps } \\
\text { families like these live better. }\end{array}$ & $\begin{array}{l}\text { It's up to you. } \\
\text { Choose to } \\
\text { help Diego } \\
\text { and Camila } \\
\text { today! }\end{array}$ \\
\hline Justice - Jeans & $\begin{array}{l}\text { Ensure hard } \\
\text { working } \\
\text { Hondurans are } \\
\text { justly rewarded }\end{array}$ & $\begin{array}{l}\text { Facing a conventional market } \\
\text { system that offers only pennies } \\
\text { for every pair of jeans, } \\
\text { working Hondurans have } \\
\text { organized into democratically } \\
\text { run cooperatives to offer the } \\
\text { world designer jeans. } \\
\text { Your purchase guarantees that } \\
\text { workers receive a fair price for } \\
\text { their labour, the equivalent of a } \\
\text { living wage that meets or } \\
\text { exceeds the legal minimum } \\
\text { wage, and that labour laws are } \\
\text { adhered to. } \\
\text { The result for you is a product }\end{array}$ & $\begin{array}{l}\text { Take } \\
\text { responsible } \\
\text { action and } \\
\text { make a world } \\
\text { of difference }\end{array}$ \\
\hline
\end{tabular}




\begin{tabular}{|c|c|c|c|}
\hline & & $\begin{array}{l}\text { you can be proud to wear } \\
\text { because your purchase reflects } \\
\text { how you think the world } \\
\text { should be. }\end{array}$ & \\
\hline Hedonic - Shoes & $\begin{array}{l}\text { Indulge your feet } \\
\text { in exotic } \\
\text { Honduran athletic } \\
\text { shoes }\end{array}$ & $\begin{array}{l}\text { Free your feet from the } \\
\text { ordinary. } \\
\text { Make athletic activities more } \\
\text { playful. } \\
\text { Take your feet to the } \\
\text { extraordinary. }\end{array}$ & $\begin{array}{l}\text { Your feet will } \\
\text { look good } \\
\text { and feel great }\end{array}$ \\
\hline Utility - Shoes & $\begin{array}{l}\text { Comfort and } \\
\text { effective } \\
\text { performance with } \\
\text { Honduran athletic } \\
\text { shoes }\end{array}$ & $\begin{array}{l}\text { Designed and built to help you } \\
\text { perform at your highest levels. } \\
\text { Lightweight fabric contributes } \\
\text { to the breathability of the shoe. } \\
\text { Air pockets in the sole help } \\
\text { cushion your foot for every } \\
\text { impact. }\end{array}$ & $\begin{array}{l}\text { Your high } \\
\text { performance } \\
\text { shoe }\end{array}$ \\
\hline Altruism - Shoes & $\begin{array}{l}\text { Support a poor } \\
\text { young Honduran } \\
\text { family now with } \\
\text { every stride you } \\
\text { make }\end{array}$ & $\begin{array}{l}\text { Diego and Camila are children } \\
\text { living in impoverished } \\
\text { conditions and struggle to } \\
\text { access clean water and food. } \\
\text { Their parents work hard in } \\
\text { their local textile factory and } \\
\text { need to keep their jobs. } \\
\text { Every athletic shoe purchase } \\
\text { you choose to make helps } \\
\text { families like these live better. }\end{array}$ & $\begin{array}{l}\text { It's up to you. } \\
\text { Choose to } \\
\text { help Diego } \\
\text { and Camila } \\
\text { today! }\end{array}$ \\
\hline Justice - Shoes & $\begin{array}{l}\text { Ensure hard } \\
\text { working } \\
\text { Hondurans are } \\
\text { justly rewarded }\end{array}$ & $\begin{array}{l}\text { Facing a conventional market } \\
\text { system that offers only pennies } \\
\text { for every pair of shoes, } \\
\text { working Hondurans have } \\
\text { organized into democratically } \\
\text { run cooperatives to offer the } \\
\text { world athletic shoes. } \\
\text { Your purchase guarantees that } \\
\text { workers receive a fair price for } \\
\text { their labour, the equivalent of a } \\
\text { living wage that meets or } \\
\text { exceeds the legal minimum } \\
\text { wage, and that labour laws are } \\
\text { adhered to. }\end{array}$ & $\begin{array}{l}\text { Take } \\
\text { responsible } \\
\text { action and } \\
\text { make a world } \\
\text { of difference }\end{array}$ \\
\hline
\end{tabular}




\begin{tabular}{|l|l|l|}
\hline & $\begin{array}{l}\text { The result for you is a product } \\
\text { you can be proud to wear } \\
\text { because your purchase reflects } \\
\text { how you think the world } \\
\text { should be. }\end{array}$ \\
\hline
\end{tabular}

